\title{
Mentor teachers in primary education: The delicate balance between their mentor and teacher roles
}

Wilhelmina Marieke Jaspers 
Leden beoordelingscommissie:

Prof. dr. A. L. van Baar

Prof. dr. D. Beijaard

Prof. dr. J. W. F. van Tartwijk

Prof. dr. M. L. L. Volman

Dr. R. M. van der Rijst

\section{Wilhelmina Marieke Jaspers}

Mentor teachers in primary education: The delicate balance between their mentor and teacher roles

ISBN/EAN: 978-94-028-1746-1

Copyright (C) 2019 W. M. Jaspers

All rights reserved. No part of this thesis may be reproduced, stored or transmitted in any way or by any means without the prior permission of the author, or when applicable, of the publishers of the scientific papers.

Layout and design by Eduard Boxem, persoonlijkproefschrift.nl

Printed by Ipskamp Printing, proefschriften.net 


\title{
Mentor teachers in primary education: The delicate balance between their mentor and teacher roles
}

\author{
Mentoren van leraren in opleiding in het primair onderwijs: \\ Een lastig evenwicht tussen de mentorrol en leerkrachtrol \\ (met een samenvatting in het Nederlands)
}

\section{Proefschrift}

\author{
ter verkrijging van de graad van doctor aan de \\ Universiteit Utrecht \\ op gezag van de \\ rector magnificus, prof.dr. H.R.B.M. Kummeling, \\ ingevolge het besluit van het college voor promoties \\ in het openbaar te verdedigen op
}

vrijdag 15 november 2019 des middags te 12.45 uur

door

\section{Wilhelmina Marieke Jaspers}

geboren op 6 november 1983

te Utrecht 


\section{Promotoren:}

Prof. dr. T. Wubbels

Prof. dr. P. C. Meijer

\section{Copromotor:}

Dr. F. J. Prins 


\section{CONTENTS}

$\begin{array}{lll}\text { Chapter } 1 & \text { General Introduction } & 7\end{array}$

Chapter 2 Mentor Teachers: Their Perceived Possibilities and 17

Challenges as Mentor and Teacher

Chapter 3 Mentor Teachers' Practical Reasoning about Intervening $\quad 49$

During Student Teachers' Lessons

Chapter 4 Mentor Teachers' Intervening during Student Teachers' 95

Lessons in Primary Education: A Multilevel Vignette Study

Chapter 5 Changing Mentor Teachers' Intended Intervening During 139

Student Teachers' Teaching In Primary Education

$\begin{array}{lll}\text { Chapter } 6 & \text { General Discussion } & 179\end{array}$

$\begin{array}{lr}\text { References } & 199\end{array}$

$\begin{array}{ll}\text { Nederlandse samenvatting } & 214\end{array}$

$\begin{array}{ll}\text { Woord van dank } & 227\end{array}$

$\begin{array}{ll}\text { About the author } & 230\end{array}$ 


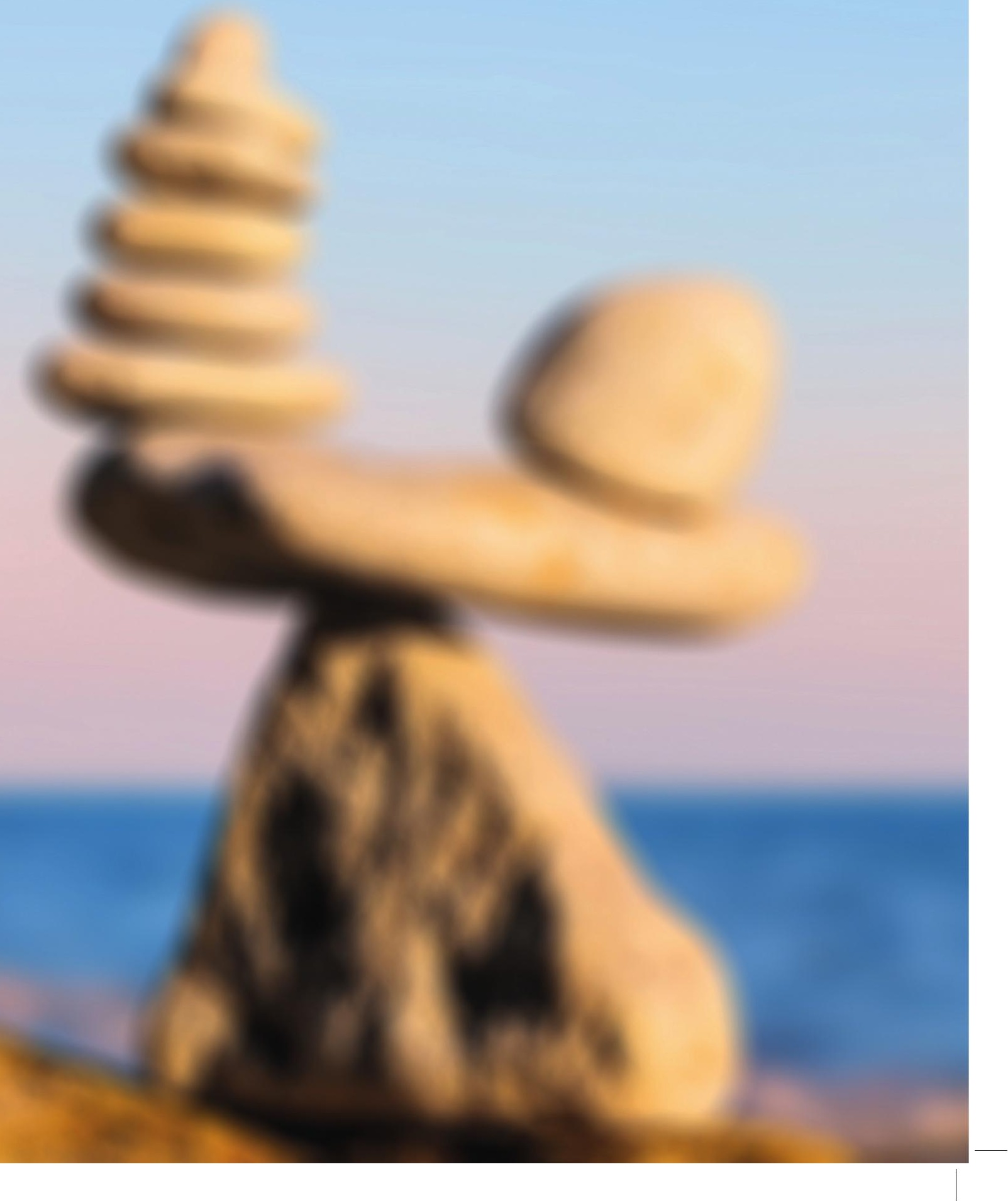




\section{CHAPTER}

\section{General Introduction}

Imagine that you are a grade-4 teacher in a primary school classroom, and you are teaching your 25 lovely 7 and 8-year-old pupils as you are used to doing five days a week. It is Tuesday, so your student teacher, who is doing her third year internship teaching in your class, is also present. Today, the student teacher will teach the pupils a mathematics lesson for one hour, which you have prepared together very well. After the break, the student teacher starts her lesson. You are sitting at the back of the classroom, observing your pupils and the student teacher. First everything is going well, but after a while more and more pupils start chatting and are no longer on task. You see that the student teacher does not notice that the pupils are chatting. You decide to wait a little longer. Five minutes later, almost all your pupils are not working on task anymore. What would you do?

This situation illustrates a dilemma mentor teachers (MTs) in primary education frequently experience when mentoring a student teacher (ST) in their classroom. On the one hand, MTs have a responsibility to the pupils, and on the other, MTs are responsible for guiding STs' learning. In the situation above, the question is whether the MT would intervene, and if so, when, how, and why. This dissertation concerns MTs combining the mentor and teacher roles and the (potential) role conflicts that MTs might experience when the ST is teaching the MT's pupils. In short, this dissertation addresses the delicate balance between the MT's mentor and teacher roles. 


\section{Mentor and teacher roles in primary education}

The student teaching experience is an important aspect of teacher training (Hobson, Ashby, Malderez, \& Tomlinson, 2009). In particular, MTs significantly influence the development of STs (Beck \& Kosnik, 2002; Borko \& Mayfield, 1995; Furlong, 2000; Wang, Odell, \& Schwille, 2008). Although in many countries being a (good) teacher allows one to become an MT (Hobson et al., 2009), becoming a good MT does not naturally emerge from being a good teacher (Orland, 2001). Much is known about what MTs are supposed to do as mentors, for example, pre-lesson preparation, observations, and post-lesson evaluation (e.g., Hobson, 2002; Kent, 2001), but what MTs actually do during STs' teaching, that is, at the actual moment STs are practicing teaching, is not well known. At this very moment of teaching, the ST as a learner could be guided in teaching, but mentoring research providing insights into MTs' specific actions at this moment is scarce. At least in the Netherlands, when mentoring the STs in primary education, MTs are not only teacher educators of the STs who are responsible for guiding them in their learning; simultaneously, as teachers they have a responsibility for the development and wellbeing of their pupils. This combination of mentor and teacher roles might be challenging for MTs (e.g., Collison \& Edwards, 1994; Edwards, 1998; Goodfellow, 2000; Rajuan, Beijaard, \& Verloop, 2007). Specifically, in primary education, as opposed to secondary education, MTs might be concerned for the pupils in their care. In primary education the relationship between teachers and their pupils may differ because primary teachers teach fewer and younger pupils than secondary teachers and spend more time with them. Also, in primary education, all subjects are taught to one class of pupils, whereas in secondary education one subject is usually taught for several classes (Wang, 2001). These differences might influence the role of MTs in both contexts. For example, in the Netherlands, STs in secondary education may teach their 'own' class, whereas in primary education the ST and MT are generally both in the same class; in primary education the ST performs activities, while the MT is also present as the teacher of that class (Goodfellow, 2000). Consequently, MTs in primary education might be more frequently exposed to STs' mistakes and may have more occasions to be concerned about their pupils' learning. As a result, in primary education MTs might perceive more and greater challenges between the mentor and teacher roles than in secondary education, and additionally, MTs' stronger 
relationships with their pupils might also reinforce their concerns for their pupils (Stanulis, 1995) and spur them to give the STs little autonomy (Goodfellow, 2000).

Thus, giving STs room for practicing teaching skills might be more challenging for primary education MTs than for secondary teachers. A typical and challenging situation for MTs might occur when an ST is teaching the MT's pupils and the MT observes the ST making a mistake or facing difficulties in teaching. Such situations might be valuable learning experiences for STs, giving them the opportunity to learn from their mistakes and thus improve their teaching. However, in such a situation, MTs might find it hard to refrain from directive interventions and allow STs to fail when simple interventions during their teaching could immediately improve the situation (Kent, 2001). To improve their teaching, STs need sufficient autonomy (Feiman-Nemser, 2001) and adequate responsibility and freedom in the classroom (e.g., Collison \& Edwards, 1994). When MTs are more concerned with pupils' wellbeing than with STs' learning (e.g., Edwards, 1998) and thus intervene in STs' lessons, the learning of the STs is potentially put at risk. Although various articles on mentoring have pointed to MTs' tendency to intervene (e.g., Glenn, 2006; Kent, 2001; Rajuan et al., 2007; Woods \& Weasmer, 2003), few explicitly examined the characteristics of interventions, MTs' considerations concerning intervening, or what factors may predict or influence MTs' intervening.

In this dissertation, we aim to gain insight into MTs' perceptions of and experiences with combining the mentor and teacher roles. Also, we aimed to understand MTs' intervening, specifically MTs' considerations for their intervening, what factors predict and influence MTs' intervening, and whether MTs' intervening can be changed. Such insights can eventually be a step forward toward improving MTs' guidance at the actual moment of STs' practice, which might facilitate STs' development. We will not address what is good intervening behaviour, or what is the effect of intervening on pupils or STs. Before such questions can be answered, we first need to understand what MTs actually do and consider during STs' teaching practicing. 


\section{How STs learn at the workplace}

STs in primary education learn to teach at the teacher training institute as well as in their teaching practicum in school. Placement in a school has been reported to be an important aspect of teacher training (Hobson, Ashby, Malderez, \& Tomlinson, 2009), and both STs and MTs consider the student teaching experience to be the most important aspect of school-based teacher training (Hobson, 2002; Richardson-Koehler, 1988).

How STs practice or learn during their teacher training period is described from various perspectives. STs could learn by doing and by observing a more experienced other, in the form of apprenticeship learning (e.g., Lave \& Wenger, 1991). STs could learn by reflection, in which the ST as learner critically observes his or herself in order to improve acting and thinking (Schön, 1983), or by explicitly relating what they learn at the institute to what they see in schools (e.g., Jones, Reid, \& Bevins, 1997). Also, STs could learn through discovery learning and (collaborative) investigative learning, in which STs improve their skills and education by investigating their own teaching. In order to do so, (student) teachers need to learn investigative skills, which they apply in their classrooms (e.g., Cochran-Smith \& Demers, 2008). Thus, during STs' teaching practice period there are various ways for them to practice and learn to become a teacher.

In the Netherlands, STs generally take courses in the teacher training institute and are placed at various schools. Compared to other countries, STs spend quite a lot of time in schools in the Netherlands, namely a quarter of their four years of study. Their placements vary from one day a week for a whole year to some intensive periods in which they are at the teaching practicum school for a full week. In their final year, STs are placed more days per week for a full period of three months. Over the years, STs' responsibility for the pupils increases as they work toward full responsibility at the end of their final year. During the practice periods STs have to perform various tasks or assignments. Also, they have to prepare lessons with a preparation form, in which, among other things, they articulate the objective of the lesson, the pupil and teacher activities, and their own learning goal as ST, and they teach lessons and are supposed 
to evaluate the lessons and reflect on their learning goal. A university supervisor visits STs twice per placement. The guidance of the ST in his or her learning process at or near the workplace is organised through mentoring (Eraut, 2011). The teacher of the class in which the ST has been placed is the MT of the ST.

\section{Mentoring ST's learning}

MTs appear to be the most influential actors in the student teaching experience (Collison \& Edwards, 1994) and significantly influence the development of STs (Beck \& Kosnik, 2002; Borko \& Mayfield, 1995; Furlong, 2000; Wang et al., 2008). In guiding STs, MTs need to support STs in practicing and acquiring the knowledge, beliefs, and skills that enable the STs to teach (Borko \& Mayfield, 1995; Hammerness et al., 2005) and help STs to become effective practitioners, for example, by modelling good professional practice (Roehrig, Bohn, Turner, \& Pressley, 2008), by supporting and challenging the STs (e.g., Maynard, 2000), and by planning, observing, and analysing lessons (e.g., Hobson, 2002). More specifically, MTs, through a form of apprenticeship learning (e.g., Lave \& Wenger, 1991), can act as expert role models as STs watch the complex performance as novices and are progressively guided to take increasing responsibility (cf. Furlong, 2000). The MT and ST can also discuss and reflect upon the ST's experience and talk about the complex processes involved in professional action (Schön, 1983), or MTs explicate their implicit, pedagogical content knowledge to the ST (e.g., Zanting, Verloop, Vermunt, \& Van Driel, 1998) and stimulate the ST to link this practical knowledge to the theoretical knowledge learned in the teacher training institute (e.g., Jones et al., 1997). Moreover, MTs are supposed to supervise STs in the practical research they perform in their classrooms (e.g., Cochran-Smith \& Demers, 2008). Thus, various ways of mentoring are described, but several studies describe mentoring as having a low impact on STs' learning (e.g., Borko \& Mayfield, 1995; Wang \& Odell, 2002), which might be a result of the complexity of being a good mentor (Hall, Draper, Smith, \& Bullough, 2008; Hawkey, 1997; Orland, 2001). To improve mentoring, a range of studies has been performed, especially in secondary education (e.g., Hobson, Ashby, \& Tomlinson, 2009; Orland-Barak, 2001). These studies concern, for example, particular aspects of mentoring conversations and student-mentor interaction (Braund, 2001; Crasborn, Hennissen, Brouwer, Korthagen, \& Bergen, 2011; Hawkey, 1998; Orland-Barak, 2005; 
Orland-Barak \& Klein, 2005), the student teachers' perceptions and expectations of mentors and mentoring (Edwards, 1997; Hobson, 2002; Maynard, 2000; Zanting \& Verloop, 2001), specific mentor roles such as assessor and supporter (e.g., Tillema, Smith, \& Leshem, 2011), initiator, imperator, encourager, and advisor (Crasborn et al., 2011), and effective mentoring strategies such as supporting and challenging the STs (e.g., Maynard, 2000), the availability of effective and structured guidance and support (e.g., Bullough \& Draper, 2004; Wang et al., 2008), and planning, observing, and analysing lessons (e.g., Hobson, 2002). However, most of the aforementioned studies have been conducted in secondary education and do not consider the prominent role that MTs also perform, namely already being the teacher of the pupils in the classroom in which the ST is practicing teaching.

\section{Research questions and overview of the chapters}

In this dissertation we want to gain insight into the possibilities and challenges that MTs experience when they combine their mentor and teacher roles, and more specifically we want to understand MTs' intervening and the factors related to it, and whether we can influence these factors and MTs' intervening. To gain these insights, a wide array of methodological and analytical approaches was employed. Four studies were conducted, which are reported in the individual chapters as outlined below.

At the beginning of our research we wanted to explore what happens when MTs are mentors and teachers. We sought insight into how MTs perceive the combination of both roles. Thus, in Chapter 2, we started by exploring MTs' perceptions and experiences as mentors and teachers, addressing the research question: What possibilities and challenges do mentor teachers in primary education perceive and experience when they combine their mentor and teacher roles? Data were gathered by retrospective semistructured interviews with seven MTs. Analyses were performed in three rounds that resulted in various categories, themes, quotations, and frequencies per theme per MT. The qualitative interview study of Chapter 3 built on our findings in Chapter 2. We focused on MTs' challenges in combining the mentor and teacher roles at the actual moment the ST is teaching and explored MTs' intervening and considerations on intervening. The guiding research question was: What is mentor teachers' practical 
reasoning concerning whether, when, and how to intervene during student teachers' lessons in primary education? Data were gathered by semi-structured interviews $(N=18)$ during which MTs were specifically asked to explain why they would intervene or not in situations that MTs had experienced. A coding system was developed based on Fenstermacher's (1986) practical argument, which consists of a series of premises, namely, situational premises, which describe the context or situation in which an action occurs; value premises, which are moral and ethical beliefs; and empirical premises, which are statements about the consequences of actions. In Chapter 4, in a multilevel vignette study, we elaborated on the overview of premises related to MTs' intervening and sought deeper insight into how MTs would intervene and which factors triggered MTs' intentions to intervene. The accompanying research questions were: 1) What value and empirical premises are important to MTs? 2) What is the general direction and intensity of MTs' intervening? 3) How do situational characteristics (STs' experience, trigger type, trigger severity) and personal characteristics (MTs' value and empirical premises) contribute to MTs' likelihood of abstaining from intervening, of intervening directed toward the pupils, or of intervening directed toward the ST?, and 4) To what extent do situations and MTs predict differences in MTs' intensity to intervene and what is the relative importance of trigger type, trigger severity, STs' experience, value and empirical premises in MTs' intensity to intervene? We developed a questionnaire, including 14 vignettes in which we manipulated situational characteristics and for which 159 MTs indicated whether and how they would intervene. Also, MTs' value premises and empirical premises were measured. Multilevel analyses were applied to determine the relative contributions of situational and personal characteristics to MTs' intervening direction and intensity. As a next step, when we knew which factors triggered MTs' intervening, we tried to change MTs' intended intervening by reinforcing the MTs' mentor or teacher role. Chapter 5 presents this multilevel intervention study and addresses the following research question: Does reinforcing the mentor or teacher role affect a) MTs' relative preference for teaching values over mentoring values; b) MTs' empirical premises concerning the effects of intervening; c) $M T s^{\prime}$ tendency to abstain from intervening, to intervene directed toward the ST, or to intervene directed toward the pupils, and; d) MTs' intended intervening intensity? To answer this question, we performed a between-subject pre-test post-test experiment. 
In the first condition we reinforced MTs' value and empirical premises by providing information on the importance of the mentor role (value premise) and by providing information on research that describes the relation between teaching situations and STs' wellbeing and development (empirical premises). The second condition was a control condition with no treatment. In the third condition we reinforced MTs' value and empirical premises by providing information on the importance of the teacher role (value premise) and by providing information on research that describes the relation between teaching situations and pupils' wellbeing and development (empirical premises). Finally, in Chapter 6 of this dissertation we present a summary of the results of the studies, integrate and explain the main findings, and address practical implications and suggestions for further research.

The different chapters of this dissertation are based on articles that have been published in or submitted to international journals. As a consequence, some overlap between chapters is inevitable. Table 1 provides an overview of the different chapters and the research questions. 
Table 1. Overview of the Chapters, Research Questions, and Methods

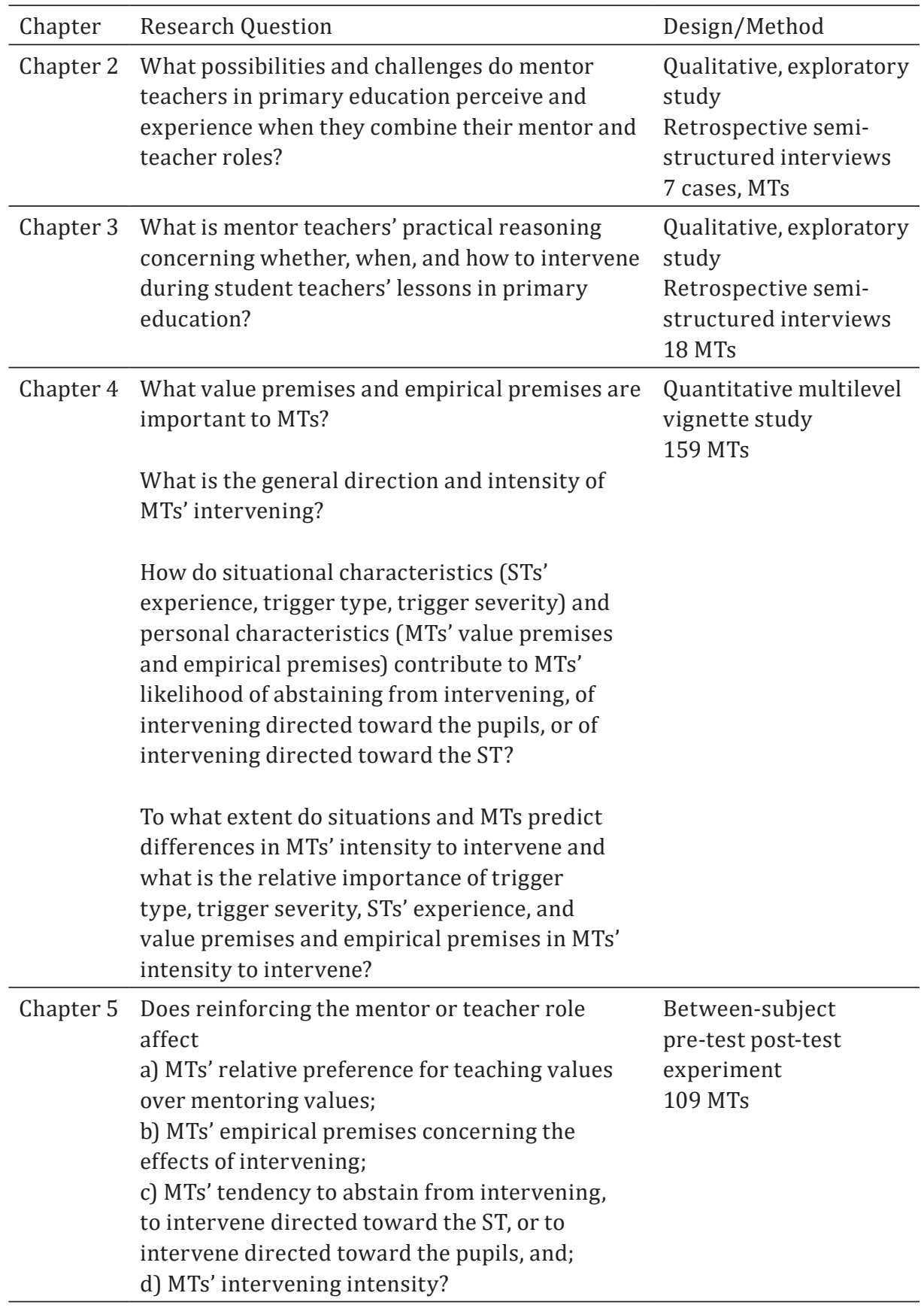




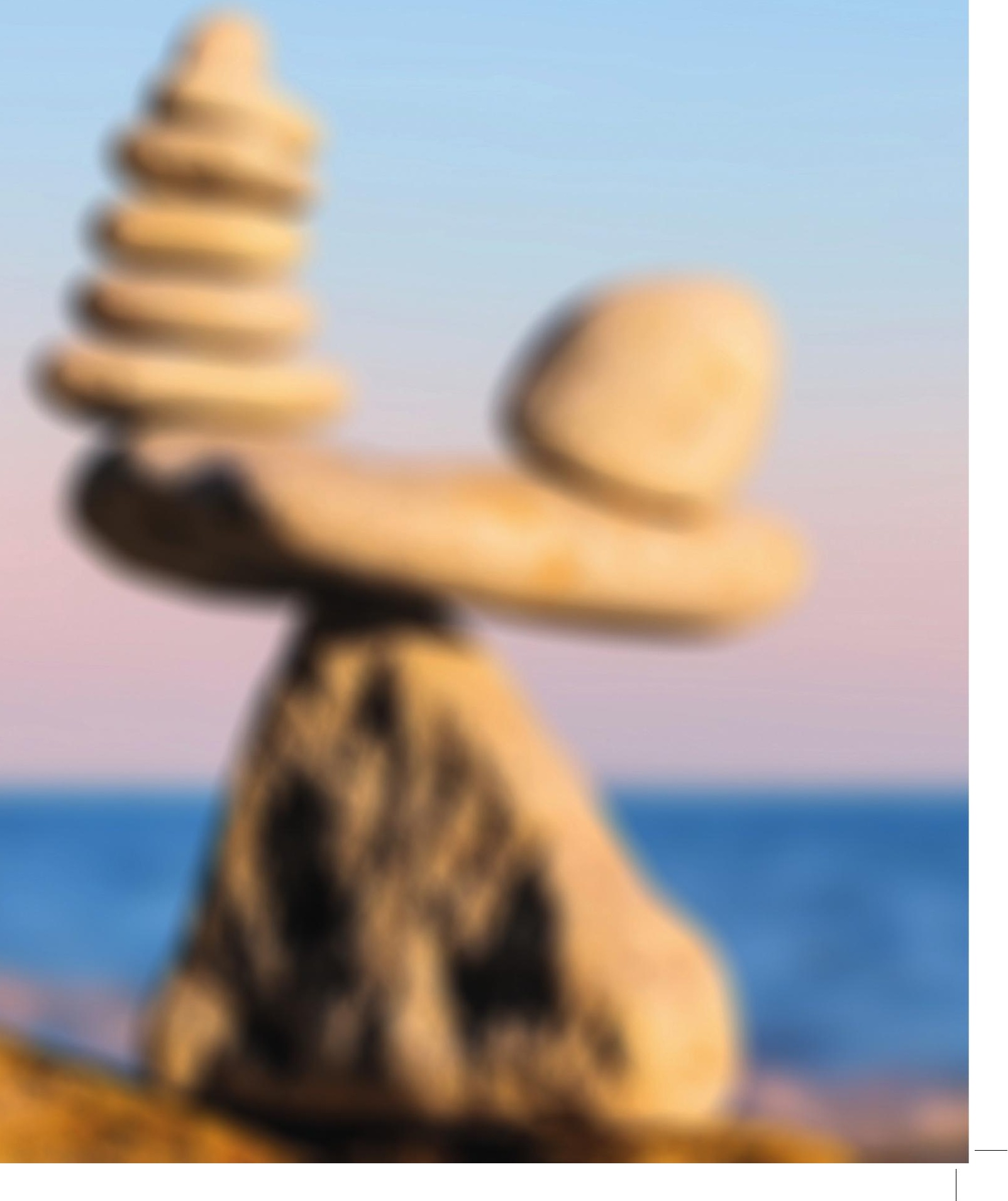




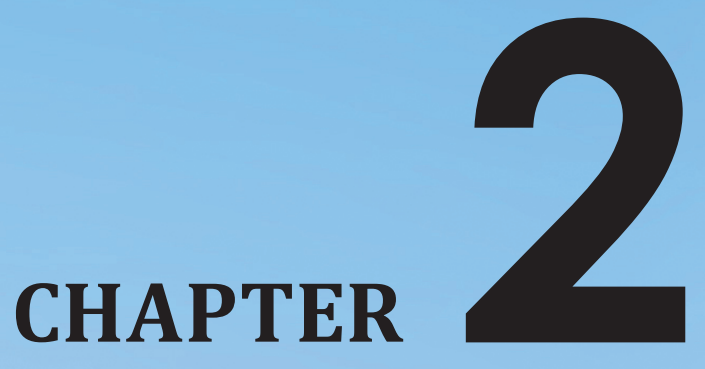

\section{Mentor Teachers: Their Perceived Possibilities and Challenges as Mentor and Teacher ${ }^{1,2}$}

This interview study, including seven case studies of mentor teachers in primary education, explores the possibilities and challenges these mentor teachers perceive when they (sequentially and simultaneously) combine the teacher and mentor roles. Mentor teachers perceive two challenges while simultaneously performing both roles in the same classroom: to transfer (or not) responsibility for the class and pupils to the student teacher and to intervene (or not) in classroom procedures. Mentor teachers felt that being the teacher of the pupils was their primary task and being a mentor of the student teacher generally was perceived as an aside and additional task.

1 This chapter is based on: Jaspers, W. M., Meijer, P. C., Prins, F., \& Wubbels, T. (2014). Mentor teachers: Their perceived possibilities and challenges as mentor and teacher. Teaching and Teacher Education, 44, 106-116. doi:10.1016/j.tate.2014.08.005

2 Acknowledgement of author contributions: J, Me and W designed the study; J recruited participants and collected the data; J and Me developed the interview questions; J constructed the coding scheme; J analysed the data; J drafted the manuscript; P, Me, and $\mathrm{W}$ had a substantial role during the thorough revision of the manuscript. J, Me, P and W participated in finalising the manuscript. Me and W supervised the study. 


\section{INTRODUCTION}

Student teachers (STs) in primary education learn to teach at the teacher training institute as well as at their teaching practicum school. The placement in the school, and in particular the contribution of mentor teachers (MTs), is very important for STs' teacher training (Furlong, 2000; Hobson, Ashby, Malderez, \& Tomlinson, 2009; Wang, Odell, \& Schwille, 2008; Williams et al., 1998). STs and MTs consider the student teaching experience to be the most important aspect of school-based teacher training (Hobson, 2002; Richardson-Koehler, 1988) and MTs appear to be the most influential actors in the student teaching experience (Collison \& Edwards, 1994). If MTs, who are responsible for pupils in their class and for supervising an ST, have such a prominent role in STs' learning to teach, it is worth exploring the MT role more deeply.

Mentoring is considered a complex task (Hall, Draper, Smith, \& Bullough, 2008; Hawkey, 1997; Orland, 2001). An MT needs to have specific mentoring skills, such as interpersonal skills (Rippon \& Martin, 2006), and knowledge about mentoring, such as being able to teach about teaching (Leatham \& Peterson, 2010). In general, MTs do have a lot of knowledge about teaching. However, some MTs find it difficult to talk about their teaching (Edwards \& Collison, 1995; Malderez, Hobson, Tracey, \& Kerr, 2007) or are not used to teaching others how to teach (Leatham \& Peterson, 2010). Also, MTs may find it difficult to guide adults in their learning process, for example by challenging them enough (Elliott \& Calderhead, 1993). Often, MTs are not trained to help others learning to teach (Hobson et al., 2009) and do not know what is expected from them (Grimmett \& Ratzlaff, 1986).

The combination of the mentor role and teacher role might be especially challenging. MTs, as mentors, must support STs in practicing and acquiring the knowledge, beliefs, and skills that will enable them to teach in ways that are fundamentally different from how they were taught (Borko \& Mayfield, 1995; Hammerness et al., 2005). On the other hand, MTs, as teachers, are responsible for the development and wellbeing of their own pupils, and these two goals may diverge. More specifically, the learning of the STs can be at risk when MTs are more concerned with pupils' wellbeing than 
with STs' learning (e.g., Edwards, 1998). For example, STs may not have been given sufficient freedom, autonomy, and responsibilities in the classroom (e.g., Collison \& Edwards, 1994), resulting in no, or insufficient, ST learning or in learning that is even contradictory to what was taught at the teacher training institute.

How MTs address and perceive these two roles during mentoring remains unknown. Knowledge about these perceptions and experiences may help MTs in their development as MTs and may increase the effectiveness of MTs' guidance of STs. Therefore, the aim of this study is to examine MTs' perceptions and experiences of the combination of the mentor and teacher roles.

\section{Theoretical Framework}

The study of mentoring and various mentoring roles is blossoming (e.g., Hawkey, 1997; Jones, 2001; Kwan \& Lopez-Real, 2005; Orland-Barak, 2001; Zanting, Verloop, Vermunt, \& Van Driel, 1998), but the majority of these studies focus on specific mentor roles, such as assessor and supporter (e.g., Tillema, Smith, \& Leshem, 2011), initiator, imperator, encourager, and advisor (Crasborn, Hennissen, Brouwer, Korthagen, \& Bergen, 2011). Research on the combination of the mentor and teacher roles is scarce, especially on MTs' perceptions of this combination. According to Pajares (1992), peoples' beliefs and perceptions strongly affect their behaviour. Knowledge about MTs' perceptions will provide insights into their classroom practice, as mentor and teacher. We will address indications from the literature that describe characteristics of the combination of the teacher and mentor roles. We also address the development of both roles and describe implications of performing both roles in MTs' classrooms.

\section{The development of the mentor and teacher role}

One branch of the literature covers the mutual influence of the development of the teacher and mentor roles. The relation between the teacher and mentor roles is found to be positive for the development of both roles. Being a (good) teacher allows one to become a (good) MT (Hobson et al., 2009). Conversely, Lopez-Real and Kwan (2005) concluded based on a large-scale evaluation that mentoring STs could enhance professional growth as a teacher. 
The combination of the mentor role and teacher role does not only give possibilities to grow in both roles but also may challenge the combination of these roles. In various studies, Orland-Barak (Orland, 2001; Orland-Barak, 2001, 2002, 2005, 2010) described the learning processes of experienced teachers who become mentors. She concluded that reading a mentoring situation does not naturally emerge from being a good teacher (Orland, 2001). She described learning to mentor as "learning a second language of teaching" (Orland-Barak, 2001, p. 54). Orland-Barak (2002; 2005) explained the complexity of the translation from the teacher to the mentor role. Because the research by Orland-Barak concerns mentoring of in-service (colleague) teachers in secondary education, the applicability of her findings to mentoring STs in primary education remains to be seen.

Mentoring in secondary education may differ from primary education, because in secondary education usually one subject is taught for several classes, whereas in primary education all subjects are taught to one class of pupils (Wang, 2001). This difference might influence the role of MTs in both contexts. For example, in the Netherlands, STs in secondary education may teach their "own" class, whereas in primary education the ST and MT generally are both in the same class; in primary education the ST performs activities, while the MT is also present as the teacher of that class (Goodfellow, 2000). Therefore, MTs in primary education are more frequently exposed to STs' mistakes and may be more triggered to be concerned about the pupils' learning. As a result, in primary education MTs might perceive more and greater challenges between the mentor and teacher roles than in secondary education. Furthermore, the relationship between teachers and their pupils may differ because primary teachers educate fewer and younger pupils than secondary teachers and spend more time with these pupils. This stronger relationship might reinforce MTs' concerns for their pupils (Stanulis, 1995) and spur them to give little autonomy to the STs (Goodfellow, 2000). Thus, giving STs room for practicing teaching skills might be more challenging for primary education MTs than for secondary teachers. These differences suggest that findings on mentoring in secondary education may not be directly applied to primary education and that research on mentoring of STs' learning to teach in primary education may be worthwhile. 
Generally, in the literature on mentoring in primary education, the combination of teacher and mentor roles appears as an aside in some studies (e.g., Goodfellow, 2000). For example, 35 MTs in Jacques' (1992) study mentioned that being a successful teacher of children did not guarantee success in teaching adults and Hopper (2001) suggested that teachers may find teaching STs without treating them like children difficult. Furthermore, MTs may not have been required to talk about teaching in the past, although they may have been teaching children for many years, as suggested by Malderez et al. (2007). MTs might even be disinterested in participating in mentor training and choose to teach themselves to mentor, like one of five MTs followed for 5 months by Stanulis (1995). However, these studies on mentoring in primary education do not intentionally investigate MTs' perceived problems when mentoring STs in their classrooms.

\section{The performance of the mentor and teacher roles in the classroom}

Another branch of literature concerns the implications of performing the teacher and mentor roles in the classroom, and some positive aspects of combining both roles have been found. For example, MTs feel that having an ST allows for the possibility of working with pupils in smaller groups (Collison \& Edwards, 1994), and MTs regard their STs as a useful additional resource that increases their freedom to undertake other work in the school (Edwards \& Protheroe, 2004).

Conversely, also challenging aspects of combining both roles were described. We will mention three difficulties that directly impact MTs' mentoring of the ST in the class. The first difficulty is the possible lack between STs' new insights and more traditional school routines of the MT (Alsup, 2006; Boyle-Baise \& McIntyre, 2008; Cabaroglu \& Tillema, 2011; Graham, 1997). This may prevent STs from learning more general applicable principles during their teaching experience. MTs may be practically oriented (Williams et al., 1998), making insufficient use of reflection on the relation between the theoretical concepts from the teacher training institute and the practical principles within the schools (e.g., Sundli, 2007; Wang \& Odell, 2002). 
The second difficulty is the time constraint that prevents MTs from effectively carrying out both roles (Jacques, 1992). Cross (1999) found that when there was a conflict of interest, it tended to be the STs, rather than the pupils, who suffered.

The third difficulty is the tension between mentor and teacher roles and MTs dual loyalty to STs' learning as well as pupils' learning (Rajuan, Beijaard, \& Verloop, 2007). Due to this dual loyalty, or dual role, the goals of being a mentor and being a teacher could be in conflict. MTs, in their mentor role, might want STs to practise and learn from difficult situations. Conversely, in their teacher role they might want to protect their pupils against possible mistakes of STs. For example, what would MTs do when STs make mistakes in the lesson content, or when STs' classroom management is inadequate? Literature on this tension is scarce. Some studies examined mentoring solely, and provided indications about the influence of the teacher role on mentoring strategies before and after the lessons of the ST. For instance, Edwards and Protheroe (2004) found that MTs hand over their classrooms to trial-and-error learning, observe lessons, and give feedback; however, MTs do not always create an efficient learning environment for their STs due to their teacher loyalties. MTs may tend to prioritise pupils' curriculum progress (Edwards \& Collison, 1995). Their feedback aims to limit the possible mistakes made by the ST so that (the development of) the pupils in the class will not be harmed (Edwards \& Protheroe, 2004). Furthermore, MTs may create tasks that are too structured for STs, in order to protect students and children from failure, and so that little to no supervision by the MTs is necessary (Collison \& Edwards, 1994). It might be that this results in an inappropriate degree of autonomy that does not allow STs to learn from mistakes, to make decisions, and to develop their own teaching styles (e.g., Feiman-Nemser, 2001). Therefore, MT's contribution to ST's learning in MT's classroom and the extent of this contribution is not straightforward.

Additionally, a few studies suggested that there is a tension between the mentor and teacher roles, although the focus in these studies was not explicitly on MTs' perceptions of the actual performance of the mentor role when the ST is teaching. For instance, in an extensive review of the cooperating teacher literature, Clarke, Tricks, and Nielsen (2013) generated eleven different categories that suggest the variety of ways that MTs 
participate, one of which is called "teachers of children". Based on previous studies (e.g., Edwards \& Protheroe, 2004; Evans \& Abbott, 1997; Feiman-Nemser, 2001; Goodfellow, 2000), Clarke et al. stated that "cooperating teachers are first and foremost teachers of children" (p. 23). However, Clarke et al. did not explicate this statement in more detail, and none of the cited studies really did explicitly investigate MTs' perceptions of the mentor and teacher roles. Evans and Abott (1997) explained that some MTs in their study felt that their mentor role detracted from what they perceived as their main role of teaching. Rajuan et al. (2007) found that MTs wanted to ensure that their pupils feel they are gaining and not losing by having STs teach them. MTs feel concerned with the children in their care due to their loyalty as a teacher (e.g., Edwards, 1998; Stanulis, 1995) and thus MTs may feel that the mentoring activities take them away from their pupils (e.g., Jacques,1992; Stanulis, 1995). Therefore, MTs might feel that the freedom allowed to the ST in working with children is to the detriment of their children, as was reported by the MT in the study by Goodfellow (2000).

We conclude that (1) most results on the combination of the mentor and teacher roles were based on studies in which these roles were performed in different places, at different moments, and often in secondary education; (2) research results on different mentor roles in primary education are available, but studies that explicitly aim to simultaneously examine the role of a teacher and mentor in one class are lacking; and (3) conclusions on combining the mentor and teacher roles often are not based on rigorously investigating MTs' perceptions of combining both roles, but on general statements of MTs on mentoring without exploring more deeply MTs' perceptions and experiences of these roles. Given these conclusions, our study examines nuances related to the combination of the MT's responsibility for the ST and the pupils, because when the combination of both roles is challenging, MT's contribution to ST's learning process may be hindered.

\section{Research question}

The aim of our study is to determine how MTs perceive the relation between (the presumably opposite goals of) both roles, and the performance of both tasks, and how MTs manage to attain both goals. We also want to determine the possibilities 
and challenges MTs experience when they act as the teacher of their pupils and as MT of the ST who practises teaching skills with these same pupils. The results of this study may contribute to a clearer perspective of MTs' contribution to STs' learning. The following research question was examined: What possibilities and challenges do mentor teachers in primary education perceive and experience when they combine their mentor and teacher roles?

\section{METHOD}

\section{Context and participants}

This study was performed in the context of a four-year undergraduate teacher education programme for primary education in the Netherlands, where, primary education is obligatory for all children from age 4 (grade 1) until age 12 (grade 8). Each class contains approximately 30 pupils and one teacher teaches all subjects. The average school size in the Netherlands is 214 pupils.

The teacher education programme in which this study was performed leads to a Bachelor of Science degree in education and a certificate to teach grade 1 through 8. The average age of the STs is approximately 20 years, ranging from 17 to 26. During the programme, STs take courses in the university and are placed at various schools. In the first, second and third year, STs complete two placements per year. Each placement per school takes one day per week for a period of five months and an additional full week twice. In their final year, STs are placed two days per week. Over the years, the ST's responsibility for the pupils increases working toward full responsibility for two days at the end of their final year. The teacher of the class in which the ST has been placed becomes the MT of the ST. In general, each class is assigned one or two STs annually. Usually, the MTs are not trained in mentoring. Being an MT is not a paid position, however, some MTs have a small reduction of their teaching load. A university supervisor visits STs twice per placement. 
Participants were recruited from the institute's list of all MTs who were involved in supervising an ST at the time. To be able to look for patterns across a diverse group of MTs, the selection of participants was guided by practical considerations, such as being available to make an appointment, and by methodological criteria. We wanted to ensure that females and males, participants working in all grade levels, kindergarten through grade 8 , various experiences in teaching and mentoring, and working in different types of urban and rural schools were all represented. The response rate was $64 \%$. The main reason given by MTs for not participating was a lack of time. Eventually, seven MTs were selected and participated on a voluntary basis.

The participants' characteristics are shown in Table 1.

Table 1. Participants' Characteristics

\begin{tabular}{|c|c|c|c|c|c|}
\hline \multirow[t]{2}{*}{ MT } & \multicolumn{2}{|c|}{ Experience in years } & \multirow[t]{2}{*}{ Gender } & \multirow{2}{*}{$\begin{array}{l}\text { Grade level } \\
\text { taught }\end{array}$} & \multirow[t]{2}{*}{ Type of school } \\
\hline & Mentoring & Teaching & & & \\
\hline 1: Ann & $+/-33$ & 35 & $\mathrm{~F}$ & 8 & $\begin{array}{l}\text { Urban school with } \\
\text { average SES }\end{array}$ \\
\hline 2: Bill & 27 & 30 & M & 8 & $\begin{array}{l}\text { Urban school with } \\
\text { average SES }\end{array}$ \\
\hline 3: Carol & 26 & 27 & $\mathrm{~F}$ & 4 & $\begin{array}{l}\text { Urban school with } \\
\text { average SES in Special } \\
\text { Education }\end{array}$ \\
\hline 4: Diane & $+/-24$ & 26 & $\mathrm{~F}$ & 6 & $\begin{array}{l}\text { Urban school with } \\
\text { average SES }\end{array}$ \\
\hline 5: Emma & $+/-15$ & 30 & $\mathrm{~F}$ & $1 / 2$ & $\begin{array}{l}\text { Urban school with } \\
\text { average SES }\end{array}$ \\
\hline 6: Fiola & $+/-8$ & 10 & $\mathrm{~F}$ & 5 & $\begin{array}{l}\text { Urban school with } \\
\text { average SES }\end{array}$ \\
\hline 7: Gina & $1 / 2$ & $1 \frac{1 / 2}{2}$ & $\mathrm{~F}$ & 7 & $\begin{array}{l}\text { Rural school with high } \\
\text { SES }\end{array}$ \\
\hline
\end{tabular}

Note. As promised to the interviewees, pseudonyms have been substituted for their real names. 


\section{Data collection}

This article, which is the first publication on this dataset, includes seven retrospective semi-structured interviews with MTs. We used retrospective interviews because we wanted to gather MTs' perceptions of various moments in the past and from their entire career path (Kelchtermans, 1993). The interviews aimed to explore MTs' perceptions of combining the mentor and teacher roles, the relationship between mentoring and teaching in general, and specifically MTs' experiences with this combination during the last mentoring period. Additionally, the MTs were asked to describe their teaching and mentoring history and development, their learning instances, key moments (positive and negative), dilemmas, and their main tasks and values in performing the teacher and mentor roles. In this study, we focused only on the parts in which the MT talked about the combination of the mentor and teacher roles (see also the section Data analysis). The questions were open-ended because of the exploratory design of the study (Miles, Huberman, \& Saldaña, 2014). Examples of questions are: "What is, in your perception, the relation between the mentor and teacher roles?", "How do you think, can both roles positively influence each other?", "What tensions did you experience between both roles?" Probing questions were also used, such as "Why?" or "Can you give an example?" Before interviewing the MTs, the interview questions were piloted with a mentor who did not participate in the actual study. Based on this pilot, some questions were added or restated in a more transparent way. Sample interview questions are listed in the Appendix.

\section{Procedure}

All interviews were held four to maximally eight weeks after the student placement in the MT's classroom. The MTs provided informed consent and were interviewed by the first author in Dutch, their native language. The interviews lasted an average of 85 minutes, ranging from 63 to 105 minutes. They were recorded, transcribed verbatim, and analysed. Interview excerpts presented in this paper have been translated into English and checked by a native speaker. 


\section{Data analysis}

The transcribed interviews were analysed in three phases. In the first phase, firstly fragments were created by turn taking between interviewer and MT. To be able to interpret MTs' statements, the questions of the interviewer were also part of the selected fragments. Secondly, the fragments to be analysed were selected: given the purpose of our research to get information about the combination of both roles, all fragments that provided information on the mentor and teacher roles, about the combination of mentoring and teaching, or in which the relationship between the ST and the pupils was described were included in further analyses. All fragments in which MTs only talked about their teacher or their mentor role were not included. The first coder (the first author) is an experienced teacher in primary education and a teacher educator. She discussed the results with a second coder, an educational researcher with a focus on classroom climate in primary education, who was not involved in this study otherwise, until consensus about the selected fragments was reached.

In the second phase, by using sensitising concepts to guide our analysis (Bowen, 2006), the data were analysed inductively and compared continuously until patterns emerged (Glaser \& Strauss, 1967). The authors, who are all experienced teacher educators, agreed that the MTs' perceptions of the combination of both roles could be categorised into two main processes. These processes were coded as the two main categories sequential role development and simultaneous task performance, which are described in more detail in the Results section. Each fragment could get multiple codes. Subsequently, the two coders independently coded one interview using these two categories, which resulted in an adequate reliability (Kappa $=.84)$.

In each category, after rereading and discussing the fragments, we found reinforcing and challenging combinations of both roles. For the reinforcing combinations, the perceived direction of the influence was also coded, either from the teacher on the mentor role or vice versa. Again, a fragment could contain multiple codes. After two rounds of collaborative coding, the coders then independently coded an interview with an adequate reliability (Kappa $=.81)$. As a result of phase 2 , two main categories 
each with three subcategories were identified. These subcategories are described in more detail in the Results section.

In the third phase, we noted recurring and remarkable themes after various rounds of consultation and discussions: core issues that MTs were discussing in each of the six categories. We generated codes that captured the phrases mentioned by the MTs for each theme, such as "own experience as ST", "expert or model", and "intervene". We listed the codes per category, and we tallied each code per MT and per fragment while examining the fragments again to possibly allocate more than one code per fragment. We then calculated the code frequencies per category and MT. During this process, we found that a few new codes needed to be added, existing codes needed to be merged or modified, and some codes needed to be deleted. For example, the codes "more educational possibilities" and "other educational possibilities" were merged because they could not be distinguished in the fragments. After various rounds of collaborative coding, the two coders independently coded the themes for another interview, which resulted in a good percentage of agreement (average for 6 categories: 95\%). Generally, the themes with the highest frequencies will be reported. However, sometimes we chose to report themes that were not frequently mentioned, but were nevertheless important in our view. We continuously reviewed the interview transcripts for the appropriateness of the themes mentioned and the quotations used when reporting the results. The (sub)categories, including descriptions and themes, are listed in Table 2 and Table 3. The number of fragments included in the analysis per category was 71 on average (ranging from 35 to 125 ; Total $=423$ ).

In order to triangulate the results about MTs' perceptions of the combination of the mentor role and teacher roles, we checked whether utterances that concerned one of the roles separately had added new insights about MTs' perceptions of their roles. 


\section{RESULTS}

MTs described a wide variety of perceptions and experiences concerning the combination of the mentor and teacher roles. All seven MTs described two different processes that they experienced when both roles were combined. The first, sequential role development, designated the development of the mentor and teacher roles in a sequential order. The second, simultaneous tasks performance, portrayed the combination of the mentor and teacher roles in performing both tasks simultaneously during the process of mentoring the ST.

For each category, we distinguished three subcategories. Two of the subcategories were teaching reinforcing mentoring and mentoring reinforcing teaching, in which the perception of the relation between both roles was described as strengthening, promising, positive, or easy, and in which the perceived direction of the influence was found, either from the teacher role on the mentor role or vice versa. The third subcategory was challenging, which represents the perception of the relation between both roles as competing, conflicting, negative, or difficult. A direction was not added to this subcategory because MTs did not explain the direction in these cases. Table 2 and Table 3 present an overview of the descriptions and frequencies of the (sub)categories and the corresponding themes.

Next, the possibilities and challenges of the combination of the two roles will be described, explained, grounded with frequencies and proportions, and illustrated with quotes. Analyses of MTs' descriptions of the mentor and teacher roles separately did not result in new insights and added value and will thus not be reported.

\section{Sequential role development}

The category sequential role development refers to reinforcing or hindering of the development of one role by the other. 


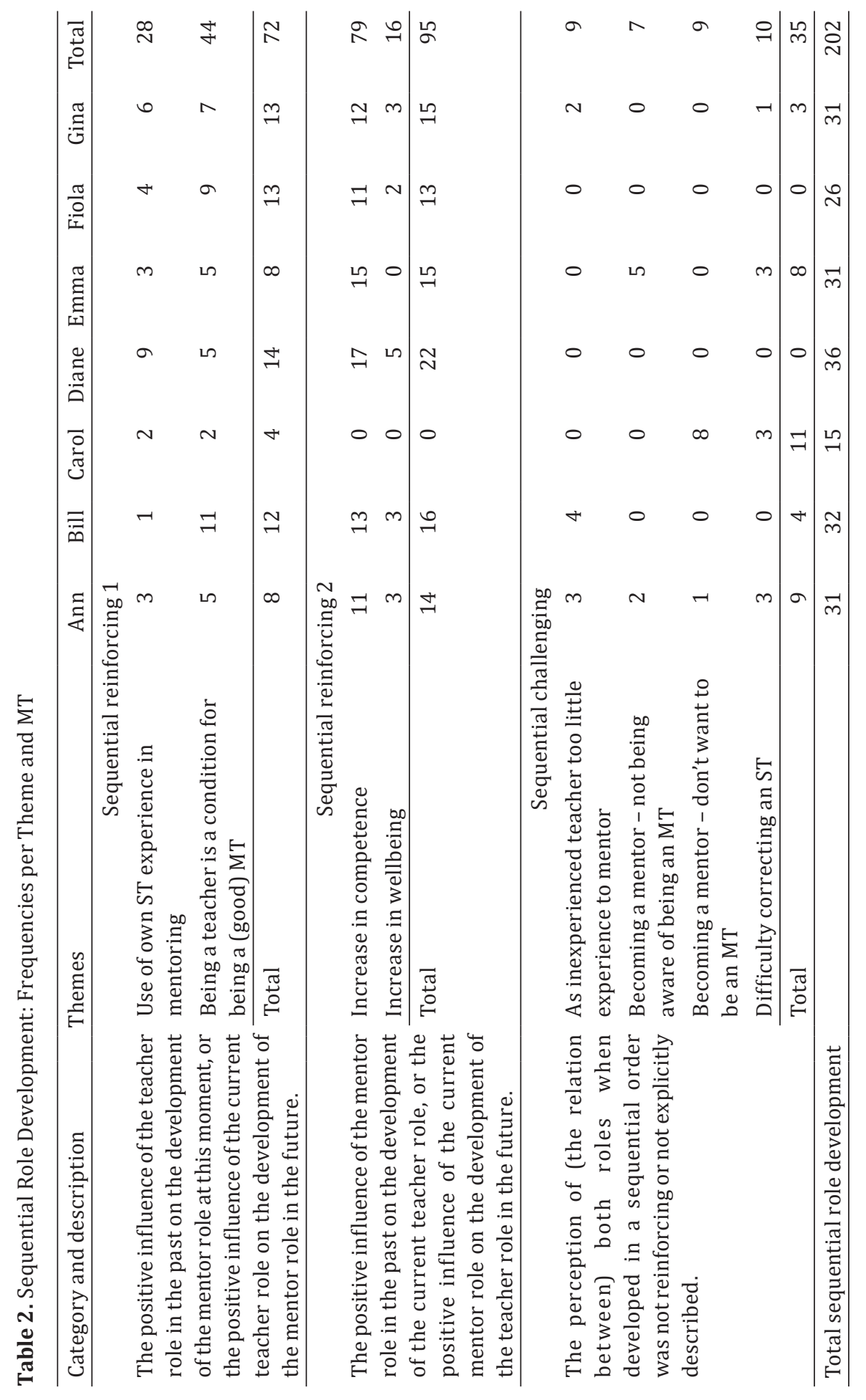




\section{The teacher role reinforces the development of the mentor role}

We found that MTs in our study perceived that simply being a teacher helped to reinforce being and developing as an MT (see Table 2, sequential reinforcing 1, 72 fragments). All respondents explained how they use their teacher skills to mentor STs. For example, Gina explained: "I think that, because I am a teacher, I can be very clear in my explanations, because you are explaining very often, and simplifying things for the pupils, and that is actually the same for students. You have to explain it to them in such a way that they think 'oh, yes [I understand]'”. The MTs even mentioned that being a good teacher was a condition for good mentorship. They said that the more experienced they became as teacher, the more competent they felt in mentoring. As Ann said: "When I started, I thought, 'how on earth will I be able to mentor the ST[...]' The longer you are in the class[room], the more you know education, the more experienced you are, and the better you can help people."

All MTs explained that they knew what they could expect from an ST because they had been STs themselves. They used their own ST experiences from the past in their mentoring. For example, Gina said: "Once, I had an MT myself, and I learned a lot from her. Actually, I'm copying her a bit."

\section{The mentor role reinforces the development of the teacher role}

MTs perceived that being a mentor positively influenced their competence and wellbeing as a teacher (see Table 2, sequential reinforcing 2, 95 fragments). Regarding their competence growth, six MTs mentioned that the presence of the ST in their class made them more aware of their own teaching. They said that STs gave feedback and challenged them to reflect on their own teaching by discussing educational and pedagogical topics. Experienced MTs stated that mentoring STs kept them fresh and sharp and prevented them from teaching too automatically and routinely and from getting bored. Ann: "She [the ST] pondered her lesson very consciously, which spurs you to start thinking again. [...] You get stuck in a method, of course. And then, you think, that's also a possibility [...] Should I change something?" Inexperienced MTs felt they became more confident in their own teaching because they could help STs more than they had expected. Gina: "I think you become more conscious that you really can teach something 
to STs, that they can learn from me to be good teachers, and that I know something about that." Furthermore, the MTs became more aware of their pupils' learning and behaviour and gained new insights and lesson ideas from the ST: "Sometimes, I see STS handle [situations] differently. I try to take the good things from it and hope to remember them, so I can use them in the future." (Emma).

Additionally, five MTs explained their increase in wellbeing due to mentoring an ST. For example, Bill said: "[...] that [the mentoring] keeps it nice and exciting. [...] I feel comfortable; I like the students. I think a student is an additional value. I feel comfortable with that."

\section{Sequential developing the mentor and teacher role is challenging}

MTs experienced challenges between their two roles (see Table 2, sequential challenging, 35 fragments). First, three experienced and inexperienced mentors explained that they did not feel confident and competent enough in their mentor role when they first began teaching and lacked significant teaching experience: "At the beginning of mentoring, I was nervous. You are barely developed as a teacher yourself, and you already have to tell and show someone else how to teach." (Bill)

Second, four MTs explained the experienced difficulty when feeling they had to correct an ST who was not prepared for the lessons or had a negative attitude. As Ann said: "Correcting a kid, when I'm not content, is much easier than correcting an ST. That's always very difficult."

Third, an interesting but small group of 16 fragments illustrated MTs' perceptions of the sequential development of both roles in relation to their perceived core professional role. We found that MTs had different self-perceptions as MTs, but that MTs unanimously felt that their teacher role prevailed over their mentor role. MTs sometimes even did not (want to) see themselves as MTs at all. In some fragments, MTs explicitly stated that they wished they did not have to perform their mentoring tasks or even did not want to be an MT, especially when they felt it was difficult to develop or maintain a good relationship with the ST, when the ST had a negative or 
impolite attitude or when STs' skills were not what the MT expected. For example, Ann said: "If an ST asks me to explain common fractions, I think: 'No, that isn't my task. For that, you shouldn't be with me. I'm here for the pupils, not for the ST'." Carol said: "Well, I'm like, I rather want to do it myself, you know, in the class." Two MTs explained that, when an ST did not show any improvement in teaching skills, they did not want to be responsible for the development of the ST, because they felt that this development was the responsibility of the teacher training institute. For example, Carol said: "On $a$ certain moment [...] I thought, you know 'It is not my responsibility'. [...]. I think the teacher training institute is responsible to take care that people who graduate indeed could teach."

While we found that MTs sometimes did not want to be a mentor, we also found that MTs sometimes did not feel that they were acting as a mentor or seemed unaware of their mentor role. For example, MTs frequently could not explain how they coped as mentors with problematic or surprising mentoring situations. When asked about this challenge (e.g., What could you do in this situation?), instead of explaining what they should do as an MT, they began to describe STs' characteristics in that situation, as they had done before, or described the impact this challenge had on their teaching role. The following excerpt illustrates that MTs sometimes did not identify themselves very much with the mentor role:

\footnotetext{
Interviewer: "How would you typify yourself as an MT?"

Emma: "Uuh, I always try to adapt to the pupils' needs, to how they are as pupils...[...]"

Interviewer: "That's as a teacher, right?"

Emma: "Yes."

Interviewer: "And how is that as an MT?"

Emma: "As an MT? Uuuh....[Silence]....Well, I hope, uhhh...It's difficult. Can you ask your question again?"

Interviewer: "How would you typify yourself as an MT? And then you answered as a teacher, about the pupils..."

Emma: "Yes...well, by giving the example, I hope they can do something with that."
} 
Fragments such as the ones above indicated that MTs often did not consider the mentor role and were unaware of their feelings in this role.

\section{Simultaneous task performance}

The category simultaneous task performance refers to the actual simultaneous performance of the mentor and teacher roles or tasks. MTs mentioned three situations that influenced their experience and perception of the combination of both roles. We first introduce these situations and then present the possibilities and challenges of simultaneously performing both tasks.

\section{Mentoring situations}

The first situation MTs mentioned is that they are teaching their pupils themselves. In this situation, MTs clearly saw themselves mainly as teachers and not as mentors; therefore, they did not feel tension between the roles in this situation. Although MTs explained that being a role model was one of their most important tasks as an MT, most did not explain if and how they discussed what the STs had seen.

Second, MTs mentioned pre- and post-lesson conferences. MTs found it easier to perform their mentoring tasks and more easily assumed their mentor role during these conferences when the pupils were away. However, MTs also explained that STs were perceived as guests in the classroom and needed to adapt to the established routines. Therefore, MTs mainly acted as teachers who advised STs on their teaching in this specific classroom during these pre- and post-lesson conferences. The focus was mainly on organisational issues and the specifics of individual pupils or class characteristics. Strikingly, MTs rarely discussed STs' development or the (potential) contributions of MTs to furthering STs' growth. They were much more focused on their pupils than on STs' development. Additionally, some MTs explained that being a mentor was only a side task on top of their other teacher tasks. They did not always have the opportunity or feel it necessary to have pre- or post-lesson conferences or to perform other mentoring activities. 
In the third situation MTs mentioned, STs were going to teach or were actually teaching. In this situation, MTs most clearly experienced the challenge of simultaneously performing the mentor and teacher tasks. MTs worried about pupils' development and STs' activities. These challenges will be described in the sections "(Not) transferring responsibilities" and "(Not) intervening."

\section{Teacher tasks reinforce mentor tasks when simultaneously performed}

MTs perceived being a teacher as a strengthening and even essential aspect of their mentor role (see Table 3, simultaneous reinforcing 1, 56 fragments). In particular, they felt that they were able and (inevitably) required to help STs learn to control their class because they were teachers in the same classroom. Therefore, all MTs felt that they could mentor because they were a teacher and had a class. MTs described two important duties in mentoring. The first duty concerned the need to make the class available to the ST and to hand over the teaching responsibilities. Five MTs explained that they allowed the STs to practise teaching as much as possible so the STs could learn by doing. For example, Bill said: "What I see, is that, above all, you need to let your students practise many hours. Above all, they have to do it a lot. They have to do a lot with kids, and then...then the experience and understanding comes spontaneously."

All MTs expressed the need to be a role model and an expert in teaching (in their own class), which constituted the second duty. As Fiola said: "The first two times, just look at me and get the feeling, and then we talk about it. What did you see, and ask me questions. Why did I do it like that?" The MTs thought that because they were experts, they could 1) give an example of teaching and being a teacher; 2) give STs insight into specific characteristics of the pupils and educational topics (e.g., rules and routines) related to the organisation of the classroom; 3) give STs feedback on the performed lessons; and 4) help STs to prepare and actually lead lessons. 


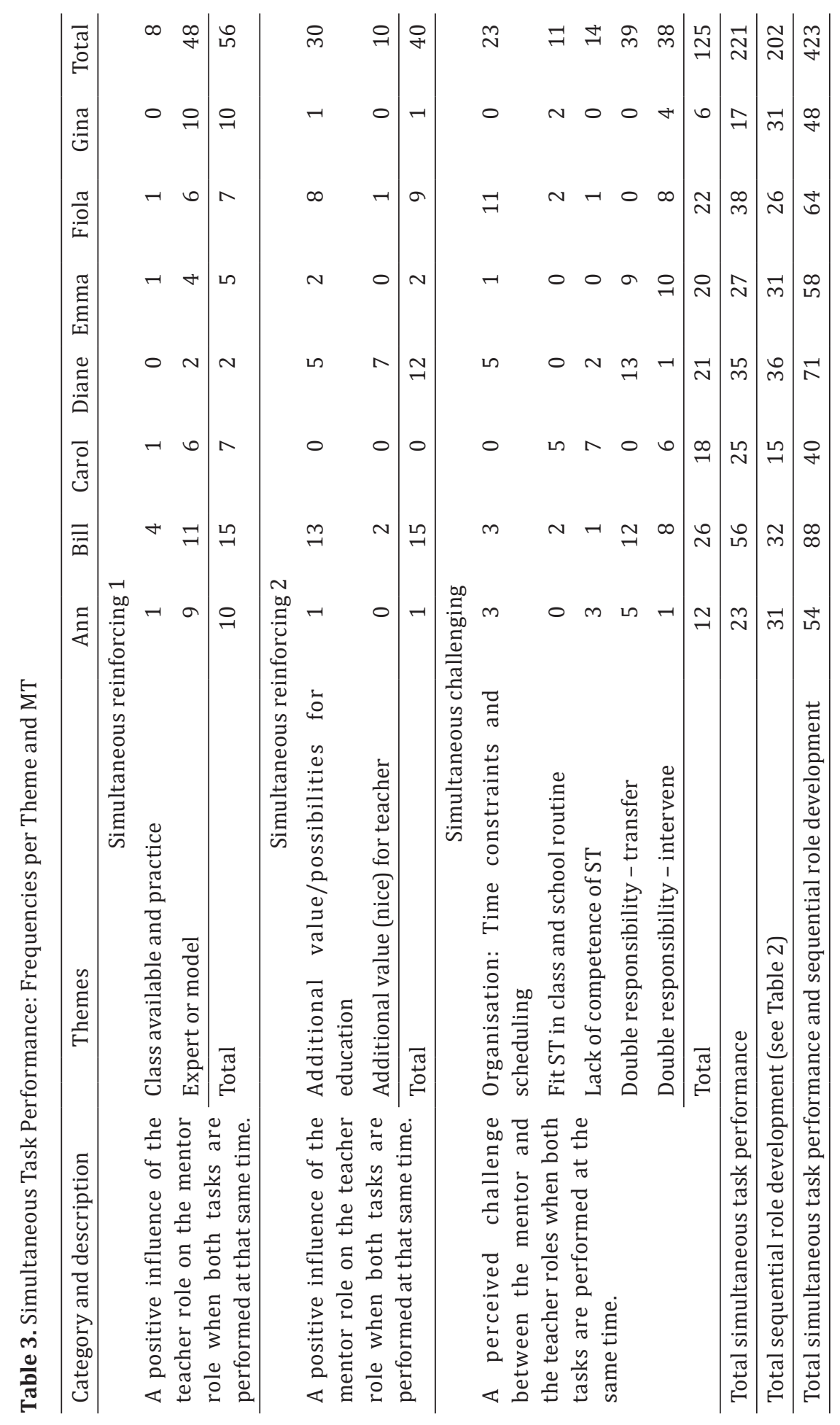




\section{Mentor tasks reinforce teacher tasks when simultaneous performed}

We found that MTs perceive benefits as teachers from being MTs (see Table 3, simultaneous reinforcing 2, 40 fragments). Having an ST in the classroom was thought to enrich the teaching experience and provide mentors with more educational opportunities. Three MTs explained the positive feelings they experienced from STs' presence. Diane said: "I think that when you collaborate pleasantly, it just leads to more satisfaction."

Furthermore, six MTs explained that student teaching provided opportunities to divide the class into two groups, to teach collaboratively, to engage in other educational activities with the children that were too complicated to manage with only one teacher, such as science lessons in which pupils conduct various experiments, or to accomplish practical tasks for their class(room) that are otherwise too time-consuming. These MTs described STs in such terms as (educational) assistant, a colleague, having two more hands, eyes and ears in the class, or an additional value. Bill noted the following on an ST correcting pupils' work very well: "Oh, Yes! .... That saves me an enormous amount of work. How lovely is that! That's what I mean with that added value, right?" From these statements, we infer that mentors did not feel the need to mentor when students were performing well; they simply forgot their mentoring tasks. In these cases, the contentment of teachers overruled their responsibilities of the mentor role.

\section{Simultaneously performing mentor and teacher tasks is challenging}

Although MTs primarily perceived developing both roles in a sequential order positively (only $17 \%$ of the fragments were not positive), the actual simultaneous performance of both tasks was thought to be challenging or even competing (see Table 3, simultaneous challenging, 125 fragments). We found various challenges, such as planning issues (5 MTs, e.g., time constraints and modifying the pupils' educational schedule to fit the STs' assignments), managing STs' ideas and behaviour to fit in the established order and regular class routines (4 MTs), lack of STs' competence (5 MTs), and challenges due to the double responsibility for pupils as well as the ST (7 MTs). We will elaborate on this last challenge (most often mentioned, 77 fragments, and by all seven MTs), which clearly illustrates the complex nature of actually performing 
both roles simultaneously. MTs wanted STs to practise and learn, but they also wanted their pupils to learn and feel comfortable. MTs felt these goals could conflict with each other. We distinguished two subcategories: (not) transferring responsibilities and (not) intervening.

\section{(Not) transferring responsibilities}

Four MTs considered transferring teacher responsibilities to STs challenging, as illustrated by the following excerpt: "[The] first point is that you [the MT] are in front of a class and that things should run smoothly. And the second point is that you can hand over the class to the ST bit-by-bit." (Diane)

MTs primarily coped with this challenge by regulating the amount, ease, rapidity, and type of responsibilities they transferred, and the way they transferred the responsibilities to the ST. MTs felt that the ease and rapidity with which they transferred their responsibilities to the ST depended on the ST's capabilities. For example, Ann explained her mentoring of a very competent student: "The steps you normally take are much smaller. Now, I would normally think a first-year student could not give some of the lessons. So, you can give it away, in more confidence [...] With other STs it is often, well, you have to guide them very carefully..." Furthermore, Emma said: "To leave the lesson to the student. Well, you know... I think, you see quickly enough how a student approaches the children, and if you can let it all go. I think that, when you think: 'that's not going well', then you do not do that as quickly because you do not want it to escalate."

\section{(Not) intervening}

We found that all seven MTs mentioned a second challenge of simultaneously performing the mentor role and teacher role. When MTs felt that pupils were not being taught well by the STs, all MTs start thinking whether to intervene or not. Diane said: "I think, for example, when the lesson of an ST is getting totally out of hand, then... there are boundaries...should I intervene or not?" The MTs intervened in various ways, from taking over class by verbally or non-verbally addressing one or more pupils to silently guiding the ST. For example, Carol explained that she at first corrected pupils' behaviour by looking at them or by just being there, but when the ST could not be 
convinced that the pupils needed more structure, she stopped signalling pupils so that the ST would experience what was actually happening. Some MTs consciously decided to intervene, whereas others explained that they only subsequently realised that they had intervened again. For example, Gina said: "For me... It's a learning experience, to stay silent the whole time because you see so many things..." Therefore, some MTs simply left the classroom (for short periods) so they could not intervene, and the ST was forced to be independent. Finally, some MTs just intervened in the ST's lessons. When they detailed their actions in response to undesired classroom behaviour, they explained how they guided pupils toward the desired behaviour: For example, Emma said: "Look, when things are getting messy, than soon you will say: 'Come on, guys, that's not the way we do things'." Furthermore, Fiola said: "At that moment, I say: 'Stop! All of you, take a step back. If you want to ask something, or whatever, than you ask for attention. And not everybody all at once."”

MTs mentioned various reasons for intervening in the STs' lessons and considerations of the benefits and consequences of intervening. Some MTs mentioned to intervene when STs made mistakes in the subject matter or organisational issues, whereas others only mentioned to intervene if pupils misbehaved or the class was disorderly. For example, Carol said: "When I saw pupils hurting themselves, I removed them and spoke with them. [...] Afterwards, I spoke with the ST. She thought that this kind of lesson could be more free; I then explained again that that's not possible with these pupils." However, some MTs explained that disorderly situations were the very situations that are important for STs to practise; therefore, they did not intervene. Other reasons for intervening were the MTs' need to protect the ST, or estimation that abstaining from intervening would damage the classroom climate for the rest of the day, or thinking that intervening was in the self-interest of the MT. Finally, intervening might be a result of the MT not being able to cope with her emotions. Gina said the following: "Sometimes that really irritates me,...that I really don't like the behaviour of my class. That's why I say something about it to the pupils." These reasons all boil down to the MT's feeling that their primary task is teaching: "Well, I'm primarily the teacher of these children, and everything is subordinate to that, everything. Because the most important thing is that it's going well with this group...and I'm only an MT on top of that." (Bill) 


\section{Patterns in the data}

We explored patterns in the data by comparing frequencies across the various subcategories and themes and calculating correlations between categories. We found a large positive correlation $(r=.85 ; p=.016)$ between the two sequential reinforcing categories, which indicated that the more MTs perceived the mentor role as reinforcing their teacher development, the more they also perceived the teacher role as reinforcing their mentor development. We also found a significant negative correlation $(r=-.92$; $p=0.004$ ) between the subcategory "sequential teacher role reinforces mentor development" and the sequential challenging subcategory. The more MTs were positive about the influence of the teacher role on their development as mentor, the less they mentioned challenges. Other correlations between the subcategories were not found.

Related to the correlations, Tables 2 and Table 3 show that every category was mentioned by almost all MTs. However, in three specific cases a category was not mentioned by an MT. Carol, who explained that her ST did not grow enough, and did not seem to listen to her, felt that she could not contribute to the development of her ST. Carol did not mention any reinforcing aspects of mentoring for her teaching. Additionally, she mentioned many sequential challenging aspects. On the contrary, Diane and Fiola did not mention any sequential challenging aspects, but they did mention many sequential reinforcing aspects. They both noted that they were working "on an equal level" with their STs. They were teaching as a team, and thus they and the STs were growing in development and wellbeing.

The results in Tables 2 and Table 3 also show that MTs spoke differently about challenges related to the professional responsibilities of MTs toward pupils and STs. MTs explained their mentoring in three different ways according to these challenges: (1) Ann and Diane focused on the transfer of responsibilities; (2) Fiola, Carol, and Gina focused on intervening during the ST's lesson; and (3) Bill and Emma explained both. 


\section{DISCUSSION}

The research question addressed in this study was: What possibilities and challenges do mentor teachers in primary education perceive and experience when they combine their mentor and teacher roles? The aim of this study was to examine MTs' perceptions and experiences of the combination of the mentor and teacher roles, to provide insights into MT's classroom practice as mentor and teacher, and to gain more insight into the contributions of MTs to STs' learning and the difficulties MTs are facing when guiding an ST in their classroom. Our study is the first study that explicitly examined MTs' perceptions and experiences of the combination of both roles, although a tension between these roles was suggested by earlier studies with other primary aims (e.g., Collison \& Edwards, 1994; Edwards, 1998; Edwards \& Collison, 1995; Edwards \& Protheroe, 2004; Evans \& Abbott, 1997; Hopper, 2001; Jacques, 1992; Goodfellow, 2000; Rajuan et al., 2007; Stanulis, 1995). We will first discuss our most important findings, followed by limitations and further research, and the practical implications of our study.

\section{Being a teacher overrules being a mentor}

This study revealed that in primary education MTs clearly felt that being a teacher of pupils was their primary role, and being an ST mentor was perceived merely as an aside, an additional, sometimes even annoying and hindering, task. All MTs were primarily focused on the wellbeing and development of their pupils and less on their STs' development. The MTs' focus on their pupils in our research was rather strong. The tension between both roles in primary education was strong, and might be even stronger than could be expected from the literature about mentoring in secondary education. As suggested earlier, this difference between secondary and primary context might imply conceptual differences in mentoring activities, strategies, and dilemmas, as well as the challenges and considerations of the MTs COrland-Barak \& Hasin, 2010; Wang, 2001). Teachers in primary education, who usually bear responsibility for one class of young pupils, might feel a different responsibility for their pupils than secondary teachers, who have several classes and older pupils. This perceived responsibility for their pupils in primary education might overrule the 
perceived responsibility for their STs (Cross, 1999). The other way around, as Post (2007) suggests, in secondary education, MTs might choose to ignore problems that occur during an ST's lesson more often, because MTs are conscious of STs' need to be perceived as authority figures by the (older) pupils. Our study supports Wang's (2001) suggestion that the context of teaching and mentoring influences MTs' mentoring practice. Research needs to acknowledge and address the presumed differences in mentoring in primary and secondary education because insights from mentoring in secondary education might not be directly transferable to primary education.

Our result that MTs in primary education feel the teacher role overrules the mentor role might also be explained by the assertion of Leatham and Peterson (2010) that MTs do not perceive themselves as mentors or as teachers of STs. When MTs in our study talked about the strengthening of their mentor role by the teacher role, they explained the benefits in more detail then when they talked about what they learned or used as mentors from their teacher role. In general, MTs provided little detail about how they mentored. When MTs' feel their teacher role is most important, it is likely that they do not see their role in helping an adult to learn, that they do not feel they can act according to the responsibilities allied to their mentor role, and that they feel it difficult to correct STs. Correcting an ST might then be more difficult because STs are in age closer than pupils and because the only adult relationships MTs experience in school are those based on friendships with other colleagues, rather than those related to learning (Elliot \& Calderhead, 1993).

\section{Challenges in simultaneously performing the mentor and teacher role}

Our results confirm much of the research on being a teacher and mentor for sequentially acting in both roles. However, our study adds to the earlier mentioned challenges MTs face in their double responsibility when simultaneously performing both roles (e.g., Rajuan et al., 2007). MTs wanted STs to practise and learn from difficult situations; conversely, they wanted to protect their pupils against possible mistakes of STs. We found two major challenges. First, MTs experienced a challenge in deciding when and how to transfer responsibilities to the ST. The second challenge was deciding whether 
to intervene during STs' lessons. This last challenge has been described to some extent by Post (2007). She described six effective mid-lesson interventions of MTs, namely ignore, intervene, interject, interact, interrupt and intercept. In her description of these six types of interventions, and in her explanation of the effectiveness of each intervention for STs' learning, Post focused on the development of the ST. Based on our findings, we suggest that MTs' decision whether, when and how to intervene, could also be strongly influenced by their teacher role and their focus on pupils' learning.

In mentoring an ST, MTs continuously experience a dilemma, in their pre- and postlesson conversations, when transferring the responsibilities to the student, as well as during STs' teaching. MTs have to continuously balance serving the needs of pupils' and STs' development. We found that MTs tended to prioritise pupils' benefits, rather than STs' development. We argue that in order to improve MTs' contribution to STs' learning, MTs need to be aware of their mentor role, and have to take into account not only the development of the pupils but also of the STs.

In our study, the majority of the MTs perceived both possibilities and challenges of the combination. However, two MTs did not mention any challenge, and they did more often notice reinforcement of the mentor role on the teacher role than the other MTs. In contrast, another MT mentioned many challenges and no reinforcement. This might be explained by the relationship between MT and ST, which is an important factor for a successful student teaching period (Bullough \& Draper, 2004; Maynard, 2000). A good match might explain the positive feelings of wellbeing and competence that MTs experience and may have several causes. First, MT's mentoring strategies might fit STs' learning needs (Rajuan et al., 2008). Mentoring strategies such as providing emotional and psychological support may positively influence STs' learning (Bullough \& Draper, 2004; Feiman-Nemser, 2001; Maynard, 2000). Second, a good match between the MT's and ST's pedagogical views might result in the ST approaching the pupils in a way the MT wants. STs might then teach relatively well because the MT's rules and routines fit with their view of teaching. Third, a good match between MT and ST may be caused by MTs' acknowledgement of the ST as a teacher as well as a learner. The two MTs who did not mention any challenges described a participatory and reciprocal way 
of teaching and equality in the relationship with their STs. An equal relationship and MTs' awareness of STs as learners may allow MTs to share their expert interpretation of classroom events and pupils' learning. These MTs may enhance the capacities for interpretation of and response to STs (Edwards \& Protheroe, 2010) and provide STs with sufficient space to "show their stuff" (Awaya et al., 2003, p. 54). Fourth, a mutual liking of the mentor and ST may lead to a positive relationship.

In sum, when MTs and STs do have a good relationship, as was described by the two MTs who did not mention any challenges between the mentor and teacher role, MTs seemed to be more excited about the mentoring and the positive influence of the mentor role on their own, and their STs', competence and wellbeing.

\section{Limitations and further research}

Although our findings provide additional understandings to the literature, several limitations apply. The limited number of cases only allows for a first exploration of MTs' perceptions of challenges and possibilities of combining teacher and mentor roles in primary education. In addition, participation in the study was voluntary. MTs who experience more struggles might have refused to participate; therefore, the ones who have been sampled may be relatively highly satisfied with their mentoring.

We used retrospective interviews to gather our data. Looking back after a certain period on earlier experiences might yield biased results. MTs' interpretations of their experiences might be influenced by later experiences or MTs' recall of experiences might not be adequate (Kelchtermans, 1993; Kvale, 2007). In addition, MTs were asked about their experiences and perceptions. What actually happened in classrooms or during mentoring conversations was not directly investigated. Perceptions, possibilities and challenges that our MTs reported will have to be confirmed by observing MTs when actually mentoring STs.

We suggest that future studies explore MTs' considerations when they simultaneously perform their teaching and mentoring tasks, especially when the ST is teaching their pupils. In addition, observing what happens in class in situations that challenge 
experienced MTs is an important research avenue to explore. As Hobson et al. (2009) noted, much research on mentoring relies solely on MTs' retrospective accounts, and observations in mentoring situations that ask for simultaneous role performance are a useful addition. Finally, we suggest investigating MTs' role perceptions and their implications for the quality of the STs' learning environment.

\section{Implications}

Our finding that MTs clearly felt that being the teacher of the pupils was their primary role and being an ST mentor was perceived as an aside may have implications for their role in the STs' process of learning to teach. Our study suggests that MTs merely facilitate training of STs by giving them their class and letting them teach as much as possible (Eraut, 2004), that MTs often think that mentoring means nothing more than providing a place for STs to practice their teaching and offering a little support (Borko \& Mayfield, 1995; Hall et al., 2008), and that MTs rarely explain why they teach the way they teach (Jones, Reid, \& Bevins, 1997; Zanting, et al., 1998). When confirmed in a larger sample, these results might explain findings from mentoring studies that describe the low impact mentoring had on STs' learning (e.g., Borko \& Mayfield, 1995; Wang \& Odell, 2002). The role perceptions of MTs in our study may negatively affect the quality of the STs' learning environment. To reduce this impact, STs will have to be able to reflect independently to learn to teach. Teacher training institutes will have to prepare STs for such reflection.

Our study showed that when the MTs discussed how their mentor and teacher roles sequentially developed, MTs perceive both roles to be complementary with the potential to reinforce each other. Being a (good) teacher is a condition for becoming a (good) MT, and by being an MT, they said, their competence and wellbeing as a teacher increased. However, we also found that teachers did not automatically develop mentor skills or responsibilities. This finding is a clear call for professionalisation of primary education mentors. Our study confirmed that MTs mentor the way they teach (Martin, 1997; Orland, 2001; Orland-Barak, 2001, 2002, 2005; Orland-Barak \& Yinon, 2005). Accordingly, MTs do not mentor according to the principles of the mentoring literature, such as stimulating STs into deeper levels of thinking and reflection (Feiman-Nemser, 
2001), promoting inquiry (Stanulis, 1995) and explaining the rationales behind the teaching approaches they use (Zanting et al., 1998). We recommend induction and professionalisation activities to include attention to MTs' need to acknowledge STs as teachers and as learners (Awaya et al., 2003), and to include careful and sufficient attention to and adequate reflection on the development of both roles, and, when appropriate, a separation of the mentor and teacher roles. Based on the findings of Orland-Barak (2001, 2002, 2005), who investigated the passage from being a teacher of pupils to becoming a mentor of teachers in secondary education, we recommend MTs to gain insights into the differences between their teacher and mentor roles. The goals of both roles differ and can conflict. To help STs learn, MTs need to be aware of their mentor role. Paying sufficient attention to this role shift, taking a new role, and coping with the tensions this role shift might introduce is important (Pillen, Beijaard, \& Den Brok, 2013). When MTs become more aware of their mentor role and the goal conflict between both roles, MTs will better be able to recognise the ST as learner and to mentor according to STs' learning goals and learning needs (e.g., Feiman-Nemser, 2001). 


\section{APPENDIX: SAMPLE INTERVIEW QUESTIONS}

\section{Roles}

- What do you think are the characteristics of a good mentor and a good teacher?

- What, in your perception, is your role or task as a mentor and as a teacher?

- How would you typify yourself as a mentor and as a teacher?

\section{Development}

- How has mentoring (this student) influenced or changed you as a mentor and as a teacher?

- What mentoring situation do you remember very clearly? For example, did you have a positive experience, in which you thought: "Oh, yes...", as an "eye opener"? How did this situation stimulate your development?

\section{Dilemma}

- Did you have any problems, such as conflict situations, dilemmas, or an (internal) conflict, as a mentor teacher? How did you cope with that? How have you changed due to this dilemma/situation?

\section{Relation}

- What, in your perception, is the relationship between the mentor and teacher role?

- Do you think both roles can positively influence each other?

- Do you ever experience tension between these roles? 


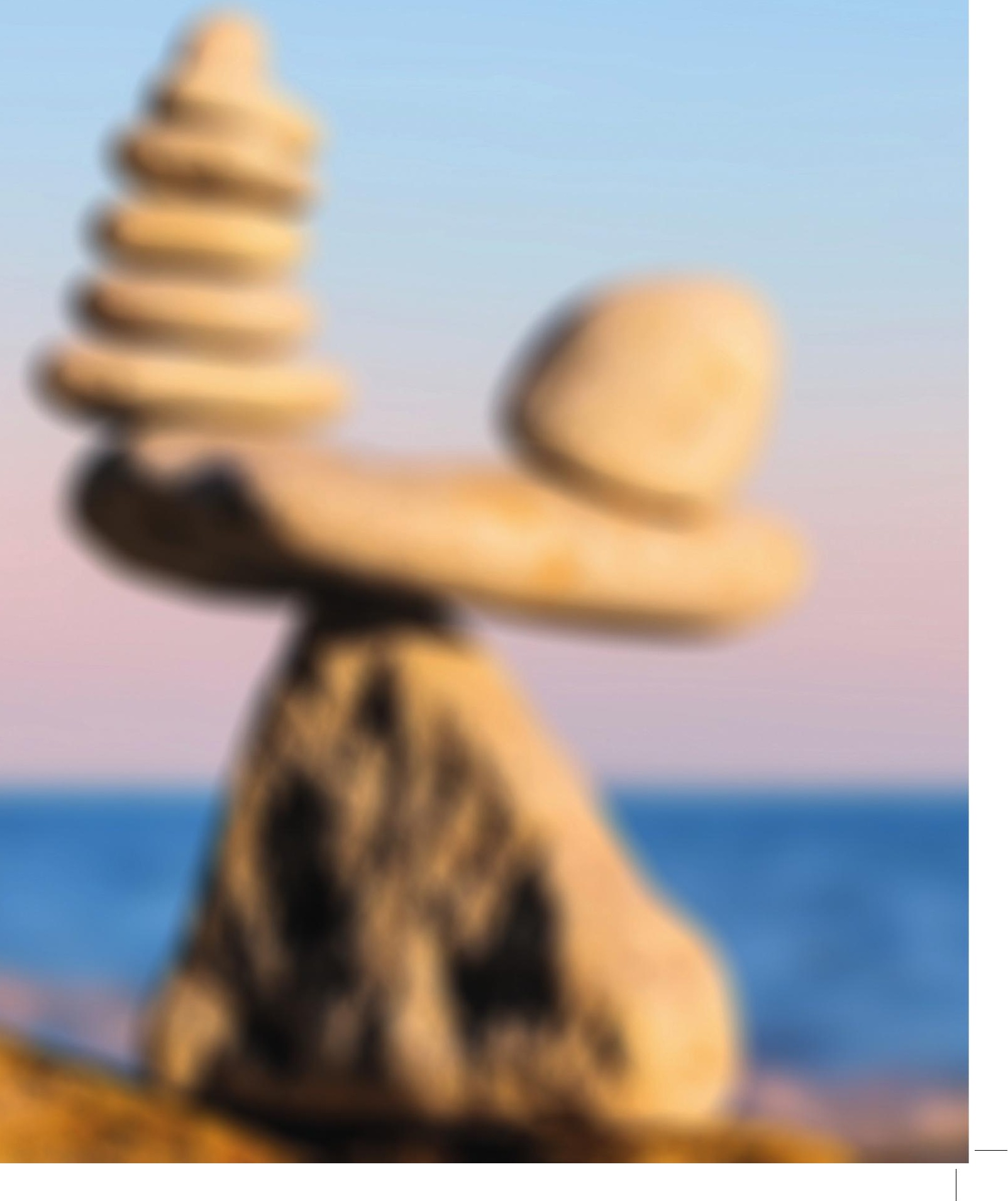




\section{CHAPTER}

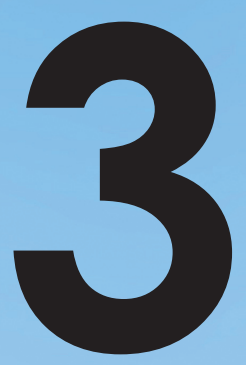

\section{Mentor Teachers' Practical Reasoning about Intervening During Student Teachers' Lessons ${ }^{3,4}$}

In this exploratory study, we analysed mentor teachers' reasoning about whether, when, and how to intervene during student teachers' lessons. We applied Fenstermacher's (1986) theory on practical arguments and found that mentor teachers intervene primarily by guiding their pupils. Mentor teachers balance situational premises (e.g., student teacher and pupil characteristics, and triggers such as pupils behaving disruptively or student teachers making mistakes in the lesson content), value premises concerning mentoring and teaching, and empirical premises about the effects of intervening on students teachers' and pupils' wellbeing and development. We suggest mentor teachers' intervening to not only cater to pupils' but also to student teachers' development needs.

3 This chapter is based on: Jaspers, W. M., Prins, F., Meijer, P. C., \& Wubbels, T. (2018). Mentor teachers' practical reasoning about intervening during student teachers' lessons. Teaching and Teacher Education, 75, 327-342. doi:10.1016/j.tate.2018.07.004

4 Acknowledgement of author contributions: J, P, Me and W designed the study; J recruited participants and collected the data; J and Me developed the interview; J constructed the coding scheme; J and P analysed the data; J drafted the manuscript; J, P, Me, and W participated in finalising the manuscript and approving it; P, Me, and W supervised the study. 


\section{INTRODUCTION}

Mentoring during student teaching has been reported to be an important aspect of teacher training (Hobson, Ashby, Malderez, \& Tomlinson, 2009), and mentor teachers (MTs) significantly influence the development of student teachers (STs) (Anderson, 2007; Beck \& Kosnik, 2002; Borko \& Mayfield, 1995). Good MTs help STs become effective practitioners, for example, by modelling good professional practice (Roehrig, Bohn, Turner, \& Pressley, 2008). Other studies, however, describe mentoring as having a low impact on STs' learning (e.g., Borko \& Mayfield, 1995; Wang \& Odell, 2002), which might be a result of the complexity of being a good mentor (Hall, Draper, Smith, \& Bullough, 2008; Hawkey, 1997; Orland, 2001). Particularly challenging for being a good mentor is the combination of being a mentor and a teacher in one's own classroom (Jaspers, Meijer, Prins, \& Wubbels, 2014, see Chapter 2). As mentors, MTs support STs in practicing and acquiring the knowledge, beliefs, and skills that enable the STs to teach in ways that are fundamentally different from how the MTs themselves were taught (Borko \& Mayfield, 1995; Hammerness et al., 2005). As teachers, MTs are responsible for the development and wellbeing of their pupils. These two responsibilities might compete with each other (e.g., Collison \& Edwards, 1994; Edwards, 1998; Goodfellow, 2000; Jaspers et al., 2014, see Chapter 2; Rajuan, Beijaard, \& Verloop, 2007). An earlier study (Jaspers et al., 2014, see Chapter 2) revealed that MTs felt that being a teacher of the pupils was their primary task, and being an ST mentor was generally perceived as an aside, an additional task. A typical and challenging situation for MTs occurred when an ST was teaching the MT's pupils and the MT observed an interruption to the normal course of events. Such situations might be valuable learning experiences for STs, giving them the opportunity to learn from mistakes and thus improve their teaching. Jaspers et al. (2014, see Chapter 2), however, found that in these situations, MTs tend to intervene by guiding the pupils. When MTs intervene for example, because they are more concerned about the wellbeing of pupils than of the ST's learning, the latter can be at risk (e.g., Edwards, 1998). As a result, STs are not provided with adequate responsibility, autonomy, and freedom in the classroom (e.g., Collison \& Edwards, 1994). 
MTs might have various reasons, as mentor as well as teacher, for their intervening or abstaining from intervening when the normal course of events in the classroom is disturbed. Insight into such reasoning and MTs' explanations for intervening or abstaining might help improve the impact of mentoring, and specifically, the quality of MTs' ST guidance during ST teaching. Therefore, the present study aimed to explore the practical reasoning concerning whether, when, and how to intervene during STs' lessons. After describing what is known about MTs' interventions and considerations during STs' teaching, we will summarise Fenstermacher's (1986) theory on practical arguments which we will use as a heuristic to obtain insight into MTs' practical reasoning.

\section{MTs' interventions}

Various articles on mentoring have mentioned MTs' tendency to intervene (e.g., Glenn, 2006; Kent, 2001; Rajuan et al., 2007; Woods \& Weasmer, 2003), but few explicitly examined the characteristics of interventions. Ben-Peretz and Rumney (1991) reported that MTs differ in terms of their active involvement in lessons. Some MTs tend to interrupt during STs' lessons, while others do not. MTs corrected the STs as well as the pupils when pupils misbehaved or became too noisy. Wang (2010) distinguished three categories of interventions: 1) active intervention, including both direct (the MT intervenes in the lesson herself) and indirect (the MT prompts some pupils to ask the ST questions); 2) passive intervention (an MT responds to a question by the ST); and 3) no intervention. Post (2007) described six intervention strategies that increase in the extent of classroom process disruption and in pupils' and ST's awareness of MT's intervention. The lowest disruption evolved from "ignore" (the MT does not respond at the time a problem occurs). The most disruptive is "intercept," which means the MT takes over the lesson and brings it to closure, such as when the class is out of control and the ST lacks the skills to re-establish authority. Ben-Peretz and Rumney (1991), Post (2007), and Wang (2010) describe various interventions, but these do not cover all interventions mentioned by the MTs in our previous study. Specifically, the tendency of these MTs to intervene by guiding the pupils is underexposed (Jaspers et al., 2014, see Chapter 2). 


\section{MTs' considerations}

Whether, when, and how MTs intervene might be explained by a role conflict MTs might perceive because of the dual loyalty to STs' learning and pupils' learning (Clarke, Triggs, \& Nielsen, 2014). Although MTs hand over their classrooms to the STs, observe lessons, and provide feedback, MTs have been reported to feel concerned about the children in their care (Edwards, 1998; Hopper, 2001; Stanulis, 1995). In order to protect both students and pupils from failure, MTs create safe places and carefully structured tasks for STs (Collison \& Edwards, 1994) and their feedback aims to prevent potential ST mistakes (Edwards, 1998; Edwards \& Protheroe, 2004). When STs make mistakes and face difficulty in teaching, MTs find it hard to refrain from directive interventions and to allow STs to fail when simple interventions during their teaching could have immediately improved the situation (Kent, 2001).

In research that explored MTs' reasons for intervening, Wang (2010) found that MTs' major reason for intervening was "caring about pupils." Other principles underlying a decision to intervene concern "ST self-esteem," "ST authority," "professional identity," "solving problems," "accumulating experience" (Wang, 2010), "teaching strategies," "content," and "discipline of pupils" (Ben-Peretz \& Rumney, 1991). However, according to Wang, various other underlying values and principles for intervening have not yet been discovered.

\section{Practical reasoning about intervening}

The relation between MTs' actions and thoughts is complex (cf. Kagan, 1992; Pajares, 1992; Zanting, Verloop, \& Vermunt, 2001). Teachers' beliefs and knowledge are often implicit and thus difficult to make explicit (Zanting et al., 2001). Fenstermacher (1986) presented a method (as suggested by Green (1976), based on an interpretation of the work of Aristotle) to illuminate teachers' reasoning about acting: the practical argument. Practical arguments are post hoc descriptions of practical reasoning that teachers indicate as fair and accurate accounts of actions and that serve to explain or justify what a teacher did (Fenstermacher \& Richardson, 1993). When a person thinks about what he or she did or ought to do in a specific situation, given the commitment to the roles he or she has undertaken, this is a case of practical reasoning (Pendlebury, 
1990). Practical reasoning takes place not only in retrospect when considering actions that have already been performed (Fenstermacher, 1986) but also when thinking about what we might do (for example, intended and hypothetical actions) in a particular set of circumstances (Pendlebury, 1990). In this study, we apply Fenstermacher's (1986) practical argument as a heuristic to investigate MTs' reasoning about intervening, without making a distinction between actual performed actions and actions described in another way.

A practical argument consists of a series of premises contributing to the decision or intention to act in response to questions such as "What shall I do?" or "Why did I do that?" (Morine-Dershimer, 1987). Fenstermacher and Richardson (1993) distinguished four types of premises:

1) The value premises indicate the desirable conditions, desired state of affairs, or a value or expression of moral good that the actor associates with these consequences. For example, "As a teacher, I want my pupils to learn; as an MT, I want my ST to learn."

2) The stipulative premises are statements that define, interpret or establish meaning, and are examined using theory or well-grounded conceptions of the learner, the subject matter, and the form and manner of instruction. For example, "Well-managed classrooms yield gains in learning."

3) The empirical premises are statements of principles denoting the consequences that might be expected to follow the action. The empirical premise can often be appraised using evidence gained from careful observation and study. For example, "Direct instruction is a proven way to manage classrooms."

4) The situational premises describe the context or situation in which the action occurs. For example, "My ST is teaching my pupils not confirming the principles of direct instruction and the pupils are not behaving well."

These four premises in the argument, whether explicitly stated by the teacher discussing an action, or implicitly found in the teacher's description of the event, lead to the action, or intention to act, or to avoiding the action (Morine-Dershimer, 
1987). In the above, this might be, for example "I am intervening / I will intervene by organising my class according to the principles of direct instruction" or "I am intervening / I will intervene by making my ST organise the class according to the principles of direct instruction."

Although practical arguments have been criticised by some (e.g., Confrey, 1987; Munby, 1987), others explain how and why investigating practical arguments might clarify the complex practice of teaching (e.g., Pendlebury, 1990), because these show links between specific thoughts and specific actions (Morine-Dershimer, 1987). Fenstermacher's practical argument has been found to be an effective approach for understanding the actions and reasoning of teachers (Fenstermacher, 1987), student teachers (Morine-Dershimer, 1988; Tidwell \& Heston, 1998; Vesterinen, Toom, \& Krokfors, 2014), and teacher educators (Tidwell \& Heston, 1998).

We expect practical arguments also to be useful in understanding MTs' practical reasoning because these comprehensively capture many reasoning aspects, such as the situation, MTs' beliefs, and their relation to actual actions and intentions to act. Thus, the influence of MTs' double roles and values on the reasoning and the relation between premises and actions might become clear. We expect that exploring MTs' practical arguments will provide insight into the type of premises contained in MTs' practical reasoning, particularly given the MTs' commitment to both roles when the ST is teaching MT's pupils.

Additionally, a practical argument focuses on the MTs' decision-making process and not on whether the MT's action is right or wrong. This suits our research aim, namely, to explore how MTs deal with those conflicting values, how this influences MTs' actions, and which reasons MTs use in explaining their interventions. The following research question will be examined: What is mentor teachers' practical reasoning concerning whether, when, and how to intervene during student teachers' lessons in primary education? By using the practical argument approach, we will answer the following subquestions: How do MTs intervene? How can situational, value, stipulative and empirical premises be characterised? Which premises do MTs use when they explain 
their intervening or intention to intervene? In addition, we will explore the mutual relation between the premises and how MTs' practical reasoning for intervening can be described.

\section{METHOD}

\section{Participants and context}

In this qualitative, exploratory study, MTs were interviewed about their reasoning concerning intervening. The aim of our study was to explore the breadth of MTs' practical reasoning about their actions. Therefore, we invited MTs with a variety of characteristics. The first seven MTs were recruited by telephone from an institute's list of MTs mentoring STs at the time. The response rate was 64\%, and the primary reason for MTs' nonparticipation was lack of time. After the seven MTs were interviewed, we decided to increase the number of situations in which MTs reasoned about intervening. Consequently, we continued inviting MTs by telephone and asked STs of two cohorts of the institute to invite their MTs to participate personally. We stopped recruiting when sufficient heterogeneity was reached. This resulted in a total sample size of eighteen MTs. The MTs worked in all grade levels, from kindergarten to Grade 8, and had a varying amount of experience in teaching and mentoring, from one year to more than 30 years. The participants worked in urban and rural schools, in regular and special education, and they mentored both female and male STs in various years of their study. The participant group consisted of two males and sixteen females. Four MTs were trained in mentoring. Most of these MTs had a positive attitude toward mentoring, although some of them were not enthusiastic about the ST they were mentoring at that time and about participating in the research. However, we convinced them to participate because we also wanted to capture these experiences.

This study was performed in the context of a four-year undergraduate teacher education programme for primary education in the Netherlands. In this programme, STs follow university courses and are placed in various schools where they teach under 
the supervision of an MT. Each class contains approximately 30 pupils, and one teacher teaches all the subjects. The MT responsible for the class in which the ST has been placed guides and assesses the ST. Over the years of study, STs' responsibility for the pupils increases until they assume full responsibility in their final year. The average age of the STs is approximately 20 years old (ranging from 17 to 26).

\section{Data collection and procedure}

In all eighteen interviews, MTs talked about the combination of the mentor and teacher role in general and reasoned about their intervening in situations in which an ST was teaching the MT's pupils. The questions were open-ended because of the exploratory design of the study (Miles, Huberman, \& Saldaña, 2014). An example of an interview question is as follows: "What tensions did you experience between both roles?" In the interviews, MTs explained their intervening during STs' lessons and the considerations for their intervening, based on specific situations they actually experienced and remembered as well as hypothetical situations in which they stated how they might intervene or not.

MTs' reasoning about intervening was collected in two different groups of MTs. First, seven MTs participated in semi-structured interviews about their perceptions of combining the mentor and teacher roles, as described above. Second, in the semistructured interview with the remaining eleven MTs, we chose to provide the MTs with an extra stimulus to come up with more examples of various situations in which they reasoned about intervening. Preceding the semi-structured interview, we were present during an ST's lesson in the MT's classroom. When situations occurred in which the MT seemed to have the intention to intervene or actually intervened, we made a note of it and used these situations as extra input for the semi-structured interview. These situations were used to encourage MTs to talk about situations in which they were likely to intervene, actually did intervene, or abstained from intervening. We asked MTs to explain their actions. Examples of questions concerning the situations included the following: "Why would you or did you intervene/not intervene? What were/are your considerations for that action?" Probing questions were also used, such as "Why?" or "Can you give an example?" These questions were asked for the actually performed 
actions and, subsequently, for situations that MTs had experienced in the past. To gain insight into MTs' reasoning about intervening in various situations, these questions were also used to explore hypothetical situations. In these cases, MTs stated their actions as hypothetical or intended actions. During the last interviews, we noticed that MTs provided information that already had been gathered during the earlier interviews.

All interview questions were piloted with three mentors who did not participate in the actual study. Based on this pilot, some questions were added or restated in a more transparent way. Sample interview questions are listed in the Appendix.

For all interviews, the MTs orally provided informed consent. The interviews, which lasted 20 to 125 minutes, were conducted by seven research assistants, mostly in pairs but always with one MT. The 18 interviews were all audiotaped, transcribed, and analysed in the same way.

\section{Data analysis}

From the interview data, 61 fragments were selected in which MTs talked about situations when the ST is or becomes (partly) responsible for the teaching of the pupils. These fragments were analysed in three phases.

In the first phase of analysis, we selected segments that contained information about MTs' reasoning about their actions during STs' teaching, and we coded the main categories in these fragments according to the four premises of Fenstermacher and Richardson (1993) and (avoidance of) actions. During coding, it appeared that we could not distinguish between empirical and stipulative statements because MTs did not clarify the origin of what they stated, whether it be experiences and previous observations (empirical premise), or conceptions of evidence (stipulative premise). Because there were barely references to conceptions of evidence, we labelled these premises as empirical. MTs used various situations in explaining their intervening, such as situations experienced in the past, situations that were observed during the lesson, hypothetical situations (what would they have done if the situation had been 
slightly different), and situations in the future. As a result, MTs stated their actions, or avoidance of actions, in various wordings in the interviews, such as (not) actually performed actions, hypothetical actions, and intended actions. In the analysis, these were all categorised as actions. To improve the validity of our findings, two raters independently rated the statements in actions and the three premises for half of the interviews. Then, they discussed their differences until consensus was reached. Thereafter, the remaining half of the interviews were analysed in the same manner by the first author. Additionally, an audit control ${ }^{5}$ (Akkerman, Admiraal, Brekelmans, \& Oost, 2008) was performed, in which the auditor concluded that all information that should be considered when investigating MTs' practical reasoning about intervening was coded and fully covered.

In the second phase of analysing the interviews, using the ATLAS.ti computer program, subcategories and common themes within the described actions and premises were formed and used as codes. The subcategories will be described in the Results section. The coding of the premises by two raters resulted in good interrater reliability agreement (see Table 1).

In the third phase to explore how MTs explained their actions and what factors triggered these actions, we coded the relation between the premises and described actions. For each premise statement, we coded which action, namely, intervening (directed toward the ST or at the pupils), not intervening, or other actions, according to the MT, was related to that premise statement. The interrater reliability for this analysis was good (Kappa =.81).

5 Audit report available upon request. 
Table 1. Actions, Premises, Number of Subcategories, Inter Rater Reliability, and Number of Subcategories after Combining to Make Results Synoptic

\begin{tabular}{lccc}
\hline Action/Premises & $\begin{array}{c}\text { Subcategories } \\
\text { used for Kappa }(N)\end{array}$ & Kappa & $\begin{array}{c}\text { Subcategories } \\
\text { in results }\end{array}$ \\
\hline Action & 10 & .919 & 5 \\
$\begin{array}{l}\text { Situational premise - situational } \\
\text { characteristics }\end{array}$ & 12 & .963 & 10 \\
$\begin{array}{l}\text { Situational premise - situational } \\
\text { triggers }\end{array}$ & 12 & .889 & 7 \\
$\begin{array}{l}\text { Value premise } \\
\begin{array}{l}\text { Empirical premise - general } \\
\text { empirical premises }\end{array}\end{array}$ & 19 & .842 & 15 \\
$\begin{array}{l}\text { Empirical premise - specific } \\
\text { empirical premises }\end{array}$ & 25 & .842 & 16 \\
\hline
\end{tabular}

Note. ${ }^{\text {a }}$ After the interrater reliability was established, we merged some subcategories to make our findings synoptic. For example, in the category "situational characteristics", we merged the code "STs' competence" and "MTs' confidence in the ST."

The following excerpt (Figure 1) provides an illustration of the coding procedure using Fenstermacher's (1986) practical argument theory.

\begin{tabular}{|c|c|c|c|c|}
\hline \multicolumn{2}{|c|}{ Interview fragment } & \multirow{2}{*}{$\begin{array}{l}\text { Phase 1: } \\
\text { Premises } \\
\text { SP }\end{array}$} & \multirow{2}{*}{$\begin{array}{c}\text { Phase 2: } \\
\text { Subcategories } \\
\begin{array}{c}\text { Sit. trigger: pupil } \\
\text { related - disruptive } \\
\text { pupil(s) }\end{array}\end{array}$} & \multirow{2}{*}{$\begin{array}{c}\begin{array}{c}\text { Phase } 3: \\
\text { Relation } \\
\text { action }\end{array} \\
\text { Not intervene }\end{array}$} \\
\hline MT8: & $\begin{array}{l}\text { "Take Ben for example, he } \\
\text { was doing the same thing all } \\
\text { the time. }\end{array}$ & & & \\
\hline & The ST was not noticing it. & SP & $\begin{array}{l}\text { Sit. characteristic: ST } \\
\text {-other }\end{array}$ & Not intervene \\
\hline & $\begin{array}{l}\text { But if you [the MT] withdraw } \\
\text { yourself and sit on the } \\
\text { couch, you see lots of things } \\
\text { happening that you wouldn't } \\
\text { have seen otherwise. }\end{array}$ & EP & $\begin{array}{l}\text { General EP: teaching } \\
\text { - other }\end{array}$ & Not intervene \\
\hline & $(\ldots)$ & & & \\
\hline & $\begin{array}{l}\text { I do have the tendency [to } \\
\text { intervene], }\end{array}$ & Action & $\begin{array}{l}\text { Intervene direction } \\
\text { unclear }\end{array}$ & \\
\hline & but I won't do it." & Action & Not intervene & \\
\hline
\end{tabular}


Int.: "Why not?"

MT8: "Because it is her lesson.

She has to learn from it,..

VP

And when I interfere, I undermine...Some pupils will get the idea that I'm undermining the authority of the other.

Because I'm still the teacher. That is always the case.

But if I would, on top of that, interfere they will be like: ah well, this is a teacher I do not have to listen to.

That is not necessary."

Int.: "And do you always do that, that you don't interfere?"

MT8: "No, unless I think it is dangerous. For example, what I saw with Mary,

Eh, Yes, I want to avoid accidents.

Eh, yes, sometimes, you simply cannot resist,

When you walk past someone and you notice that he is doing nothing

then you tap his shoulder, or eh..

But, in principle, I try not to interfere, except if it becomes really dangerous."

EP

EP

EP

EP

SP

VP

EP

SP

VP
Mentoring: ST should Not intervene teach by herself
Mentoring: ST should Not intervene develop
General EP: Teaching Not intervene and mentoring
- implications of intervening

General EP: T\&M: Not intervene double role in general
General EP: T\&M: Not intervene implications of intervening

Teaching: orderly working atmosphere

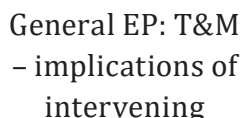

Sit. trigger: pupil

related - wellbeing at risk

Teaching: pupils' wellbeing should not be at risk

Specific EP: MT other

Sit. Trigger: pupil related - disruptive pupil(s)

Action

Intervene directed toward the pupils
Intervene

direction

unclear

Intervene

direction unclear

Intervene

direction unclear

Intervene

direction unclear

Intervene

directed toward the pupils

Other

Not intervene$$
\text { pupils }
$$
should not intervene

Figure 1. Excerpt from interview with MT8. Int. = Interviewer; SP = situational premise; Sit. = Situational; VP = value premise; $\mathrm{EP}=$ Empirical premises; $\mathrm{T} \& \mathrm{M}=$ teaching and mentoring. 
Finally, to convey a sense of how combinations play a role in practical reasoning, we explored how the premises aggregately appear in MTs' reasoning about intervening.

\section{RESULTS}

The results are presented in three parts. Part 1 addresses the various types of actions that we found in the interviews in MTs' practical reasoning. In Part 2 the situational premise, value premise, and empirical premises are described and the relation between each premise and the actions are elaborated. Finally, in Part 3, we combine the premises and explore how MTs use the combination of premises to reason about their intervening.

\section{Part 1: MTs' actions during STs' teaching}

Coding the main categories yielded 220 actions (i.e., actual performed, hypothetical, and intended actions). After coding the subcategories, we distinguished three types of actions, namely, intervening, not intervening, and other actions. In Table 2, frequencies and examples of these actions are provided.

In the first action, intervening, we distinguished three types of direction of the interventions, namely, 1) toward the pupils, 2) toward the ST, or 3) undetermined.

The second action, not intervening, included not only explicit mentions of the MTs not intervening, or not having the intention of intervening, but also explanations of what they did or would do in that situation aside from intervening, and thereby implicitly stating not to intervene. Examples of these explanations were "then I can let go more easily" or "then I transfer the teacher responsibilities more and more" or "then I fade out my guidance." 
Table 2. Actions: Frequencies, Number of MT's Mentioning an Action, and Examples

\begin{tabular}{|c|c|c|c|}
\hline Actions & Freq. & $\operatorname{MT}(N)$ & Examples \\
\hline Intervene & 117 & 17 & \\
\hline Directed toward pupils & 42 & 15 & $\begin{array}{l}\text { Then I shout: "Stop! You know you are not } \\
\text { allowed to do that!" (MT 18). }\end{array}$ \\
\hline Directed toward ST & 18 & 9 & $\begin{array}{l}\text { Then I say to the ST: "Listen, do not clean } \\
\text { up yourself. Have a seat, and give the pupils } \\
\text { specific tasks, and look what will happen. } \\
\text { Observe." (MT1). }\end{array}$ \\
\hline Direction unclear & 57 & 14 & Then I want to interfere (MT8). \\
\hline Not intervene & 36 & 11 & $\begin{array}{l}\text { It is not that I'll intervene in the group of } \\
\text { pupils that the ST is teaching (MT11). }\end{array}$ \\
\hline Other actions & 67 & 17 & $\begin{array}{l}\text { Observe the ST (19), observe the pupils } \\
\text { (7), discuss after lesson (9), teach a } \\
\text { group of pupils in the classroom (6), do } \\
\text { something else in the classroom (6), leave } \\
\text { the classroom (15). }\end{array}$ \\
\hline Actions - Total & 220 & 18 & \\
\hline
\end{tabular}

We labelled the third category of actions as other actions. These were all actions that MTs explicitly mentioned when they reasoned about what they do or would do when the ST is teaching, and that were not labelled as intervening or not intervening, for example, observing the pupils, or leaving the classroom.

The MTs in our study mentioned intervening in around half of the actions and when MTs said they intervened or would intervene (117 quotations, 17 MTs), in nearly half of the instances (60 quotations, $15 \mathrm{MTs}$ ), they were specific about the direction of their intervening, namely, toward the pupils or toward the ST. During the other half (57 quotations, $14 \mathrm{MTs}$ ), they described their intervening in more general terms, such as “...then, I intervene." If MTs indicated how they would or did intervene, they mentioned guiding the pupils (42 quotations, $15 \mathrm{MTs}$ ) more than guiding the ST (18 quotations, 9 MTs).

The manner in which MTs (would) intervene toward the pupils varied, in their own words, from making eye contact, signalling to a pupil, answering questions from pupils, speaking or shouting to the whole group of pupils, or practicing the teacher role again. 
An example of the latter is MT10, who explained: "I noticed that when the pupils started their craft activity, and some were even working already, I started taking up my teacher role again." The way in which MTs talked about guiding STs during teaching varied from short organisational tips to guiding the ST and gradually reducing this guidance. For example, MT1 would tell the ST: "Listen, don't clean up yourself. Have a seat, and give the pupils specific tasks and look what will happen. Observe!" MT4 explained: "I will not let the ST do everything immediately. In the beginning, the difficulty of keeping order remains the [mentor] teacher's responsibility, and then you can let go, step by step."

\section{Part 2: Situational, value and empirical premises; Relations between premises and actions}

To obtain insight into why and when MTs intervene, we analysed the premises and how MTs used them to explain their (not) intervening. Here we will elaborate on these premises and their relation to MTs' actions.

\section{Situational premises}

When coding the main categories, we found 199 statements on situational premises, divided into two categories (see Table 3). The first category is labelled situational characteristics of the ST, the MT, the pupil(s) and the lesson. The second category is labelled situational triggers, which are deviations from the MTs' perceptions of how things should be done appropriately in the classroom and that prompted MTs to consider intervening. In the second analysis phase, we subcoded these situational premises.

\section{Situational characteristics}

The MTs mentioned 71 situational features in the argumentations for their actions and intentions to act. We distinguished these in terms of characteristics of the pupils (3 statements, 2 MTs); characteristics of the ST (25 statements, 10 MTs), such as STs' study year and competence; characteristics of the MT (21 statements, 10 MTs); and characteristics of the lesson (22 statements, 7 MTs). In particular, MTs' location in the classroom was an important MT characteristic that could explain MTs' intervening (12 statements, 8 MTs). For example, MT10 said: "Now, I sat too close to the pupils. I noticed I had the intention to quickly correct certain pupils because I was sitting close by." 


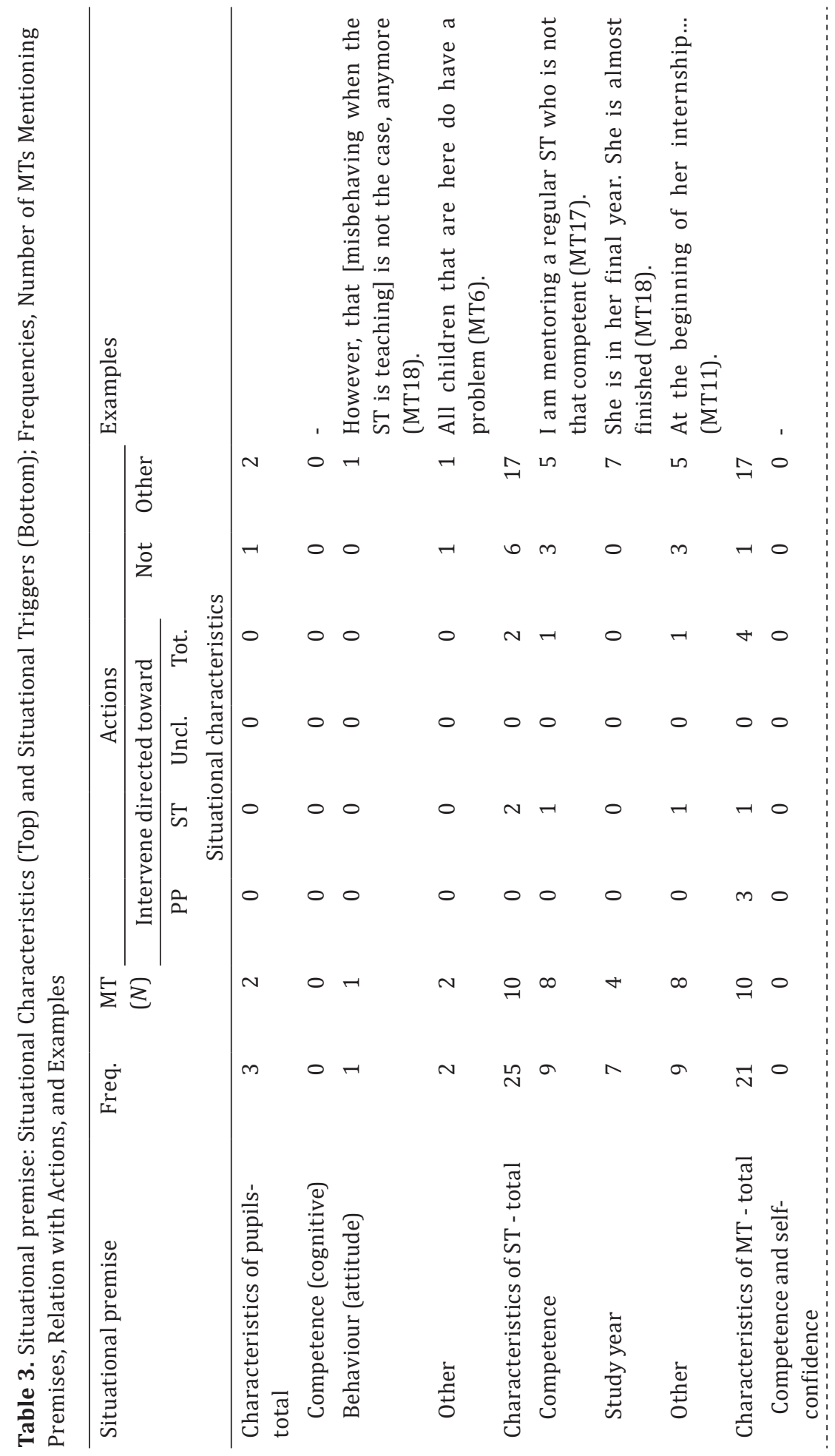




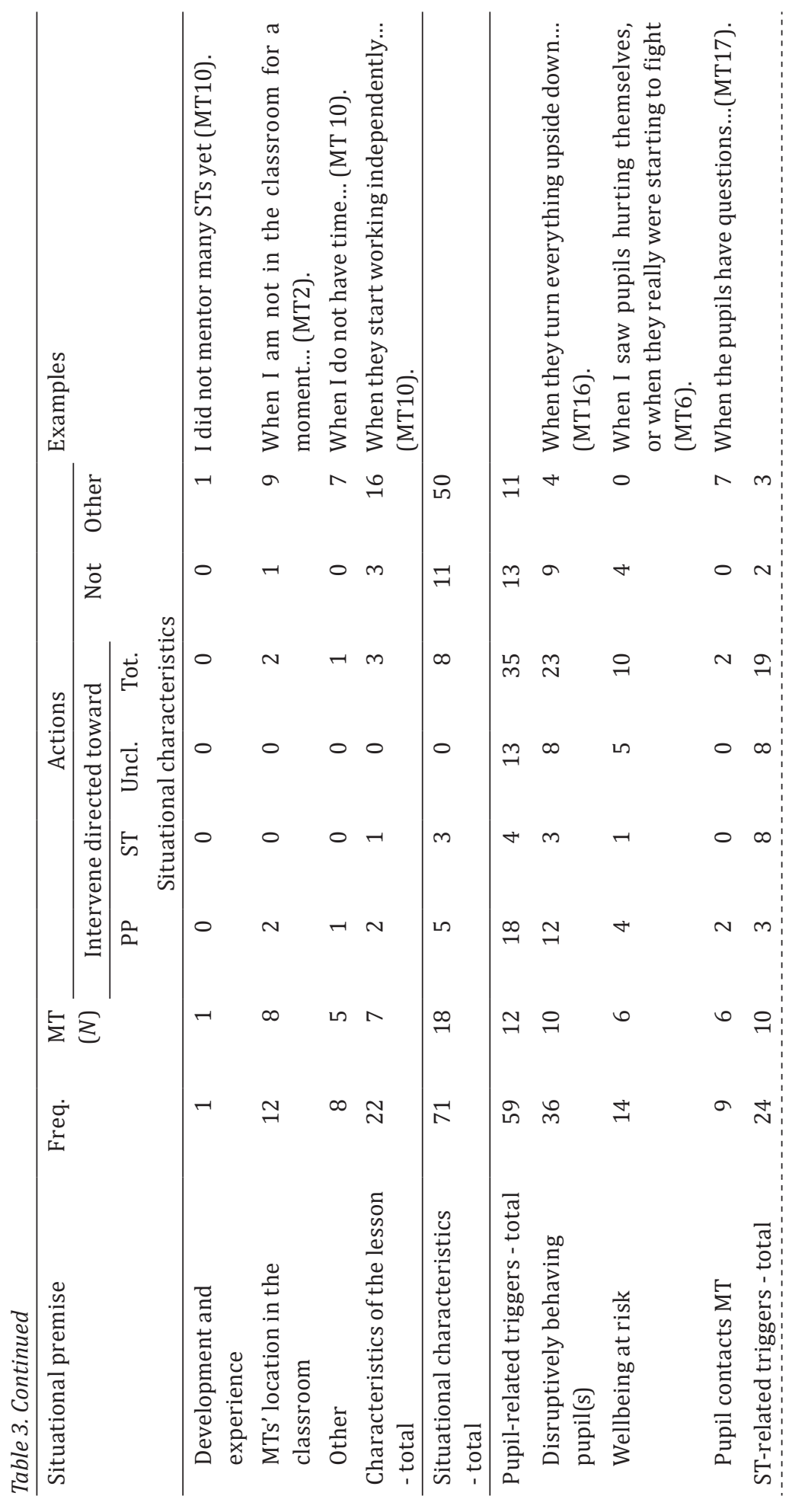




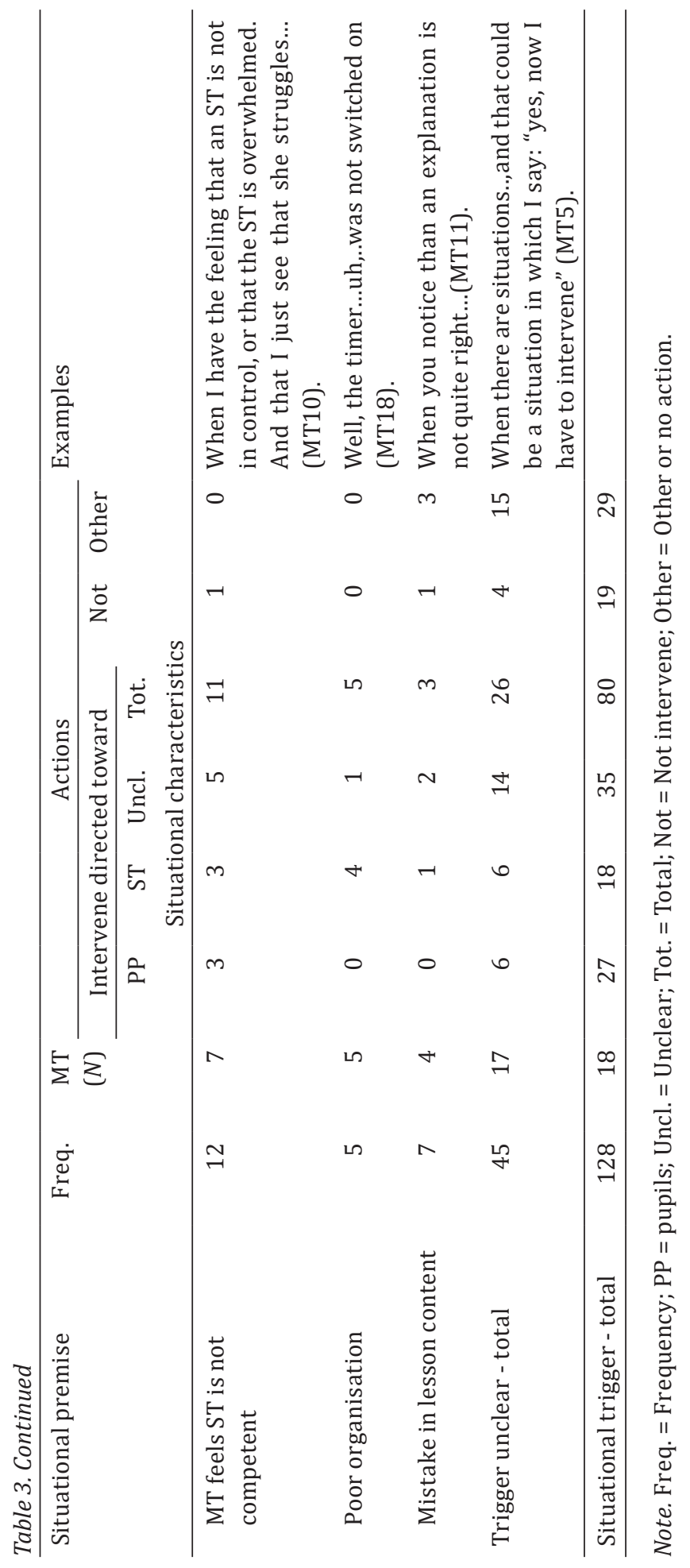




\section{Situational triggers}

The 128 situational triggers were divided into three main categories (see Table 3): pupil-related triggers (59 statements, $12 \mathrm{MTs}$ ), ST-related triggers (24 statements, $10 \mathrm{MTs}$ ), and triggers that could not be clearly classified as pupil- or ST-related (45 statements, 17 MTs). The most frequently mentioned situational trigger (36 in total) is one or more pupils who are not behaving well, for example, when pupils are noisy or are not following the rules.

\section{Situational characteristics and situational triggers and actions}

In coding the relation, we coded what action or intention to act could follow situational characteristics and situational triggers. Table 3 shows the frequencies of the premises mentioned by the MTs and the relation between each premise and the actions. MTs hardly mentioned relations between situational characteristics and their actions. They merely explained whether they intervene by referring to situational triggers. We also found that the direction of MTs' intervening was related to the situational triggers. In cases of pupil-related triggers, for example, when pupils behaved inappropriately, were not quiet, or were not working, the MTs would mostly react by guiding the pupil(s) in question. MT18, for example, said: "Well, for example, when the pupils bring two litres of water to my sand table, I shout: 'Stop, you know you are not allowed to do that."' The other way around, in cases of an ST-related trigger, such as when an ST made a mistake in the lesson content or exhibited ineffective organisation, MTs' interventions were directed toward the ST. For example, MT13 said: "Well, very occasionally, I whisper: 'Don't forget this...,' or 'You are forgetting to...'”'

\section{Value premises}

Coding the main categories yielded 214 value premises used by MTs to explain their actions and intentions to act during STs' teaching. When coding the subcategories, we distinguished three types: teaching values, mentoring values, and a combination of teaching and mentoring values. In Table 4, the frequencies and examples of the value premises are described. 


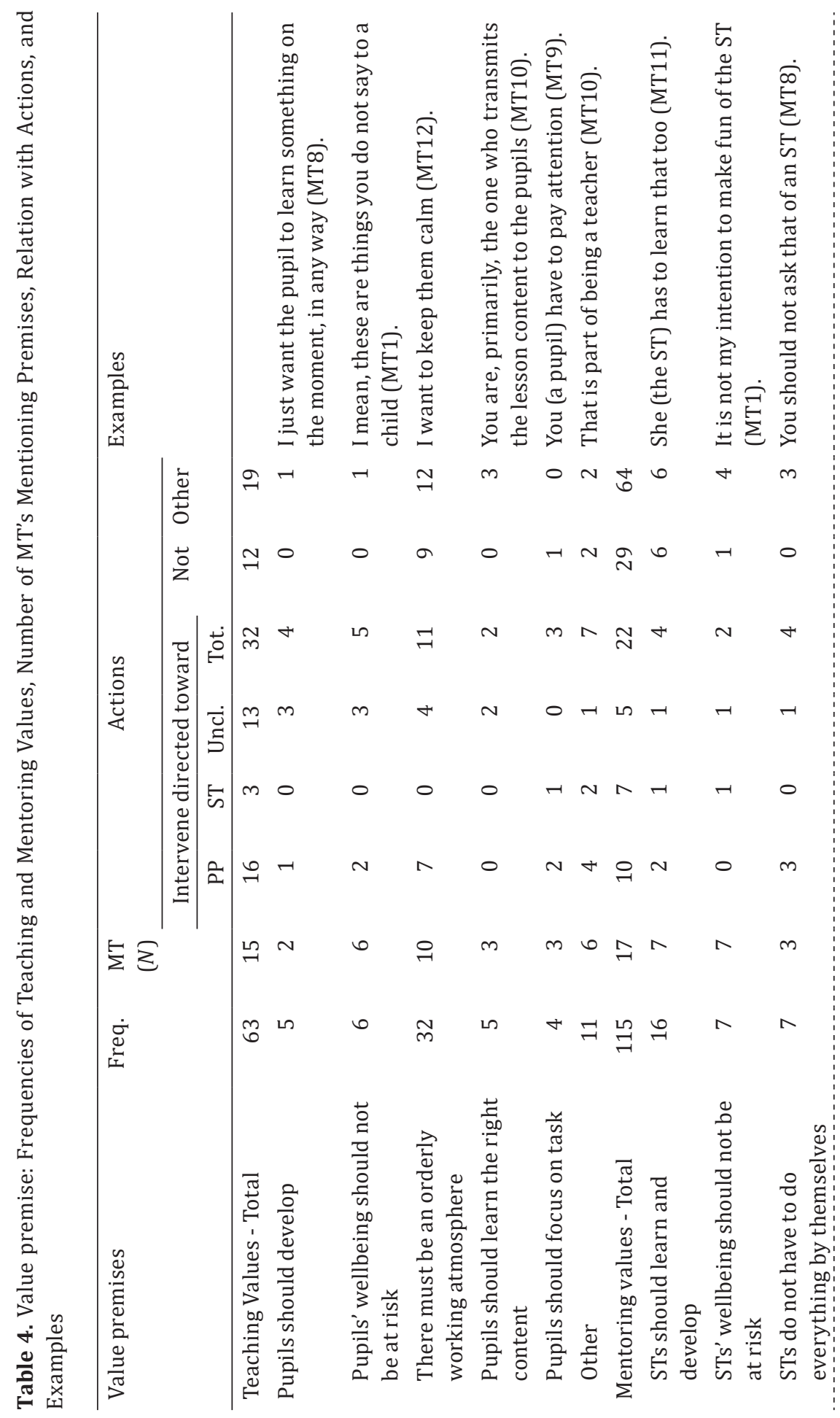




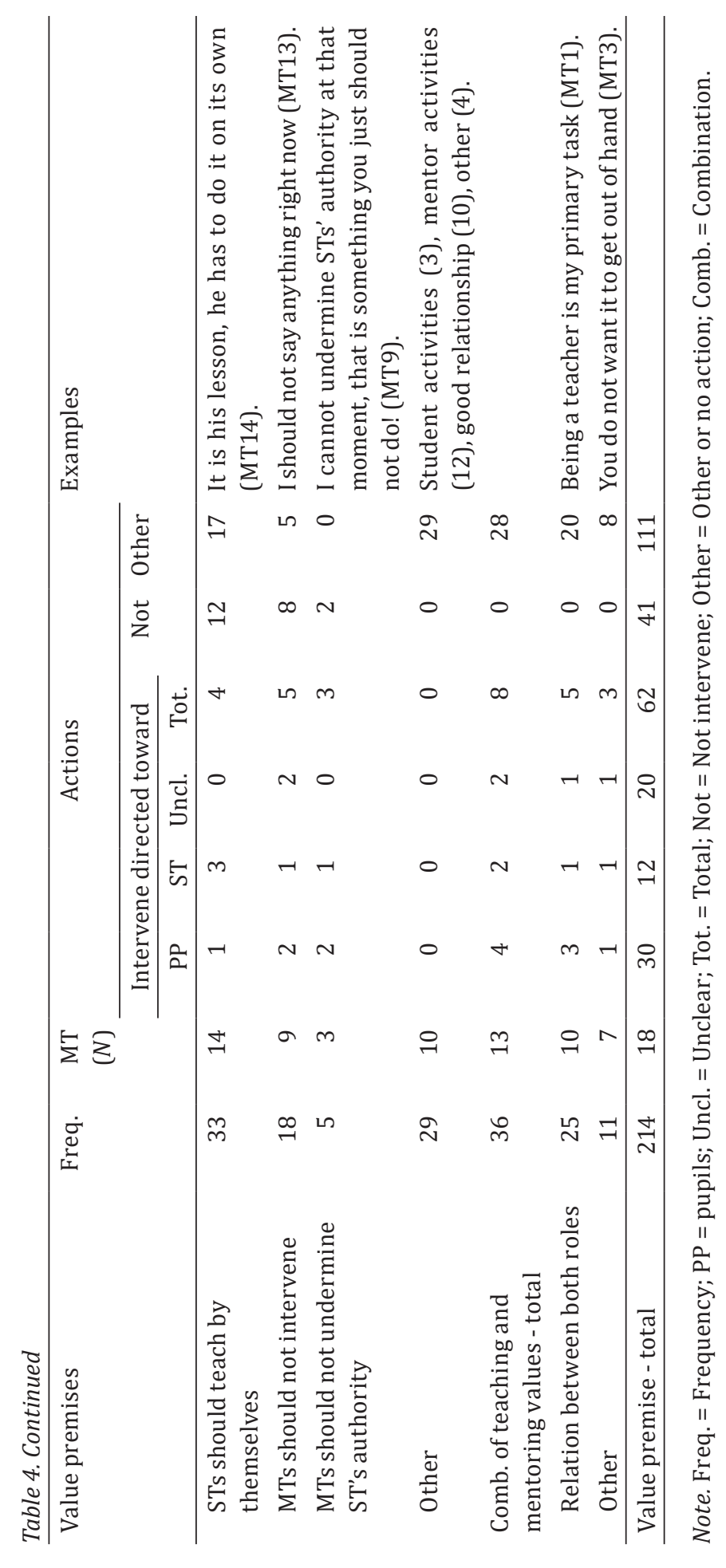


The 63 teaching values (15 MTs) reflected the MTs' belief that, in the context in which the ST is teaching, pupils' wellbeing should not be at risk (6 quotations, 6 MTs) and pupils should develop ( 5 quotations, $2 \mathrm{MTs}$ ), learn the right content ( 5 quotations, 3 MTs), and focus on task (4 quotations, 3 MTs). They also hoped for an orderly working atmosphere in which pupils behave and learn the rules (32 quotations, 10 MTs). Based on these frequencies, we interpreted that MTs feel that it is very important to have a quiet and orderly class with well-behaved pupils.

MTs mentioned a larger number of mentoring values (115 quotations, 17 MTs) than teaching values, and said most frequently that STs need to develop (16 quotations, 7 MTs), need to do the teaching by themselves (33 quotations, 14 MTs), and that MTs should not intervene (18 quotations, 9 MTs).

In the combination of teaching and mentoring values (36 statements, $13 \mathrm{MTs}$ ), MTs explained what they thought was right to do both from a teacher and mentor perspective. For example, MT4 said: "The first point is that you [the MT] are in front of the class and that things should run smoothly. And the second point is that you can hand over the class to the ST bit by bit. And I think..., you are responsible for the student, and for your group, so always the final responsibility." Additionally, MT11 said: "[...] [As an MT] that you should not intervene too much, that you want the student to gain experience...but... as a teacher you think: ooh, again a missed opportunity to [transmit] the lesson content." This last quotation illustrates that there could be a conflict between mentoring and teaching values. Namely, while MTs find it extremely important that STs practice on their own, they also want their pupils to work, behave, and learn the right content. In many situations, MTs realise one of these two values is at risk.

\section{Value premise and actions}

Based on coding the relation between MTs' value premises and their actions, in Table 4, we see that when MTs explained why they did or would intervene, they mentioned a larger number of teaching values (32 statements) than mentoring values (22 statements). When MTs described why they did not or would not intervene, they primarily explained this using mentoring values (29 statements) rather than 
teaching values (12 statements). This might indicate that for the MTs in our study, intervening during STs' lessons is related to the pupils' learning and development, and not intervening during STs' lessons is related to STs' learning and development.

Regarding the direction of intervening, MTs explained their interventions toward the pupils more in terms of teaching (16 statements) than mentoring values (10 statements), and in contrast, they substantiated their student guidance more with mentoring (7 statements) than with teaching values (3 statements). Interestingly, although the value "STs should learn and develop" was mentioned 16 times, this value was only used once in relation to the MTs' intervention directed toward the ST. These numbers suggest that stimulating STs' development is hardly given as a reason to guide the ST during the teaching.

Possibly as a result of the value conflict, MTs' actions are not always consistent with all of their values and not all values seem to fit their actions. For example, regarding the mentoring value "MTs should not intervene," we see in five statements that even in situations when MTs said they should not intervene, they also explained why they nonetheless did so. For example, MT13 said: "Well, yes, the only thing I catch myself doing is that sometimes I do intervene. That is just a reflex. [...] That is not always with an intention, you know, well, sometimes it is just as a reflex that I'm like uhh 'shush!' And then I think...I shouldn't say anything right now, but that is just a reflex [...] see, when you have been a teacher for 27 years, then, uh, you catch yourself sometimes automatically intervening, because being a teacher is such a large part of yourself." Regarding the mentoring value "STs should teach by themselves," in four statements, the MTs said that they would intervene. 


\section{Empirical premises}

When coding the main categories, we found 439 empirical premises in MTs' reasoning about their actions during STs' teaching (see Table 5). We distinguished two main types. The general empirical premises are MTs' ideas and theories about teaching, mentoring, and pupils' and STs' behaviour, and learning in general. The specific empirical premises are context-dependent premises about the characteristics of a specific ST, a specific pupil or class, and a specific MT. We will discuss these premises in relation to the actions and intentions to act that MTs mentioned in their reasoning.

\section{General empirical premises and actions}

In the argumentation for their intervening, MTs mentioned general empirical premises 298 times, which we divided into general empirical premises about 1) teaching, 2) mentoring, and 3) the combination of teaching and mentoring.

\section{Teaching}

The first empirical premise is about teaching, pupils, and pupils' learning and behaviour (43 statements, $14 \mathrm{MTs}$ ). The most frequently mentioned premise (16 statements, 10 MTs) was about maintaining order and the pupils' feelings of authority. MTs explained that pupils are used to their own teacher and that they tend to provoke the ST. This premise is used both to justify not intervening, and to justify intervening. For example, MT10 explained that she would not intervene "because I'm their teacher many days a week, and they [the pupils] see me more as an authority than the ST [...] and I just want the ST to get that as well." MT11 explained her reasons for intervening as follows: "Well, it's about the rules of this class..., when the ST is here..., the pupils, however, start to test them more often, but, then I will say something about it because of the pupils."

\section{Mentoring}

The second general empirical premise is about mentoring, STs, and STs' learning (73 statements, 16 MTs). MTs mostly mentioned the influence of (not) intervening on the ST (17 statements, $10 \mathrm{MTs}$ ). They used this premise as reason for not intervening as well as for intervening. Some MTs explained that intervening has a positive effect; namely, that it could be pleasant for the ST and could be seen as helping. Other MTs explained that intervening could negatively influence STs' wellbeing and authority. 


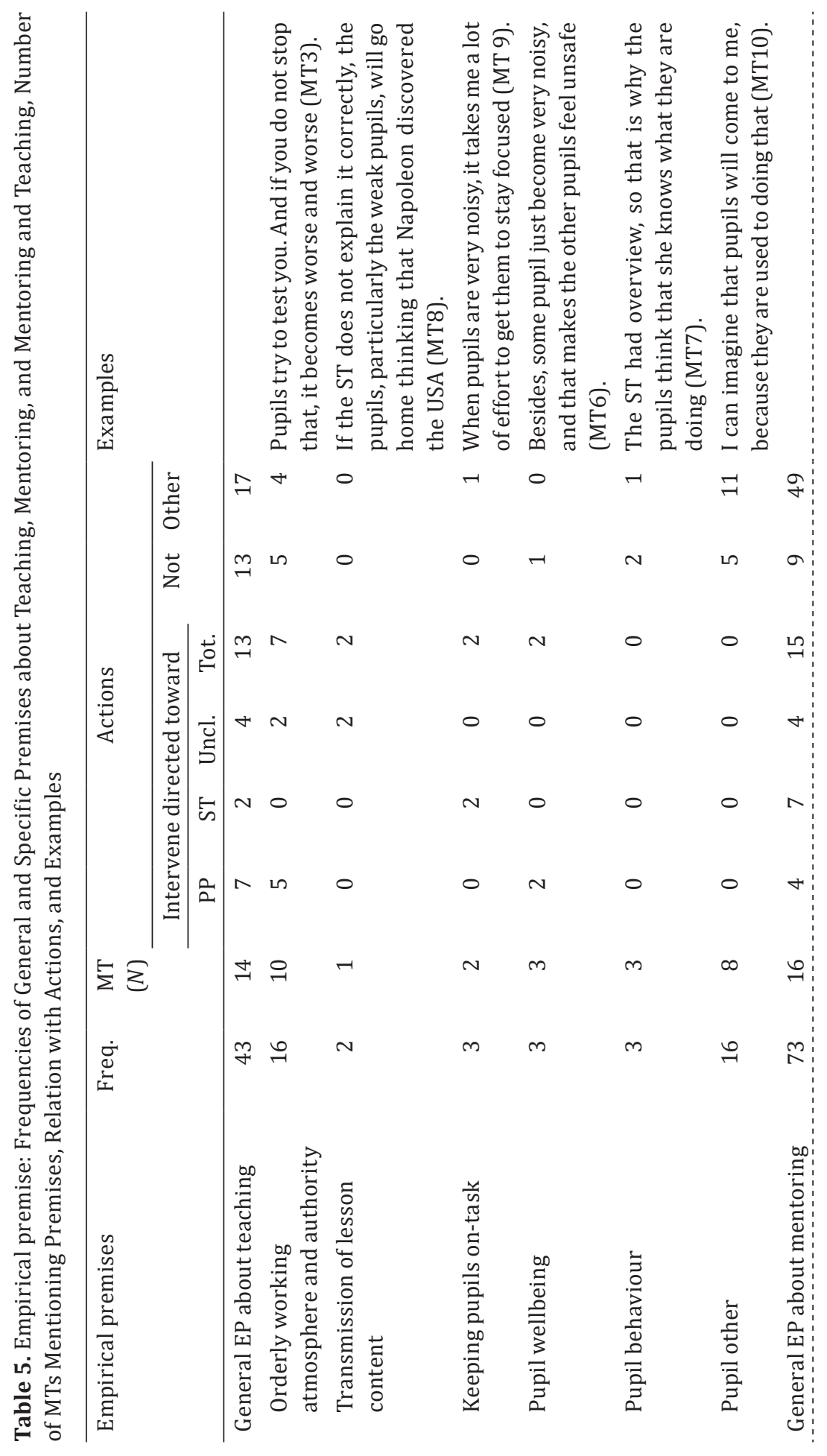




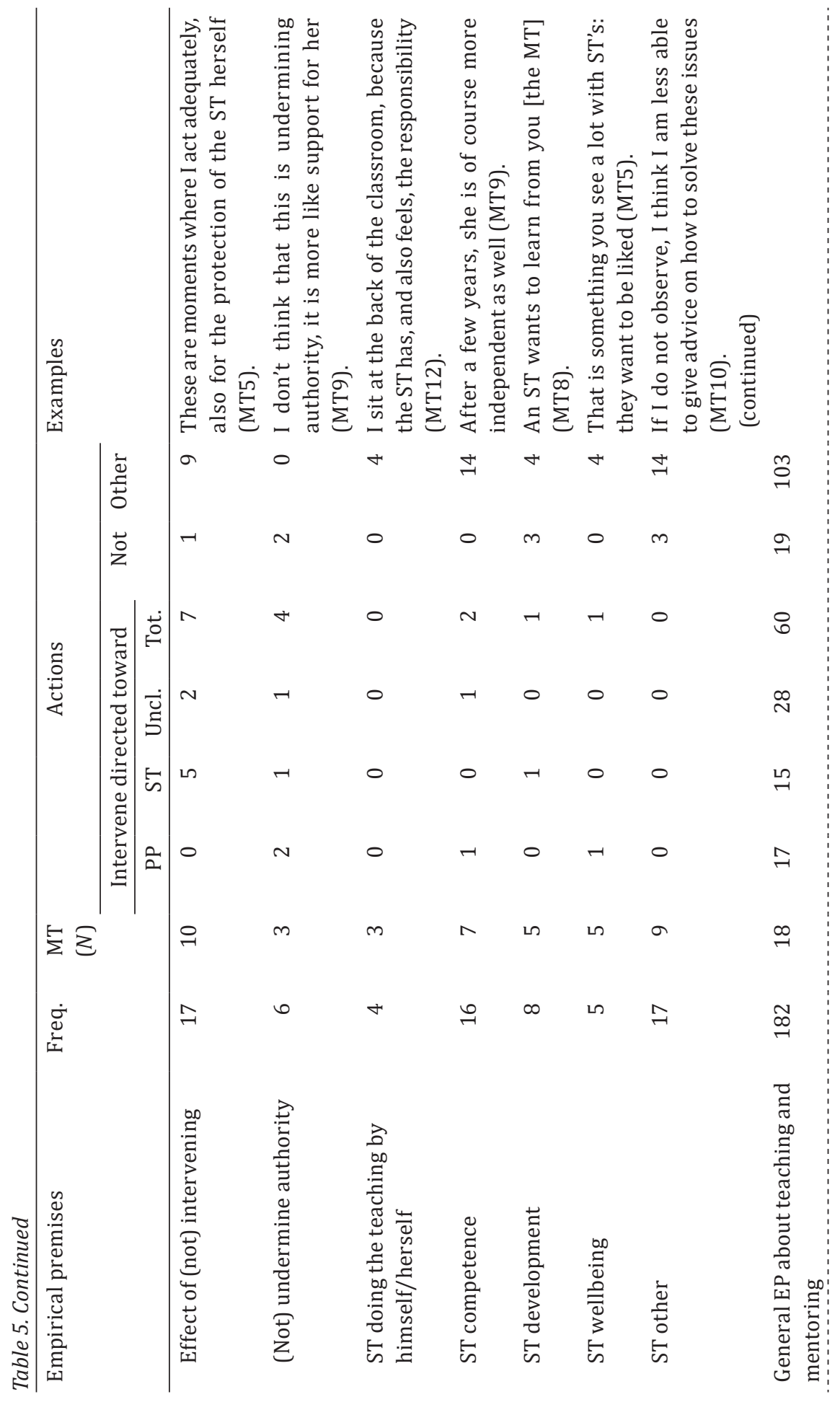




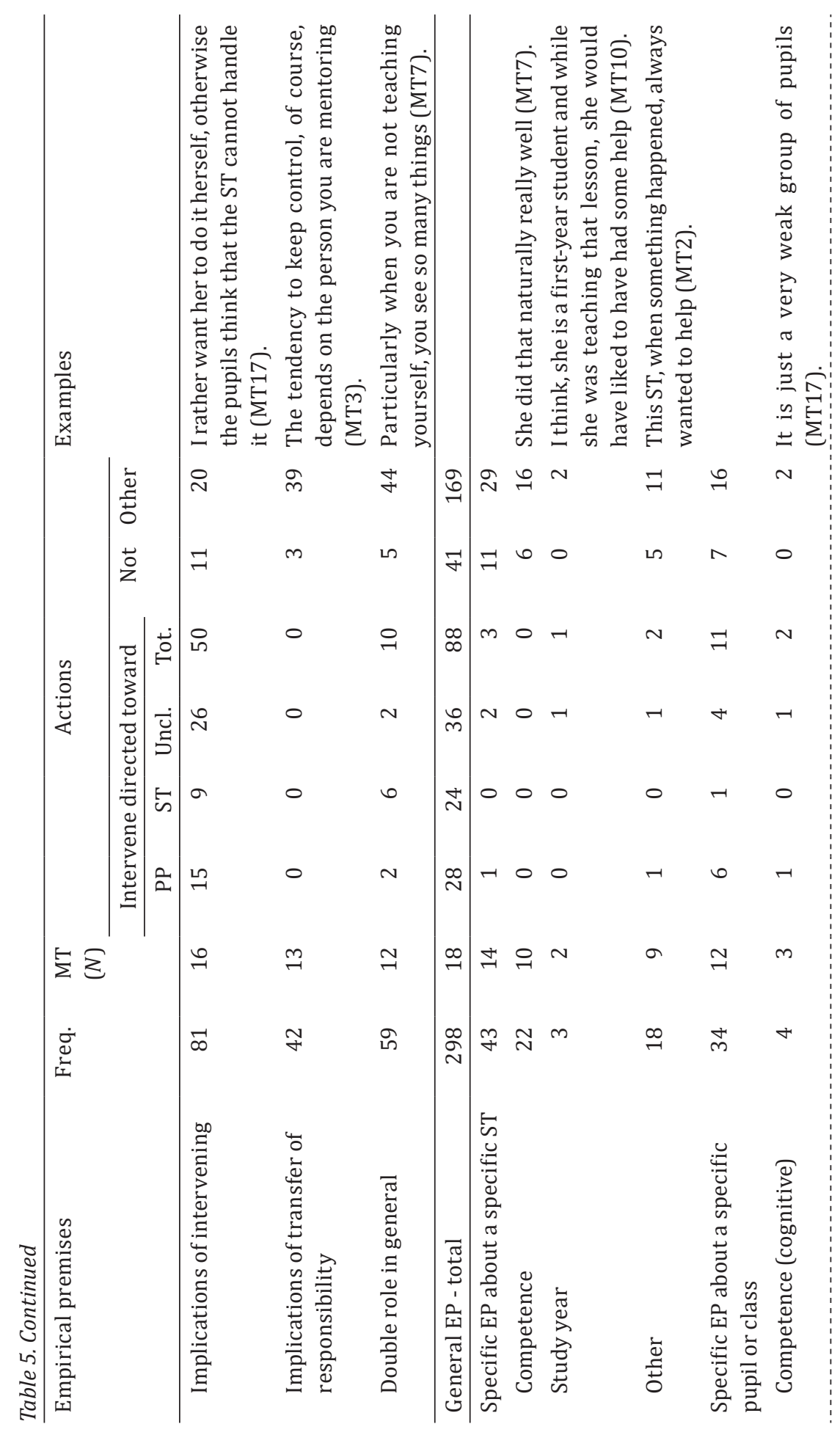




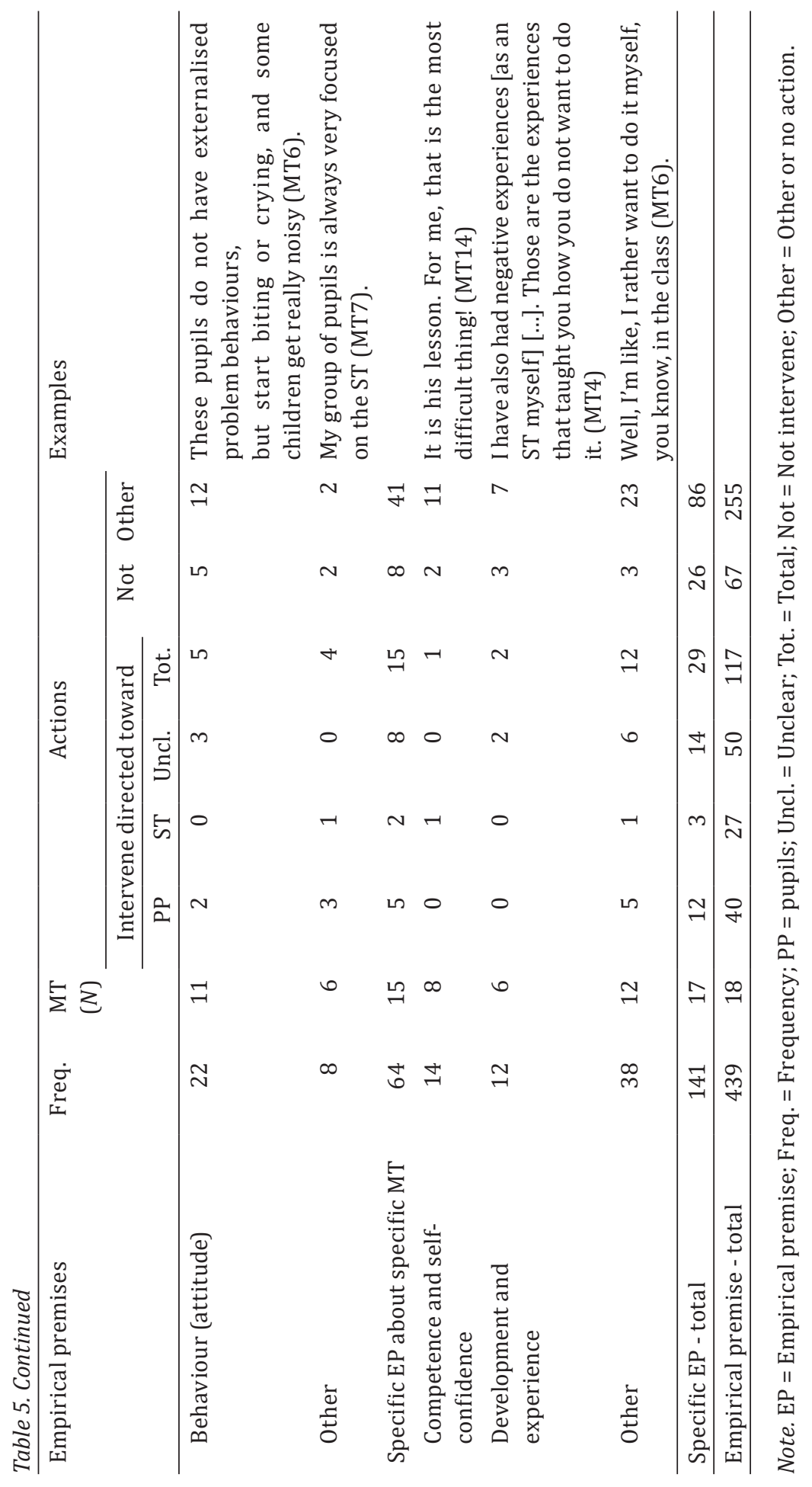


Another general empirical premise about mentoring that was frequently mentioned by the MTs was STs' competence (16 statements, 7 MTs). However, this premise is barely mentioned in MTs' explanation for their (not) intervening (2 statements, 2 MTs). This suggests that MTs in our study do not use the empirical premise of general STs' competence as reason for their (not) intervening, or they do not justify their actions during STs' lessons in relation to the STs' general competence.

Additionally, MTs did not frequently mention premises about STs' development as a reason for their intervening (1 statement) and not intervening (3 statements). Only MT1 mentioned STs' development as a reason for showing the ST where to look at or what to do during her teaching: "Because for the ST as well, there are learning experiences during a lesson." MT14 argued for abstaining from intervening as follows: "I think for the ST, it is also more pleasant that he becomes more independent by this," and "At a certain point, he has to do it by himself after he has graduated." For many MTs in our study, their actions seem unrelated to general empirical premises about STs' development.

\section{Combination of teaching and mentoring}

The third general empirical premise, which was mentioned most often in MTs' argumentation for their actions (182 statements, $18 \mathrm{MTs}$ ), combines teaching and mentoring. We divided this premise into three categories: implications of intervening (81 statements, $16 \mathrm{MTs}$ ), implications of transfer of responsibility (42 statements, 13 MTs), and the double role in general (59 statements, 12 MTs). In this study, we aimed to acquire insight into MTs' reasons for their intervening; therefore, we will focus here on the premises about intervening.

MTs' general empirical premises about intervening were related to the positive and negative effects of (abstaining from) intervening on the ST and the pupils. MTs explained that the negative effects of intervening are that the STs' authority is undermined, that pupils do not learn to listen to another person, and that intervening could be disruptive for both the ST and the pupils. Additionally, the STs' wellbeing could be negatively affected. For example, MT10 said: "Because you put the ST in a quite 
vulnerable position [...] because, the ST can feel quite offended by that." The negative effect of not intervening mentioned by the MTs is that things might get messy, that pupils do not learn appropriate behaviour, and that pupil or ST wellbeing is harmed. Furthermore, if MTs do not intervene, an environment that is not conducive for ST learning and teaching might be created.

According to the MTs, a positive effect of intervening might be a contribution to STs' wellbeing, and STs could experience the interventions as support. It could help them learn and become aware of the specific situation in which they can improve their teaching. MTs also explained that intervening could be positive for "an orderly working atmosphere" and could ensure that pupils resume working on their tasks. MTs said that by not intervening, STs could benefit, because then the ST has the teaching responsibility, could experience what is actually happening, and has the opportunity to learn to solve problems by him- or herself. However, no positive effects of not intervening for the pupils were mentioned.

\section{Specific empirical premises and actions}

MTs used not only general empirical premises (as "general rules") in their reasoning but also empirical premises (141 statements) referring to the specific context (as "exceptions" to the general rules) to justify their actions. We found three types: the characteristics of 1) a specific ST, 2) a specific pupil or class, and 3) a specific MT.

\section{Specific ST}

In their argumentation for their actions, MTs used empirical premises about the characteristics of a specific ST (43 statements, 14 MTs), such as the ST's competence (22 statements, $10 \mathrm{MTs}$ ). MTs are more likely to decide to abstain from intervening if an ST is exceptionally competent. For example, MT7 mentioned that in their first year, STs generally need some help when the pupils are getting noisy. However, at that moment she had an extraordinarily capable and confident first-year ST. She said: "This ST, she had an overall view, spoke to the pupils in a positive way, and noticed all the pupils very well." Therefore, the MT decided in the particular situation not to intervene (yet) and to observe a little longer in order to see if the ST could solve the problem herself. 


\section{Specific pupil or class}

MTs refer in the argumentation for their actions to the characteristics of a specific pupil or a specific class (34 statements, $12 \mathrm{MTs}$ ), such as a pupil's competence (4 statements, $3 \mathrm{MTs}$ ) and pupils' behaviour (22 statements, $11 \mathrm{MTs}$ ). MTs were more likely to intervene if a specific pupil or group of pupils needed more guidance, or had difficulty with appropriate behaviour. For example, when a specific pupil was not paying attention during the ST's explanation, MT18 decided to signal to this specific pupil. This pupil, according to the MT, really needed to focus during this lesson; she would not have signalled if another pupil was not paying attention. She said: "For him, it is just very important, because his vocabulary is limited."

\section{Specific MT}

The third specific empirical premise concerns characteristics of the MTs themselves (64 statements, $15 \mathrm{MTs}$ ), such as their own competence (14 statements, 8 MTs) and experience (12 statements, 6 MTs) as an MT. For example, MTs explained that in the past, they intervened more than they do currently, because they were not yet experienced in teaching and mentoring.

Interestingly, on comparing the three specific empirical premises, we found that the MTs in our study explained their actions and intentions to act more often using specific premises about their own characteristics (64 statements) than using premises about ST characteristics (45 statements), or pupil characteristics (34 statements). MTs might feel that their own characteristics, specifically their competence and experience, greatly influence their intention to intervene. Additionally, MTs argued that in specific situations, they did not intervene based on premises about STs' competence, but that they did intervene based on premises about pupils' specific behaviour. Table 5 shows that almost all interventions justified with specific empirical premises were directed toward the pupils. Apparently, MTs in our study did not use specific empirical premises when they explained their intervening toward the ST. This might indicate that MTs do not guide STs during their lessons based on STs' specific characteristics or learning needs. 
Based on the described relations between the premises and actions, MTs' reasoning process might seem to be conscious and deliberate. However, regularly during STs' teaching (and therefore during MTs' mentoring), this is not the case. Approximately a third of the MTs reported that there are many situations in which they intervened intuitively: as soon as they observe a trigger, they directly jump in, without deliberation or conscious decision-making. They do not think about their values and their interventions; they just intervene by guiding the pupils. When MTs were asked why they acted as they did, they explained that they did not even know that they had intervened or explained that they had intervened without thinking. For example, MT17 said: "Uh, I think, actually I'm the teacher then. Because I know the ST is able to do it herself, but that does happen without me knowing it. Because it is in my system like that. So I act like that, actually, ...it is more like a reflex, [...] so then, shortly, my teacher role surfaces." When interviewed about such situations, however, they were able to make the values and empirical premises underlying their actions explicit, enabling us to describe their unconscious reasoning process.

\section{Part 3: How MTs use the combination of premises to reason about their intervening}

So far, we have described whether and how MTs intervene, what premises they used, and how these premises separately related to MTs' actions. In Figure 2, we summarise our findings, namely, situational premises (Table 3), value premises (Table 4) and empirical premises (Table 5), leading to actions (Table 2) when an ST is teaching the MT’s pupils.

Generally, in their reasoning, the MTs in our study weighed, whether consciously or unconsciously, 1) the situational premises, which include information gathered by immediate observations of the situational triggers and the characteristics of the ST, the pupils, the MT, and the lesson; 2) their value premises concerning mentoring and teaching; and 3) their general empirical premises, such as ideas and theories concerning mentoring and teaching in general, and their specific empirical premises about themselves as an MT and about a specific ST or specific pupils. Based on an MT's personal balancing of these factors, an MT would intervene or would not intervene in a particular situation. 

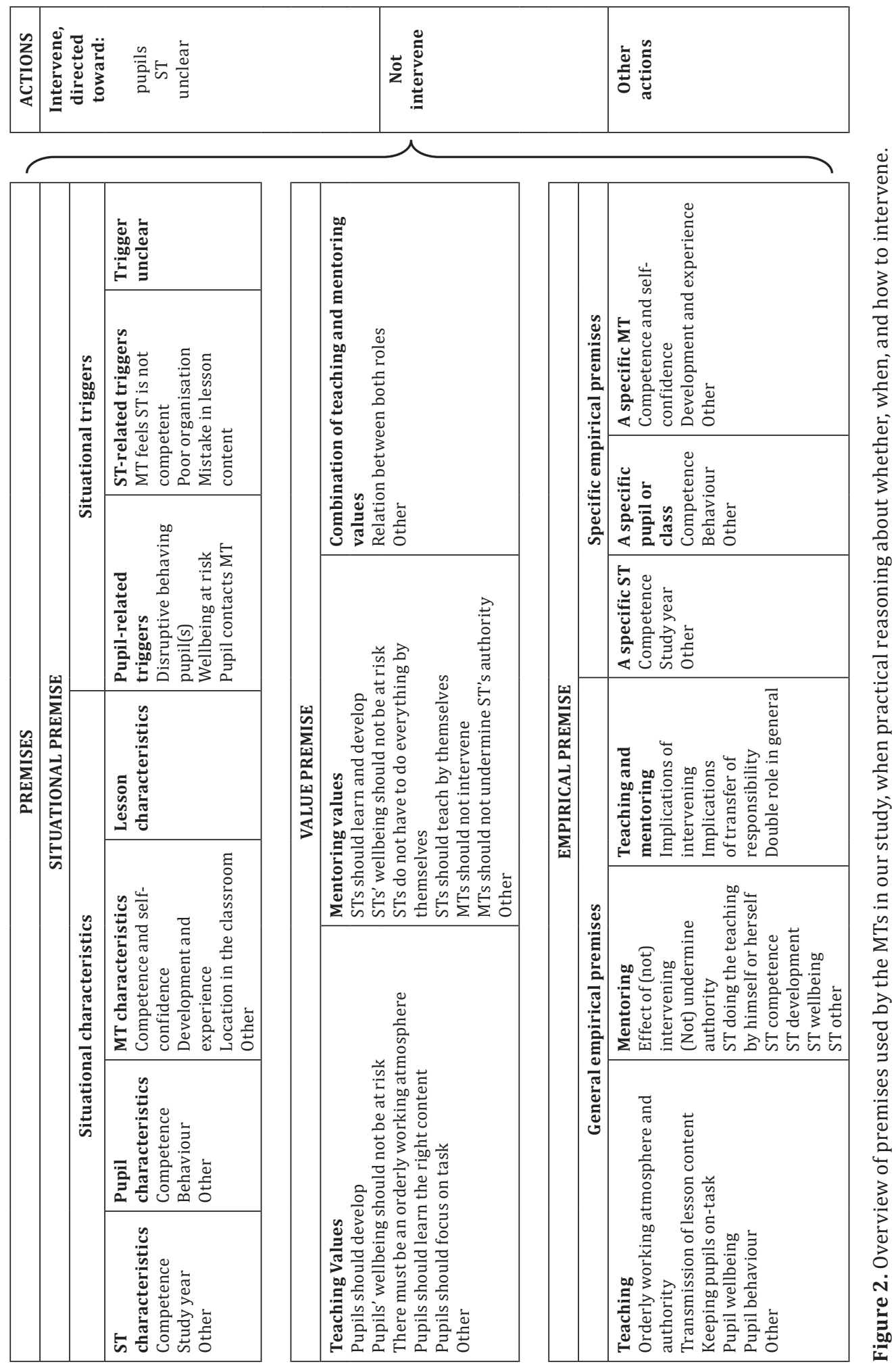
Now, we will show examples of the MTs' reasoning by describing a succession of situations in which the severity of the situational trigger increases. This growing severity leads to changing successive practical arguments illustrating how MTs' practical reasoning leads to intervening or abstaining from intervening.

\section{No situational trigger - MTs do not think about intervening}

While the ST was teaching the pupils, MTs continuously and intuitively assessed the lesson situation. As long as they observed that everything was going well, MTs did not perceive a situational trigger and did not experience tension between the observed situation and their basic values, namely, that "STs should teach by themselves," and that “there must be an orderly working atmosphere." Additionally, both MTs' mentoring and teaching values were fulfilled. Therefore, MTs did not think about intervening. The empirical premises in this situation were not about (abstaining from) intervening.

\section{Not a serious trigger - MTs think about intervening, but do not intervene}

When something in the situation changed, for example, when a few pupils started chatting, the MTs noticed a situational trigger. They experienced a situation where what they observed did not correspond with what they thought to be good or effective. In this situation, MTs experienced a conflict between their mentoring and teaching values. As a mentor, they believe that "STs should teach by themselves." However, with an increasingly severe trigger, this value came into conflict with their teaching value that "there must be an orderly working atmosphere," and this caused MTs to think about what they should do. When not intervening, MTs mentioned the positive effects on the ST of abstaining from intervening as an empirical premise, or they mentioned the negative effects of intervening on the pupils or the ST, such as "when an MT intervenes, ST's authority is undermined."

MTs continuously and carefully, and often unconsciously, considered whether they should intervene. For each trigger, MTs evaluated the severity of the trigger. The lowest degree of severity is that there was no threat (yet) for the wellbeing and development of the pupils or the ST. The highest degree is a severe risk for ST's and/ or pupils' wellbeing and development. MTs talked about a "threshold." When they felt 
the degree of the trigger was too disadvantageous or too severe because one of their values was harmed too much, they felt that the threshold for intervening had been crossed, and they intervened. MTs varied in their perception of what the threshold for intervening was. According to the mix of situational characteristics, the weight a particular MT gives to his or her mentoring and teaching values, and the strength of his or her empirical premises, the threshold or turning point from not yet intervening to intervening differs.

In principle, when the trigger was not yet perceived as highly severe, MTs' teaching value that "there must be an orderly working atmosphere" was not much harmed. Furthermore, the situation corresponded to MTs' mentoring values "STs should do the teaching alone" and "MTs should not intervene," and therefore, MTs tried not to intervene. Such abstaining from intervening was justified, for example, with the empirical premise of "if an MT intervenes, ST's authority is undermined."

\section{Intense trigger - MTs intervene}

If the situational trigger accumulated and became more intense, for example, because all of the pupils were shouting, MTs experienced considerable tension between the observed situation and their values about the desired situation. Additionally, in this situation, the value conflict between their basic values "STs should teach by themselves" and "there must be an orderly working atmosphere" was extensive. In order to regain their desired situation and to solve the value conflict, MTs intervened. When asked to provide argumentation for their intervening, MTs mostly emphasised their teaching values, such as "there must be an orderly working environment" and, compared to the previous situation, became aware of additional values, such as "STs' wellbeing should not be at risk" and "pupils' wellbeing should not be at risk."

In addition, other values (mostly the mentoring values), such as "STs should teach by themselves" and "MTs should not intervene" seemed to be less important, since the action "intervening" did not correspond with their previously mentioned value. Additionally, empirical premises that justified their abstaining from intervening, such as "if an MT intervenes, ST's authority is undermined," were overruled by other 
empirical premises about the negative effects of abstaining from intervening, about the positive effects of intervening, or by other statements that justified their intervening, such as "STs are not able to do everything on their own."

To summarise, when MTs perceive a situational trigger and MTs do not intervene, they might experience a tension between their teaching values and their actions, and when MTs do intervene, they might feel a tension between their mentoring values and their actions. Therefore, based on MTs' actions, one can identify the values that an MT eventually deems the most important. When the severity of the trigger grows, most MTs intervene in the end, from which we can determine that for most MTs, eventually, the teaching values become more important than the mentoring values.

Thus, in each particular situation, MTs balance the degree of the situational trigger that is perceived with their personal mentoring and teaching value and empirical premises. The MT's personal balance eventually leads to the specific threshold from not yet intervening to actually intervening for a particular MT in a particular situation.

\section{DISCUSSION}

This study examined MTs' practical reasoning concerning whether, when, and how to intervene during STs' lessons. We will discuss our most important findings, followed by the implications, and suggestions for further research.

\section{MTs frequently intervene toward the pupils}

MTs reported that they rather frequently and often intuitively intervened, although they also mentioned that they should not intervene during STs' lessons. When examining the premises in the practical arguments, it appeared that MTs mentioned various plausible reasons for intervening after they did so and deemed their interventions well considered. However, when intervening in the classroom, their intervening was not always deliberate. In most situations during STs' teaching when 
MTs observed that something was going wrong, MTs acted and intervened as teachers. This might be explained by the MTs' ingrained habit of intervening by guiding the pupils. MTs spend more time teaching than combining teaching and mentoring; thus, as teachers, they are used to intervene toward the pupils all day long. Therefore, when the ST is teaching and the mentor is mentoring, MTs may tend to behave as teachers. MTs' teacher experience with these specific pupils may prevent them from acting as the STs' mentor. Our study thus supports that becoming an MT and, specifically, guiding an ST during his or her teaching is not something that spontaneously develops from simply being a teacher (e.g., Bullough, 2005; Orland-Barak 2002; 2005; Zeichner, 2005). Rather, mentoring is a new skill that MTs have to develop.

Our findings concerning MTs' intervening by guiding the pupils are in line with observations from a study investigating MT and ST co-teaching (Van Velzen, Volman, \& Brekelmans, 2014). Co-teaching was conceptualised as a combination of modelling (the MT shows the ST teacher behaviour by teaching the pupils) and scaffolding (the MT provides support during ST's lesson enactment, directly aimed at facilitating ST's teaching). In Van Velzen et al.'s study, ST and MT explicitly agreed to co-teach, enabling the MT to deliberately guide the ST when practicing teaching. What appeared promising is that most MTs and STs appreciated the opportunity for MTs to collaborate with their ST during lesson enactments and that they experienced co-teaching as a valuable way of mentoring. However, Van Velzen et al. also found that only one out of four MTs, and only in some situations, actually scaffolded the ST. Essentially, all four MTs were modelling. Just as seen in our study, the MTs in Van Velzen et al.'s study did not easily take up their mentor role, and rather acted as teachers by modelling the teaching behaviour and guiding the pupils.

\section{Awareness of mentoring role is related to MTs' interventions}

The MTs' awareness of their mentoring role, and their expressed mentoring and teaching values, seems to be related to their actions. We noticed that some MTs in our study were unaware of their double role; during the interviews, they explained that they had not thought about the combination of their mentor and teacher roles before. Additionally, we found that the interventions by most MTs in our study were mainly 
directed toward the pupils, which the MTs typically justified with teaching values. Furthermore, although we did find value premises about pupil and ST development, MTs did not use empirical premises about pupils' development and barely (only described once by one MT) supported their guiding of the ST with any empirical or stipulative insights about ST development. In justifying their intervening, MTs primarily explained that they react to the disorder in the classroom and try to create a quiet and calm classroom with well-behaved pupils. Good classroom management might be seen as a prerequisite for pupil and ST learning. These findings support other studies that found that MTs create safe places and carefully structured tasks for STs (e.g., Collison \& Edwards, 1994). MTs' skill for and knowledge of STs' learning might limit them to merely handing over the class to teach (Edwards \& Protheroe, 2004). Furthermore, based on the near absence (only described once by one MT) of statements about the relation between the mentoring value "STs should develop" and MTs' intervening directed toward the ST, we conclude that MTs do not frequently actively guide STs during their teaching for encouraging STs' development. In any case, MTs do not explain their ST guidance with reference to their task of stimulating STs' development. This conclusion is supported by the lack of research findings used by the MTs in our study in their reasoning. It appears that many MTs do not explicitly mention and do not seem to know which learning theory they use when mentoring the ST during their practice.

\section{MTs continuously try to fulfil both their mentor and teacher roles}

MTs try to combine their mentor and teacher roles as well as possible. From MTs' justification of their actions, we learned that MTs continuously, consciously or unconsciously, evaluate the information observed in the situation, and compare this with their mentoring and teaching values and with what they know about the effects of intervening. Our study showed that in situations in which the ST is teaching, MTs possess the basic teaching value that there must be an orderly working atmosphere, and the basic mentoring values that MTs should not intervene during STs' teaching and that STs should teach on their own as much as possible. Although these values seem quite often to be in conflict when the ST is teaching (cf., Collison \& Edwards, 
1994; Edwards, 1998; Goodfellow, 2000; Rajuan et al., 2007), in many situations, MTs did not report these as conflicting values. Frequently, MTs explained they did not experience the two values as incompatible, did not think about them as opposite goals, or were not aware of a clash until they were asked about it. Nevertheless, when analysing MTs' actions and their justification of their actions, we saw MTs struggle with the combination of both roles. During STs' teaching, MTs constantly attempted to solve the value competition between mentoring and teaching values through their intervening. MTs searched for a way to fulfil two goals with one action: they searched for one intervention in order to meet both their mentoring and teaching values as closely as possible. Additionally, in MTs' reasoning after their intervening, they were continuously searching for reasons that justified both their mentoring and teaching values. MTs tried to substantiate their intervening, directed toward the pupils and toward the ST, as beneficial for both pupils and ST. MTs explained their interventions directed toward the pupils, with the purpose of getting the pupils to resume their expected behaviour. In addition, they suggested this intervention to be good for the ST, as illustrated by "the ST could need some little help" and "the ST should be able to continue the lesson." A few MTs also mentioned that they hoped that "the ST could learn something from observing MTs' intervening." In contrast, MTs described that their intervening directed toward the $S T$ is good for the ST, because then the ST could experience what was happening in that moment. Additionally, by intervening and guiding the ST toward good teaching, the positive "side-effect" was that pupils' behaviour was regulated again.

\section{Practical argument theory}

In our research, we used Fenstermacher's (1986) practical argument as a heuristic to illuminate MTs' thinking about their intervening. This appeared to be time consuming but led us to a detailed understanding of the MT reasoning process. By using the situational, value and empirical premises, and the actions or intentions to act, we were able to describe MTs' reasoning. Furthermore, it appeared that MTs' actions could be explained with the situational, value and empirical premises. The MTs in our study did not explicate the origin of their insights in their reasoning as being either empirical or stipulative; in fact, we barely found any reasoning in which MTs mentioned research or 
conceptions of evidence. MTs' reasoning was primarily based on previous observations and their own experiences. Therefore, introducing the stipulative premise had no benefit to understanding the data in our study, which is different from the experiences of Morine-Dershimer (1987) and Fenstermacher and Richardson (1993).

Premises appeared to be particularly valuable elements for examining the reasoning of MTs, who perform teacher and mentor roles simultaneously. We were able to describe how MTs argued their practices with considerations as mentor and teacher, and could illuminate the inconsistencies between MTs' (intended) actions and their considerations. For example, MTs explained how, when, and why they did intervene, although they also stated that it would be good not to intervene. According to Kagan (1992), acting and thinking could be inconsistent, because the relation between the cognitions and actions is situation-specific. Based on the situation or context, teachers might be triggered to act differently to what could be expected from their cognitions. In our research, we found that based on situational triggers, MTs mainly acted as teachers, which was not always consistent with their value and empirical premises as mentors.

For Fenstermacher (1986), a complete practical argument is an argument that includes all types of premises. Generally, the MTs in our study did not provide a complete argument. We used the premises as building blocks in creating an integrated overview of the general practical reasoning process concerning their intervening. Our findings not only support but also expand results from previous research that had demonstrated that various types of interventions and some concerns exist (BenPeretz \& Rumney, 1991; Post, 2007; Wang, 2010). Our study shows that when the ST is teaching the MT's pupils, MTs continuously estimate the situational triggers (situational premise) and (un)consciously relate this to their mentoring and teaching values (value premise), general empirical premises about mentoring and teaching, and their specific empirical premises about these pupils and the specific ST (empirical premise). When MTs assess the situation as no longer contributing to their mentoring or teaching goals, MTs intervene in order to recreate the desired situation in which their mentoring and teaching values can be fulfilled again. 


\section{Implications}

The first implication of our findings is that MTs should become more aware of the impact of the combination of being a mentor and being a teacher in one's own classroom and particularly of their tendency to intervene without thinking. Mentoring principles, such as clinical supervision (which requires MTs to observe ST's teaching in a process of pre-lesson preparation, observations, and post-lesson evaluation; e.g., Kent, 2001), scaffolding, or co-teaching, might ignore the dilemmas MTs face due to their responsibility toward the ST as well as for the pupils or the MTs' disposition to intervene. Generally, in our study, most MTs were driven by their wish to care for their pupils and their inexperience in thinking as mentors. Courses for mentor professional development provided by educators have been suggested in the past, and their positive effects have been demonstrated (Killian \& Wilkins, 2009; McIntyre \& Killian, 1987). We recommend including support in these courses for MTs' quest to combine the mentor and teacher roles and to teach MTs about the impact of their teacher role on their mentoring actions, especially in the actual moment the ST is teaching. In addition, when teacher educators visit their ST in the school, they can specifically address their combination of their mentor and teacher role as an MT and their ST guidance and support during STs' lessons.

Furthermore, professionalisation courses should help MTs gain insight in their practical reasoning concerning intervening. When MTs become aware of the underlying reasons for their tendency to intervene, they might make other substantiated decisions. Our overview can help MTs to reflect on their practical reasoning about intervening, encourage them to consider their dual loyalty, and stimulate them to start thinking and acting more as mentors. Furthermore, MTs' practical reasoning could be improved by careful elicitation and reconstruction of practical arguments, for example, by being questioned by another MT, using questions such as "Why did you do that?" (Fenstermacher \& Richardson, 1993). By eliciting MTs' justification of their actions, more complete practical arguments, including new premises, can be formed, which might result in MTs more deliberately and effectively guiding the ST at the actual moment of teaching practice. 
Moreover, professionalisation trajectories should stimulate MTs to use learning theories and to think about STs as learners. When MTs recognise the ST as a learner (Awaya et al., 2003) who needs to be guided in learning to teach-also at the very moment of practicing-MTs will be able to mentor more effectively according to the STs' learning goals and needs (e.g., Feiman-Nemser, 2001). Teacher educators could also teach STs how to address MTs, and their dual loyalty to the ST as well as for the pupils. STs can be taught to be aware of their own learning process and learning goals, and how they can profit from and ask for MTs' deliberate guidance during practicing the teaching. We recommend that STs and MTs discuss their roles during the pre-lesson conferences and agree upon how the ST is guided during this lesson. The MT and ST could, for example, discuss the focus (topic or learning need) of MTs' guidance, and whether and how the MT will intervene in the upcoming lesson. In the post-lesson conference, the MT and ST could evaluate not only the ST's teaching but also the way the MT guided the ST in his or her learning goal(s). Additionally, MTs might inform the pupils about their role division. Furthermore, the notice that MTs rarely justify their interventions in terms of pupils' or STs' learning might be important information for teacher education institutes.

Another implication of our findings is that researchers investigating mentoring should consider MTs' tendency to act as teachers. Currently, most mentoring research focuses only on the mentor tasks and ignores the influence of the responsibility MTs feel for their pupils, although this might influence the research findings. Additionally, when investigating (mentor) teachers' thoughts about behaviour, we recommend researchers to consider applying Fenstermacher's (1986) practical argument, because it appeared to be a valuable heuristic to gain a detailed understanding of the MT reasoning process.

\section{Further research}

In this exploratory, qualitative study, we took a first step toward exploring MTs' practical reasoning about intervening. Through our analysis, we were able to describe MTs' explanations for their actions and interventions in some detail. However, some issues remain to be resolved. 
We asked MTs about their actions, and their reasoning concerning their intervening. We did not measure the actual number of interventions during an ST's lesson. We also did not investigate the precise relation between what MTs said they do or would do and what they actually do. Future research could investigate the relation between MTs' actions as part of their reasoning and their actual performed actions. In addition, we do not yet know if and how MTs' actions could be predicted and influenced. A next step in investigating MTs' practical reasoning could be a large-scale study (cf. Smith \& Ingersoll, 2004) that provides insight into the impact of various premises on MTs' interventions. Additionally, we suggest further research to investigate changes in MTs' intervening behaviour, for example because of priming, the self-confrontation method, or reconstructing practical arguments.

In our study, the ST perspective of intervening was not included. In order to be able to conclude which mentoring behaviour contributes to STs' wellbeing and development, the STs should also be asked about their experiences with and perceptions of MTs' interventions. Furthermore, in order to improve the effectiveness of mentoring, it could be useful to study whether and how STs and MTs discuss MT's roles and intervening during ST's lessons with each other in pre- and post-lesson conferences. It is possible that STs and MTs may have agreed on MT's interventions and therefore, MT's guidance during ST's teaching could be related to ST's learning goals and learning needs (e.g., Feiman-Nemser, 2001).

As in previous research (Jaspers et al., 2014, see Chapter 2), in this study, we found that MTs, particularly when the ST is teaching their pupils, are searching for a way to combine their mentor and teacher roles. How the simultaneous performance of both roles might be supported, how MTs could guide the ST in the moment of practicing teaching, and which intervening strategies are most effective could be examined by future research. More specifically, it would be interesting to investigate how, for example, scaffolding or synchronous coaching (guidance by an experienced teacher saying keywords into a microphone to a teacher wearing an earplug (Voerman, Meijer, Korthagen, \& Simons, 2015), as deliberate ways of MTs' intervening, can be used in the educational context of STs practicing to become teachers. 
In trajectories for mentor professional development and when investigating ST mentoring, we suggest taking into account the influence of the teacher role on MTs' ST guidance. For the specific situation when an ST is teaching the MT's pupils, our study showed that MTs, primarily triggered by classroom management problems, intervene rather frequently, not always consciously, and often by performing their regular teacher behaviour of guiding the pupils. When MTs' intervening becomes more related to STs' development, this might help improve STs' learning. 


\section{APPENDIX: SAMPLE INTERVIEW QUESTIONS}

\section{General questions about the combination of both roles}

- What, in your perception, is the relationship between the mentor and teacher role?

- What, in your perception, is your role or task as a mentor and as a teacher?

- Can you give an example of a situation in which both roles are combined?

- Do you think both roles can positively influence each other?

\section{Open questions about tensions}

- Do you ever experience tension between these roles? Can you give an example?

- Did you have any problems, such as conflict situations, dilemmas, or an (internal) conflict, as a mentor teacher? How did you cope with that?

- Can you describe a situation in which you found it difficult to mentor the student teacher?

\section{Questions about actions and considerations}

- In the situation (describe situation) you did (describe action). Do you remember?

- Why did you do that?

- What were/are your considerations for that action?

- Next time, in a comparable situation, would you act in the same way? Why?

- When would you have (not) intervened? Why?

- If you consider intervening, which considerations do you have? Can you give an example? 


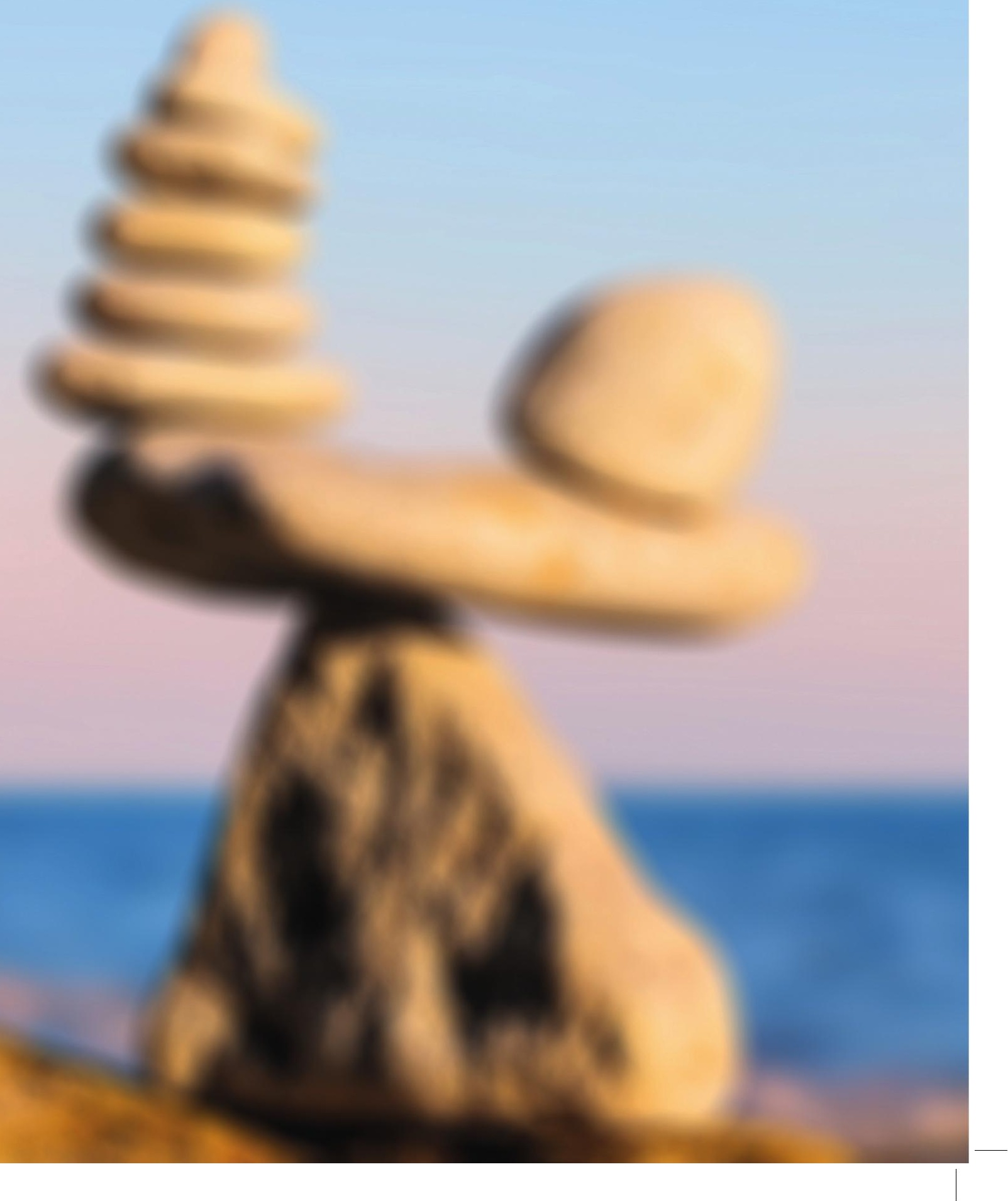




\section{CHAPTER}

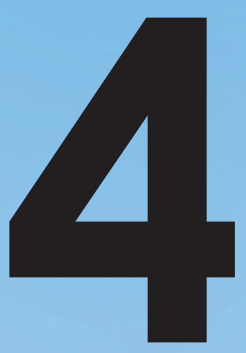

\section{Mentor Teachers' Intervening during Student Teachers' Lessons in Primary Education: A Multilevel Vignette Study ${ }^{6,7}$}

This multilevel vignette study examined mentor teachers' intended direction and intensity to intervene during student teachers' lessons in primary education and the factors that trigger mentor teachers' intervening. Based on Fenstermacher's (1986) theory of premises leading to actions, we developed vignettes in which we manipulated trigger type, trigger severity, and student teacher experience. 159 mentor teachers indicated whether and how they would intervene in such situations. Results showed that mentor teachers prefer teaching values over mentoring values and that they intervene quite intensely. Of the variance in intervening intensity $17 \%$ was located in the situation and $28 \%$ in the mentor teacher. We suggest that explicitly emphasising to mentor teachers that their intervening should serve both pupils and student teachers might improve student teacher's learning during their teaching practice.

6 This chapter is based on: Jaspers, W. M., Prins, F., Mainhard, T., Meijer, P. C., \& Wubbels, T. (Submitted). Mentor teachers' intervening during student teachers' lessons in primary education: A multilevel vignette study.

7 Acknowledgement of author contributions: J, P and W designed the study; J recruited participants and collected the data; J and P developed the instruments; J and Ma analysed the data; J drafted the manuscript; J, P, Ma, Me, and W participated in finalising the manuscript; P, Me and W supervised the study. 


\section{INTRODUCTION}

Imagine a student teacher (ST) teaching 25 pupils in a primary school classroom. Her mentor teacher (MT), who normally teaches these pupils, sits at the back of the classroom, observing her pupils and the ST. After a while, the pupils start chatting and are no longer on task. What should this MT do? Options are for example to intervene forcefully by taking over the lesson, to subtly intervene (e.g., whispering at the ST or the pupils), or not to intervene. These different actions have potentially different consequences for the pupils and the STs. When developing strategies to improve STs' learning during student teaching practice, it is helpful to understand why MTs choose to intervene or not and, if they intervene, how. The present study aims to gain insight into when and how MTs intervene and the factors that trigger their intervening. Potential predictors for MTs' intervening are situational characteristics, such as mistakes made by the ST (e.g., Ben-Peretz \& Rumney, 1991) or the ST's level of experience (Post, 2007), and the MT's personal characteristics, such as their values (Wang, 2010), beliefs, and personal knowledge of mentoring and teaching (Jaspers, Prins, Meijer, \& Wubbels, 2018, see Chapter 3). The current study aims to investigate 1) MTs' direction and intensity to intervene, 2) MTs' values and beliefs about mentoring and teaching, and 3) the relative importance of situational and personal characteristics in MTs' intervening direction and intensity. We used a combination of vignettes and multilevel analyses. By using a set of vignettes (descriptions of imaginary situations), we were able to systematically present several classroom situations in which MTs could intervene or not. Multilevel analyses made it possible to determine the relative contribution of situational and personal characteristics to MTs' intervening direction and intensity.

\section{MTs' intervening}

Whether and how STs are guided during their lessons varies per MT and situation. Some MTs tend to interrupt the ST's lesson while others do not (Ben-Peretz \& Rumney, 1991). Jaspers et al. (2018, see Chapter 3) found that some MTs intervene frequently, primarily by guiding the pupils, and quite disruptively, for example, by taking over the lesson. To contribute to STs' development, it might be helpful to actively guide STs during practice because then they can be aware of the specific situation in which 
they can improve their teaching (Maynard, 2000; Schwille, 2008). In contrast, such interventions might also be detrimental for ST learning, when one considers that learning to teach is a matter of practice (Hagger \& McIntyre, 2006) and experience (Borko \& Mayfield, 1995); when MTs step into the STs' lessons, the STs do not have the opportunity to manage the class on their own, which can harm their confidence (Izadinia, 2015; Maynard, 2000) and self-esteem (Wang, 2010).

MTs' intervening can vary in both direction and intensity. Some studies describe how MTs do or should intervene. According to a cross-national, exploratory study by Schwille (2008) in which 26 pairs of MTs and STs were observed and interviewed in order to conceptualise a shared vision of "good mentoring," MTs' guidance during the STs' lessons helps the STs learn to teach. Post (2007) argues that to be effective, MTs should intervene at the very first moment they encounter an ST-pupils incident, and as non-disruptively as possible because, otherwise, the MT might miss the opportunity to help the struggling ST. Based on her own observations and extensive experience as a full-time university supervisor, Post described six interventions with increasing disruptiveness, ranging from "ignore," which means the MT deliberately does not respond, to intervene, interject, interact, interrupt, and "intercept," which means taking over the lesson. The four intermediate interventions are directed toward STs. Wang (2010), through observations and interviews with 36 MTs, distinguished three categories of interventions: 1) active intervention, including both direct (the MT intervenes in the lesson herself) and indirect (the MT prompts pupils to ask the ST questions); 2) passive intervention (the MT responds to a question by the ST); and 3) no intervention. Contrary to Post (2007), Wang (2010) did not describe the interventions as directed toward the ST. Ben-Peretz and Rumney (1991) found in their 35 observations of ST lessons that MTs corrected not only the ST but also the pupils. Additionally, Jaspers et al. (2018, see Chapter 3) concluded, based on analyses of MTs' reasoning for their intervening, that MTs tended to intervene by guiding the pupils rather than by guiding the ST. This latter study also showed that MTs tended to intervene frequently, not always consciously, and that they sometimes intervened quite disruptively, for example, by taking over the lesson. 
The studies conducted to date base their conclusions primarily on observations or interviews and describe how MTs do or might intervene. A fruitful next step in this line of research is to conduct a study on MTs' intentions to intervene in a set of systematically varying classroom situations, which allows for examining what factors predict the intensity and direction of MTs' intervening.

\section{Predictors of MTs' intervening}

The general reasoning process in which MTs consider whether, when, and how to intervene can be described by applying Fenstermacher's theory on practical arguments (cf. Fenstermacher, 1986; Jaspers et al., 2018, see Chapter 3;). Practical arguments are post hoc descriptions of practical reasoning that teachers indicate as fair and accurate accounts of actions that explain or justify what a teacher did (Fenstermacher \& Richardson, 1993). A practical argument consists of situational, value and empirical premises (Fenstermacher, 1986) contributing to the decision or intention to act in response to questions such as "What shall I do?" or "Why did I do that?" and eventually resulting in an action, intention to act, or avoidance of action (Morine-Dershimer, 1987). When someone thinks about what he or she did or ought to do in a specific situation, given the commitment to the roles they have, this is a case of practical reasoning (Pendlebury, 1990).

Jaspers et al. (2018, see Chapter 3) described MTs' practical reasoning regarding their intervening (or abstaining from intervening) in STs' lessons and found several factors that seemed to be related to MTs' intensity to intervene, and whether their intervening was directed toward the pupils or the ST. When an ST is teaching, MTs (often unconsciously) consider the various characteristics of the situation (situational premises) and compare these to their personal values regarding mentoring and teaching (value premises) and their personal knowledge and beliefs about how intervening will affect the ST's and pupils' wellbeing and development (empirical premises). Below, we elaborate on these situational and personal factors and how they might predict the intended direction and intensity of intervening. 


\section{Situational factors}

Situational factors, or situational premises, are a first aspect that might impact MTs' direction and intensity of intervening. The situational premise is a description of the situation or context in which an action takes place (Fenstermacher, 1986). In primary education, in the context in which an ST teaches the MT's pupils, MTs may observe situations that trigger them to consider intervening. In the reasoning process concerning the direction and intensity of intervening MTs might consider the trigger type, the trigger severity, and the characteristics of the people involved in the situation, such as the pupils' and STs' age (Post, 2007), the STs' skills or competence (Jaspers et al., 2018, see Chapter 3; Post, 2007), the STs' teaching experience, and the pupils' competence and behaviour (Jaspers et al., 2018, see Chapter 3).

\section{Trigger type}

Various triggers may cause MTs to intervene, such as problems concerning teaching strategies (Ben-Peretz \& Rumney, 1991), a mistake made by the ST in the lesson content that misinforms pupils (Ben-Peretz \& Rumney, 1991; Jaspers et al., 2018, see Chapter 3; Wang, 2010; Weasmer \& Woods, 2003), or the ST demonstrating insufficient classroom management skills (Jaspers et al., 2018, see Chapter 3; Ben-Peretz \& Rumney, 1991; Wang, 2010; Weasmer \& Woods, 2003). The current study focuses on difficulties with classroom management and mistakes in lesson content because these were the triggers most often mentioned by MTs when they reasoned about their intervening (Jaspers et al., 2018, see Chapter 3). Classroom management refers to teacher actions that are intended to create an environment that supports and facilitates both academic and social-emotional learning (Evertson \& Weinstein, 2006). MTs perceive good classroom management as an important condition for pupil and ST learning (Collison \& Edwards, 1994), and they have difficulties in transferring responsibility for the pupils to the ST (Glenn, 2006; Jaspers, Meijer, Prins, \& Wubbels, 2014, see Chapter 2). Therefore, when MTs perceive that STs are having classroom management problems, we expect the MTs to intervene. We expect MTs' intervening to be directed toward the pupils because previous studies have shown that this is the case during classroom management problems (Ben-Peretz \& Rumney, 1991; Jaspers et al., 2018, see Chapter 3). 
A second trigger for considering intervening is when the ST makes a mistake in the lesson content, for example, giving a wrong explanation of a concept. Such mistakes are misleading for the pupils and could impair their learning (Ben-Peretz \& Rumney, 1991; Wang, 2010). Because MTs want the pupils to learn the right content (Edwards, 1998; Post, 2007), MTs may decide to correct the mistake by correcting the ST (BenPeretz \& Rumney, 1991; Post, 2007). Therefore, we expect MTs' intended intervening in the case of a mistake in lesson content to be directed toward the ST.

\section{Trigger severity}

When perceiving a trigger, whether and how an MT will intervene depends not only on the type but also on the severity of the trigger (Post, 2007), in particular, the MT's appraisal of the severity of that trigger (Jaspers et al., 2018, see Chapter 3). From research on teacher responses in situations where pupils disturb the harmonious and cooperative learning atmosphere (Feldmann, 2001), we know that some pupils may feel that when teachers fail to address the disruption, this authorises them to display more misbehaviour. The longer the misbehaviour continues, the more intense the response will need to be (Feldmann, 2001). Hence, we expect that the more severe the trigger is, the more intense MTs intend to intervene.

\section{ST characteristics}

ST characteristics are the third situational premise that might impact MTs' intervening. In the current study, the focus is on ST experience, because MTs most frequently mentioned this characteristic when they reasoned about intervening (Jaspers et al., 2018, see Chapter 3). During teacher training, STs may experience various teaching contexts and situations (Calderhead, 1991; Edwards, 1998; Nettle, 1998) that make them more experienced and probably more competent (Calderhead, 1991; Sugrue, 1997). Less-experienced STs normally have less knowledge, skills, and competence than more-experienced STs do (Kagan, 1992; Sugrue, 1997); thus, they will probably have more difficulty in teaching. As a result, MTs might feel more triggered when a lessexperienced ST is teaching than when a more experienced ST is teaching. Additionally, MTs might feel that less-experienced STs might need more general help and guidance during their teaching (Glickman \& Gordon, 1987; Post, 2007). Therefore, we expect 
that the less experienced the ST is, the more intensely MTs' intention to intervene will be and the more their intervening will be directed toward the pupils.

\section{Personal factors}

In addition to situational factors, personal factors can also possibly impact MTs' intended direction and intensity to intervene. When an MT observes that a situation no longer corresponds with his or her wishes for her pupils, the MT's personal values and beliefs might be challenged, and he or she may feel that the dual loyalty as mentor and teacher is at stake (Edwards, 1998; Rajuan, Beijaard, \& Verloop, 2007; Orland-Barak, 2001). Whether and how MTs intervene might be influenced by their values (Jaspers et al., 2018, see Chapter 3; Wang, 2010), their personal knowledge of mentoring and teaching (Jaspers et al., 2018, see Chapter 3), and their own competence and experience (Jaspers et al., 2018, see Chapter 3; Post, 2007). In the current study, two personal factors are included, namely, value premises and empirical premises.

\section{Value premises}

Value premises are moral and ethical considerations and indicate teachers' goals or desired conditions (Fenstermacher \& Richardson, 1993). Values (implicitly) act as points of reference in decision-making (Halstead, 1996), regulate teacher behaviour (Kagan, 1992; Pajares, 1992), and are reflected in what teachers choose to permit or encourage in the classroom (Wang, 2010). Differences in values probably predict differences in ST guidance. However, the goals MTs want to achieve as mentors do not always correspond with their teaching goals (Edwards, 1998; Jaspers et al., 2014, see Chapter 2; Rajuan et al., 2007). Especially when they notice that the normal course of events in the classroom has been disrupted, MTs might experience a conflict between mentoring and teaching values; such a conflict causes MTs to consider intervening (Jaspers et al., 2018, see Chapter 3). Often, this value conflict results in MTs' intervening being directed toward the pupils because they feel that mentoring is a task that is additional to their most important task: being a teacher (Jaspers et al., 2014, see Chapter 2; Wang 2010). In this study, we examine whether MTs prefer teaching values over mentoring values. 
Wang (2010) found that MTs who consider STs' self-esteem and authority as the first priority adopt a practice of intervening with a low intensity or even no intervening at all. MTs appear to choose less-intrusive intervening behaviour (Post, 2007) when they perceive STs' authority as necessary to act as teachers (Beck \& Kosnik, 2002) and STs' freedom to explore teaching ideas as a critical factor in professional learning (Patrick, 2013; Rajuan, et al., 2007). Therefore, we expect MTs with a relative preference for mentoring values over teaching values to intervene less intensely and mainly directed toward the ST.

\section{Empirical premises}

A second personal factor that might impact MTs' intervening is MTs' empirical premises. Empirical premises are based on earlier observations that can be tested by new observations (Fenstermacher \& Richardson, 1993) and are often referred to as practical knowledge (Fenstermacher, 1994; Gholami \& Husu, 2010). Teachers construct practical knowledge based on their experiences. This plays a role in their decisionmaking (Roehler, Duffy, Herrmann, Conley, \& Johnson, 1988) and guides their actions (Zanting, Verloop, \& Vermunt, 2001).

In reasoning about intervening, MTs use empirical premises about how intervening (or abstaining from intervening) can positively or negatively affect STs' and pupils' wellbeing and development (Jaspers et al., 2018, see Chapter 3). MTs may believe that learning to teach is just a matter of practice (Hagger \& McIntyre, 2006) and experience (Borko \& Mayfield, 1995). Therefore, MTs might think that not intervening will help STs learn to teach because they are given the opportunity to make mistakes, to solve problems on their own (e.g., Oosterheert \& Vermunt, 2001; Van Eekelen, Boshuizen, \& Vermunt, 2005), to feel trusted, to explore their own teaching styles, and to not feel their authority is undermined (Jaspers et al., 2018, see Chapter 3; Rajuan, et al., 2007). MTs might also think that when they do step into STs' lessons, STs have no freedom to manage the class on their own, which can harm their confidence (Izadinia, 2015; Maynard, 2000), self-esteem (Wang, 2010), and wellbeing (Jaspers et al., 2018, see Chapter 3). However, MTs also might have the empirical premise that intervening might help STs in learning to teach because the STs will be aware of a specific situation in 
which they can improve their teaching (Jaspers et al., 2018, see Chapter 3; Maynard, 2000; Schwille, 2008). Additionally, by intervening, MTs can prevent STs from making mistakes (Post, 2007), can limit or prevent further problems (Wang, 2010), and can restore an orderly classroom atmosphere in which pupils return to their tasks (Jaspers et al., 2018, see Chapter 3). MTs might believe that abstaining from intervening will create an environment that is not supportive and conducive to STs' learning and teaching and could be harmful for pupils' learning and STs' wellbeing (Jaspers et al., 2018, see Chapter 3).

Given these contradicting expectations, we will explore in the current study whether and how MTs' empirical premises regarding the positive effect of intervening (or abstaining from intervening) on pupil and ST wellbeing and development will affect their intended direction and intensity of intervening.

\section{The current study}

In the current study, we aim to describe MTs' value premises concerning mentoring and teaching as well as their empirical premises regarding the effects of intervening on pupil and ST wellbeing and development. We also aim to gain insight into whether, in which direction (ST versus pupils), and how intense MTs intend to intervene in STs' lessons. Next, we want to determine the extent to which situational and personal factors are related to MTs' intensity and direction of intervening. We examine the relative importance of situational characteristics such as ST experience, trigger type, and trigger severity and the MTs' personal characteristics in terms of value and empirical premises in MTs' intended intensity and direction of intervening.

We have four research questions. Our first and second questions are descriptive: Q1) What value and empirical premises are important to MTs? and Q2) What is the general direction and intensity of MTs' intervening? The third and fourth questions investigate how MTs' intervening is predicted: Q3) How do situational characteristics (ST experience, trigger type, trigger severity) and personal characteristics (the MT's value and empirical premises) contribute to an MT's likelihood of abstaining from intervening, of intervening directed toward pupils, or of intervening directed 
toward the ST? and Q4) To what extent do situations and MTs predict differences in MTs' intensity to intervene and what is the relative importance of trigger type, trigger severity, ST experience, and value and empirical premises in MTs' intensity to intervene?

\section{METHOD}

\section{Participants and context}

We asked 461 MTs to participate, and 159 MTs (25 males and 132 females; 2 did not indicate their gender) participated on a voluntary basis. The main reasons given by MTs for not participating were that they were already participating in other research programmes or they lacked the time. For privacy reasons, not every MT indicated the school at which they worked, but from those who did, we found that usually one or two MTs per school participated. Most MTs were mentoring currently or had mentored an ST in the past six months. Eight MTs had mentored an ST three to six years ago. MTs varied in age from 23 to $70(M=42.2 S D=11.6)$. The average teaching experience was 17.1 years $(S D=10.6)$, and the average experience in mentoring was 10.4 years $(S D=8.0)$.

This study was performed in the context of a four-year undergraduate teacher education programme for primary education in the Netherlands. STs enrolled in university courses and were placed at various schools as part of the programme. The MT who was responsible for the class in which the ST had been placed guided and assessed the ST. During the course of the programme, STs' responsibility toward the pupils increased until they assumed full responsibility in their final year of study.

\section{Design}

We presented the MTs vignettes involving various teaching situations with various ST types and teaching problems to elicit their responses, namely, their intended intensity and direction of intervening in such a situation. Further, a questionnaire 
that measured MTs' personal value and empirical premises was presented. Due to the various combinations of manipulated variables within the vignettes and, therefore, the hierarchical data-structure of the vignette data (and considering our question to find the relative importance of various predictors), we performed multilevel analyses.

Vignettes are descriptions of imaginary situations that can be used to determine which circumstances influence peoples' attitudes and beliefs and to better understand peoples' actions in specific situations (Schoenberg \& Ravdal, 2000). In the development of our text-based vignettes, we aimed to create authentic descriptions of situations that 1) were representative of what MTs regularly experience during ST lessons, 2) elicited MTs to consider their intervening, and 3) would highlight variations in MTs' intended actions. To describe situations that were authentic, the vignettes were created by the first author, who had experience as a primary teacher, and by four student assistants who were STs in primary education at that time and were familiar with teaching and classroom situations. From a previous study (Jaspers et al., 2018, see Chapter 3), we also used observed situations and MTs' reasoning in considering these situations and their intervening. To improve the authenticity of the vignettes, various pilots were performed. In the first round of pilots and adaptations, three respondents individually indicated for each vignette whether and how they would intervene and then discussed the comprehensibility and authenticity of the vignettes. In every pilot, the respondents discussed whether and how they would intervene, and in their reasoning, they mentioned the variables that we had manipulated. We concluded that the vignettes were adequate for measuring the intended actions. Then, three MTs not involved in the first pilot round and the coordinator of the teacher training internship, who was experienced in both supervising STs and guiding MTs in their mentoring, were asked to give their critical opinions of the entire instrument. Based on this second pilot, we changed, among other things, the intervening scale from a 5-point scale to a continuous scale without discrete values because the respondents mentioned that such a scale would give them the feeling they could more precisely indicate how they personally would intervene. The MTs involved in the pilot did not participate in the main inquiry. 
In developing the vignettes, we operationalised ST experience by varying the year of study (i.e., a first-year versus a third-year student). Trigger type was manipulated by distinguishing between lesson content and classroom management problems. Thus, the combination of these two variables led to four types of vignettes (see Table 1). Additionally, trigger severity was included. We designed the vignettes with a variety in the level of trigger severity to determine at which severity level MTs would intervene. Every vignette had three or four versions that differed in severity level: low, medium, medium-high, and high. All other variables, such as the STs' gender (all female) and pupil characteristics (for example, average competence) were the same for all vignettes. Table 1 gives an overview of the 14 vignettes, and Figure 1 gives two examples of vignettes.

Table 1. Overview of Vignettes

\begin{tabular}{|c|c|c|c|}
\hline \multicolumn{2}{|c|}{ Trigger } & \multicolumn{2}{|c|}{ ST experience } \\
\hline Type & Severity & First-year ST & Third-year ST \\
\hline \multirow{3}{*}{$\begin{array}{l}\text { Mistake } \\
\text { in lesson } \\
\text { content }\end{array}$} & Low & $\begin{array}{l}\text { 2.1 First-year ST making } \\
\text { a small mistake in lesson } \\
\text { content }\end{array}$ & $\begin{array}{l}\text { 1.1 Third-year ST making } \\
\text { a small mistake in lesson } \\
\text { content }\end{array}$ \\
\hline & Medium & $\begin{array}{l}\text { 2.2 First-year ST making a } \\
\text { medium mistake in lesson } \\
\text { content }\end{array}$ & $\begin{array}{l}\text { 1.2 Third-year ST making a } \\
\text { medium mistake in lesson } \\
\text { content }\end{array}$ \\
\hline & High & $\begin{array}{l}2.3 \text { First-year ST making } \\
\text { a large mistake in lesson } \\
\text { content }\end{array}$ & $\begin{array}{l}\text { 1.3 Third-year ST making } \\
\text { a large mistake in lesson } \\
\text { content }\end{array}$ \\
\hline \multirow{4}{*}{$\begin{array}{l}\text { Difficulties } \\
\text { with } \\
\text { classroom } \\
\text { management }\end{array}$} & Low & $\begin{array}{l}\text { 3.1 First-year ST having } \\
\text { small difficulties with } \\
\text { classroom management }\end{array}$ & $\begin{array}{l}4.1 \text { Third-year ST having } \\
\text { small difficulties with } \\
\text { classroom management }\end{array}$ \\
\hline & Medium & $\begin{array}{l}\text { 3.2 First-year ST having } \\
\text { medium difficulties with } \\
\text { classroom management }\end{array}$ & $\begin{array}{l}\text { 4.2 Third-year ST having } \\
\text { medium difficulties with } \\
\text { classroom management }\end{array}$ \\
\hline & $\begin{array}{l}\text { Medium- } \\
\text { High }\end{array}$ & $\begin{array}{l}\text { 3.3 First-year ST } \\
\text { having medium-large } \\
\text { difficulties with classroom } \\
\text { management }\end{array}$ & $\begin{array}{l}4.3 \text { Third-year ST } \\
\text { having medium-large } \\
\text { difficulties with classroom } \\
\text { management }\end{array}$ \\
\hline & High & $\begin{array}{l}\text { 3.4 First-year ST having } \\
\text { large difficulties with } \\
\text { classroom management }\end{array}$ & $\begin{array}{l}\text { 4.4 Third-year ST having } \\
\text { large difficulties with } \\
\text { classroom management }\end{array}$ \\
\hline
\end{tabular}




Vignette 1.1
Sophie (21 years old) is student teaching in your class (grade 4). She is a third-year
student, and she has been your intern for three months now. Today, she is teaching about
insects. During your collaborative lesson preparation, Sophie seemed well prepared.
However, when telling the pupils how to distinguish spiders from insects, Sophie says
that spiders always have six legs and that insects have eight legs. Of course, this is wrong.
Spiders have eight legs, and insects have six.
What would you do?
Vignette 3.1
Susy (18 years old) is in her first year of study. She has been student teaching in your
class, grade 4 , for three months now. Today, Susy is teaching a math lesson. After a few
minutes, two pupils at the back of the classroom, Kay and Ann, start quietly whispering
about things other than math. You don't know whether she has failed to see it or she
doesn't want to say something about it. Nevertheless, she isn't going to do something
about it and just continues her instruction.
What would you do?

Figure 1. Examples of vignettes.

\section{Measures}

\section{Intensity of intervening}

The intended intensity to intervene was measured on an intensity-to-intervene-scale. To give the participants a clear view of the "intensity of intervening", participants were informed about this concept before reading the vignettes. After reading each vignette, MTs answered the question "What would you do?" by sliding a pointer on a continuous scale. The left side of the scale was labelled as not intervene, and the right side as very intensely intervene. Only the extremes of the scale were labelled. The Cronbach's $\alpha$ of .88 indicated that the internal consistency of intensity scores of the fourteen situations was high.

\section{Direction of intervening}

After indicating the intensity to intervene for a situation, the participants were asked to indicate for that particular situation whether they would intervene mainly 
by guiding the ST or whether they would intervene by mainly guiding one or more pupils. Based on MTs' reasoning for intervening in our previous study (Jaspers et al., 2018, see Chapter 3), we decided that when MTs indicated to intervene very intensely, it would equal to taking over the lesson, and thus, MTs' intervening was mainly aimed at guiding the pupils. Therefore, when MTs scored 5.0 on the intervene scale, there was no option to indicate the direction of intervening. In addition, when MTs scored 0.0 on the intervene scale, the direction to intervene was labelled "Abstaining from intervening," and no option was presented to the MTs. Thus, for direction to intervene three categories were used: 1) Abstaining from intervening, 2) Intervening mainly directed toward the ST, and 3) Intervening mainly directed toward the pupils.

\section{Value premises}

MTs' value premises were measured by paired comparisons. In paired comparisons, a participant compares each object with every other object. This is an effective method to compare objects that can only be subjectively and intuitively assessed (David, 1988; Thurstone, 1927). We designed an instrument to measure teaching values as compared to mentoring values, including four mentoring and four teaching values (see Table 2) that MTs' had indicated in Chapter 3 (Jaspers et al., 2018) to be important in their decisions whether to intervene during ST lessons.

Table 2. Value Premises

\begin{tabular}{|c|c|}
\hline Teaching values & Mentoring values \\
\hline I think it is most important that... & I think it is most important that... \\
\hline ... the pupils develop. & ... the ST develops. \\
\hline ... there is an orderly working atmosphere. & ... the ST's authority is not undermined. \\
\hline ... the pupils learn the right content. & ... the ST teaches mostly on his or her own. \\
\hline
\end{tabular}

On the questionnaire, each of these eight values was combined with every other value $((8 \times 7) / 2=28$ combinations $)$, and respondents had to choose the most important one (see Figure 2). 
I think it is most important that...

... the pupils develop.

... there is an orderly working atmosphere.

Figure 2. Example of a combination of two values for which MTs indicated the one they found most important.

For every participant, a total score for each value was computed by counting all times that value was picked as the preferred one. Then we created the value premises scale by adding up the totals of the four mentoring values. This scale measured MTs' relative preference for teaching values compared to mentoring values, ranging from 6 (strong preference for mentoring values over teaching values) to 22 (strong preference for teaching values over mentoring values). A score of 14 meant that an MT found mentoring and teaching values evenly important. The Cronbach's $\alpha$ of the mentoring value premise scale was .71 .

Six MTs had missing scores in one or more of the 28 combinations of values. One MT was missing one score on a combination of a teaching value with another teaching value. For this MT, a score of 1 was added when we counted the teaching values. One MT had one score missing on a combination of a mentoring value with another mentoring value. For this MT, a score of 1 was added when we counted the mentoring values. Four other MTs had more than one score missing on combinations of mentoring and teaching values. These four MTs were not included in the value premises scale.

\section{Empirical premises}

MTs' empirical premises about the positive effects of (the intensity of) intervening on the ST and the pupils were measured by having respondents indicate their level of agreement with statements. These statements were developed based on empirical premises described in Chapter 3 (Jaspers et al., 2018). Six dimensions concerning effects on STs (for example, the effect of intervening on the ST's learning process), and four dimensions concerning effects on pupils (for example, the effect of intervening on class atmosphere), were combined with four intensities of intervening: not intervening, cautiously intervening, intensely intervening, and taking over the lesson. This resulted 
in 40 statements. MTs indicated for these statements how strongly they agreed with that statement on a 6-point scale ranging from strongly disagree to strongly agree.

Based on the four intensities of intervening and the effect on either the ST or the pupils, eight subscales were created. Four subscales measured the positive effect of various ways of intervening on ST wellbeing and development and another four on the effects on pupil wellbeing and development. To create the scales, the items that were negatively phrased were recoded (namely, ST's authority is undermined, ST's learning process is disturbed, and pupils' learning process is disturbed). For one MT, the scores were missing. To create reliable scales, nine items were removed. Table 3 gives an overview of the eight subscales, examples of statements in each subscale, the Cronbach's $\alpha$, and the number of items.

Table 3. Empirical Premises: Subscales, Examples, Cronbach's $\alpha$, and Number of Items

\begin{tabular}{|c|c|c|c|}
\hline Scale & Example & $\alpha$ & $k$ \\
\hline $\begin{array}{l}\text { EP1 - Positive effect on ST of not } \\
\text { intervening }\end{array}$ & $\begin{array}{l}\text { If I do not intervene, the ST experiences } \\
\text { what is happening at the moment. }\end{array}$ & .63 & 5 \\
\hline $\begin{array}{l}\text { EP2 - Positive effect on ST of } \\
\text { cautiously intervening }\end{array}$ & $\begin{array}{l}\text { If I intervene cautiously, the ST could } \\
\text { teach the prepared lesson. }\end{array}$ & .61 & 5 \\
\hline $\begin{array}{l}\text { EP3 - Positive effect on ST of } \\
\text { intensely intervening }\end{array}$ & $\begin{array}{l}\text { If I intervene intensely, the ST learns a } \\
\text { lot. }\end{array}$ & .78 & 4 \\
\hline $\begin{array}{l}\text { EP4 - Positive effect on ST of taking } \\
\text { over the lesson }\end{array}$ & $\begin{array}{l}\text { If I take over the lesson, that is pleasant } \\
\text { for the ST. }\end{array}$ & .78 & 5 \\
\hline $\begin{array}{l}\text { EP5 - Positive effect on pupils of not } \\
\text { intervening }\end{array}$ & $\begin{array}{l}\text { If I do not intervene, that is pleasant for } \\
\text { the pupils. }\end{array}$ & .72 & 3 \\
\hline $\begin{array}{l}\text { EP6 - Positive effect on pupils of } \\
\text { cautiously intervening }\end{array}$ & $\begin{array}{l}\text { If I intervene cautiously, an orderly } \\
\text { class atmosphere is created. }\end{array}$ & .70 & 3 \\
\hline $\begin{array}{l}\text { EP7 - Positive effect on pupils of } \\
\text { intensely intervening }\end{array}$ & $\begin{array}{l}\text { If I intervene intensely, the pupils work } \\
\text { on task again. }\end{array}$ & .78 & 3 \\
\hline $\begin{array}{l}\text { EP8 - Positive effect on pupils of } \\
\text { taking over the lesson }\end{array}$ & $\begin{array}{l}\text { If I take over the lesson, pupils' learning } \\
\text { process is disturbed. }\end{array}$ & .78 & 3 \\
\hline
\end{tabular}

Note. $N=158$. EP = Empirical premise; $k=$ number of items. 


\section{Demographic characteristics}

In the last part of the questionnaire, MTs were asked 14 questions about their demographic characteristics, such as gender, age, and years of experience as MT and teacher.

\section{Procedure}

All MTs received an email in which they were invited to participate in this research. When they chose to participate, they received a hyperlink to the online electronic questionnaire. MTs who did not start or complete the questionnaire received one reminder. Before starting the questionnaire, participants were informed that their answers would be analysed and reported anonymously, and they were asked to sign an informed consent form. Participants were asked to complete the questionnaire at a time they would not be disturbed and in which they could complete the whole questionnaire at once. The questionnaire presented the 14 vignettes to measure the MTs' intention to intervene and consisted of items to measure their value premises, empirical premises, and demographic characteristics. Completing the questionnaire took an average of 30 minutes. It was not possible to go back to a previous question. Participants were asked not to discuss the questions with colleagues until they had completed the questionnaire. To increase the number of responses, schools received the aggregated results of their school if at least five MTs participated. Moreover, three tablets were raffled for the MTs who participated in this study. The Faculty Ethics Review Board (FERB) of the faculty of Social and Behavioural Sciences of Utrecht University approved this study.

\section{Data analysis}

\section{Q1 and Q2: MTs' value and empirical premises and their intervening}

Descriptive analyses were performed to gauge MTs' value and empirical premises and the general direction and intensity of MTs' intervening. We also examined the associations between value and empirical premises and between direction and intensity. 


\section{Q3: MTs' direction to intervene}

To analyse the variability in MTs' intervening direction (a categorical variable, i.e., Abstaining from intervening, Intervening mainly directed toward the ST, and Intervening mainly directed toward the pupils), we considered nesting the vignette data (14 vignettes) within the MTs. We followed the approach of Heck, Thomas, and Tabata (2012) to estimate logistic mixed multilevel models with a logit link function (Hox, Moerbeek, \& Van de Schoot, 2018) in SPSS, Version 24. In this analysis, the probability of being in one of the other categories is compared against the probability of being in the reference category. We used "Intervening mainly directed toward the ST" as the reference category. The vignettes were entered as level 1 units, which were nested in the MTs (level 2 units).

We first estimated the unconditional empty model (M1) in which the situational level (Level 1) was nested in the personal level (Level 2) and which included no predictors. Then, in the second model (M2), the situational predictors (i.e., trigger type [lesson content or classroom management], trigger severity [low, medium, medium-high, high], and ST experience [first- or third-year student]) were entered, and in the third model (M3), the personal predictors (i.e., MTs' value premises and eight scales of empirical premises, all continuous variables grand mean centred) were added. For these models, we performed T-tests to check whether the variance in MTs' intervening direction was significantly predicted by the fixed effects (Heck et al., 2012). Then, we checked whether an additional personal factor, namely MT mentoring experience, predicted the MTs' intervening direction.

\section{Q4: MTs' intensity to intervene}

To investigate the degree to which variability in intensity was due to situations versus MTs, we viewed the responses of the MTs as being nested within two higher levels: the MT and the vignette or situation (i.e., we used a cross-classified multilevel model). Conceptually, we wanted to be able to assess both, the stable, on all teachers' shared influence of situations as well as the stable pattern of MTs' responses over several situations. First-level units were the 2226 (159 MTs $\times 14$ vignettes) intensity to intervene ratings from the MTs. 
The intensity to intervene scale was not normally distributed due to the high frequency of extreme scores (0.0 and 5.0), but the residuals of the multilevel models showed no significant diversion from normality. First, an intercept-only model (M1) was investigated (i.e., variance decomposition) in which the MT and situation (vignette) were entered at the second level. Next, in the full model (M2), we entered all predictors (situational and personal characteristics, all continuous variables grand mean centred). The full model had 16 parameters, the four of the intercept-only for the random effects of intercepts and residual as well as the fixed effect of the intercept, plus one parameter for each of the fixed predictors. After that, we checked whether the model improved by adding MT mentoring experience.

As suggested by Shi, Leite, and Algina (2010), we included the interaction effect between the cross-classified factors in our model, but this interaction was not significant.

In line with Hox, Moerbeek, and Van de Schoot (2018), the increase of model fit for each successive model was tested using the likelihood ratio test based on the deviance of the models, and the significance of fixed effects (i.e., the predictors) was tested with Wald tests.

\section{RESULTS}

\section{Q1: Descriptive information regarding MTs' value and empirical premises}

\section{MTs' value premises}

In Table 4, the means for the eight value premises are shown. The teaching value "Pupils should feel comfortable in class" scored highest. The mentoring value "STs should teach mostly on their own" scored lowest. Of the four mentoring values, "The ST should develop" had the highest score. 
Table 4. Mean and SD of the Value Premises

\begin{tabular}{lll}
\hline Value premises & $M$ & $S D$ \\
\hline Teaching values & & \\
Pupils should feel comfortable in class. & 5.95 & 1.34 \\
Pupils should develop. & 5.47 & 1.16 \\
There must be an orderly working atmosphere. & 2.49 & 1.72 \\
Pupils should learn the right content. & 3.90 & 1.66 \\
Mentoring values & & \\
STs should feel comfortable in class. & 2.37 & 1.52 \\
STs should develop. & 3.52 & 1.35 \\
STs' authority should not be undermined. & 2.25 & 1.35 \\
STs should teach mostly on their own. & 2.04 & 1.33 \\
\hline
\end{tabular}

Note. $N=153$.

The mean for the value premises scale (the relative preference for teaching values over mentoring values) was $17.80(S D=2.93$, Min. $=8$ and Max. $=22)$. A one-sample t-test showed that, on average, the mean value score was significantly different from the centre of the scale, which is $14(t=16.15,<.001)$, indicating that MTs considered teaching values to be more important than mentoring values. Most of the MTs (83.9\%) had a relative preference for teaching values over mentoring values.

\section{MTs' empirical premises}

Table 5 shows the means of the eight empirical premise scales. MTs scored highest on the positive effect of cautiously intervening on pupils (EP6; $M=4.63$ ) and second highest on the positive effect of cautiously intervening on STs (EP2; $M=4.23$ ), meaning that MTs strongly agreed that cautiously intervening is positive for the wellbeing and development of pupils and STs. MTs had the lowest scores on the positive effect on the ST of taking over the lesson (EP4; $M=2.64)$ and the positive effect on the pupils of not intervening ( $E P 5 ; M=2.65$ ). MTs believed that taking over the lesson is not positive for STs' wellbeing and development. They also believed that abstaining from intervening is not positive for pupils' wellbeing and development. 
Table 5. Mean, SD, Minimum and Maximum Scores on the Eight Empirical Premises Subscales

\begin{tabular}{lcccc}
\hline Empirical premises & $M$ & SD & Min. & Max. \\
\hline EP1 - Positive effect on ST of not intervening & 3.82 & .70 & 1.60 & 6.00 \\
EP2 - Positive effect on ST of cautiously intervening & 4.23 & .65 & 2.60 & 5.80 \\
EP3 - Positive effect on ST of intensely intervening & 2.94 & .85 & 1.00 & 4.75 \\
EP4 - Positive effect on ST of taking over the lesson & 2.64 & .81 & 1.00 & 4.80 \\
EP5 - Positive effect on pupils of not intervening & 2.65 & .74 & 1.00 & 4.33 \\
EP6 - Positive effect on pupils of cautiously intervening & 4.63 & .63 & 2.33 & 6.00 \\
EP7 - Positive effect on pupils of intensely intervening & 3.50 & .88 & 1.00 & 5.33 \\
EP8 - Positive effect on pupils of taking over the lesson & 3.58 & .90 & 1.67 & 5.33 \\
\hline
\end{tabular}

Note. $N=158 . \mathrm{EP}=$ Empirical premise.

\section{Association between value premises and empirical premises}

We investigated the relationships between the value premises and the eight empirical premises (see Table 6).

We performed preliminary analyses to ensure no violation of the assumptions of normality, linearity, and homoscedasticity. Value premises were not significantly correlated with any of the empirical premises, which indicated that value premises and empirical premises are not the same. The correlations between the various empirical premises varied from small to large. 


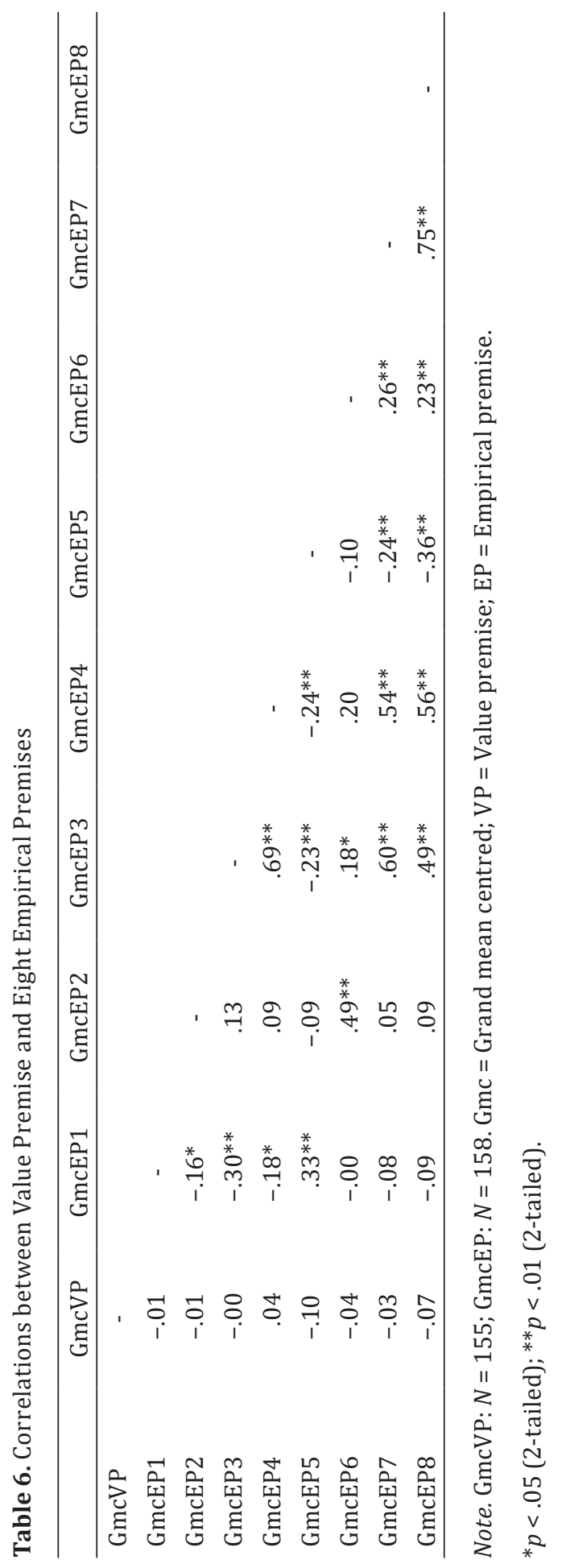




\section{Q2: Descriptive information regarding MTs' intended intervening}

In Table 7, per vignette, the proportions of MTs' intended directions to intervene and the average scores of MTs' intended intervening intensity are shown. In 272 (12.2\% of the total of 2,226) of the intervening ratings, MTs indicated that they would not intervene (score $=0.0$ ), and in 155 ratings (7\%), MTs indicated that they would intervene very intensely (score $=5.0$ ). All other ratings were evenly distributed over the other intensities. Most MTs (88\%) indicated that they would intervene in at least eleven of the fourteen vignette situations.

The number of intended interventions directed toward pupils and those directed toward STs, on average over the 14 vignettes, were almost the same $(44.1 \%$ and $43.7 \%$, respectively). However, the proportion of intervening directed toward the ST varied strongly over the vignettes, namely, from $11.9 \%$ to $75.5 \%$. Additionally, some MTs mainly intervened directed toward the STs, while other MTs mainly intervened directed toward the pupils.

MTs' average score on the intensity to intervene scale was 2.35 (5-point scale; $S D=1.65 ; N=159$ ). For each vignette, on average, the scores were above 1 . The average intensity scores varied over the fourteen vignettes, indicating that the variety in MTs' intended intervening seems to be related to the situation.

For all vignettes, there were MTs who would not intervene (score 0.0) and MTs who would intervene by taking over the lesson (score 5.0). This indicates that the variety in MTs' intervening seems also to be related to the person.

A bootstrapped chi-square test for independence showed a large positive association between MTs' intensity and direction of intervening, $\chi^{2}(924, n=2226)=2950.66$, $p=<.001$, Cramer's V =.81. The higher the intensity ratings were, the more often MTs' intervening was directed toward pupils. 


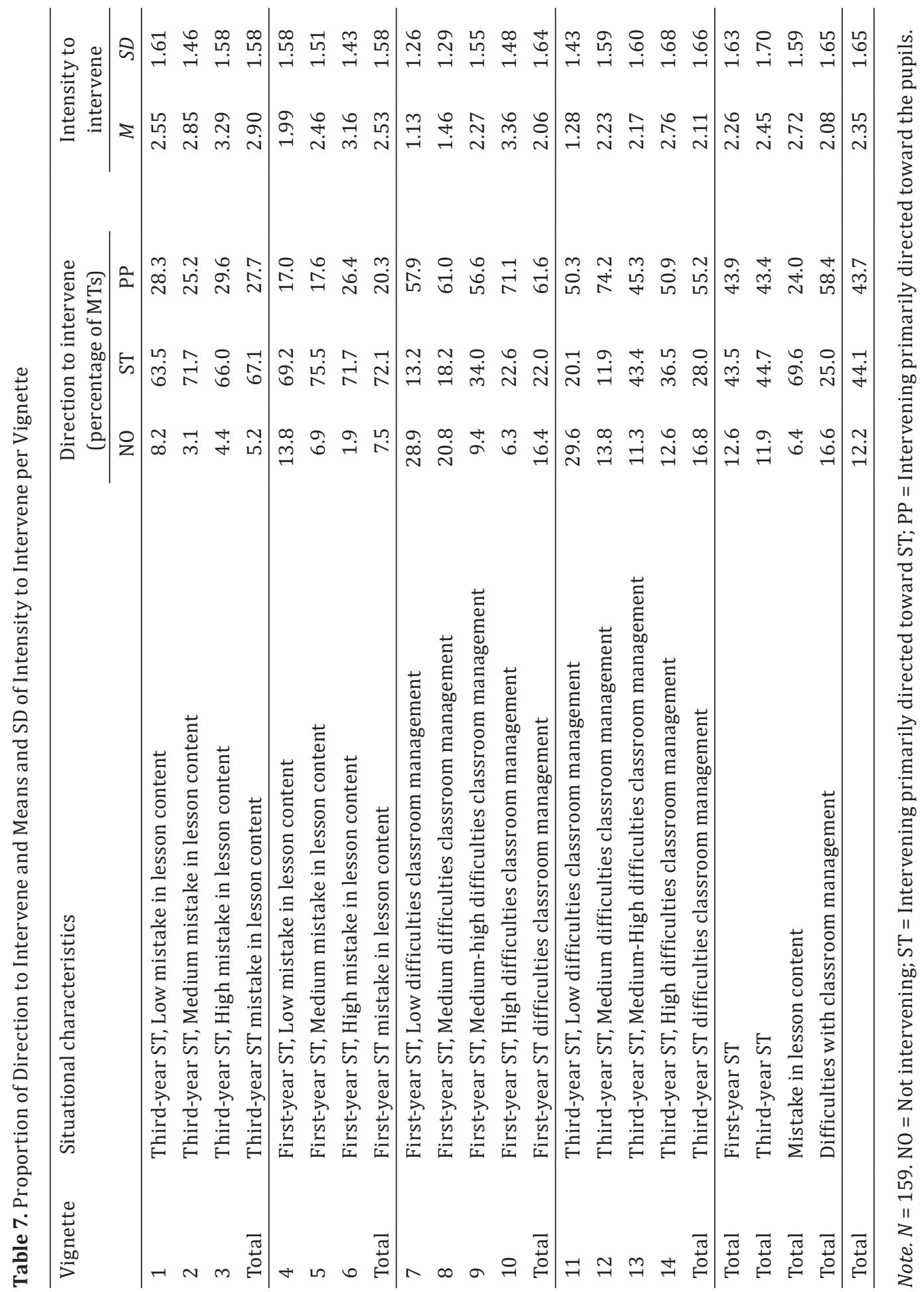




\section{Q3: Predicting MTs' direction to intervene}

To investigate the relative contribution of situational and personal characteristics to MTs' intended direction to intervene we performed logistic mixed multilevel analyses (see Analysis section) with the situational level (level 1) nested in the personal level (level 2). The dependent variable was MTs' intervening direction, in terms of abstaining from intervening versus intervening directed toward the ST, and intervening directed toward the pupils versus intervening directed toward the ST (see Table 8).

The intercept for "abstaining from intervening" clearly indicated that the likelihood for abstaining from intervening was smaller than for intervening directed toward the ST, $\log$ odds $=-1.64, p<.001$. The likelihood that an MT would intervene toward the pupils versus the ST was almost similar, $\log$ odds $=-0.02, p=.785$. Indeed, the probability of not intervening was small, with $.09(0.20 /(0.20+0.98+1)$; the probability for MTs' intervening directed toward the pupils was $.45(0.98 /(0.20+0.98+1)$, and intervening directed toward the ST was $.46(1 /(0.20+0.98+1)$. The variance components indicate that these probabilities varied across MTs $\left(\sigma_{{ }_{\text {not intervening }}^{2}}^{2}=1.56, S E=0.28 ; \sigma_{\text {(intervening }^{2}}^{2}\right.$ directed toward the pupils $\mathrm{s}=0.20, S E=0.06$ ). For not intervening versus intervening directed toward the ST, the intra-class correlation (ICC) was 0.32, indicating that MTs were rather stable in abstaining from intervening. For intervening directed toward pupils versus intervening directed toward the ST, the ICC was 0.06., indicating that whether MTs intervene directed toward the pupils or the ST is less stable per MT.

\section{Situational characteristics}

In the next model (M2) (see Table 8), the three situational predictors, namely, trigger type (lesson content or classroom management), trigger severity (low, medium, medium-high, high), and ST experience (first- or third-year student) were added. 


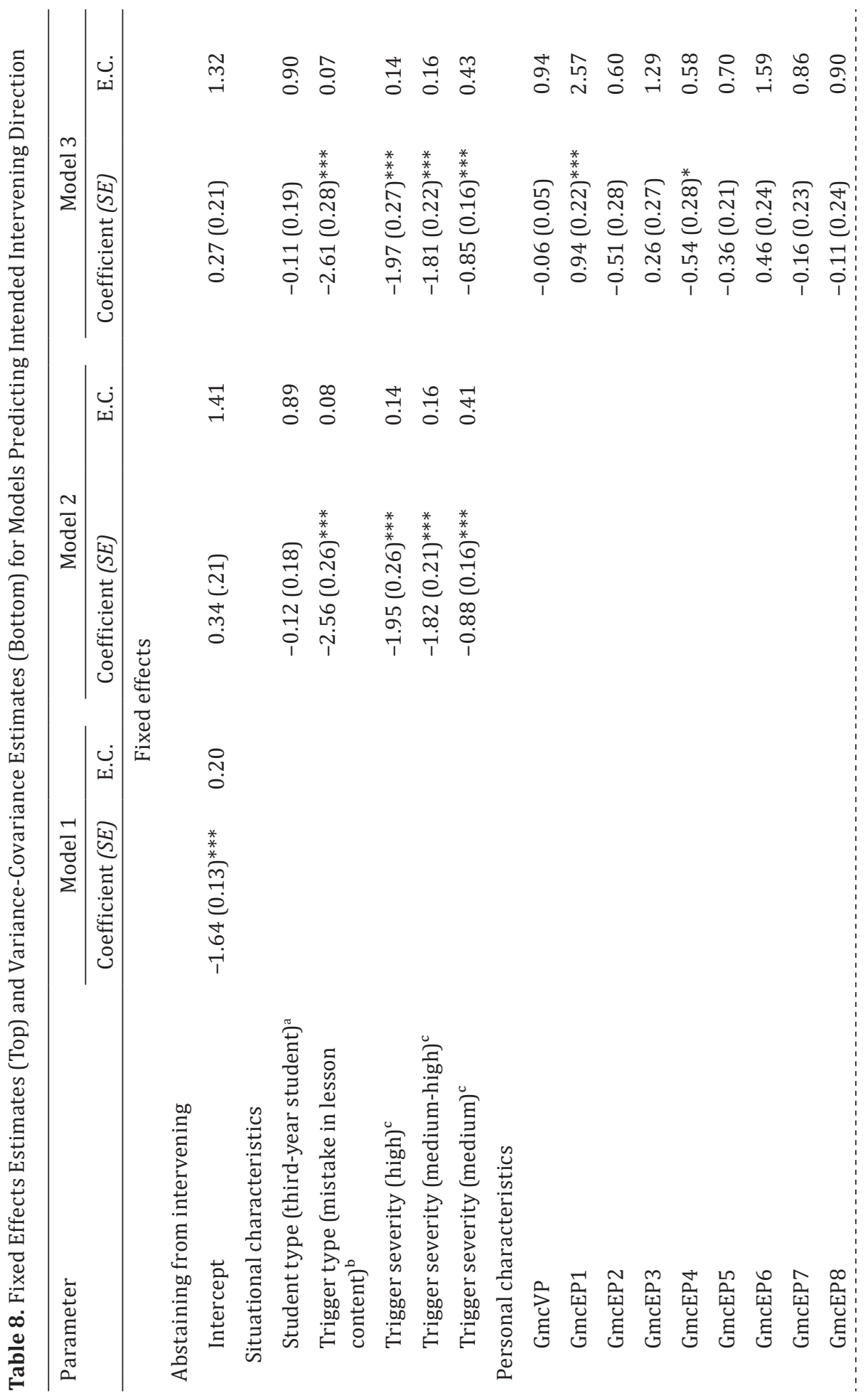




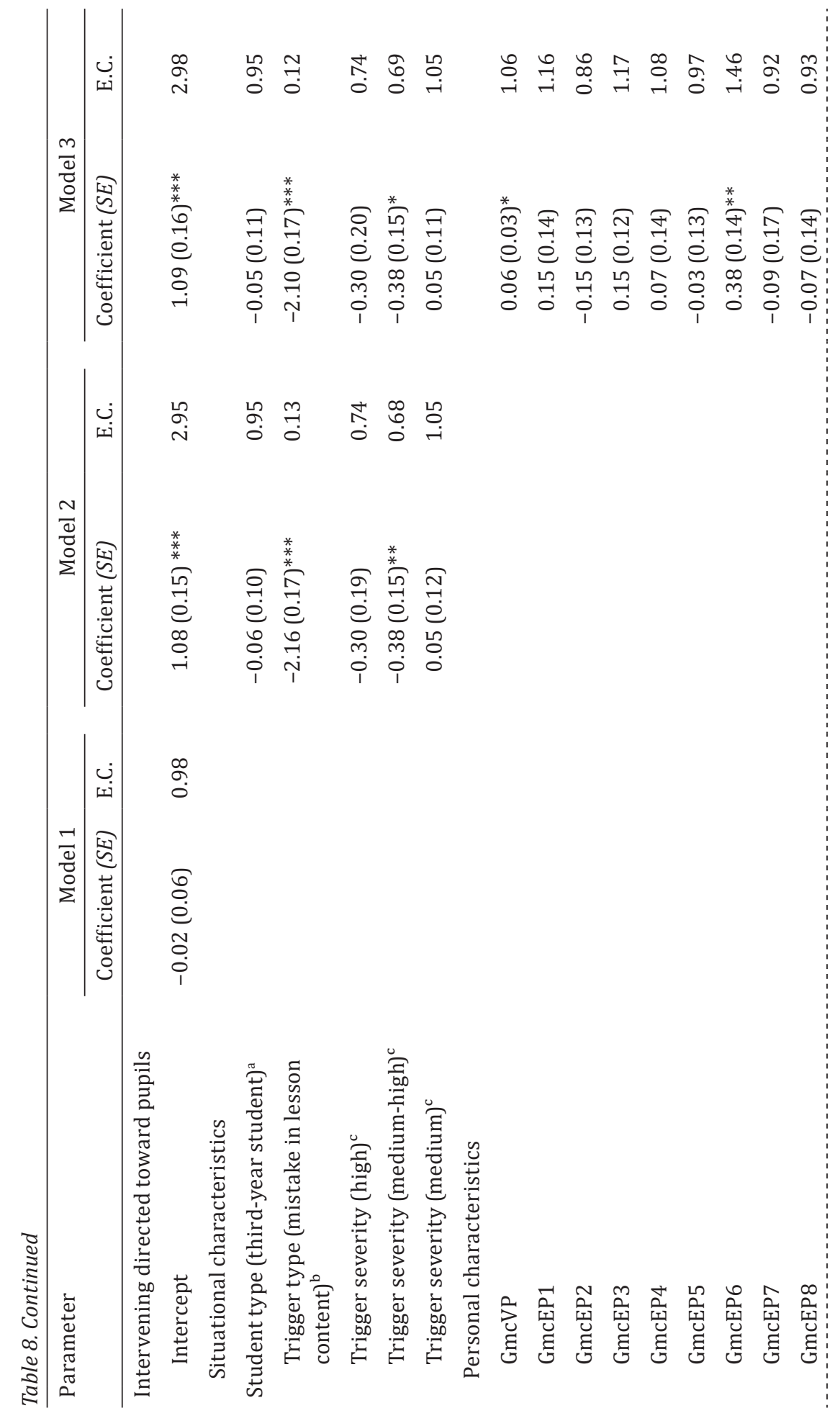




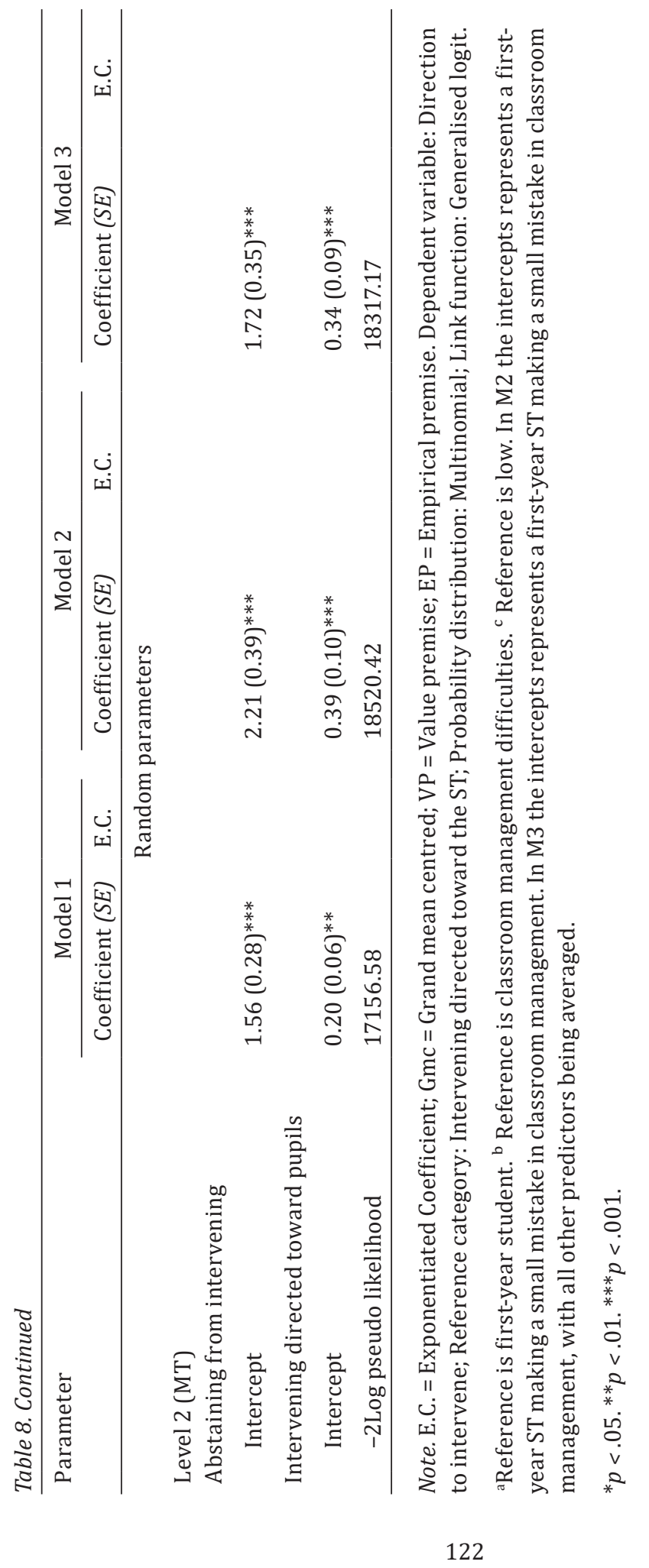




\section{Abstaining from intervening versus intervening directed toward the ST}

In line with our expectation, the probability of intervening directed toward STs was larger in the case of high-, medium-high-, and medium-severity triggers than in the case of low-severity triggers. Thus, when the trigger severity was low, MTs were most likely to abstain from intervening. Further, not intervening (versus intervening directed toward the ST) was more likely in the case of classroom management difficulties than with a mistake in lesson content. Contrary to what we expected, student type was not a statistically significant predictor.

\section{Intervening directed toward the pupils versus intervening directed toward}

\section{the ST}

MTs were more likely to intervene directed toward the ST in the case of a mediumhigh-severity trigger than in the case of a low-severity trigger. High- and mediumseverity triggers did not differ in their effect, as did student type. Further, as expected, MTs were more likely to intervene directed toward the ST in the case of a mistake in the lesson content than in case of classroom management difficulties.

The exact probabilities of MTs' intervening direction, based on model 2, are presented in Table 9. For example, if the vignette depicted a first-year ST making a mistake of high severity in the lesson content, the probability that an MT would decide to not intervene is .01, the probability that the MT would intervene directed toward the pupils is .20, and the probability that the intervening would be directed toward the ST is .79. 
Table 9. Probabilities of MTs' Intervening Direction for Specific Combinations of Situational Predictors

\begin{tabular}{|c|c|c|c|c|c|c|c|}
\hline \multicolumn{2}{|c|}{ Trigger } & \multicolumn{3}{|c|}{ First-year ST } & \multicolumn{3}{|c|}{ Third-year ST } \\
\hline Type & Severity & NO & ST & PP & NO & ST & PP \\
\hline \multirow{3}{*}{$\begin{array}{l}\text { Mistake } \\
\text { in lesson } \\
\text { content }\end{array}$} & Low & .07 & .69 & .23 & .07 & .71 & .23 \\
\hline & Medium & .03 & .71 & .25 & .03 & .73 & .24 \\
\hline & High & .01 & .79 & .20 & .01 & .80 & .19 \\
\hline \multirow{4}{*}{$\begin{array}{l}\text { Difficulties } \\
\text { with } \\
\text { classroom } \\
\text { management }\end{array}$} & Low & .26 & .19 & .55 & .25 & .20 & .55 \\
\hline & Medium & .12 & .21 & .66 & .12 & .23 & .66 \\
\hline & Medium-high & .07 & .31 & .62 & .07 & .32 & .61 \\
\hline & High & .06 & .30 & .65 & .05 & .31 & .64 \\
\hline
\end{tabular}

Note. $\mathrm{NO}=$ Abstaining from intervening; $\mathrm{ST}=$ Intervening directed toward the ST; $\mathrm{PP}=$ Intervening directed toward the pupils. Due to rounded numbers, the probabilities do not always add up to 1.00 .

\section{MTs' personal characteristics}

In the third model, the predictors referring to personal characteristics were added (i.e., MTs' value premises and MTs' eight empirical premises). In Table 8 the fixed and residual effects for this full model (M3) are shown. Because the other five empirical premise subscales did not significantly predict MTs' intended intervening direction, the change in deviance from the model with the situational predictor $\left(\sigma_{\text {(notintervening }^{2}}^{2}=2.21\right.$, $\left.S E=0.39 ; \sigma_{\text {(intervening directed toward the pupils }}^{2}=0.39, S E=0.10\right)$ to the model with the personal predictors $\left(\sigma_{\text {(not intervening }^{2}}^{2}=1.72, S E=0.35 ; \sigma_{(\text {intervening directed toward the pupis }}^{2}=0.34, S E=0.09\right.$ ) does not decrease. Here, we focus on the personal characteristics that do predict MTs' intervening direction.

\section{Abstaining from intervening versus intervening directed toward the ST}

MTs who believed that abstaining from intervening has a positive effect on the ST (GmcEP1) were more likely to abstain from intervening than to intervene directed toward the ST. Similarly, MTs' responses indicated that the more MTs believed that taking over the lesson has a positive effect on the ST, the less likely they are to abstain from intervening than to intervene directed toward the ST (GmcEP4). The other 
empirical premises and the value premise were unrelated to MTs' abstaining from intervening versus MTs' intervening directed toward the ST.

\section{Intervening directed toward the pupils versus intervening directed toward}

\section{the ST}

MTs with a relative preference for teaching values over mentoring values were more likely to intervene by guiding the pupils than by guiding the ST. This means that, as we expected, the more MTs' relatively prefer mentoring values over teaching values, the more likely they are to intervene directed toward the ST rather than the pupils.

Most of the empirical premises did not predict MTs' intervening directed toward the ST versus pupils. Only GmcEP6 was positively related to MTs' intervening direction. MTs who believed that cautiously intervening has a positive effect on pupils (GmcEP6) were more likely to intervene directed toward the pupils than toward the ST.

We also checked whether MT mentoring experience predicts MTs' intervening direction, but this was not a significant predictor.

\section{Q4: Predicting MTs' intensity to intervene}

To investigate whether the variability in the intended intensity to intervene was due to the situation or the person, we tested cross-classified multilevel models with MT responses nested in situations and MTs (see Analysis section). The ICC in the interceptonly model (M1) indicated that $17 \%$ of the variance in intensity of intervening was due to the situation, and $28 \%$ of the variance was due to the MT. The remainder was residual variance. As a next step, the predictors (i.e., student type, trigger type, trigger severity, MTs' value premise and MTs' eight empirical premises) were entered in the model (M2) (see Table 10); $\chi^{2}(12, N=159)=7600.46-7309.07=291.39, p<.01$. Thus, including the predictors improved the model.

\section{Situational characteristics}

Table 10 shows that from the three manipulated situational variables, two variables, namely trigger type and trigger severity, significantly predicted MTs' intervening 
intensity when all predictors (situational and personal) were added to the model. MTs' responses indicated that they would intervene more intensely in situations in which an ST made a mistake in the lesson content than when an ST had difficulties with classroom management. As expected, when the trigger grew in severity, MTs' intervening became more intense. Contrary to what we expected, ST experience was not significantly associated with MTs' intensity to intervene. There is no evidence that MTs would intervene more intense in the case of a first-year student compared to a third-year student.

\section{MTs' personal characteristics}

Table 10 shows that MTs' personal value premise significantly predicted their intended intervening intensity, when all predictors (situational and personal) were added to the model. In line with our expectations, MTs with a relative stronger preference for teaching values over mentoring values intervene more intensely. Also confirming our expectations, the more MTs believed that abstaining from intervening has a positive effect on STs, the less intensely MTs intended to intervene, and the more MTs believed that taking over the lesson has a positive effect on STs, the more intensely they intended to intervene. Of the eight empirical premises included as MT characteristics, only these two were associated with MTs' intervening intensity.

Additionally, we checked whether MT mentoring experience predicted MTs' intervening intensity, but this was not a significant predictor.

In sum, almost all variance (90\%) due to situation and $32 \%$ of the variance due to the MTs was explained by the predictors in our model. The total explained variance of intervening intensity was $25 \%$, which is, according to Cohen (1988) a medium-tolarge effect. 
Table 10. Fixed Effects Estimate (Top) and Variance-Covariance Estimate (Bottom) for Models Predicting Intended Intervening Intensity

\begin{tabular}{lccc}
\hline Parameter & Model 1 & \multicolumn{2}{c}{ Model 2 } \\
\cline { 2 - 4 } & $B(S E)$ & $B(S E)$ & $\beta$ \\
\hline Intercept & Fixed effects & & \\
Situational characteristics & & & \\
$\quad$ Student type & & $0.59(0.20)^{* *}$ & \\
Trigger severity & & $0.18(0.13)$ & .06 \\
Trigger type & & $0.56(0.06)^{* * *}$ & .35 \\
Personal characteristics & & $0.90(0.13)^{* * *}$ & .27 \\
GmcVP & & & \\
GmcEP1 & & $0.07(0.02)^{* *}$ & -.13 \\
GmcEP2 & & $-0.36(0.10)^{* *}$ & -.15 \\
GmcEP3 & & $0.02(0.12)$ & .01 \\
GmcEP4 & & $0.07(0.12)$ & .04 \\
GmcEP5 & & $0.26(0.12)^{* *}$ & .12 \\
GmcEP6 & & $-0.02(0.10)$ & -.01 \\
GmcEP7 & & $0.21(0.12)$ & .08 \\
GmcEP8 & & $-0.01(0.12)$ & -.01 \\
& & $-0.01(0.12)$ & -.00 \\
\hline Residual (level 1) & $1.49(0.05)^{* * *}$ & $1.48(0.05)^{* * *}$ & \\
MT (level 2) & $0.78(0.10)^{* * *}$ & $0.53(0.07)^{* * *}$ & \\
Situation (level 2) & $0.47(0.18)^{*}$ & $0.05(0.02)^{*}$ & \\
-2Loglikelihood & 7600.46 & 7309.07 & \\
\hline
\end{tabular}

Note. $\mathrm{Gmc}=$ Grand mean centred; $\mathrm{VP}=$ Value premise; $\mathrm{EP}=$ Empirical premise . Dependent Variable $=$ Intensity to intervene.

${ }^{*} p<.05 .{ }^{* *} p<.01 .{ }^{* * *} p<.00$. 


\section{DISCUSSION}

In this study, we aimed to describe MTs' value and empirical premises and to gain insight into whether and how MTs intend to intervene during STs' lessons in primary education. We also examined how situational characteristics (ST experience, trigger type, trigger severity) and personal characteristics (MTs' value and empirical premises) contribute to the likelihood that MTs will abstain from intervening, will intervene directed toward the pupils, or will intervene directed toward the ST. Further, we wanted to determine to what extent situational characteristics and MTs personal characteristics predict differences in MTs' intervening intensity and which factors predict MTs' intensity to intervene. Understanding why MTs intervene is essential for improving STs' learning during student teaching. Our innovative multilevel vignette approach might have made MTs feel less assessed than if they were observed and may have prevented socially desirable answering tendencies (Gould, 1996). By using vignettes, we aimed for an understanding of MTs' generic intervening not related to specific STs (Schoenberg \& Ravdal, 2000). In addition, the vignette approach enabled us to reach many respondents within a short period of time, making our findings more representative. Finally, the vignette approach made it possible to present the participants with carefully constructed realistic situations and allowed us to manipulate and control various situational factors that might influence peoples' intentions and behaviour (Aguinis \& Bradley, 2014). We specifically and systematically investigated what MTs would do when a first- or third-year ST is teaching and is having difficulties with classroom management or makes a mistake in the lesson, all with a variety of problem severity. Additionally, we measured MTs' personal characteristics, such as their value and empirical premises. With the combination of these personal characteristics and MTs' intervening ratings for specific situations, we performed multilevel analyses that resulted in a detailed picture of the complexity of MTs' intervening.

Below, we will first describe MTs' intended intervening. Secondly, we will address personal predictors, especially mentoring values, because these seem to explain to a large part MTs' intervening. Third, we will discuss the situational factors that appeared 
to trigger MTs to intervene, and we will elaborate on MTs' possible lack of stimulating STs' development. Finally, directions for further research will be described.

\section{MTs tend to intervene}

First of all, this quantitative study showed that, over all described situations, in almost ninety percent of the ratings MTs would intervene to at least some intensity. The probability that MTs will abstain from intervening is only $9 \%$. Most of the MTs intervened in more than three quarters of the described situations. This result confirms the findings from qualitative research that MTs do frequently intervene (Jaspers et al., 2018, see Chapter 3). Furthermore, we found that, for the situations presented in the vignettes, MTs intervene as much directed toward the pupils as toward the STs and that in about seven percent of the situations, MTs tend to intervene by taking over the lesson. These findings add new insights to the results from studies about intervening, for example by Ben-Peretz and Rumney (1991), Post (2007), and Wang (2010). These studies mostly focused on one direction of MTs' intervening, and they did not systematically relate the types of teaching problems with MTs' intervening.

Our finding that MTs do intervene, intervene quite intensely, and also directed toward the pupils (and not only directed toward STs) is noteworthy because in the mentoring research literature, MTs' intervening toward STs and pupils has rarely been investigated. In practice, when MTs tend to intervene frequently, this will possibly influence STs' development. Our findings stress the importance of addressing MTs' behaviour during STs' teaching in mentoring research and practice in addition to the pre- and post-lesson phases.

In this study, we assumed that MTs' differences in intervening intensity could be affected by the situation (vignette) and the person (MT). With our multilevel vignette design, we found that, indeed, MTs' intervening intensity was due to both the situation ( $17 \%$ of the variance) and the person ( $28 \%$ of the variance). In total a quarter of the variance in MTs' intervening intensity was explained by their value and empirical premises and the situational factors, trigger type, and trigger severity. We also found that MTs' intervening direction is affected by situational as well as personal factors. 
Next, we will elaborate on the relative contribution of personal and situational factors in predicting MTs' intervening.

\section{Personal factors predicting intervening}

An important finding of this study is that MTs indicated that that they find teaching values to be more important than mentoring values, which confirms our earlier exploratory research that MTs feel that being a teacher is their most important task, and being a mentor is an additional task (Jaspers et al., 2014; 2018; see Chapters 2 and 3). For example, on average, MTs prefer the teaching value "pupils should learn the right content" above the mentoring value "STs should teach mostly on their own." As a result of their preference for teaching values, MTs tend to behave as teachers when the ST is teaching. Multilevel analyses showed that MTs with a relative preference for teaching values intervene more intensely and more often directed toward the pupils than MTs with a relative preference for mentoring values. We argue that this preference for teaching values over mentoring values might interfere with being a good MT and guiding the ST during teaching practice.

Although much effort was put into making ecologically valid vignettes, we do acknowledge that our findings are based on hypothetical situations. In this study, we asked MTs to imagine that they were the MT of the ST teaching their hypothetical class and asked them to indicate how they would intervene. Although the vignettes in our study were developed to be ecologically valid to simulate real-life experiences as best as possible and although the situations were evaluated as authentic by the MTs in the pilots, the vignettes are still imaginary situations. The vignettes might not fully represent what MTs experience when they observe the ST teaching their own pupils. In their own classrooms with pupils they really know, the impact of their preference for teaching values over mentoring values might be larger than in our vignette study. MTs would probably be more concerned about the children in their care (Edwards, 1998; Hopper, 2001; Stanulis, 1995) and, therefore, would intervene more easily and more often. 
In addition to MTs' value premise, empirical premises about the positive effects of intervening (or abstaining from intervening) on the ST or pupils might lead to MTs' frequently intervening and their intervening toward pupils. Our results show that MTs have empirical premises regarding what actions are effective during STs' teaching that may be difficult to combine. For instance, MTs believe that intervening intensely and by taking over the lesson has a positive effect on pupils, but at the same time, they believe that such intervening is not positive for the ST. Additionally, MTs believe that abstaining from intervening is positive for the ST but is not very positive for the pupils. MTs' empirical premises about actions that are positive for STs but not positive for pupils suggest a conflict between their mentoring and teaching roles. Apparently, MTs not only experience conflicts between their values as mentor and teacher, but they also have personal beliefs that are conflicting and force them to act in different ways. It is possible that MTs try to combine both roles by cautiously intervening. For example, when pupils start chatting with each other, and the ST does not notice, an MT might intervene by whispering to those pupils. Thus, the MT might hope to prevent these pupils from not paying attention (and not disturbing the other pupils), and at the same time to give the ST the possibility to proceed with the prepared lesson. That MTs try to combine their mentor and teacher roles by cautiously intervening is supported by our finding that MTs most strongly believe that cautiously intervening is positive for the wellbeing and development of pupils as well as the wellbeing and development of the ST. They might hope that cautiously intervening is beneficial for both the ST and pupils; that is, it will not disturb the ST nor distract the pupils' attention. However, whether cautiously intervening indeed would be most effective for ST learning remains unknown.

Our findings that most MTs prefer teaching values over mentoring values and that MTs believe in empirical premises that could lead to incompatible behaviours may have implications for MT professional development courses. These courses could strengthen MTs' mentoring values and their awareness of the importance of STs' learning and development. Consequently, MTs' intervening could become less intense and more directed toward the ST, and MT guidance might become more deliberate. We recommend professional development courses to include support for MTs' quest 
to combine their mentoring and teaching tasks as well as discussions of their values concerning mentoring and teaching and the conflict they (perhaps unconsciously) might experience between being a teacher and being a mentor. When MTs learn to consciously consider both perspectives and the combination of mentoring and teaching values, they might be better able to intervene more deliberately at the moment the ST is practicing teaching.

\section{Situational factors predicting intervening}

The multilevel design enabled us to describe the relative importance of three situational characteristics. In separate analyses, we found that MTs' direction and intensity of intervening were both affected by situational triggers. As the trigger severity grew, MTs intervened more intensely, and MTs' direction of intervening in the case of small problems (more often abstaining from intervening) differed from their intervening in situations with larger problems (more often intervening directed toward STs). As mentioned earlier, we found that an MT will intervene as much directed toward the pupils as toward the STs. When the situational predictors were added, we found that when confronted with an ST making a mistake in lesson content, MTs indicated that they would intervene more intensely and merely toward the ST compared to situations in which MTs were triggered by an ST having difficulties with classroom management. In the latter situations, MTs intervened less intensely and merely directed toward the pupils. In practice, MTs possibly encounter an ST is having classroom management difficulties more frequently than an ST making a mistake in lesson content (compared to the $50 \%$ of the situations in our research). As a result, this might indicate that in real classroom situations, MTs might intervene more directed toward the pupils than the ST.

Interestingly and unexpectedly, MTs' intended direction to intervene as well as MTs' intended intensity to intervene were not predicted by ST experience. Contrary to what we found in Chapter 3 (Jaspers et al., 2018) when MTs reasoned about their intervening in interviews, MTs' actions were more influenced by the classroom or teaching situation than by the ST's experience. Thus, it is plausible that MTs think that their intervening is influenced by the ST (or should be) but that in practice, there is hardly 
any difference in mentoring a first- or third-year student as far as it concerns actual intervening. According to Kagan (1992), acting and thinking could be inconsistent because the relation between the cognitions and actions is situation-specific. Thus, based on a specific situation or context, teachers might be triggered to act differently than what could be expected from their cognitions. For example, MTs might know that they should adjust their mentoring according to the ST's competence, but when confronted with a chaotic classroom situation, MTs may mainly act as teachers of their pupils, which may not always be consistent with their empirical premises as mentors. This interpretation is in line with our finding that MTs feel that teaching values are more important than mentoring values. Moreover, MTs spend more time teaching than combining teaching and mentoring. Thus, as teachers, they are used to reacting to what happens with the pupils in the class; that is, they think and act like teachers and do not think about themselves as teacher educators (cf., Bullough, 2005, OrlandBarak, 2002, 2005, Zeichner, 2005). Becoming an MT and, specifically, guiding an ST during his or her teaching is not something that spontaneously develops from simply being a teacher. Furthermore, MTs might not recognise the ST as a learner. This might prevent them from adapting their mentoring according to the ST's learning needs and competence, again pointing to the importance of courses for MTs.

Based on our findings that MTs' intervening is more dependent on problematic teaching situations than on the ST, we recommend professional development courses for MTs to focus on the importance of ST learning and development, for example by providing information about how MTs can adapt their mentoring behaviour to the stage of the ST's performance and learning curve (Maynard, 1996). We also recommend discussion, for example, about what characterises STs as learners, ST learning phases in becoming a teacher, MTs' expectations of STs in various years of their study or with various competences, and what all of this means for ST guidance during student teaching.

It would be interesting for MTs to discuss with each other how they can contribute to STs' development. Considering our finding that most MTs frequently intervene during STs' teaching, discussions could be held on when, how intense, and to whom the intervening should be directed based on the situation and the particular ST. 
Additionally, MTs could consider their intervening more structurally to be incorporated in the mentoring cycles. In every pre-lesson conference, the MT and ST could agree about the MT's guidance during the ST's teaching before the ST starts teaching. More specifically, when the MT and ST determine the ST's specific learning goal that the ST is going to practice the upcoming lesson, they also could agree on the method the MT will use to help the ST to accomplish this goal. Then during the ST's teaching, the MT can and probably should intervene (based on the learning goal), for example, by explicitly guiding the ST at the moment he or she is supposed to perform the new skills (for example by saying "now do this," "don't forget to do that"), or by saying keywords into a microphone as the ST is wearing an earpiece (e.g., Voerman, Meijer, Korthagen, \& Simons, 2015; Rock et al., 2009). Another way to guide the ST during practice is by deliberately modelling the teaching behaviour the ST has to learn ("See, when I do this, the pupils do/learn that..."). When MTs model good professional practices, it helps STs to become effective practitioners (Roehrig, Bohn, Turner, \& Pressley, 2008). Then, in the post-lesson conference, the MT and ST can discuss when and why the MT intervened and what the effect was on the ST and (eventually) the pupils. When the MT and ST collaboratively reinterpret what happened (what the pupils were or were not doing, what the ST was or was not doing, and how both of these affected [or not] the pupils' learning), MTs have to explicate the practical knowledge underlying their teaching, which appears to be positive for STs' development (Zanting et al., 2001). In addition, especially when the MT intervened rather intensely, reflection on what happened might be supportive for the ST's wellbeing and self-esteem.

\section{Further research}

In this study, we operationalised ST experience as the years of study that an ST had followed, but this factor did not appear to be related to MTs' intervening. To investigate whether there are ST characteristics that predict MTs' intervening, in future research vignettes could be developed that better operationalise the variety in ST competence, for example, by explicating how competent the ST is as assessed by the MT or by varying the learning goal of the ST. Further research could also investigate whether pupil characteristics, such as age and competence (Jaspers et al., 2018, see Chapter 3; Post, 2007), or other trigger types, such as STs having difficulties with teaching 
strategies (Ben-Peretz \& Rumney, 1991) influence MTs' intervening. With two personal characteristics included in this study (value and empirical premises about mentoring and teaching) about a third of the personal variance in intervening was accounted for. Additionally, we checked whether MT mentoring experience explained MTs' intervening, but this was not the case. Other personal predictors that might be investigated are for example MTs' teaching experience, competence, and age (Jaspers et al., 2018, see Chapter 3; Post, 2007). In this study, we investigated MTs' intervening in a regular grade 4 scenario in primary education. It is possible that the pupils, for example, those who might need more guidance, might influence MTs' intervening (Jaspers et al., 2018, see Chapter 3). Additionally, mentoring in primary education might differ from secondary education, for example, due to the age of the pupils, the number of pupils that a teacher teaches, the time spent with one group of pupils, and the relationship between the teacher and the pupils. Consequently, our results cannot be easily generalised to secondary education. Further research could investigate how MTs do or would intervene in secondary education.

With the multilevel vignette approach, we were able to examine the relative impact of personal and situational characteristics on MTs' intervening. We consider this to be an import step in revealing what MTs intend to do when the ST is practicing teaching. As a next step, we suggest to investigate by observations how MTs actually intervene in real teaching situations. Such observations could be combined with stimulated recall interviews (Calderhead, 1981), which involve the MT replying on the videotaped classroom situation to stimulate the MT to recall the decision making about the action. According to the meta-analysis of Hobson et al. (2009), observational research is important as alternative research method to strengthen the current evidence base. There is no conclusive evidence on the convergence of what people say they do and what they actually do in practice (Hughes, 1998). Research that observes MTs in their own classroom might give further insight into the influence of MTs' own pupils on their intervening.

Further, in order to improve effectiveness of mentoring, it could be useful to study how the simultaneous performance of mentoring and teaching roles might be supported, 
how MTs could guide STs in the moment of practicing teaching, and which intervening strategies are most effective. More specifically, it would be interesting to investigate how deliberate ways of MTs' intervening can be used in the educational context of STs practicing to become teachers and how cautiously intervening affects pupil and ST wellbeing and development. It also could be useful to study whether and how the ST and MT discuss the MT's roles and intervening during the ST's lessons with each other in pre- and post-lesson conferences and how this is related to the MT's intervening and guidance of the ST during the actual teaching. Additionally, we suggest further research to examine if and how MT guidance during the ST's teaching is or could be related to the ST's learning goals and learning needs (e.g., Feiman-Nemser, 2001). In addition, the STs' perspectives on MTs' intervening were not included in this study. To be able to conclude which mentoring behaviour contributes to STs' wellbeing and development, future research should examine the STs' perceptions and experience. For example, when ST and MT are observed, STs could be asked if and how they experienced MTs' intervening, why they think the MT intervened, and what they learned from it.

In this study, Fenstermacher's (1986) practical reasoning appeared to be a useful method to gain insight in factors related to actions. We showed that, concerning mentoring, teaching and intervening, value premises and empirical premises are not related and, therefore, can and maybe should be distinguished. When we want to improve our thinking about intervening, MTs' value premises as well as their empirical premises should be target of intervention.

Finally, we suggest further research to investigate changes in MTs' intervening behaviour, for example, by using the self-confrontation method (Hermans \& HermansJansen, 1995) or by reconstructing practical arguments (Fenstermacher \& Richardson, 1993). This study showed that MTs with a relative preference for mentoring values over teaching values intervene less intensely and more by guiding the ST instead of intervening directed toward the pupils. Further research could investigate whether MTs can develop stronger mentoring values and whether this influences MTs' intervening. 
To conclude, this study showed that MTs do intervene during STs' teaching, they intervene quite intensely, and also directed toward the pupils. MTs' intervening direction and intensity are mainly triggered by the severity and type (mistakes in lesson content and difficulties with classroom management) of the observed teaching situation, and not by the ST's experience. This can be explained by MTs' preference for teaching values over mentoring values. MTs' intervening caused by their teacher role might not contribute to STs' learning during practice. Explicitly emphasising to MTs that STs are learners, that MTs are teachers of pupils as well as of STs, and that intervening should serve both, might help MTs to support STs in their growth and in becoming good teachers. 


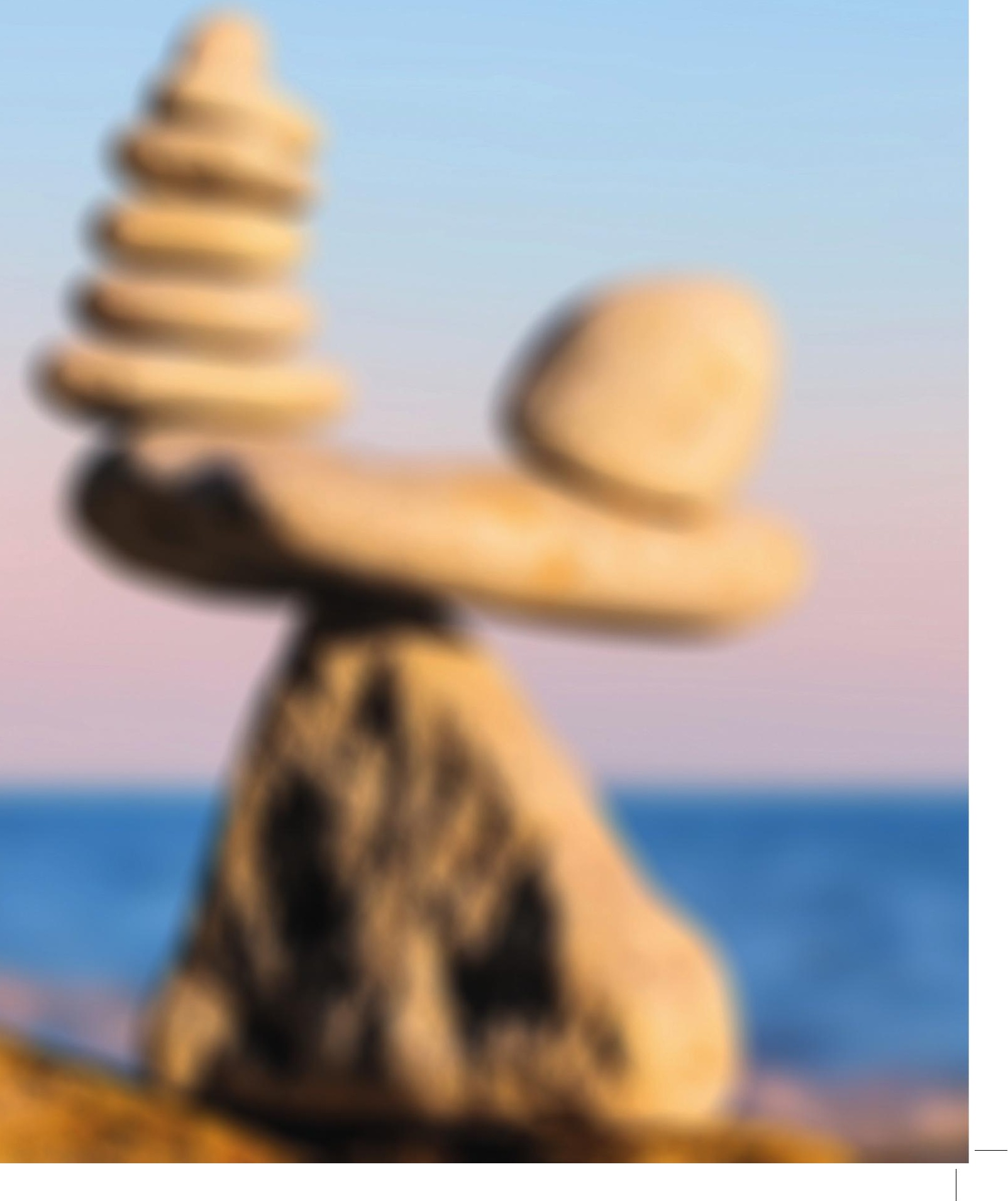




\section{5}

Changing Mentor Teachers' Intended Intervening During Student Teachers' Teaching In Primary Education ${ }^{8,9}$

Based on Fenstermacher's (1986) practical argument theory, this experimental vignette study investigated whether we could change mentor teachers' value premises and empirical premises and their intended intervening direction and intensity during student teachers' teaching in primary education. In a between-subject pre-test posttest design, with a three-minute video clip as intervention, we reinforced mentor teachers' value and empirical premises concerning mentoring or teaching. Mentor teachers indicated for 14 vignettes whether and how they would intervene. We found that MTs' value premises and intentions to intervene were affected. Mentor teachers reinforced on the mentor role $(n=37)$ intended to intervene significantly less intensely and more directed toward the student teacher, and their preference for teaching values over mentoring values decreased. Mentor teachers reinforced on the teacher role $(n=35)$ intended to intervene more intensely and more strongly preferred teaching values over mentoring values. To improve mentor teachers' guidance during student teachers' teaching practicing and, ultimately, student teacher learning, we suggest that mentor teachers should be explicitly informed about the effects of interventions in teaching situations on pupils' and student teachers' wellbeing and development.

8 This chapter is based on: Jaspers, W. M., Prins, F., Mainhard, T., Meijer, P. C., \& Wubbels, T. (Submitted). Changing mentor teachers' intended intervening during student teachers' teaching in primary education.

9 Acknowledgement of author contributions: J, P and W designed the study; J recruited participants and collected the data; J and P developed the instruments; J and Ma analysed the data; J drafted the manuscript; J, P, Ma, Me, and W participated in finalising the manuscript; P, Me and W supervised the study. 


\section{INTRODUCTION}

The student teaching experience in the school has been reported to be an important aspect of teacher training (Hobson, Ashby, Malderez, \& Tomlinson, 2009). In particular, mentor teachers (MTs) significantly influence the development of student teachers (STs) (Beck \& Kosnik, 2002; Borko \& Mayfield, 1995; Furlong, 2000; Wang, Odell, \& Schwille, 2008). MTs support STs in practicing and acquiring the knowledge, beliefs, and skills that enable them to teach (Borko \& Mayfield; Hammerness et al., 2005) and help STs to become effective practitioners, for example, by modelling good professional practice (Roehrig, Bohn, Turner, \& Pressley, 2008), supporting and challenging the STs (e.g., Maynard, 2000), and planning, observing, and analysing lessons (e.g., Hobson, 2002). One potentially essential aspect of effective mentoring that might support ST learning in primary education is how MTs behave during actual ST teaching in the classroom.

Research concerning MTs' guidance of STs during STs' actual teaching practice is scarce, though that might be an important moment when the MTs could contribute to STs' learning. We know that MTs in primary education do not always feel they are the mentor of the ST and do not always consider the ST as learner (Jaspers, Meijer, Prins, \& Wubbels, 2014, see Chapter 2; Jaspers, Prins, Meijer, \& Wubbels, 2018, see Chapter 3). MTs basically feel that they are the teacher of their pupils and that mentoring is an additional task (Jaspers et al., 2014; 2018, see Chapters 2 and 3), and their teaching values are felt to be more important than their mentoring values (Jaspers et al., submitted, see Chapter 4). Also, when an ST is teaching the MT's pupils, MTs experience tensions between being a mentor and a teacher. As mentor, MTs feel they have to support the ST in practicing the teaching, and as teacher, MTs feel responsibility for the development and wellbeing of the pupils (Jaspers et al., 2014, see Chapter 2). Particularly when MTs observe problematic teaching situations, for example an ST having difficulties with classroom management where pupils are not working on task, MTs are (often unconsciously) confronted with their values about mentoring (for example, the ST should teach mostly on his or her own) and teaching (for example, there should be an orderly working atmosphere) (Jaspers et al., 2018, see 
Chapter 3). In such situations, MTs perceive their dual loyalty to their roles as mentor and teacher (Edwards, 1998; Rajuan, Beijaard, \& Verloop, 2007; Orland-Barak, 2001), experience a conflict between mentoring and teaching values, and intervene rather frequently, primarily by guiding the pupils, and also quite disruptively, for example by taking over the lessons (Jaspers et al. 2018, see Chapter 3). To improve STs' learning to teach, STs need sufficient autonomy (Feiman-Nemser, 2001), adequate responsibility and freedom in the classroom (e.g., Collison \& Edwards, 1994), and the opportunity to make mistakes and solve problems on their own (e.g., Oosterheert \& Vermunt, 2001; Van Eekelen, Boshuizen, \& Vermunt, 2005). Thus, when MTs intervene, STs' valuable learning experiences are potentially put at risk.

To be able to help MTs with the tension they experience when combining the mentor and teacher roles, it is useful to know whether we can influence MTs' considerations concerning intervening and whether we can actually change their intervening intensity and direction. From our previous study (Jaspers et al., submitted, see Chapter 4), we know that MTs' intervening is influenced by their value premises (moral and ethical beliefs; Fenstermacher, 1986) concerning mentoring and teaching, and empirical premises (statements about consequences of actions; Fenstermacher, 1986) concerning mentoring and teaching. After MTs have been provided with research findings related to value and empirical premises, they might make more well thought-through decisions, possibly resulting in altered intervening. Therefore, in the present experimental study, by using vignettes (descriptions of hypothetical situations), we aim to gain insight into whether MTs' value and empirical premises concerning mentoring and teaching can be changed and whether MTs' intended intervening intensity and direction can be changed.

First, we will elaborate on MTs' intervening intensity and direction and will describe the practical argument theory, which includes value and empirical premises. Then we will describe the relation between MTs' intervening and their value and empirical premises, and explain how reinforcing MTs' premises might result in a change in MTs' intervening. 


\section{MTs' intervening intensity and direction}

Whether and how MTs intervene during STs' lessons varies by mentor teacher and by situation (Ben-Peretz \& Rumney, 1991; Jaspers et al., submitted, see Chapter 4). Wang (2010) distinguished three categories of interventions: 1) active, including that the MT him/herself intervenes in the lesson or prompts pupils to ask the ST questions; 2) passive (an MT responds to a question by the ST); and 3) no intervention. Post (2007) described six interventions, increasing in the extent of classroom process disruption, that range from "ignore", which means the MT deliberately does not respond, to "intercept", where the MT takes over the lesson. The four intermediate interventions, intervene, interject, interact, and interrupt, are all directed to the ST. Jaspers et al. (2018, see Chapter 3) found that MTs intervene both toward the ST and the pupils (MTs' intervening direction) and with a variety of intensities (MTs' intervening intensity). They also found various reasons for MTs to intervene or abstain from intervening. Additionally, Jaspers et al. (submitted, see Chapter 4) found that MTs' (abstaining from) intervening and the direction and intensity of intervening are influenced by situational characteristics of the STs' lesson and by MTs' personal characteristics (Jaspers et al., submitted, see Chapter 4). Situational characteristics, for example, include problems concerning teaching strategies (Ben-Peretz \& Rumney, 1991), a mistake made by the ST in the lesson content or misinforming pupils (Ben-Peretz \& Rumney, 1991; Jaspers et al., submitted, see Chapter 4; Wang, 2010; Weasmer \& Woods, 2003), the ST demonstrating insufficient classroom management skills (Ben-Peretz \& Rumney, 1991; Jaspers et al., 2018, see Chapter 3; Wang, 2010; Weasmer \& Woods, 2003), and the severity of what is going wrong (Jaspers et al., submitted, see Chapter 4). Personal characteristics that are important predictors of MTs' intervening direction and intensity are MTs' value and empirical premises (Jaspers et al., submitted, see Chapter 4), which are the focus of the current research.

\section{Practical arguments}

Practical arguments can illuminate the complex process of teachers' reasoning about acting (Fenstermacher, 1986), as well as encourage a change of teacher actions (Richardson, 1990). A practical argument consists of a series of premises, namely, situational premises, which describe the context or situation in which the action occurs; 
value premises, which are moral and ethical considerations that indicate the desirable conditions, desired state of affairs, or a value or expression of moral good that the actor associates with these consequences; and empirical premises, which are statements of principles denoting the consequences that might be expected to follow the action and are based on earlier observations that also could be tested by new observations (Fenstermacher \& Richardson, 1993). These premises contribute to the decision or intention to act, in response to the question "What shall I do" or "Why did I do that?" (Morine-Dershimer, 1987). When someone thinks about what he or she did or ought to do in a specific situation, this is a case of practical reasoning (Pendlebury, 1990). Jaspers et al. (2018, see Chapter 3) found that the concept of practical reasoning can be used to describe mentor teachers' reasoning about their intervening.

\section{Value premises predicting MTs' intervening}

MTs appear to choose a low intrusive intervention (Post, 2007) when they perceive STs' authority to act as teachers (Beck \& Kosnik, 2002) and their freedom to explore teaching ideas as critical factor of STs' professional learning (Patrick, 2013; Rajuan et al., 2007; Wang, 2010). Jaspers et al. (submitted, see Chapter 4) found that the less MTs prefer teaching values over mentoring values, the less they intended to intervene intensely and the more their intervening was directed toward the ST instead of the pupils.

\section{Empirical premises predicting MTs' intervening}

Whereas the relation between the value premises and MTs' intervening is relatively clear, the relation between empirical premises and MTs' intervening is more ambiguous. Some research argues that for mentoring during STs' teaching to contribute to STs' development, MTs should actively guide the STs while practicing the teaching (Maynard, 2000; Schwille, 2008), because by doing so STs become aware of the specific situation in which they can improve their teaching (Maynard, 2000; Schwille, 2008), and struggling STs can be helped (Post, 2007). Moreover, by intervening MTs can prevent STs from making mistakes (Post, 2007), can limit or prevent further problems (Wang, 2010), and can recreate an orderly classroom atmosphere in which pupils work on their tasks (Jaspers et al., 2018, see Chapter 3). Other authors argue that MTs 
should not intervene, because learning to teach is just a matter of practicing (Hagger \& McIntyre, 2006) and experiencing it (Borko \& Mayfield, 1995), and that STs need the opportunity to make mistakes, solve the problems on their own (e.g., Oosterheert \& Vermunt, 2001; Van Eekelen et al., 2001), feel trust and support, and satisfy their desire for freedom to explore their own teaching styles, and they should not feel that their authority is being undermined (Jaspers et al., 2018, see Chapter 3; Rajuan et al., 2007). When MTs do step into STs' lessons, STs have no freedom to manage the classes on their own, which can damage their confidence (Izadinia, 2015; Maynard, 2000), selfesteem (Wang, 2010), and wellbeing (Jaspers et al., 2018, see Chapter 3). However, by abstaining from intervening, MTs might believe that they create an environment that is not supportive and conducive to STs' learning and teaching and could be harmful to pupils' learning and STs' wellbeing (Jaspers et al., 2018, see Chapter 3). Jaspers et al. (submitted, see Chapter 4) found three empirical premises that predicted MTs' intervening direction and intensity. First, the more MTs believe that abstaining from intervening has a positive effect on STs, the less intensely MTs intend to intervene and the more likely they are to abstain from intervening. Second, the more MTs believe that taking over the lesson has a positive effect on STs, the more intensely MTs intend to intervene and the more likely they are to intervene by guiding the ST. Third, the more MTs believe that cautiously intervening has a positive effect on pupils, the more likely it is that they will intervene directed toward the pupils instead of toward the ST.

\section{Reinforcing MTs' premises}

By reinforcing MTs' premises, which we describe as the process of making MTs more aware of their already existent value and empirical premises, MTs' subjectively reasonable beliefs might become objectively reasonable (Green, 1976). Reinforcing premises might enhance the MT's ability to think more deeply and powerfully about an action (Morine-Dershimer, 1987) and might help MTs to use defensible theory and research findings, which might advance MTs' competence (Fenstermacher \& Richardson, 1993). Attempts to reinforce MTs' premises and to encourage MTs to change their actions should begin by examining their value premise (MorineDershimer, 1987) or by introducing a new value premise (Fenstermacher \& Richardson, 1993). Jaspers et al. (submitted, see Chapter 4) found that MTs, although they are 
the mentors of STs, feel that being the teacher of the pupils was more important and that teaching values are more important than mentoring values. Encouraging MTs to give more prominence to a specific value premise by informing an MT about specific research findings or being prompted by a critical other (Fenstermacher \& Richardson, 1993; Morine-Dershimer, 1987) may serve to reinforce MTs' already existent value premises (Morine-Dershimer, 1987) and could help to identify the value conflicts MTs face and to deal with them more effectively (Morine-Dershimer, 1988). Moreover, Fenstermacher and Richardson (1993) claim that teachers often act without explicit prior deliberation, and Jaspers et al. (2018, see Chapter 3) found that MTs barely used premises referring to research findings or theoretical evidence when reasoning about intervening. Reinforcing the premises, by providing research findings, for example, about the effect of specific situations on ST or pupil learning, could make MTs more aware of their value and empirical premises, and help them to act in a more thoughtthrough manner, and therefore might result in a change in MTs' actions (Fenstermacher \& Richardson, 1993).

In a previous, exploratory interview study, we described MTs' practical reasoning about their (abstaining from) intervening during STs' lessons and provided an overview of premises that MTs mentioned when they reasoned about their intervening (Jaspers et al, 2018, see Chapter 3). In a following quantitative vignette study, Jaspers et al. (submitted, see Chapter 4) found that MTs' direction and intensity of intervening can be predicted with some of these premises. Aside from the situational characteristics, such as the severity of the teaching problem, MTs' personal value and empirical premises also appeared to affect their intervening (Jaspers et al., submitted, see Chapter 4). By using this influence of MTs' value and empirical premises on MTs' intervening, and based on the underlying theory of the practical argument, we might be able to change MTs' intervening by reinforcing MTs' value and empirical premises.

\section{The current study}

By showing MTs a short video clip in which research information is provided that encourages MTs to think about teaching and mentoring, we wanted to find out whether MTs' value and empirical premises and their intervening during STs' teaching can be 
changed. Based on Fenstermacher's (1986) practical argument theory, we assumed that by reinforcing value and empirical premises by providing research findings concerning the mentor or teacher role, MTs would be encouraged to give more prominence to the values of the mentor or teacher role, which consequently might result in changed intervening.

The research question of our study was: Does reinforcing the mentor or teacher role affect a) MTs' relative preference for teaching values over mentoring values; b) MTs' empirical premises concerning the effects of intervening; c) MTs' tendency to abstain from intervening, to intervene directed toward the ST, or to intervene directed toward the pupils, and; d) MTs' intended intervening intensity?

We expected that when MTs are reinforced on the mentor role, they tend to abstain more often from intervening, to intervene less intensely, and to intervene directed more toward the STs than toward the pupils. Also, we expected these MTs to have a decreased preference for teaching values over mentoring values. Regarding the empirical premises, we expected these MTs to more strongly agree with the empirical premise that abstaining from intervening is positive for STs, and to less strongly agree with the empirical premise that taking over the lesson is positive for STs. We explored how the empirical premise concerning the effect on pupils of cautiously intervening is affected. For MTs who are reinforced on the teacher role, we expected their value premises, empirical premises, and intervening to change in the opposite direction to MTs reinforced on the mentor role. Finally, we expected MTs who are not reinforced to not change in value premises, empirical premises, and intended intervening direction and intensity. 


\section{METHOD}

\section{Design}

We performed an experimental between-subject pre-test post-test study, in which we used vignettes (descriptions of hypothetical situations) for which MTs indicated whether and how they would intervene. We created three conditions. In the mentor condition (Condition M), we reinforced MTs' value and empirical premises by providing information on the importance of the mentor role (value premise) and by providing information on research that describes the relation between teaching situations and STs' wellbeing and development (empirical premises). The second condition was a control no-treatment condition (Condition C). In the third condition (Condition T), we reinforced MTs' value and empirical premises by providing information on the importance of the teacher role (value premise) and by providing information on research that describes the relation between teaching situations and pupils' wellbeing and development (empirical premises). The independent variables were Condition and Occasion: Occasion 1 and Occasion 2, the pre- and post-test before and after MTs' premises were reinforced. The dependent variables were the value and empirical premises, the intended direction of intervening, and the intended intensity of intervening. Figure 1 shows an overview of the research design.

\begin{tabular}{|l|}
\hline \multicolumn{1}{|c|}{ Occasion $\mathbf{1}$} \\
\hline Pre-test \\
Questionnaire : \\
-14 vignettes, version A, \\
Intended intervening: \\
- Intensity \\
- Direction \\
- Value premises \\
- Empirical premises \\
- Demographic \\
characteristics \\
\hline
\end{tabular}

\begin{tabular}{|c|c|}
\hline \multicolumn{2}{|c|}{ Occasion 2 (three weeks later) } \\
\hline $\begin{array}{l}\text { Condition } \mathbf{M} \\
\text { Reinforced on mentor } \\
\text { role }\end{array}$ & $\begin{array}{l}\text { Post-test } \\
\text { Questionnaire : }\end{array}$ \\
\hline $\begin{array}{l}\text { Condition C } \\
\text { Control condition }\end{array}$ & $\begin{array}{l}\text { Intended intervening: } \\
\text { - Intensity } \\
\text { - Direction }\end{array}$ \\
\hline $\begin{array}{l}\text { Condition } \mathbf{T} \\
\text { Reinforced on teacher } \\
\text { role }\end{array}$ & - Empirical premises \\
\hline
\end{tabular}

Figure 1. Experimental between-subject pre-test post-test design. 


\section{The intervention}

The intervention in the $\mathrm{M}$ and $\mathrm{T}$ conditions consisted of watching a video clip (in Dutch) of approximately three minutes of an interview with a scholar about mentoring an ST during the ST's teaching and the respective effects on the ST or the pupils. We used two scripts for the video clips based on the findings reported above on MTs' reasoning about intervening (Jaspers et al., 2018, see Chapter 3) and research presented in the introduction of the present article. In both scripts (see Appendix) the scholar explained the effects of problems in lesson content or classroom management on either the STs' or pupils' wellbeing and development. In the interviews reinforcing the mentor or teacher role, the scholar focused on the goal, responsibility, and values of being respectively an MT or a teacher (value premises). Then he described research about the influence of the teaching problems on STs' or pupils' wellbeing and development, respectively (empirical premises). All other information and phrasings were in both scripts as similar as possible. In both scripts the empirical premises were provided to MTs as results from scientific research by using phrases like "We know from scientific research..." or "Research has shown that...". The scholar explicitly did not provide any information about MTs' actions or intervening or about the relation between MTs' behaviour and STs' or pupils' wellbeing or development.

\section{Participants}

Participants were recruited from the institute's list of all MTs who were involved in supervising an ST at the time. In total, 461 MTs in primary education in the Netherlands were invited to participate, and 159 of them filled out the first questionnaire. Eventually 109 MTs (17 males, 91 females, and 1 missing value) from at least 46 schools (not every participant indicated their school) participated on a voluntary basis on both occasions. The main reasons given by MTs for not participating were participation in other research programmes or lack of time.

Most of the MTs had mentored or were mentoring an ST in the year of the data collection (four MTs two years before, and one MT three years before). MTs varied in age from 23 to 63 years $(M=41.74, S D=11.53)$. The average teaching experience 
was 16.6 years $(S D=10.07)$ and the average experience in mentoring was 9.81 years $(S D=7.40$; see Table 1$)$.

The three groups differed significantly in age, $F(2,105)=3.229, p=.044$. The effect size, $\eta^{2}$, was .06 (medium effect). Post-hoc comparisons using the Tukey HSD test indicated that the mean age for Condition $\mathrm{M}$ was significantly higher than for Condition C; therefore, MTs' age was added as covariate in the analyses. The age of teachers in Condition T did not differ significantly from the other conditions. Also, no statistically significant differences were found between the three groups for mentoring and teaching experience, respectively: $F(2,105)=1.15, p=.322 ; F(2,105)=0.20, p=.820$.

Table 1. MTs' Characteristics per Condition

\begin{tabular}{|c|c|c|c|c|c|c|c|c|}
\hline \multirow[t]{2}{*}{ Characteristics } & \multicolumn{2}{|c|}{ Condition M } & \multicolumn{2}{|c|}{ Condition C } & \multicolumn{2}{|c|}{ Condition T } & \multicolumn{2}{|c|}{ Total } \\
\hline & $M$ & $S D$ & $M$ & $S D$ & $M$ & $S D$ & $M$ & $S D$ \\
\hline Age & 45.32 & 12.14 & 38.69 & 9.31 & 41.09 & 12.20 & 41.74 & 11.53 \\
\hline $\begin{array}{l}\text { Teaching } \\
\text { experience }\end{array}$ & 18.00 & 10.23 & 14.62 & 7.55 & 17.34 & 11.96 & 16.66 & 10.07 \\
\hline $\begin{array}{l}\text { Mentoring } \\
\text { experience }\end{array}$ & 10.35 & 8.39 & 9.25 & 6.86 & 9.80 & 6.96 & 9.81 & 7.40 \\
\hline
\end{tabular}

Note. $N=108$. Condition $\mathrm{M}=$ Reinforced on mentor role; Condition $\mathrm{C}=$ Control condition; Condition $\mathrm{T}=$ Reinforced on teacher role.

\section{Measures}

\section{Intended intensity and direction to intervene}

To measure MTs' intended intervening intensity and direction, MTs were asked to indicate how they would intervene in various situations shown in the first occasion in vignettes that were developed in a previous study (Jaspers et al., submitted, see Chapter 4) (version A). For the second occasion, we developed 14 other parallel vignettes (version B). Vignettes are descriptions of imaginary situations that can be used to determine which circumstances influence peoples' attitudes and beliefs and to better understand peoples' actions in specific situations (Schoenberg \& Ravdal, 
2000). The text-based vignettes were authentic descriptions of situations that 1 ) were representative of what MTs regularly experience during ST lessons, 2) elicited MTs to consider their intervening, and 3) highlighted variations in MTs' intended actions, which made it possible to measure a broad spectrum of MTs' intervening. The 14 vignettes were systematically varied over three situational variables. The first variable, ST experience, distinguished the year of study of the ST (i.e. a first-year versus a third-year student). The second variable, trigger type, varied in the teaching problem that was described (i.e. an ST making a mistake in lesson content or an ST having difficulties with classroom management). The combination of these two variables led to four types of vignettes. Additionally, every vignette had three or four versions that differed in the severity level of the classroom problem: low, medium, medium-high, and high. All other variables such as the STs' gender (all female) and pupil characteristics (for example, average competence), were the same for all vignettes. The 14 vignettes of the second occasion were comparable to the 14 vignettes used in the first occasion. The same variables were manipulated and the phrasing was copied as much as possible, but, in order to reduce potential test effects, we changed some identifying characteristics, for example, the names of the ST and the pupils and the content of the lesson (for example, insects versus animals). Figure 2 gives four examples of vignettes, two for each occasion.

The intended intensity to intervene was measured on an intensity-to-intervene-scale. To give the participants a clear view of the "intensity of intervening", participants were informed about this concept before reading the vignettes. After reading each vignette, MTs answered the question "What would you do?" by sliding a pointer on a continuous scale. The left side of the scale was labelled not intervene, and the right side very intensely intervene. Only the extremes of the scale were labelled. The Cronbach's $\alpha$ values of .88 and .93 for Occasion 1 and Occasion 2, respectively, indicated that the internal consistency of intensity scores of the 14 situations for each occasion was high. 


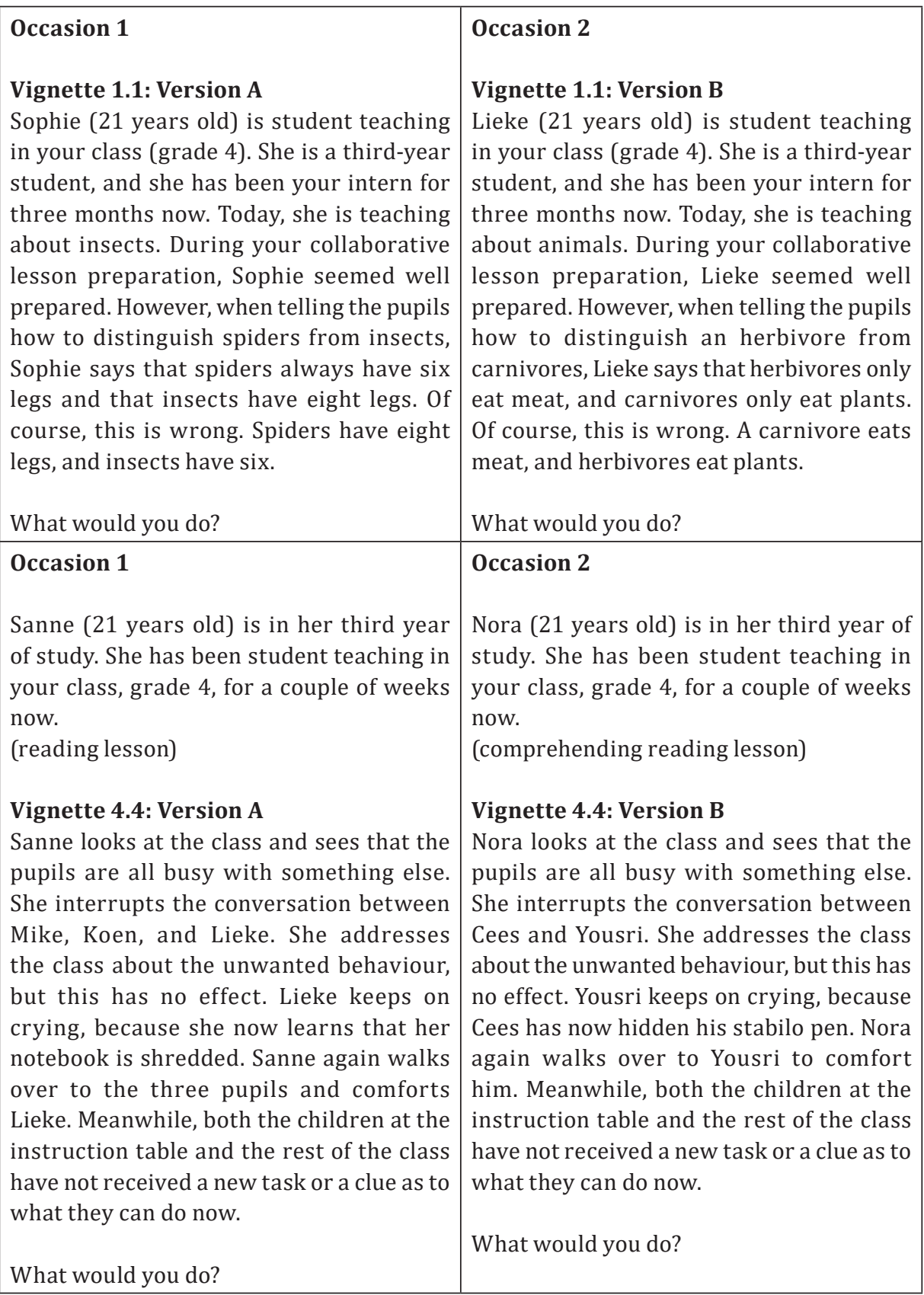

Figure 2. Examples of vignettes for Occasion 1 and Occasion 2. 
After indicating the intensity to intervene in a situation, the participants were asked to indicate their intended direction to intervene for that particular situation, namely whether they would intervene mainly by guiding the ST or whether they would intervene mainly by guiding one or more pupils. Based on MTs' reasoning for intervening in a previous study (Jaspers et al., 2018, see Chapter 3), we decided that when MTs indicated that they would intervene very intensely, we considered that as equivalent to taking over the lesson, and thus, MTs' intervening was mainly aimed at guiding the pupils. Therefore, when MTs scored 5.0 on the intervene scale, there was no option to indicate the direction of intervening. In addition, when MTs scored 0.0 on the intervene scale, the direction to intervene was labelled "Abstaining from intervening", and no option was presented to the MTs. Thus, for direction to intervene, three categories were used: 1) Abstaining from intervening, 2) Intervening mainly directed toward the ST, and 3) Intervening mainly directed toward the pupils.

\section{Value premises}

MTs' value premises were measured by paired comparisons. In a previous study (Jaspers et al., submitted, see Chapter 4) we designed an instrument to measure teaching values as compared to mentoring values, including four mentoring and four teaching values (see Table 2) that MTs had indicated in Jaspers et al. (2018, see Chapter 3) as important in their decisions whether to intervene during ST lessons.

Table 2. Value premises

\begin{tabular}{ll}
\hline Teaching values & Mentoring values \\
\hline I think it is most important that... & I think it is most important that... \\
$\begin{array}{l}\text {... the pupils feel comfortable in class. } \\
\text {... the pupils develop. }\end{array}$ & $\ldots$ the ST feels comfortable in class. \\
... there is an orderly working atmosphere. & $\ldots$... the ST's develops. \\
... the pupils learn the right content. & ... the ST teaches mostly on his or her own. \\
\hline
\end{tabular}

On the questionnaire, each of these eight values was combined with every other value $((8 \times 7) / 2=28$ combinations $)$, and respondents had to choose the most important one to them (see Figure 3). 


\section{I think it is most important that...}

... the STs develop. $\quad$... there is an orderly working atmosphere.

Figure 3. Example of a combination of two values for which MTs indicated the one they found most important.

Based on these 28 comparisons, a value premise scale ranging from 6 (strong preference for mentoring values over teaching values) to 22 (strong preference for teaching values over mentoring values) was created (see Jaspers et al., submitted, see Chapter 4 for more details), that measured MTs' relative preference for teaching values compared to mentoring values. A score of 14 meant that an MT found mentoring and teaching values equally important. The Cronbach's $\alpha$ of the mentoring value premise scale was .71. In Occasion 1, one MT had missing scores, and in Occasion 2, one MT had missing scores. These scores were not included in the value premise scale.

\section{Empirical premises}

MTs' empirical premises about the positive effects of (the intensity of) intervening on the ST and the pupils were measured by having respondents indicate their level of agreement with statements on a 6-point scale reaching from strongly disagree to strongly agree. These statements were developed based on empirical premises described by Jaspers et al. (2018, see Chapter 3). In the current study, only the three empirical premises scales were used that were related to MTs' intervening direction and intensity (Jaspers et al, submitted, see Chapter 4). Table 3 gives an overview of the three empirical premise scales, examples of statements in each scale, the Cronbach's $\alpha$ values, and the number of items. 
Table 3. Empirical Premises: Subscales, Examples, Cronbach's $\alpha$, and Number of Items

\begin{tabular}{llcc}
\hline Scale & Example & $\alpha$ & $k$ \\
\hline $\begin{array}{l}\text { EP1 - Positive effect on ST of not } \\
\text { intervening }\end{array}$ & $\begin{array}{l}\text { If I do not intervene, the ST experiences } \\
\text { what is happening at the moment. }\end{array}$ & 53 \\
$\begin{array}{l}\text { EP2 - Positive effect on ST of } \\
\text { taking over the lesson }\end{array}$ & $\begin{array}{l}\text { If I take over the lesson, that is pleasant } \\
\text { for the ST }\end{array}$ & 58 \\
$\begin{array}{l}\text { EP3 - Positive effect on pupils of } \\
\text { cautiously intervening }\end{array}$ & $\begin{array}{l}\text { If I intervene cautiously, an orderly } \\
\text { class atmosphere is created. }\end{array}$ & .70 & 3 \\
\hline
\end{tabular}

Note. EP = Empirical premise, $k=$ number of items.

\section{Demographic characteristics}

In the last part of the questionnaire, MTs were asked 14 questions about their demographic characteristics, such as gender, age, and years of experience as MT and teacher.

\section{Procedure}

All MTs received an email in which they were invited to participate in this research. When they chose to participate, they received a hyperlink to the online electronic questionnaire including the 14 vignettes and the items on value premises, empirical premises, and demographic characteristics. MTs who did not start or complete the questionnaire received one reminder. Before starting the questionnaire, participants were informed that their answers would be analysed and reported anonymously, and they were asked to sign an informed consent form. Participants were asked to complete the questionnaire at a time they would not be disturbed and in which they could complete the whole questionnaire at one sitting. Completing the questionnaire took an average of 30 minutes. It was not possible to go back to a previous question. Participants were asked not to discuss the questions with colleagues until they also had completed the questionnaire. All participants who took the first questionnaire were randomly assigned to three conditions. After three weeks, they were asked to take part in the second part under the same conditions as in the first part, being unaware of the group they were in. The MTs in the M and T conditions answered a question about the video clip in order to activate their tacit knowledge and to check whether 
they watched the video clip. Then all participants filled out the second questionnaire. To increase the response rate, schools received the aggregated results for their school if at least five MTs participated. Moreover, three tablets were put on raffle for the MTs who participated in this study. All participants received a debriefing email in which the aim and design of the study was explained, and which contained both video clips. The Faculty Ethics Review Board of the Faculty of Social and Behavioural Sciences of Utrecht University approved this study.

\section{Data analysis}

\section{MTs' value premises and empirical premises}

To examine the effect of reinforcing the mentor or teacher role on MTs' value and empirical premises, we performed multilevel analyses with SPSS, Version 24. We analysed models separately for value and empirical premises scores including the two occasions (pre-test and post-test) (Level 1) as nested within the MTs (Level 2). First, an intercept-only model (M1) was fitted. Next, in the conditional model (M2) the fixed predictors Occasion and Condition and the cross-level interaction between Occasion and Condition (Occasion 1 and Condition C as reference categories) were entered. This interaction term tested our hypotheses that MTs' change in value and empirical premises would differ depending on being reinforced on the mentor role, the teacher role, or not being reinforced. In the third model, the covariate model (M3), MTs' age (grand mean centred) was added as covariate to check whether a possible interaction effect might change due to MTs' age.

For each level of the multilevel model, preliminary checks were conducted to ensure that there was no violation of the assumptions of normality of residuals, linearity, homogeneity of regression slopes, and reliable measurement of the covariate. While the value premises scale was considerably skewed to the right (high preference for teaching values over mentoring values), the residuals were rather normally distributed. In interpreting the results, however, we must bear in mind that the chances of a type 1 error might be somewhat increased. 
In line with Hox, Moerbeek, and Van de Schoot (2018), to compute effect sizes, we used M1 as intercept-only model and calculated how much variance between MTs' scores could be explained by the predictors (Condition and Condition $\times$ Occasion) in the conditional and covariate models, for which we considered .01, .09, and .25, respectively, a small, medium, and large effect (Cohen, 1988).

\section{MTs' intended intervening direction}

To analyse the variability in MTs' intended intervening direction (a categorical variable, i.e. Abstaining from intervening, Intervening mainly directed toward the ST, and Intervening mainly directed toward the pupils) we again considered the nesting of occasions within the MTs. We followed the approach of Heck, Thomas, and Tabata (2012) and estimated logistic mixed multilevel models with a logit link function (Hox, Moerbeek, \& Van de Schoot, 2018) in SPSS, Version 24. These models compared the probability of being in one of the other categories against the probability of being in the reference category "Abstaining from intervening". In this model an extra level is added: the responses of the MTs for the 14 vignettes were entered as level 1 units, nested within occasions (Level 2), which were nested within the MT (Level 3). Firstlevel units were the 3052 (109 MTs $\times 2$ occasions $\times 14$ vignettes) direction-to-intervene ratings of the MTs.

First the intercept-only model (M1) (i.e. variance decomposition) was estimated. Then, in the second model (M2, conditional model) the fixed predictors Occasion and Condition and the cross-level interaction between Occasion and Condition (Occasion 1 and Condition $C$ as reference categories) were entered. In the third model (M3, covariate model), the personal predictors of MTs' age and the scores of MTs' value and empirical premises on Occasion 1 (all continuous variables grand mean centred) were added to control for differences in MTs' intervening direction before the intervention (Occasion 1).

\section{MTs' intended intervening intensity}

To investigate whether reinforcing the mentor or teacher role changed MTs' intended intensity to intervene, we again viewed the responses of the MTs as nested within 
occasions (Level 2), which were nested within the MTs (Level 3). The intensity to intervene scale was not normally distributed due to the high frequencies of the extreme scores (score 0 and 5), but the residuals of the multilevel models showed no obvious diversion from normality. Again, first the intercept-only model (M1) was investigated, then the conditional model (M2) with the fixed predictors Occasion and Condition and the cross-level interaction between Occasion and Condition (Occasion 1 and Condition C as reference categories), and finally a covariate model (M3) including MTs' age and the scores of MTs' value and empirical premises on Occasion 1 (all continuous variables grand mean centred) were entered.

\section{RESULTS}

\section{Descriptive statistics}

Table 4 shows for the two occasions and per condition, the means and SDs of MTs' value premise (the preference for teaching values over mentoring values), EP1 (MTs' belief concerning the positive effect on the ST of not intervening), EP2 (MTs' belief concerning the positive effect on the ST of taking over the lesson), and EP3 (MTs' belief concerning the positive effect on the pupils of cautiously intervening), and MTs' intended intervening intensity. 


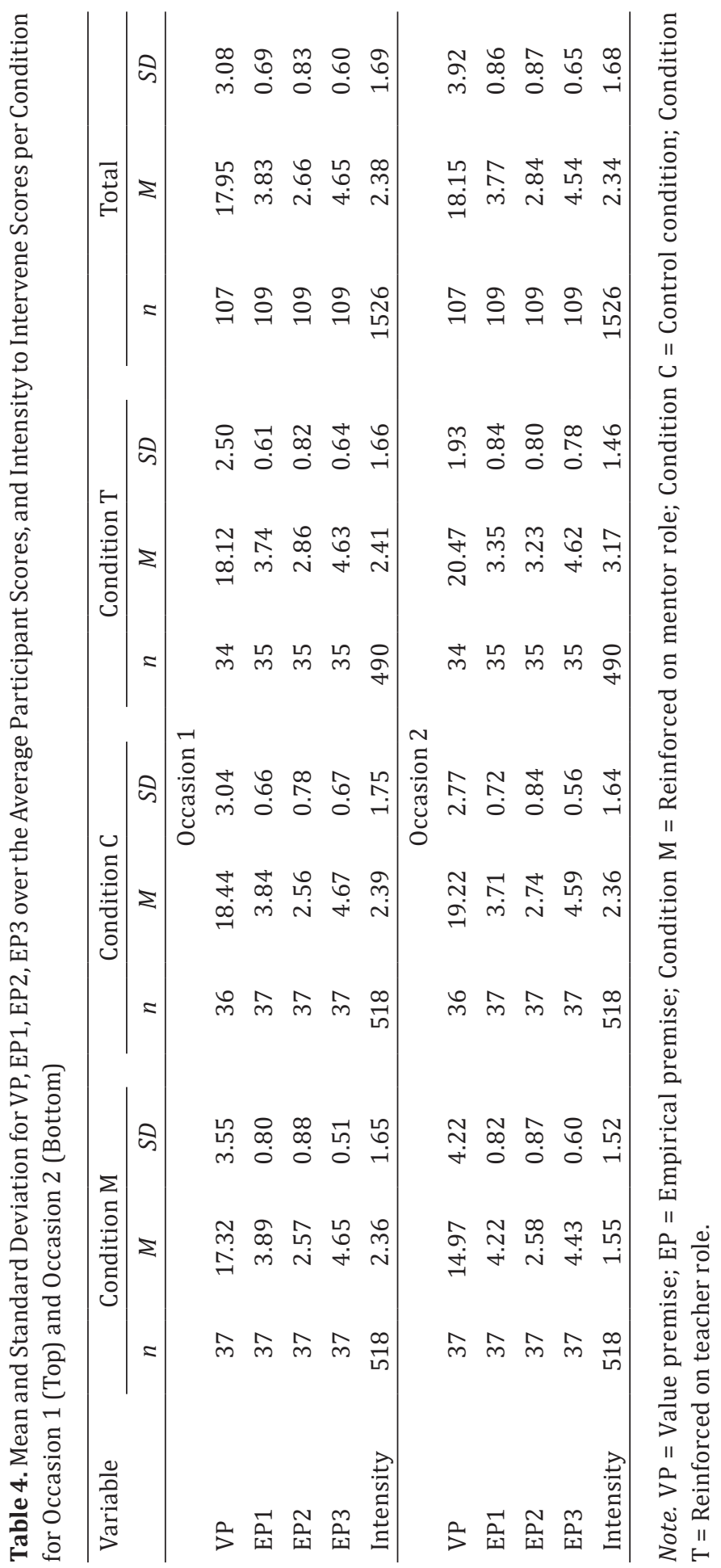


In Table 5 the percentages of MTs' intended intervening directions for the two occasions per condition are shown.

Table 5. Percentages of MTs' Direction to Intervene Scores per Condition for Two Occasions

\begin{tabular}{|c|c|c|c|c|c|c|c|c|c|c|c|c|}
\hline & \multicolumn{3}{|c|}{ Condition M } & \multicolumn{3}{|c|}{ Condition C } & \multicolumn{3}{|c|}{ Condition $\mathrm{T}$} & \multicolumn{3}{|c|}{ Total } \\
\hline & NO & ST & $\mathrm{PP}$ & NO & ST & $\mathrm{PP}$ & NO & ST & PP & NO & ST & PP \\
\hline Occasion 1 & 9.5 & 47.9 & 42.7 & 15.3 & 39.6 & 45.2 & 10.8 & 45.5 & 43.7 & 11.9 & 44.3 & 43.8 \\
\hline Occasion 2 & 20.7 & 45.2 & 34.2 & 10.4 & 46.3 & 43.2 & 4.5 & 43.9 & 51.6 & 12.0 & 45.2 & 42.9 \\
\hline
\end{tabular}

Note . NO = Abstaining from intervening; $\mathrm{ST}=$ Intervening directed toward the ST; $\mathrm{PP}=$ Intervening directed toward the pupils; Condition $\mathrm{M}=$ Reinforced on mentor role; Condition $\mathrm{C}=$ Control condition; Condition $\mathrm{T}=$ Reinforced on teacher role.

\section{Effect of reinforcing the mentor or teacher role on MTs' premises}

The results of the two-level multilevel regression analyses that tested whether MTs' value premise and empirical premises (EP1, EP2, and EP3) changed due to the intervention are shown in Tables 6 and 7, respectively.

\section{Value premise}

Compared to the intercept-only model (M1), the model fit of the conditional model (M2), in which the predictors Occasion and Condition and a cross-level interaction between Occasion and Condition were added, improved significantly, $\chi^{2}(5, N=107)=66.06, p$ $<.01$. As expected, MTs' value premise was significantly lower for Condition M and significantly higher for Condition $\mathrm{T}$ on the post-test than on the pre-test (see Table 6). MTs' preference for teaching values over mentoring values decreased in the condition that reinforced the mentor role and increased in the condition that reinforced the teacher role. Together, the predictors in this conditional model (M2) explained 32\% of the variance in MTs' value premises at the residual level, which can be considered a large effect.

In the third model, MTs' age was added as covariate. We found a negative relationship between MTs' age and MTs' value premise score, $\gamma=-0.08, p=.001$. The younger the 
MTs, the more likely they were to prefer teaching values over mentoring values. By adding the covariate, the interaction effect slightly diminished, indicating that the differences in age between the conditions might have affected MTs' change in value premises. However, we also checked the three-way interactions between age and the other predictors, but these interactions were not statistically significant, Condition $\mathrm{M}$ $\times$ Occasion $\times$ Age, $t=-0.03, p=.684$, Condition T $\times$ Occasion $\times$ Age, $t=-0.01, p=.824$.

Table 6. Fixed Effects Estimates (Top) and Variance-Covariance Estimates (Bottom) for Models Predicting Value Premise

\begin{tabular}{|c|c|c|c|}
\hline Parameter & $\begin{array}{c}\text { Model } 1 \\
B(S E)\end{array}$ & $\begin{array}{c}\text { Model } 2 \\
B(S E)\end{array}$ & $\begin{array}{c}\text { Model } 3 \\
B(S E)\end{array}$ \\
\hline \multicolumn{4}{|c|}{ Fixed effects } \\
\hline Intercept & $18.05(0.29)^{* * *}$ & $18.44(0.51)^{* * *}$ & $18.44(0.50)^{* * *}$ \\
\hline Occasion & & $0.78(0.48)$ & $0.54(0.47)$ \\
\hline Condition M & & $-1.12(0.72)$ & $-0.84(0.70)$ \\
\hline Condition $\mathrm{T}$ & & $-0.33(0.73)$ & $-0.36(0.70)$ \\
\hline Condition $\mathrm{M} \times$ Occasion & & $-3.13(0.68)^{* * *}$ & $-2.89(0.66)^{* * *}$ \\
\hline Condition $\mathrm{T} \times$ Occasion & & $1.58(0.69)^{*}$ & $1.81(0.67)^{* *}$ \\
\hline GmcAge & & & $-0.08(0.02)^{* *}$ \\
\hline \multicolumn{4}{|c|}{ Random parameters } \\
\hline Residual (level 1) & $6.11(0.83)^{* * *}$ & $4.17(0.57)^{* * *}$ & $3.88(0.53)^{* * *}$ \\
\hline MT (level 2) & $6.22(1.34)^{* * *}$ & $5.24(1.04)^{* * *}$ & $4.61(0.94)^{* * *}$ \\
\hline -2Loglikelihood & 1113.42 & 1047.36 & 1018.12 \\
\hline
\end{tabular}

Note. Condition $\mathrm{M}$ = Reinforced on mentor role; Condition $\mathrm{T}$ = Reinforced on teacher role; $\mathrm{Gmc}=$ Grand-mean centred. Condition C is reference group.

${ }^{*} p<.05 .{ }^{* *} p<.01 .{ }^{* * *} p<.001$.

\section{Empirical premises}

As expected, the EP1-scores after the intervention of MTs in Condition M were significantly higher than the EP1-scores of MTs in Condition C (see Table 7). MTs' empirical premise that abstaining from intervening is positive for STs increased in the condition that reinforced the mentor role. Contrary to our expectations, there was no significant change in the EP1-scores for MTs in Condition T. Together, the predictors in M2 explained 15\% of the variability in MTs' EP1, which is a medium effect. 


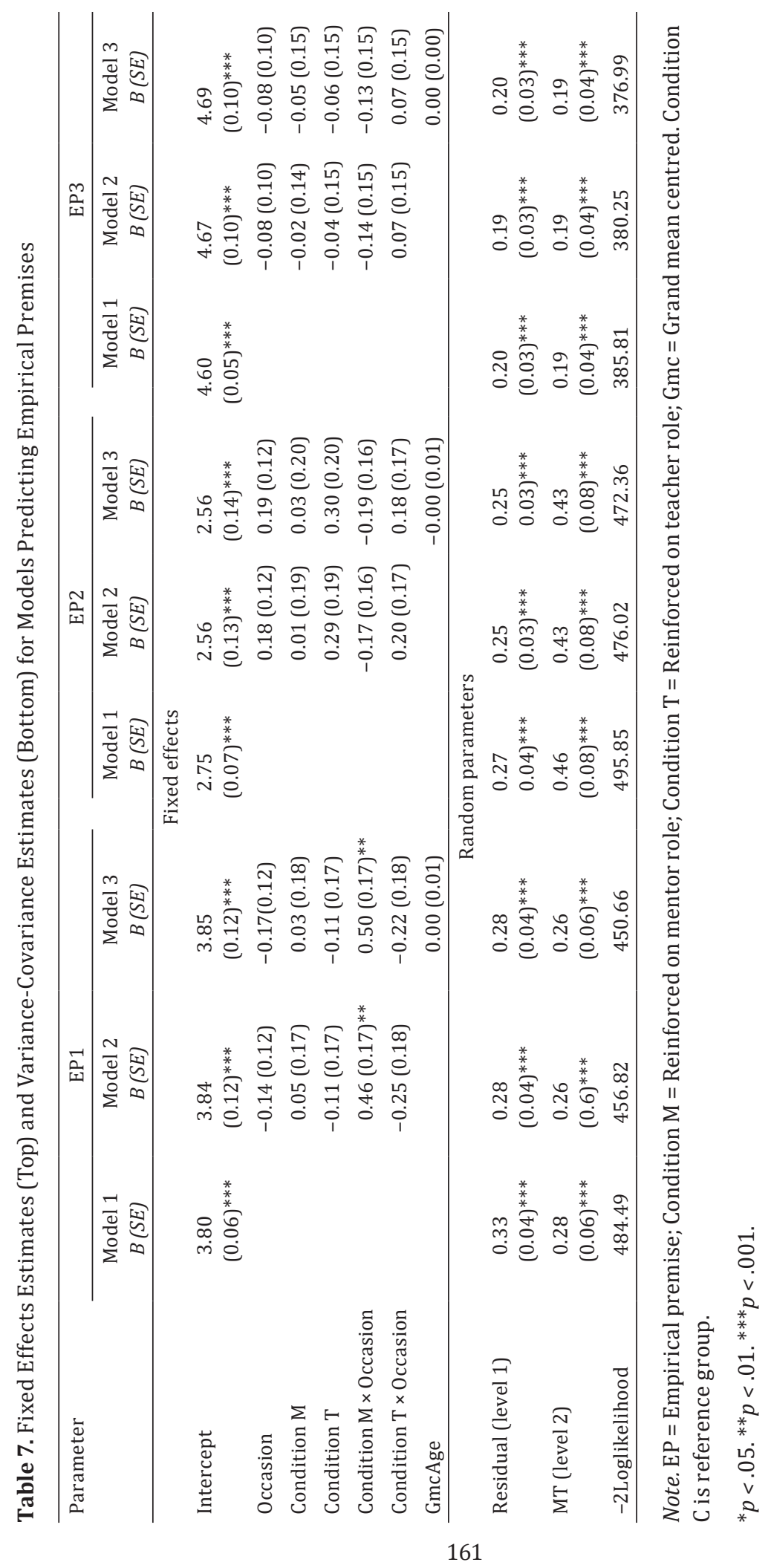


We found neither a significant change in the EP2-scores for Condition M or for Condition T, nor a significant change in the EP3-scores for either condition. This indicates that reinforcing the mentor or teacher role did not affect MTs' empirical premises concerning the positive effect on STs of taking over the lesson, and did not affect MTs' empirical premises concerning the positive effect on pupils of cautiously intervening.

In the covariate models of EP1, EP2, and EP3, MTs' age was not associated with any of the empirical premises.

\section{Effect of reinforcing the mentor or teacher role on MTs' intended intervening}

\section{Intervening direction}

To investigate how reinforcing the mentor or teacher role affected MTs' intended direction to intervene, we performed a three-level multilevel logistic analysis (see Analysis section). The dependent variable was MTs' intervening direction, in terms of intervening directed toward the ST versus abstaining from intervening, and intervening directed toward the pupils versus abstaining from intervening. An overview of the estimated models is provided in Table 8.

In the intercept-only model, the variance components at the second level indicated that the direction-to-intervene probabilities varied across occasions (within MTs) for intervening directed toward the ST versus abstaining from intervening, $\sigma_{\text {intervening directed }^{2}}$

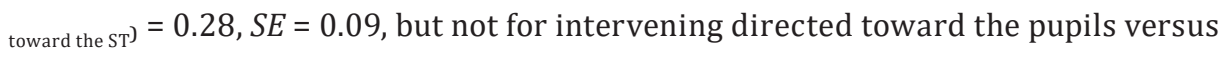
abstaining from intervening, $\sigma_{{ }_{\text {intervening directed toward the pupils }}^{2}}=0.07, S E=0.071$. This means that whether MTs intended to intervene toward the ST or to abstain from intervening changed after the intervention, but not whether they intended to intervene directed toward the pupils or to abstain from intervening. 
Table 8. Fixed Effects Estimates (Top) and Variance-Covariance Estimates (Bottom) for Models Predicting Intended Intervening Direction

\begin{tabular}{|c|c|c|c|c|c|c|}
\hline \multirow[t]{2}{*}{ Parameter } & \multicolumn{2}{|l|}{ Model 1} & \multicolumn{2}{|l|}{ Model 2} & \multicolumn{2}{|l|}{ Model 3} \\
\hline & Coefficient (SE) & E.C. & Coefficient (SE) & E.C. & Coefficient (SE) & E.C. \\
\hline \multicolumn{7}{|c|}{ Fixed effects } \\
\hline \multicolumn{7}{|c|}{ Intervening directed toward the ST } \\
\hline Intercept & $1.42(0.09)^{* * *}$ & 4.17 & $1.06(0.19)^{* * *}$ & 2.89 & $1.17(0.19)^{* * *}$ & 3.23 \\
\hline Occasion $2^{\mathrm{a}}$ & & & $0.56(0.24)^{*}$ & 1.75 & $0.65(0.26)^{*}$ & 1.91 \\
\hline Condition $\mathrm{M}^{\mathrm{b}}$ & & & $0.69(0.28)^{*}$ & 1.99 & $0.67(0.27)^{*}$ & 1.95 \\
\hline Condition $\mathrm{T}^{\mathrm{b}}$ & & & $0.45(0.28)$ & 1.57 & $0.32(0.27)$ & 1.37 \\
\hline $\begin{array}{l}\text { Condition } \mathrm{M} \times \\
\text { Occasion } 2\end{array}$ & & & $-1.44(0.34)^{* * *}$ & 0.24 & $-1.55(0.35)^{* * *}$ & 0.21 \\
\hline $\begin{array}{l}\text { Condition } \mathrm{T} \times \\
\text { Occasion } 2\end{array}$ & & & $0.23(0.39)$ & 1.26 & $0.14(0.40)$ & 1.15 \\
\hline GmcAge & & & & & $0.01(0.01)$ & 1.01 \\
\hline GmcVP & & & & & $0.07(0.03)^{*}$ & 1.01 \\
\hline GmcEP1 & & & & & $-0.46(0.12)^{* * *}$ & 0.49 \\
\hline GmcEP2 & & & & & $0.19(0.11)$ & 0.90 \\
\hline GmcEP3 & & & & & $0.09(0.15)$ & 0.83 \\
\hline \multicolumn{7}{|c|}{ Intervening directed toward the pupils } \\
\hline Intercept & $1.37(0.11)^{* * *}$ & 3.95 & $1.16(0.20)^{* * *}$ & 3.20 & $1.29(0.19)^{* * *}$ & 3.64 \\
\hline Occasion $2^{\mathrm{a}}$ & & & $0.35(0.21)$ & 1.42 & $0.45(0.23)^{*}$ & 1.57 \\
\hline Condition $\mathrm{M}^{\mathrm{b}}$ & & & $0.46(0.30)$ & 1.58 & $0.45(0.27)$ & 1.57 \\
\hline Condition $\mathrm{T}^{\mathrm{b}}$ & & & $0.29(0.30)$ & 1.34 & $0.05(0.27)$ & 1.05 \\
\hline $\begin{array}{l}\text { Condition } \mathrm{M} \times \\
\text { Occasion } 2\end{array}$ & & & $-1.41(0.30)^{* * *}$ & 0.24 & $-1.53(0.31)^{* * *}$ & 0.22 \\
\hline $\begin{array}{l}\text { Condition } \mathrm{T} \times \\
\text { Occasion } 2\end{array}$ & & & $0.66(0.35)$ & 1.94 & $0.58(0.36)$ & 1.78 \\
\hline GmcAge & & & & & $0.02(0.01)^{*}$ & 1.02 \\
\hline GmcVP & & & & & $0.12(0.03)^{* * *}$ & 1.13 \\
\hline GmcEP1 & & & & & $-0.50(0.13)^{* * *}$ & 0.61 \\
\hline GmcEP2 & & & & & $0.41(0.11)^{* * *}$ & 1.51 \\
\hline GmcEP3 & & & & & $0.08(0.16)$ & 1.09 \\
\hline
\end{tabular}


Table 8. Continued

\begin{tabular}{|c|c|c|c|c|c|c|}
\hline \multirow[t]{2}{*}{ Parameter } & \multicolumn{2}{|l|}{ Model 1} & \multicolumn{2}{|l|}{ Model 2} & \multicolumn{2}{|l|}{ Model 3} \\
\hline & Coefficient (SE) & E.C. & Coefficient (SE) & E.C. & Coefficient (SE) & E.C. \\
\hline \multicolumn{7}{|c|}{ Random parameters } \\
\hline \multicolumn{7}{|l|}{ Level 3 (MT) } \\
\hline \multicolumn{7}{|c|}{ Intervening directed toward the ST } \\
\hline Intercept & $0.36(0.13)^{* *}$ & & $0.35(0.13)^{* *}$ & & $0.15(0.10)$ & \\
\hline \multicolumn{7}{|c|}{ Intervening directed toward the pupils } \\
\hline Intercept & $0.80(0.18)^{* * *}$ & & $0.79(0.17)^{* * *}$ & & $0.39(0.12)^{* *}$ & \\
\hline \multicolumn{7}{|c|}{ Level 2 (MT × Occasion) } \\
\hline \multicolumn{7}{|c|}{ Intervening directed toward the ST } \\
\hline Intercept & $0.28(0.09) * *$ & & $0.28(0.08)^{* *}$ & & $0.27(0.09)^{* *}$ & \\
\hline \multicolumn{7}{|c|}{ Intervening directed toward the pupils } \\
\hline Intercept & $0.07(0.07)$ & & 0.00 & & $0.01(0.07)$ & \\
\hline $\begin{array}{l}\text {-2Log pseudo } \\
\text { likelihood }\end{array}$ & 23404.17 & & 23686.00 & & 23335.37 & \\
\hline
\end{tabular}

Note. E.C. = Exponentiated Coefficient; Condition $\mathrm{M}=$ Reinforced on mentor role; Condition $\mathrm{T}=$ Reinforced on teacher role; $\mathrm{VP}=$ Value premise; $\mathrm{EP}=$ Empirical premise; $\mathrm{Gmc}=$ Grand mean centred. Reference category: Abstaining from intervening; Probability distribution: Multinomial; Link function: Generalised logit.

${ }^{\mathrm{a}}$ Reference is Occasion $1^{\mathrm{b}}$ Reference is Condition C.

${ }^{*} p<.05 .{ }^{* *} p<.01 .{ }^{* *} p<.001$.

In the conditional model (M2), Condition and the interaction between Condition and Occasion were significantly associated with MTs' intervening direction, respectively, $F=3.25, p=.011, F=11.29, p=<.001$. This means that MTs' intervening direction significantly varied over the two occasions and the three conditions. More specifically, in line with our expectation, MTs reinforced on the mentor role were more likely to abstain from intervening than to intervene toward the ST or toward the pupils. Compared to Condition C, the probabilities to intervene directed toward the ST versus not to intervene and to intervene toward the pupils versus not to intervene were smaller on Occasion 2 than on Occasion 1, respectively, log odds $=-1.44,<.001, \log$ odds $=-1.41,<.001$. Contrary to what we expected, being reinforced on the teacher role (compared to Condition C) did not significantly affect MTs' intended intervening direction. 
Adding the covariates (MTs' age, pre-test value and empirical premises scores; M3), did not affect the interaction effect found in M2.

The exact probabilities based on the covariate model are presented in Table 9. For example, if an MT (with average GmcAge, GmcVP, GmcEP1, GmcEP2, and GmcEP3) was reinforced on the mentor role, the probability that he or she would decide to abstain from intervening (on Occasion 2) is .18, the probability that the MT would intervene directed toward the pupils is .35 , and the probability that the intervening would be directed toward the ST is .47 .

Table 9. Probabilities of MTs' Intervening Direction per Condition for Two Occasions

\begin{tabular}{lcccccccc}
\hline & \multicolumn{3}{c}{ Occasion 1} & & \multicolumn{3}{c}{ Occasion 2 } \\
\cline { 2 - 3 } \cline { 6 - 8 } & NO & ST & PP & & NO & ST & PP \\
\hline Condition M & .08 & .48 & .44 & & .18 & .47 & .35 \\
Condition C & .13 & .41 & .46 & & .08 & .48 & .44 \\
Condition T & .11 & .48 & .41 & & .05 & .45 & .50 \\
\hline
\end{tabular}

Note. NO = Abstaining from intervening; $\mathrm{ST}=$ Intervening directed toward the ST; $\mathrm{PP}=$ Intervening directed toward the pupils; Condition $\mathrm{M}=$ Reinforced on mentor role; Condition $\mathrm{C}=$ Control condition; Condition $\mathrm{T}=$ Reinforced on teacher role.

\section{Intervening intensity}

Table 10 shows the results of a three-level multilevel regression analysis that tested whether MTs' intervening intensity changed due to the intervention. The interceptonly model (M1) for MTs' intervening intensity revealed that $16 \%$ of the variance in intervening intensity was due to differences between Occasions (Level 2) and 17\% due to stable differences between MTs (Level 3). In the conditional model, as expected, Condition $\mathrm{M}$ and Condition $\mathrm{T}$ showed a change in intervening intensity scores across the two occasions, while Condition C showed no change. MTs' intensity to intervene was significantly lower for MTs informed about the mentor role, and significantly higher for MTs informed about the teacher role. Thus, MTs reinforced on the mentor role intend to intervene less intensely than the MTs in Condition C, and MTs reinforced on the teacher role intend to intervene more intensely than the MTs in Condition C. 
$47 \%$ of the variance in intervening intensity was explained by the interaction between Condition and Occasion (Level 2), which represents a large overall effect.

Adding the covariates (MTs' age and pre-test value and empirical premises scores; M3), did not affect the interpretation of M2. The MTs' scores on the grand-mean centred value premise and GmcEP1 and GmcEP2 significantly predicted MTs' intervening intensity. In this model, $42 \%$ of the variance in intervening intensity at level 3 was explained by the MTs' personal characteristics (GmcVP, GmcEP1, and GmcEP2), which is a large overall effect.

Table 10. Fixed Effects Estimates (Top) and Variance-Covariance Estimates (Bottom) for Models Predicting Intended Intervening Intensity

\begin{tabular}{|c|c|c|c|}
\hline Parameter & $\begin{array}{c}\text { Model } 1 \\
B(S E)\end{array}$ & $\begin{array}{c}\text { Model } 2 \\
B(S E)\end{array}$ & $\begin{array}{c}\text { Model } 3 \\
B(S E)\end{array}$ \\
\hline \multicolumn{4}{|c|}{ Fixed effects } \\
\hline Intercept & $2.36(0.08)^{* * *}$ & $2.39(0.15)^{* * *}$ & $2.41(0.14)^{* * *}$ \\
\hline Occasion & & $-0.03(0.14)$ & $-0.03(0.15)$ \\
\hline Condition M & & $-0.03(0.22)$ & $0.02(0.20)$ \\
\hline Condition T & & $0.02(0.22)$ & $-0.13(0.20)$ \\
\hline Condition $\mathrm{M} \times$ Occasion & & $-0.78(0.20)^{* * *}$ & $-0.78(0.21)^{* * *}$ \\
\hline Condition $\mathrm{T} \times$ Occasion & & $0.80(0.20)^{* * *}$ & $0.81(0.21)^{* * *}$ \\
\hline GmcAge & & & $0.01(0.01)$ \\
\hline GmcVP & & & $0.08(0.02)^{* *}$ \\
\hline GmcEP1 & & & $-0.23(0.10)^{*}$ \\
\hline GmcEP2 & & & $0.33(0.08)^{* * *}$ \\
\hline GmcEP3 & & & $0.02(0.11)$ \\
\hline \multicolumn{4}{|c|}{ Random parameters } \\
\hline Residual (level 1) & $1.89(0.05)^{* * *}$ & $1.89(0.05)^{* * *}$ & $1.88(0.05)^{* * *}$ \\
\hline MT (level 3) & $0.49(0.11)^{* * *}$ & $0.48(0.09)^{* * *}$ & $0.28(0.07)^{* * *}$ \\
\hline MT × Occasion (level 2) & $0.45(0.08)^{* * *}$ & $0.24(0.05)^{* * *}$ & $0.25(0.05)^{* * *}$ \\
\hline -2Loglikelihood & 11031.74 & 10966.99 & 10616.93 \\
\hline
\end{tabular}

Note. Condition $\mathrm{M}=$ Reinforced on mentor role; Condition $\mathrm{T}$ = Reinforced on teacher role; $\mathrm{VP}=$ Value premise; $\mathrm{EP}=$ Empirical premise $; \mathrm{Gmc}=$ Grand mean centred. Condition $\mathrm{C}$ is reference group.

${ }^{*} p<.05 .{ }^{* *} p<.01 .{ }^{* * *} p<.001$. 


\section{DISCUSSION}

With written vignettes and based on Fenstermacher's (1986) practical argument theory, we investigated whether we could change MTs' value and empirical premises, and MTs' intended intervening direction and intensity. We performed a betweensubject pre-test post-test study in which we reinforced premises by means of providing information about the importance of mentoring or teaching (value premises) and research findings about the effects of teaching situations on STs' or pupils' wellbeing and development (empirical premises). We found that MTs' value premises as well as MTs' intention to intervene indeed can be changed. These results were expected based on the practical argument theory of Fenstermacher (1986) and are in line with findings of our previous research that the value and empirical premises predict MTs' intervening (Jaspers et al., submitted, see Chapter 4). Below, we will first interpret and explain our main findings. Then we will address implications for practice and further research.

\section{MTs' value premises and intended intervening can be changed}

Reinforcing the mentor or teacher role strongly influenced MTs' intervening intensity such that MTs found the values concerning the role they were informed about relatively more important. MTs who were reinforced on the mentor role tended to intervene less intensely and were more likely to abstain from intervening. As expected, MTs' intervening intensity and value premise of the MTs reinforced on the teacher role changed in the opposite direction from those of the MTs reinforced on the mentor role. These results support the idea that reinforcing the premises by providing information encouraged MTs to give more prominence to the values of the mentor or teacher role, and consequently strengthened MTs' value and empirical premises (Morine-Dershimer, 1987). The changed premises might have made MTs' reasoning about their intervening more deliberate and reasonable, and might have helped MTs to make their practical arguments concerning intervening more elaborate and sophisticated, or as Fenstermacher and Richardson (1993) call it, "more complete". This more complete practical argument might have resulted in a change in MTs' 
actions, which Fenstermacher and Richardson call the process of reconstruction of the practical argument. Reconstruction of practical arguments can help to develop new routines, and, as our research confirmed, might be a valuable instrument to improve MTs' development (Fenstermacher \& Richardson, 1993).

Based on the reconstruction of the practical argument involved, we can explain the change process in MTs' value premises and intention to intervene. In previous research (Jaspers et al., 2018, see Chapter 3) found eight important values concerning intervening, four of them mentoring and four teaching values. According to Fenstermacher (1986), the combination of various premises leads to actions. In the present study, in the mentoring condition we reinforced mentoring values and, probably due to the information MTs received, the importance of these mentoring values was strengthened (Morine-Dershimer, 1987). Consequently, in this condition, the mentoring values might have become relatively more important, although MTs still might find teaching values most important. This might have made MTs' practical arguments concerning the mentoring values and teaching values more in balance, which might have led to more thought-through decisions and more deliberate intentions to intervene.

It is plausible to assume that in the condition that reinforced the teacher role, the same mechanism was at work but in the opposite direction. In our previous study (Jaspers et al., submitted, see Chapter 4) we already found that MTs intervened quite intensely and strongly preferred teaching values over mentoring values. In the present study we found that after reinforcing the teacher role, MTs intended to intervene even more intensely, and even more strongly preferred the teaching values over the mentoring values. Apparently, MTs could become even more convinced of the importance of their teacher role. This might suggest that MTs' value premises concerning teaching and the related intervening are not that stable, which is promising for establishing changes. 


\section{Empirical premises concerning intervening are relatively stable}

MTs' empirical premise concerning the positive effect on STs of taking over the lesson and their empirical premise concerning the positive effect on pupils of cautiously intervening were not affected by reinforcing the mentor role. Reinforcing the teacher role did not affect any of the empirical premises. One explanation for the relative stability of MTs' empirical premises might be that in our study we reinforced MTs' mentor and teacher roles by providing information about the relation between teaching situations and ST and pupil wellbeing and development. If MTs had been informed about the effects of intervening on STs or pupils, then their empirical premises concerning intervening might have changed. The lack of change in MTs' empirical premises might be explained also by findings from our previous research (Jaspers et al., submitted, see Chapter 4) that MTs strongly believe that cautiously intervening is positive for the wellbeing and development of pupils as well as the wellbeing and development of the ST. MTs might perceive cautiously intervening as a way to fulfil both roles and might see it as beneficial for both the ST and pupils; that is, it will not disturb the ST nor distract the pupils' attention. MTs tend to hold on to this belief very strongly when confronted with the tension to combine both roles. This might explain why MTs in the condition that reinforced the teacher role, as well as in the condition that reinforced the mentor role, still strongly believe in this premise concerning the positive effect on pupils of cautiously intervening.

\section{Implications}

In primary education, MTs experience tensions between their mentor and teacher role during STs' teaching of their pupils, and they frequently intervene by guiding the pupils. Naturally, MTs are concerned about the pupils, but MTs' intervening might not always contribute to STs' learning. In order to help MTs with this tension when combining the mentor and teacher roles and to clarify MTs' reasoning process, we suggest mentoring courses to encourage MTs to elicit and reconstruct their practical arguments concerning their intervening (Fenstermacher \& Richardson, 1993). MTs need to become aware of their teacher and mentor roles and to think carefully about the aim of mentoring compared to the care they feel for their pupils. When MTs are 
more aware of the double role they have to perform and of their sometimes conflicting values as mentor and as teacher (Jaspers et al., 2014, see Chapter 2), informed practical reasoning can help them in their decision process and help them to deal with these values more effectively (Morine-Dershimer, 1988). When MTs are asked by a critical other (Fenstermacher \& Richardson, 1993), for example by a colleague MT, for their considerations concerning their intervening, their subjectively reasonable beliefs can become objectively reasonable (Green, 1976), and the practical argument can improve (Morine-Dershimer, 1987) and might advance MTs' competence (Fenstermacher \& Richardson, 1993). Vasquez-Levy (1998) describes important features of practical argument engagement that could be used to articulate and reconstruct MTs' arguments in a deliberate, systematic, and caring way.

Additionally, we suggest mentoring professionalisation courses to highlight the importance of being a mentor, to encourage MTs to give more prominence to mentoring values, to reinforce MTs' premises concerning STs' learning, and to provide research findings about the effects of various teaching problems on STs' wellbeing and development. We showed that even with just a small intervention as in this study, MTs' intention to intervene can be changed. Therefore, in order to improve MTs' guidance during STs' teaching, MTs should deliberately consider the aims they have as teacher and as mentor. Only when MTs are fully aware of the dual goals they have to fulfil, their practical argument concerning what to do during STs' lessons can improve and become more balanced.

\section{Further research}

Although we based our intervention on the practical argument theory of Fenstermacher (1986) and on findings of our previous research in which we showed the relation between value and empirical premises and MTs' actions (Jaspers et al., submitted, see Chapter 4), we still have to show that reconstruction of practical arguments actually occurred and what this process looks like (Fenstermacher \& Richardson, 1993). We suggest investigating MTs' reasoning development, that is, whether MTs' practical arguments become more elaborate, and how this relates to changes in MTs' intervening. This can be done, for example, by encouraging MTs to use mentoring 
research and to explicate, in dialogue with the researcher, the reconstruction of the practical argument, and by comparing MTs' practical arguments before, during, and after reconstruction of the practical argument.

Further, in this study, we asked MTs to imagine that they were the MT of the ST teaching their hypothetical class and indicate how they would intervene. Although we used ecologically valid vignettes, we do acknowledge that our findings are based on hypothetical situations. The vignettes might not fully represent what MTs experience when they observe the ST teaching their own pupils. In their own classrooms with pupils they really know, MTs would probably be more concerned about the children in their care (Edwards, 1998; Hopper, 2001; Stanulis, 1995), which might affect their thinking about intervening. Therefore, we suggest observing how MTs actually intervene in real teaching situations before and after an intervention. Moreover, we suggest combining such observations with stimulated recall interviews (Calderhead, 1981) involving the MT replying about a videotaped classroom situation to stimulate the MT to recall the decision making about the action.

Finally, a next step is to investigate how MTs' intervening affects STs' and pupils' wellbeing and learning. It is useful to study how MTs can effectively guide STs in the moment of practicing teaching, how cautiously intervening affects pupil and ST wellbeing and development, and which intervening strategies are most effective. Additionally, as the STs' perspectives on MTs' intervening were not included in this study, future research should examine the STs' perceptions and experiences. Similar to the change in MTs' guidance during STs' teaching, it could also be useful to study whether and how MTs' mentoring strategies in pre- and post-lesson conversations might change. Reinforcing MTs' values and premises concerning STs' learning by providing research findings concerning STs as learners might also result in a change in how MTs and STs discuss the MT's roles and intervening during the ST's lessons with each other in pre- and post-lesson conferences. More specifically, we suggest further research to examine how MTs' guidance before, during, and after the ST's teaching could become more closely related to the ST's learning goals and learning needs (e.g., Feiman-Nemser, 2001) 


\section{APPENDIX: SCRIPT (IN DUTCH AND ENGLISH)}

\begin{tabular}{|c|c|c|}
\hline Part & Reinforcing the teacher role & Reinforcing the mentor role \\
\hline \multirow[t]{2}{*}{ Introduction } & $\begin{array}{l}\text { Interviewer: Hallo. We zijn in gesprek } \\
\text { met meneer Prins, onderzoeker en } \\
\text { onderwijswetenschapper aan de } \\
\text { Universiteit Utrecht. } \\
\text { Meneer Prins, kunt uangeven waar uw } \\
\text { onderzoek over gaat? } \\
\text { Interviewer: Hello. We are talking to } \\
\text { Mr. Prins, educational researcher and } \\
\text { scientist at Utrecht University. } \\
\text { Mr. Prins, can you explain what your } \\
\text { research is about? }\end{array}$ & $\begin{array}{l}\text { Interviewer: Hallo. We zijn in gesprek } \\
\text { met meneer Prins, onderzoeker en } \\
\text { onderwijswetenschapper aan de } \\
\text { Universiteit Utrecht. } \\
\text { Meneer Prins, kunt u aangeven waar uw } \\
\text { onderzoek over gaat? } \\
\text { Interviewer: Hello. We are talking to } \\
\text { Mr. Prins, educational researcher and } \\
\text { scientist at Utrecht University. } \\
\text { Mr. Prins, can you explain what your } \\
\text { research is about? }\end{array}$ \\
\hline & $\begin{array}{l}\text { Hallo. Ik doe onderzoek naar de } \\
\text { begeleiding van studenten. Het is voor } \\
\text { een leerkracht soms best lastig een } \\
\text { student te begeleiden, en daarbij te } \\
\text { weten wat het beste is om te doen. } \\
\text { Hey. I investigate the mentoring of } \\
\text { student teachers. It is sometimes quite } \\
\text { difficult for a teacher to guide a student } \\
\text { and to know what is best to do. }\end{array}$ & $\begin{array}{l}\text { Hallo. Ik doe onderzoek naar de } \\
\text { begeleiding van studenten. Het is voor } \\
\text { een praktijkopleider soms best lastig } \\
\text { een student te begeleiden, en daarbij } \\
\text { te weten wat het beste is om te doen. } \\
\text { Hey. I investigate the mentoring of } \\
\text { student teachers. It is sometimes quite } \\
\text { difficult for a mentor teacher to guide a } \\
\text { student and to know what is best to do. }\end{array}$ \\
\hline \multirow[t]{2}{*}{ Value premise } & $\begin{array}{l}\text { En wat heeft u dan precies gevonden? } \\
\text { And what exactly did you find? }\end{array}$ & $\begin{array}{l}\text { En wat heeft u dan precies gevonden? } \\
\text { And what exactly did you find? }\end{array}$ \\
\hline & $\begin{array}{l}\text { Als praktijkopleiders een student } \\
\text { begeleiden zien we vaak dat ze } \\
\text { bedenken wat goed is voor de student, } \\
\text { maar het is juist ook erg belangrijk } \\
\text { te bedenken wat er goed is voor de } \\
\text { leerlingen. Natuurlijk is de student in } \\
\text { de klas om les te leren geven, maar als } \\
\text { er iets niet helemaal goed gaat tijdens } \\
\text { de les van de student is het essentieel } \\
\text { goed na te gaan wat dit voor de } \\
\text { leerlingen betekent. Ook wanneer een } \\
\text { student in de klas stageloopt, blijft de } \\
\text { verantwoordelijk voor de leerlingen de } \\
\text { primaire taak van de leerkracht. }\end{array}$ & $\begin{array}{l}\text { Als praktijkopleiders een student } \\
\text { begeleiden, zien we vaak dat ze } \\
\text { bedenken wat goed is voor de } \\
\text { leerlingen, maar het is juist ook erg } \\
\text { belangrijk te bedenken wat er goed } \\
\text { is voor de student. Natuurlijk zijn } \\
\text { er ook de leerlingen, maar als er iets } \\
\text { niet helemaal goed gaat tijdens de les } \\
\text { van de student is het essentieel dat de } \\
\text { student daar iets van kan leren, daar } \\
\text { hebben de leerlingen uiteindelijk ook } \\
\text { het meeste aan. Het is de belangrijkste } \\
\text { taak van de praktijkopleider om de } \\
\text { student zo goed mogelijk te begeleiden } \\
\text { in het leren lesgeven. }\end{array}$ \\
\hline
\end{tabular}




\begin{tabular}{|c|c|c|}
\hline & $\begin{array}{l}\text { When a mentor teacher guides a } \\
\text { student teacher, we often see that they } \\
\text { think about what is good for the student } \\
\text { teacher, but it is also very important to } \\
\text { think of what is good for the pupils. of } \\
\text { course, the student is in the classroom } \\
\text { to learn to teach, but if something } \\
\text { does not go well during the student } \\
\text { teacher's lesson, it is essential to } \\
\text { carefully consider what this means for } \\
\text { the pupils. Even when a student teacher } \\
\text { is doing the teacher training period in } \\
\text { the classroom, the responsibility for } \\
\text { the pupils remains the primary task of } \\
\text { the teacher. }\end{array}$ & $\begin{array}{l}\text { When a mentor teacher guides a } \\
\text { student teacher, we often see that they } \\
\text { think about what is good for the pupils, } \\
\text { but it is also very important to think of } \\
\text { what is good for the student teacher. Of } \\
\text { course, there are also the pupils, but if } \\
\text { something does not go well during the } \\
\text { student teacher's lesson, it is essential } \\
\text { that the student teacher can learn } \\
\text { something from it, which ultimately } \\
\text { benefits the pupils the most. It is the } \\
\text { most important task of the mentor } \\
\text { teacher to guide the student teacher } \\
\text { as well as possible in learning to teach. }\end{array}$ \\
\hline \multirow[t]{3}{*}{$\begin{array}{l}\text { Empirical } \\
\text { premise }\end{array}$} & $\begin{array}{l}\text { En wat betekent dit dan voor de } \\
\text { leerlingen? } \\
\text { What does this mean for the pupils? }\end{array}$ & $\begin{array}{l}\text { En wat betekent dit dan voor de student? } \\
\text { What does this mean for the student } \\
\text { teacher? }\end{array}$ \\
\hline & $\begin{array}{l}\text { Als er tijdens de les van de student iets } \\
\text { misgaat, moeten de leerlingen hier zo } \\
\text { min mogelijk hinder van ondervinden. } \\
\text { If something goes wrong during the } \\
\text { student teacher's lesson, the pupils } \\
\text { should experience the least possible } \\
\text { inconvenience. }\end{array}$ & $\begin{array}{l}\text { Als er tijdens de les van de student iets } \\
\text { misgaat, moet een student daarvan } \\
\text { zoveel mogelijk van leren. } \\
\text { If something goes wrong during the } \\
\text { student teacher's lesson, a student } \\
\text { teacher must learn as much as possible } \\
\text { from it. }\end{array}$ \\
\hline & $\begin{array}{l}\text { Welbevinden } \rightarrow \text { leren } \\
\text { We weten uit wetenschappelijk } \\
\text { onderzoek dat een positief en veilig } \\
\text { klasklimaat voorwaardelijk is voor het } \\
\text { leren van de leerlingen. Als leerlingen } \\
\text { zich goed voelen, zullen ze ook meer } \\
\text { leren. }\end{array}$ & $\begin{array}{l}\text { Zelf doen + laten ervaren van fouten } \\
\text { maken } \rightarrow \text { leren } \\
\text { We weten uit wetenschappelijk } \\
\text { onderzoek dat studenten zich voor } \\
\text { een deel ontwikkelen door veel } \\
\text { ervaring op te doen in de klas. Dit } \\
\text { betekent dat studenten leren door zelf } \\
\text { veel les te geven en fouten te maken. } \\
\text { Wanneer studenten zelf problemen } \\
\text { moeten oplossen, leren studenten } \\
\text { voor verschillende situaties wat ze } \\
\text { het beste kunnen doen. Daarbij is het } \\
\text { prettig voor de student om de ruimte } \\
\text { en verantwoordelijkheid te krijgen om } \\
\text { fouten te maken en daarvan te leren. In } \\
\text { de nabespreking kunnen deze fouten } \\
\text { ook besproken worden. }\end{array}$ \\
\hline
\end{tabular}




\begin{tabular}{|c|c|c|}
\hline & $\begin{array}{l}\text { Wellbeing } \rightarrow \text { learning } \\
\text { We know from scientific research that } \\
\text { a positive and safe classroom climate is } \\
\text { an important condition for the pupils' } \\
\text { learning. If pupils feel good, they will } \\
\text { also learn more. }\end{array}$ & $\begin{array}{l}\text { ST teaching on his or her own }+ \text { make } \\
\text { mistakes } \rightarrow \text { learning } \\
\text { We know from scientific research that } \\
\text { an important part of student teachers' } \\
\text { development depends on gaining a lot } \\
\text { of experience in the classroom. This } \\
\text { means that student teachers learn } \\
\text { by teaching on their own and learn } \\
\text { from making mistakes. When student } \\
\text { teachers have to solve problems on } \\
\text { their own, they learn for different } \\
\text { situations what they can do best. In } \\
\text { addition, it is pleasant for the student } \\
\text { teacher to be given the freedom and } \\
\text { responsibility to make mistakes and } \\
\text { learn from them. These mistakes can } \\
\text { also be discussed in the post-lesson } \\
\text { conversation. } \\
\text { Sturing + hulp } \rightarrow \text { leren } \\
\text { Aan de ander kant is het ook belangrijk } \\
\text { te beseffen dat een student kan leren } \\
\text { van de hulp en aanwijzingen van een } \\
\text { praktijkopleider. Een eerstejaars } \\
\text { student heeft deze sturing vooral nog } \\
\text { nodig. Zowel een eerstejaars als een } \\
\text { ouderejaars kunnen deze hulp ook } \\
\text { als ondersteuning zien en ze kunnen } \\
\text { daardoor leren hoe ze in bepaalde } \\
\text { situaties zouden kunnen handelen. } \\
\text { Onderzoek heeft uitgewezen dat } \\
\text { dergelijke tips en aanwijzingen tijdens } \\
\text { de les van de student door studenten } \\
\text { als plezierig en zinvol worden ervaren } \\
\text { en een positief effect hebben op het } \\
\text { leren van de student, zeker wanneer } \\
\text { deze in de nabespreking nogmaals } \\
\text { besproken worden. }\end{array}$ \\
\hline
\end{tabular}




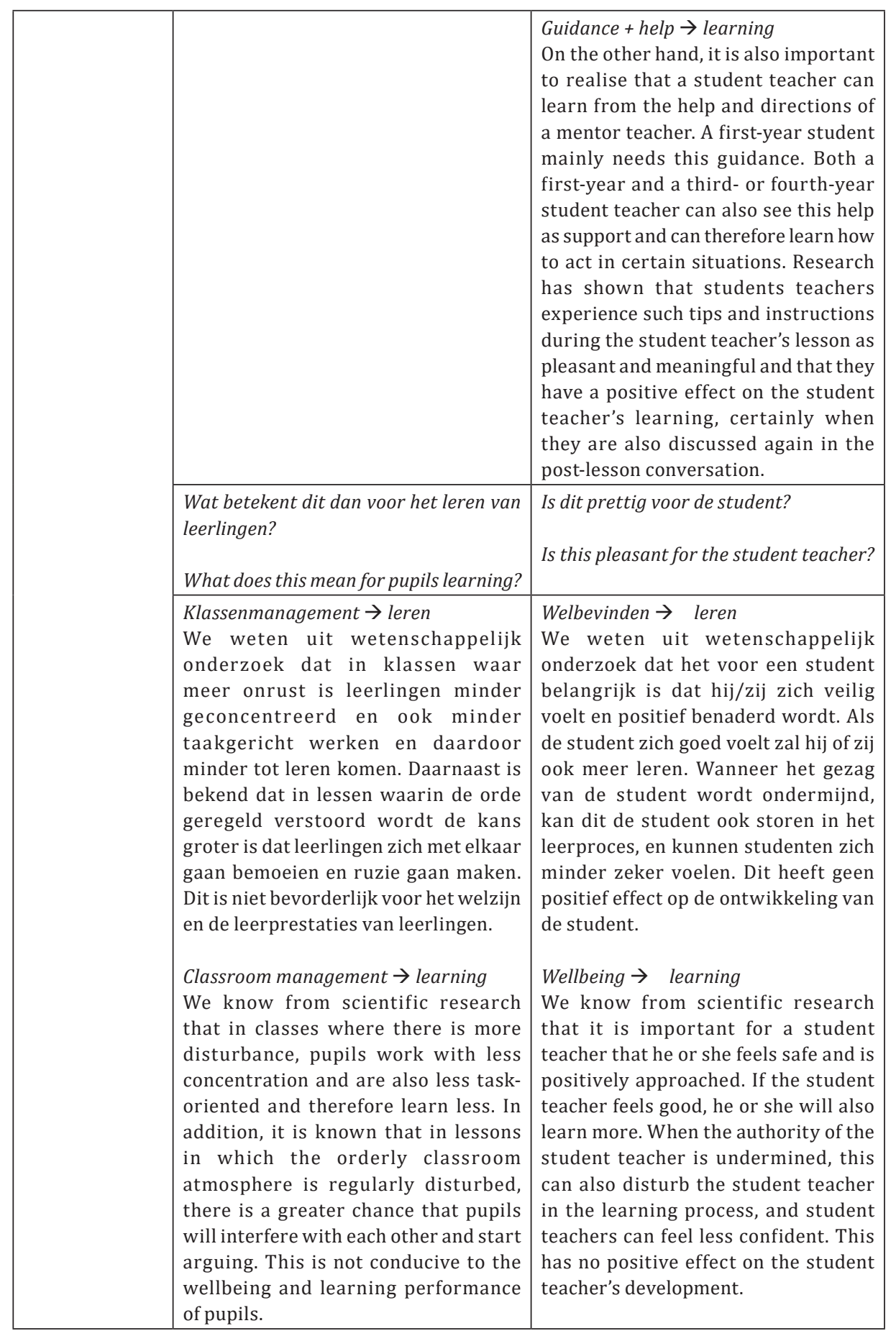




\begin{tabular}{|c|c|c|}
\hline & $\begin{array}{l}\text { En wat gebeurt er bijvoorbeeld als een } \\
\text { student iets verkeerd uitlegt? } \\
\text { And what happens, for example, if a } \\
\text { student teacher explains something } \\
\text { wrong? }\end{array}$ & $\begin{array}{l}\text { En wat gebeurt er bijvoorbeeld als een } \\
\text { student iets verkeerd uitlegt? } \\
\text { And what happens, for example, if a } \\
\text { student teacher explains something } \\
\text { wrong? }\end{array}$ \\
\hline & $\begin{array}{l}\text { Verkeerde inhoud } \rightarrow \text { leren } \\
\text { Je moet je wel goed realiseren dat als } \\
\text { leerlingen iets verkeerds leren dat } \\
\text { lastig terug te draaien is. Hoe langer } \\
\text { de verkeerde informatie in het hoofd } \\
\text { van een leerling zit, hoe moeilijker het } \\
\text { uiteindelijk voor de leerling is dit te } \\
\text { vervangen door juiste kennis. } \\
\text { Mistake in lesson content } \rightarrow \text { learning } \\
\text { You must realise that if pupils learn } \\
\text { something wrong, that is difficult to } \\
\text { reverse. The longer the pupil has the } \\
\text { wrong information in mind, the harder } \\
\text { it is for the pupils to replace it with the } \\
\text { right knowledge. }\end{array}$ & $\begin{array}{l}\text { We weten dat in veel situaties de } \\
\text { student zelf achter de fout komt, of } \\
\text { dat er al snel leerlingen zijn die de fout } \\
\text { in de gaten hebben, en de student er } \\
\text { dan op wijzen. Als de student zich zelf } \\
\text { corrigeert, of dit doet als reactie op } \\
\text { de leerlingen, krijgt een student daar } \\
\text { zelfvertrouwen van. Bovendien leert } \\
\text { hij/zij op die manier zelf beter van zijn } \\
\text { fouten. } \\
\text { We know that in many situations the } \\
\text { student teacher finds out about the } \\
\text { mistake, or that soon there are pupils } \\
\text { who are aware of the mistake, and } \\
\text { then point the student teacher to it. } \\
\text { If the student teacher corrects him } \\
\text { or herself, or does this in response to } \\
\text { the pupils, it gives the student teacher } \\
\text { confidence. Moreover, in this way he or } \\
\text { she learns better from the mistakes. }\end{array}$ \\
\hline \multirow{3}{*}{$\begin{array}{l}\text { Closure } \\
\text { Value premise }\end{array}$} & $\begin{array}{l}\text { Heeft u nog een laatste opmerking? } \\
\text { Do you have a final comment? }\end{array}$ & $\begin{array}{l}\text { Heeft u nog een laatste opmerking? } \\
\text { Do you have a final comment? }\end{array}$ \\
\hline & $\begin{array}{l}\text { Het is altijd belangrijk af te wegen } \\
\text { wat goed is voor de leerlingen, want } \\
\text { leerkracht zijn is je primaire taak. } \\
\text { It is always important to consider what } \\
\text { is good for the pupils, because being the } \\
\text { teacher is your primary task. }\end{array}$ & $\begin{array}{l}\text { Het is altijd belangrijk af te wegen wat } \\
\text { goed is voor de student, en hoe je de } \\
\text { student het best kan begeleiden in het } \\
\text { leren lesgeven. } \\
\text { It is always important to consider } \\
\text { what is good for the student teacher, } \\
\text { and how you can best guide the student } \\
\text { teacher in learning to teach. }\end{array}$ \\
\hline & $\begin{array}{l}\text { Dank } u \text { voor dit interview Meneer Prins. } \\
\text { Thank you for this interview, Mr. Prince. }\end{array}$ & $\begin{array}{l}\text { Dank u voor dit interview Meneer Prins. } \\
\text { Thank you for this interview, Mr. Prince. }\end{array}$ \\
\hline
\end{tabular}




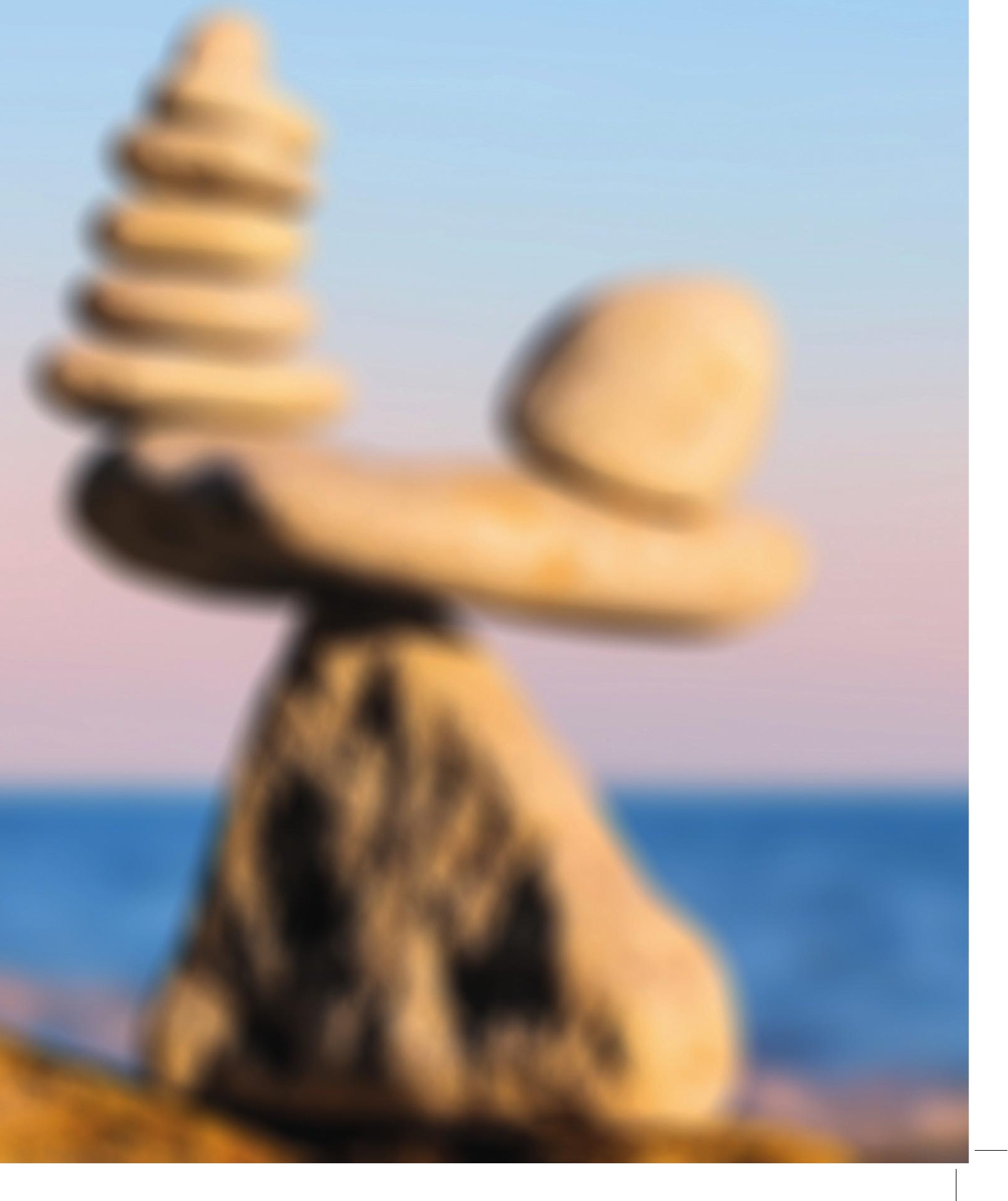




\section{CHAPTER}

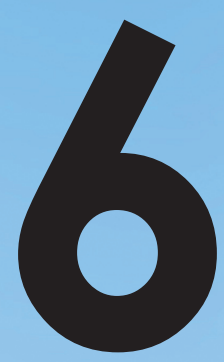

\section{General Discussion}

In this dissertation, we used a mixed methodology that led to diverse additional and consecutive insights. With the two qualitative exploratory retrospective interview studies we created a detailed picture of the mechanisms that play a role when mentoring an ST in one's own classroom and of why MTs intervene. We presented an overview of the factors related to MTs' intervening, and as a next step we tested whether some of these premises could predict and possible be used to influence MTs' intervening. With the two largescale multilevel studies in which we used standardised vignettes, we were able to predict MTs' intended intervening and show that it can be changed.

In this chapter, the major findings are summarised for each of the four studies. Then, we discuss our most important conclusions. Further, the potential implications and some suggestions for further research are presented. 


\section{Summary of the results by chapter}

In Chapter 2, we investigated how MTs perceive and experience the combination of the mentor and teacher roles. We aimed to explore the possibilities and challenges MTs perceive and experience as mentors and teachers. In seven retrospective semistructured interviews (Kelchtermans, 1993), we asked MTs, working as teachers in a primary education class and being the mentor of an ST placed in that class, about their role as an MT, their role as a teacher and the combination of those two. We used retrospective interviews because we wanted to gather MTs' perceptions of various moments in the past and from their entire career path. The transcribed interviews were qualitatively analysed individually and then compared in a cross-case analysis. We found that all MTs described two experiences of processes when both roles were combined. The first process, sequential role development, designated the development of both roles in a sequential order. MTs perceived that simply being a teacher helped to reinforce being an MT and developing as an MT. They indicated that being a good teacher is a condition for becoming a good mentor. Moreover, MTs mentioned that being a mentor positively influenced MTs' competence and wellbeing as a teacher, for example, because MTs became aware of their own teaching and learned new lesson ideas. We also found that sequentially developing the mentor and teacher roles is challenging. MTs clearly felt that being a teacher of pupils was their primary role; being an ST mentor was perceived merely as an aside - an additional task. The second process, simultaneous task performance, portrayed the combination of the mentor and teacher roles in performing both tasks simultaneously during the process of mentoring the ST. The most important contribution MTs perceived to the development of the ST was to make the classroom and pupils available to the ST. By doing this, the STs could practice their teaching skills through learning by doing. Additionally, MTs mentioned the advantage of having a student in class, which was considered as having an additional pair of hands in the classroom. This allowed the MT to profit from the activities of the student and provided time to perform other, non-mentorrelated tasks, such as correcting and grading pupils' work. We also found challenges that MTs face when simultaneously performing both roles, such as planning issues and the perceived lack of STs' competence. MTs also mentioned challenges due to the double responsibility for pupils as well as the ST. The first challenge was deciding 
when and how to transfer responsibilities to the ST. The second challenge was deciding whether to intervene during STs' lessons when the ST was teaching the MT's pupils and the MT observed an interruption of the normal course of events. We found that in these situations MTs indicated that they chose to intervene by guiding the pupils. We also found that the MTs were primarily focused on the wellbeing and development of their pupils and less on their STs' development. Based on the findings of this study, we decided in the subsequent studies to focus on MTs' challenge of combining the mentor and teacher roles during STs' teaching, with the particular aim to gain insight into MTs' intervening and their considerations related to it.

Therefore, in Chapter 3, we focused on the challenge that all MTs mentioned in Chapter 2, namely MTs' intervening and their considerations concerning intervening. The aim of this study was to explore MTs' practical reasoning concerning whether, when, and how to intervene during STs' lessons. We used Fenstermacher's (1986) work on practical arguments, consisting of situational, value, empirical and stipulative premises, and an intended or actual action, as a heuristic to illuminate MTs' thinking about their intervening. Because of the exploratory design of the study, we used retrospective semi-structured interviews (Kelchtermans, 1993). In the interviews, 18 MTs talked about combining the mentor and teacher roles and reasoned about their intervening in situations in which an ST was teaching the MT's pupils. Preceding the retrospective interviews with 11 MTs, we were present during an ST's lesson in an MT's classroom. We made a note of situations wherein the MT seemed to have the intention to intervene, or actually intervened. These situations were used to provide the MTs with an extra stimulus to reason about intervening and to consider their (abstaining from) intervening in various situations. We analysed MTs' practical reasoning about their intervening by using a coding system featuring main categories of premises and subcategories of themes. Our findings showed that during STs' teaching, MTs intervened quite frequently, mainly by guiding the pupils and sometimes quite disruptively by, for example, taking over the lesson. In justifying their intervening, MTs mentioned various reasons. Based on the analysis, we created an overview of the themes within the premises used by the MTs in our study when practical reasoning about whether, when and how to intervene. 
Generally, in their reasoning, for each particular situation the MTs in our study weighed, either consciously or unconsciously, 1) the situational premises, which included information gathered by immediate observations of the situational trigger that provoked MTs to intervene, and the characteristics of the ST, the pupils, the MT, and the lesson; 2) their value premises concerning mentoring and teaching; and 3) their general empirical premises, such as ideas and theories concerning mentoring and teaching, and their specific empirical premises about themselves as an MT and about a specific ST of specific pupils. It might be that MTs' personal balance of these variables eventually led to the specific threshold for not yet intervening to actually intervening for a particular MT in a particular situation.

The two qualitative studies, reported in Chapters 2 and 3, increased our understanding of MTs' double role, MTs' intervening during STs' lessons, and MTs' reasoning concerning intervening, represented in an overview of premises related to MTs intervening. Our next step was to quantitatively test the relation between some of the factors of the overview and MTs' intervening in order to predict MTs' intervening from these variables. Therefore, in Chapter 4, we aimed to investigate, using a bigger sample, MTs' value and empirical premises about mentoring and teaching, and MTs' intended intervening intensity and direction during STs' lessons. Also, we examined how situational characteristics (STs' experience, trigger type and trigger severity) and personal characteristics (MTs' value and empirical premises) contributed to MTs' intended intervening intensity and direction. By using a set of vignettes (which were realistic situations constructed based on Fenstermacher's (1986) premises and the findings of Chapter 3) in which we manipulated trigger type, trigger severity and ST experience, we were able to systematically present several classroom situations that prompted MTs to consider their intervening. Due to the various combinations of manipulated variables within the vignettes and, therefore, the hierarchical datastructure of the vignette data (and considering our question to find the relative importance of various predictors), we performed multilevel analyses. A total of 159 MTs indicated for 14 vignettes whether and how they would intervene in such situations. MTs' value and empirical premises were measured with a questionnaire. We found that overall in the vignette situations in almost $90 \%$ of the ratings MTs would intervene 
with at least some intensity. We also found that MTs intervened quite intensely and not only toward the ST, but also directed toward the pupils Another important finding was that MTs indicated that they found teaching values more important than mentoring values, and that MTs believed in empirical premises that could lead to conflicting or incompatible actions, namely their intention to intervene and to abstain from intervening. The multilevel analyses showed that MTs' intervening intensity was both due to the situation ( $17 \%$ of the variance) and the MT ( $28 \%$ of the variance). MTs' direction to intervene was also affected by situational as well as personal factors. We found that the more MTs preferred teaching values over mentoring values, the more intensely they intervened and the more often their intervening was directed toward the pupils. MTs' direction and intensity to intervene were both affected by trigger type (MTs intervened more intensely and directed their intervening more toward the ST when an ST made a mistake in the lesson content compared to when the ST had difficulties with classroom management) and trigger severity (when the severity of the trigger was higher, MTs intervened more intensely and it was more directed toward the ST). Interestingly, and unexpectedly, MTs' intensity and direction to intervene were not predicted by the ST's experience, namely a first- or third-year ST.

After gaining insight into the value premise and empirical premises affecting MTs' intervening, and in order to help MTs deal with the tension they experience when combining the mentor and teacher roles, in Chapter 5 we aimed to investigate whether we could influence MTs' considerations concerning intervening, and whether we could change MTs' intended intervening intensity and direction. In a between-subject pretest post-test experiment, we examined the impact of reinforcing the mentor role or the teacher role on MTs' value and empirical premises, and on MTs' intended direction and intensity of intervening. We used the data from Chapter 4 as a pre-test, and after three weeks, just before the post-test MTs were reinforced on either the mentor or teacher role or they were not provided with information about one of the roles. In the first condition, MTs' value and empirical premises were reinforced by providing information on the importance of the mentor role (value premise) and by providing information from research that described the relation between teaching situations and STs' wellbeing and development (empirical premises). The second condition was 
a control condition with no treatment. In the third condition, we reinforced MTs' value and empirical premises by providing information on the importance of the teacher role (value premise) and by providing information from research that described the relation between teaching situations and pupils' wellbeing and development (empirical premises). Multilevel analyses showed that by reinforcing either the mentor or teacher role, the intended intensity of MTs' intervening was strongly influenced. A total of $47 \%$ of the variance in MTs' intended intervening intensity was explained by our intervention, which is a large effect. We also found that by reinforcing either the mentor or teacher role, MTs found the values concerning the role they were informed about to be relatively more important, and this was a large effect (32\% explained variance). MTs reinforced on the mentor role intended to intervene significantly less intensely than the control group, and MTs reinforced on the teacher role intended to intervene significantly more intensely than the control group. Also, MTs reinforced on the mentor role more strongly agreed with the premise that abstaining from intervening is positive for the ST (15\% explained variance). To conclude, a three-minute video significantly altered MTs' intentions to intervene, which is promising for establishing changes in MTs' ST guidance.

\section{Integrating the results}

Reviewing the four studies led to the general conclusions that 1) in primary education, MTs' teacher role overrules their mentor role, showing up in MTs' intervening; 2) this intervening and MTs' value premises concerning mentoring and teaching can be changed; and 3) Fenstermacher's (1986) practical argument is a valuable heuristic to gain insight in MTs' reasoning processes and inducing change. We will now elaborate on these findings and describe possible explanations.

\section{MTs' teacher role overrules their mentor role}

The main conclusion was that MTs' teacher role overrules their mentor role. At the specific moment the ST is teaching the MT's pupils, MTs experience a tension between their mentor and teacher roles. MTs feel they are primarily the teacher of the pupils and being a mentor is an additional task, and they primarily focus on the wellbeing and development of their pupils and less on their STs' development (Chapter 2). This shows 
up in MTs' intervening, which is frequent, intuitive, quite intense, and they guide the pupils rather than the ST (Chapters 2, 3 and 4).

There are various possible explanations for this finding. The first is MTs' ingrained habit of teaching. When the ST is teaching and the mentor is mentoring, and when MTs observe a problematic teaching situation (situational premise; for example, pupils not working on a task), MTs intuitively (re)act as teachers. MTs spend more time teaching than combining teaching and mentoring; thus, as teachers, they are used to reacting to what happens with the pupils in the classroom, i.e. to intervening by guiding the pupils, all day long. Also, MTs acting as teachers can be explained by the fact that MTs perform their mentor task in their own teaching context, drawing on their strong feeling of responsibility for their pupils, and our findings showed that MTs find teaching values to be more important than mentoring values (Chapter 4). MTs' teaching experience with these specific pupils may prevent them from acting as the STs' mentor.

Related to this explanation that MTs do think and act like teachers is that MTs do not perceive themselves as mentors, as teachers of STs or as teacher educators (cf. Bullough, 2005; Leathem \& Peterson, 2001; Orland-Barak, 2002, 2005; Zeichner, 2005). MTs seemed not to acknowledge the complex status of STs who are simultaneously both teachers and learners (cf. Hopper, 2001). Our findings thus confirm that becoming an MT and, specifically, guiding an ST during his or her learning to teach is not something that spontaneously develops from being a teacher (e.g., Bullough, 2005; Orland-Barak, 2002; 2005; Zeichner, 2005). Rather, mentoring is a new skill that MTs have to develop. MTs, being inexperienced in thinking as mentors, may have weak empirical premises concerning STs' development. Consequently, MTs might not act according to their empirical premises concerning mentoring or STs' learning. Probably, MTs' empirical premises concerning mentoring do not have a lot of impact on their thinking and acting compared to the strong and more elaborate value and empirical premises concerning teaching that lead to MTs automatically intervening when noticing a problematic teaching situation. For example, in the interviews in Chapters 2 and 3, MTs mentioned that their intervening was dependent on the study year of the ST, but in our vignette study (Chapter 4), MTs' intervening was not predicted by ST experience. It is plausible 
that MTs think that their intervening is related to the STs' competence or that they know that they should adjust their mentoring according to the STs' competence, but that in practice, when confronted with a chaotic classroom situation, MTs mainly act by what they see and experience at that very moment. According to Kagan (1992), acting and thinking could be inconsistent because the relation between the cognitions and actions is situation specific. In Chapter 4, we indeed found that the situational characteristics, trigger type and trigger severity did predict MTs' intervening. We conclude that based on a specific situation or context, teachers might be triggered to act differently from what could be expected from their empirical premises concerning STs' learning. Such actions might prevent MTs from adapting their mentoring according to the STs' learning needs.

A third explanation for our finding is that MTs might lack empirical premises concerning mentoring principles. In Chapter 2, we found that MTs merely facilitated the training of STs by giving them their class and letting them teach as much as possible (cf. Eraut, 2004), and that MTs described mentoring as providing a place for STs to practice their teaching and offering a little support (cf. Borko \& Mayfield, 1995; Hall, Draper, Smith, \& Bullough, 2008). Many MTs did not seem to mentor according to the principles of mentoring literature such as stimulating STs into deeper levels of thinking and reflection (cf. Feiman-Nemser, 2001), promoting inquiry (cf. Stanulis, 1995), explaining the rationales behind the teaching approaches they use (cf. Jones, Reid, \& Bevins, 1997; Zanting et al., 1998), and lesson study (Lewis \& Hurd, 2011). In the interviews (Chapter 2), MTs basically described their mentoring as a form of apprenticeship learning (Lave \& Wenger, 1991), in which the MT is the expert modelling the teaching and transfers the responsibility of teaching bit by bit to the ST. This might explain why MTs frequently step in during STs' teaching, without thoughtful consideration. Although MTs' frequent stepping in and helping the ST with his or her teaching by guiding the pupils might be effective from an apprenticeship learning perspective, it is a one-sided approach and the MTs in our study apparently lacked scientific and practical knowledge of other mentoring perspectives. This might be explained by MTs not being sufficiently informed on mentoring according to other approaches (Evans \&Abbott, 1997; Sundli, 2007; Wang \& Odell, 2002). When MTs do not 
have empirical premises concerning how STs could learn and how MTs could encourage STs' learning, STs' teaching practice period might not be as effective as intended by the teacher training institutes.

A final explanation for the dominance of the teaching role over the mentor role refers to the mentoring context in our study, namely primary education. In our research, MTs' focus on their pupils and the tension between both roles seemed to be stronger than what might be expected from the literature about mentoring in secondary education. This difference between the secondary and primary contexts might imply conceptual differences in mentoring activities, strategies and dilemmas, as well as the challenges and considerations of the MTs (Orland-Barak \& Hasin, 2010; Wang, 2001). Teachers in primary education, who usually bear responsibility for one class of (young) pupils, might feel a different responsibility for their pupils than secondary teachers, who have several classes and older pupils. This perceived responsibility for pupils in primary education thus might contribute to overruling the responsibility for their STs (Cross, 1999). The other way around, as Post (2007) suggests, in secondary education, MTs might choose to ignore problems that occur during an ST's lesson more often, because MTs are conscious of STs' need to be perceived as authority figures by (the older) pupils. Our study thus supports Wang's (2001) suggestion that the context of teaching and mentoring influences MTs' mentoring practice. Research needs to acknowledge and address the presumed differences in mentoring in primary and secondary education because insights from mentoring in secondary education might not be directly transferable to primary education.

\section{Changing MTs' premises and intervening}

A second prominent conclusion of this dissertation is that MTs' premises and their intended intervening can be changed (Chapter 5), which is important because intervening during STs' teaching is behaviour that MTs frequently, quite intensely and rather intuitively perform (Chapters 2, 3 and 4). Such intervening could negatively affect the quality of the STs' learning. Our findings might explain findings from mentoring studies that describe the low impact mentoring had on STs' learning (e.g., Borko \& Mayfield, 1995; Wang \& Odell, 2002). 
Even though we suggest that MTs' intervening is a result of MTs routinely and automatically acting due to their ingrained habits as teachers, we found that MTs' intended intervening and their value premises can be influenced by providing them with information about the importance of the mentor role (value premise), and by providing research findings about the effect of teaching situations on ST wellbeing and development (Chapter 5). With the intervention we did not want MTs to acquire new values, but rather aimed at reinforcing already existent values, which might explain why we found that MTs' actions and values can be changed, contrary to the notion that described beliefs as stable and resistant to change (cf. Haney, \& McArthur, 2002; Liljedahl, Oesterle, \& Bernèche, 2012; Rokeach, 1986). We showed that the three-minute video clips influenced the relative importance of MTs' values. After the intervention, MTs reinforced on the mentor role still found teaching values more important than mentoring values, but the already existent mentoring values became more important, leading to MTs' mentoring values being more in balance with MTs' teaching values. Possibly, value change does not have to mean MTs suddenly thinking something completely different but could be seen as finetuning the balance between MTs' already existent values. We assume that reinforcing MTs' premises concerning mentoring strengthened these values, which might have resulted in MTs more carefully considering their mentoring goals and the learning of STs. These changed or more underpinned premises might have made MTs' reasoning concerning their intervening more objectively reasonable (Morine-Dershimer, 1987) and might have helped MTs to make their practical arguments concerning intervening more balanced, sophisticated and complete. This might have led to MTs being able to make more thought-through decisions, which might have resulted in a change in MTs' intended intervening (cf. Fenstermacher \& Richardson, 1993).

\section{Practical reasoning}

A third conclusion of the studies in this dissertation is that the practical argument theory of Fenstermacher (1986) appeared to be a valuable heuristic to gain a detailed understanding of the MTs' reasoning process and enabled us to more fully understand MTs' intervening in the complex situation of mentoring in one's own class. We used the practical argument in the qualitative (Chapter 3) as well as quantitative studies 
(Chapters 4 and 5). We perceived the practical argument theory to be particularly suitable given the MTs' commitment to their dual roles and their considerations as mentors and teachers, which enabled us to illuminate the value conflict and how this conflict resulted in MTs' intervening. By using the situational, value and empirical premises, we could show the complex relation between MTs' thoughts and intervening. The premises directly and aggregately related to MTs' intervening and comprehensively captured situational factors (situational premises) as well as personal factors (value and empirical premises). Besides, the elements of the practical argument were not only important to explain MTs' actions, but were also important levers for inducing change in intended interventions.

\section{Implications}

Based on our findings, we will describe implications for MTs, MTs' mentoring professionalisation courses, teacher educators and STs that might possibly improve MTs' contributions to STs' learning and help MTs with the delicate balance between their mentor and teacher roles.

The first implication of our findings is that MTs need to become more aware of their teacher and mentor roles and of the impact of their teacher role on their mentoring actions, especially at the moment the ST is teaching. MTs need to thoughtfully consider the aim of mentoring in the teaching context, about the care they feel for their pupils and particularly about their underlying reasons for their tendency to intervene. Courses for mentor professional development have been suggested in the past, and their positive effects on MTs' professionalisation have been demonstrated (Killian \& Wilkins, 2009; McIntyre \& Killian, 1987). We recommend that such courses include support for MTs' quest to combine the mentor and teacher roles, pay careful and sufficient attention to the complex situation of being a mentor in one's own classroom, and highlight the importance of being a mentor. Also, we suggest adequate reflection on the development of both roles, and including discussions of MTs' values concerning mentoring and teaching and the goal conflicts that MTs (perhaps unconsciously) might experience between being a teacher and being a mentor. Based on the findings of Orland-Barak (2001, 2002, 2005), who investigated the passage from being a teacher 
of pupils to becoming a mentor of teachers in secondary education, we recommend that MTs gain insights into the differences between their teacher and mentor roles. Paying sufficient attention to taking up a new role, the role shift and coping with the tensions this role shift might introduce is important (Pillen, Beijaard, \& Den Brok, 2013).

Second, to help MTs with the dilemma they experience when combining mentoring and teaching and to support MTs in clarifying their reasoning process, we suggest mentoring courses to encourage MTs to elicit and reconstruct their practical arguments concerning their intervening (Fenstermacher \& Richardson, 1993). When MTs are more consciously aware of the double role they have to perform, and of the sometimes conflicting values as mentor and teacher, appropriate practical reasoning can help them deal with these values more effectively (Morine-Dershimer, 1988). When MTs gain insight into their practical reasoning concerning intervening, are aware of their premises concerning mentoring and teaching, and consciously consider and balance the development of both pupils and STs, they might become sensitive to the underlying reasons for their tendency to intervene. Additionally, we suggest mentoring professionalisation courses to inform MTs that their premises and intervening can change through informing themselves with research findings. We showed that already with a three-minute intervention reinforcing the teacher or mentor role, MTs' intention to intervene changed (Chapter 5). Our overview of premises related to MTs' intervening (Chapter 3) and our developed vignettes (Chapters 4 and 5) can help MTs to reflect on their practical reasoning about intervening, encourage them to consider their dual loyalty, and stimulate them to start thinking and acting more as mentors. When MTs are asked by a critical other, for example, by a colleague MT, for their considerations concerning their intervening, via questions such as "Why did you do that?" (Fenstermacher \& Richardson, 1993), their subjectively reasonable beliefs can become objectively reasonable (Green, 1986), and the practical argument can improve (Morine-Dershimer, 1987), which might advance their competence (Fenstermacher \& Richardson, 1993).

Third, to better be able to guide STs during student teaching practice, we recommend that mentoring professionalisation courses pay attention to MTs' need to acknowledge 
STs as teachers and as learners (Awaya et al., 2003) who need to be guided in learning to teach-also at the very moment of practicing. When MTs do not recognise the STs as learners, it will prevent them from acting according to STs' learning needs. Therefore, MTs' professionalisation programmes should be aimed at improving MTs' awareness of the STs as learners and should encourage MTs to give more prominence to the mentoring values. This can be done by reinforcing MTs' premises concerning STs' learning through providing research findings about learning theories, the effect of various situations on STs' wellbeing and development, and how MTs can adapt their mentoring behaviour to the stage of the STs' performance and learning curve (Maynard, 1996). Encouraging MTs' awareness of STs as learners might make MTs' reasoning more in balance with their strong feelings for their pupils, probably causing their guidance to become more aligned to the STs' learning goals and needs (e.g., Feiman-Nemser, 2001).

Finally, our findings might have implications for teacher education institutes and STs. When teacher educators visit an ST at school, they can specifically address MTs' combination of their mentor and teacher roles as an MT and provide their ST with guidance and support during STs' lessons. Also, teacher educators could teach STs how to address MTs and understand their dual loyalty to the ST as well as to the pupils. In addition, STs can be taught to be aware of their own learning process and learning goals, how to reflect on their teaching process, and how they can profit from and ask for MTs' deliberate guidance during practicing teaching. Moreover, teacher training institutes could encourage STs to discuss MTs' role during STs' teaching. For example, in the first MT ST conversation, MTs can ask STs how they want to be guided during their teaching, and STs can agree on how the ST will be guided during the lessons, and whether the MT should intervene or not (and if, how). Specifically, we suggest the STs and MTs include MTs' intervening more structurally in the phases of pre-lesson, during lesson and post-lesson guidance. In every pre-lesson conference, when the MT and ST determine the ST's specific learning need or the learning goal that the ST is going to practice in the upcoming lesson, they could also agree on the MT's guidance during the ST's teaching, and specifically on the method the MT will use to help the ST accomplish this goal. The MT and ST should agree on whether and how the MT will 
intervene such that it best supports the ST. Then, during the ST's teaching, based on the learning goal, the MT can guide the ST, for example, by deliberately intervening at the moment the ST is supposed to perform new skills (for example, by saying "Now do this" or "Don't forget to do that"). Another way of explicitly guiding STs during their teaching is by saying keywords into a microphone while the ST is wearing an earpiece (e.g., Rock et al., 2009; Voerman, Meijer, Korthagen, \& Simons, 2015). Also, the ST could be guided during practice by deliberately modelling the teaching behaviour the ST has to learn ("See, when I do this, the pupils do/learn that..."). When MTs model good professional practices, it helps STs to become effective practitioners (Roehrig, Bohn, Turner, \& Pressley, 2008). Then, in the post-lesson conference, the MT and ST could evaluate not only the ST's teaching, but also when and why the MT intervened and what the effect was on the ST and (eventually) the pupils, and whether and how this helped the ST to accomplish the learning goal. When the MT and ST collaboratively reinterpret what happened, MTs have to explicate the practical knowledge underlying their teaching, which appears to be positive for STs' development (Zanting et al., 2001). In addition, especially when the MT intervened rather intensely, reflecting on what happened might be good for the ST's wellbeing and self-esteem. We believe that when MTs' intervening during STs' teaching might be more incorporated into the pre-, during, and post-lesson phases, and directly connected to STs' learning goal, this could probably make MTs' guidance before, during and after STs' teaching more focused and deliberate, and therefore might support STs' learning during their teaching practice. Incorporating MTs' intervening into the research and theory on mentoring will improve the conceptualisation of mentoring.

\section{Further research}

We need to better understand what MTs' intervening and reconstruction of their practical arguments concerning intervening in their own classrooms with their own pupils look like, how STs think about and experience MTs' intervening, and what the effect of intervening is on ST and pupil wellbeing and development. Based on our studies, we now better understand MTs' intervening, which factors are related to it, and that we can use these factors to influence MTs' considerations concerning intervening and their intentions to intervene. As a next step, we suggest further research to 
investigate MTs' intervening in their own classrooms; examine the reconstruction of practical arguments; include the ST perspective concerning intervening; investigate the effects of intervening and of incorporating intervening into the pre-, during and post-lesson phases; and acknowledge MTs' responsibility for their pupils. Such insights can further expand our understanding of MTs' intervening during STs' teaching and can eventually be used to further improve MTs' guidance during STs' teaching, and therewith to help MTs eventually be better enabled to encourage STs' development.

\section{MTs' intervening in their own classroom}

Although the vignettes used in the studies reported in Chapters 4 and 5 were realistic situations, they were also hypothetical situations that might not have fully represented what MTs experience when they observe an ST teaching their own pupils. In their own classrooms with pupils they really know, MTs would probably be even more concerned about the children in their care (Edwards, 1998; Hopper, 2001; Stanulis, 1995). We suggest further research to observe MTs during STs' teaching, because this might give further insight into the influence of MTs' own pupils on their intervening. It is plausible that MTs, when they actually see their own pupils and feel what happens in the classroom, tend to act even more as a teacher than the vignette studies showed. Additionally, the effect of an intervention on MTs' intervening in their own classrooms and on MTs' reasoning concerning their intervening in their own classrooms could be investigated through stimulated recall interviews (Calderhead, 1981).

\section{Reconstruction of the practical argument}

In this dissertation, we based our intervention (Chapter 5) on the practical argument theory of Fenstermacher (1986) and on findings of our research that showed that value and empirical premises predict MTs' actions (Chapter 4). However, we do not know how the changed premises evolved. Therefore, we suggest further research to examine the process of elicitation and reconstruction of the practical argument (Fenstermacher \& Richardson, 1993). Reconstruction of MTs' reasoning could give insight into how MTs' reasoning concerning intervening develops, whether their practical arguments become more elaborate and how this development is related to a change in their intervening. Investigating the reconstruction of MTs' practical arguments can be done, 
for example, by presenting them with vignettes and letting them reason, in dialogue with the researcher or a critical other (cf. Fenstermacher \& Richardson, 1993), about whether and how they would intervene. Additionally, reconstruction of the practical argument could help MTs to gain insight into their own considerations, could further improve their reasoning, and thus perhaps result in changed actions. Subsequently, the researcher or critical other could encourage MTs to use mentoring research and could reinforce MTs' mentor role through providing information concerning STs' learning. Then, MTs could again explicate their reasoning for the vignettes, thereby giving insight into the reconstruction of their practical argument (cf. Fenstermacher \& Richardson, 1993). Through repeating this process with more research findings, for other vignettes, and also for real mentoring situations in MTs' own classrooms, insight might be obtained into the development of MTs' reasoning and into the possible changes in their actions. Finally, we suggest follow-up research to investigate whether MTs' change in reasoning and acting is stable over time and transferable to their own mentoring context.

\section{The ST perspective}

In this dissertation, the ST perspective on intervening was not included. To be able to conclude which mentoring behaviour contributes to STs' wellbeing and development, further research should examine the STs' perceptions and experience. This can be done by asking STs about their experiences with and perceptions of MTs' interventions. More specifically, when researchers observe STs' lessons and MTs' intervening, STs could afterwards be asked if and how they experienced MTs' intervening, why they think the MT intervened, and what they learned from it. Just as MTs vary in their beliefs about what might be effective intervening, STs might also vary in how they perceive and appreciate MTs' intervening.

\section{Effect of MTs' intervening}

Although we have shown that MTs' intervening can be changed (Chapter 5), we do not know if that is needed, because we do not know what effective mentoring behaviour during STs' teaching is. Besides, what might be effective mentoring might differ per MT, ST and situation. Therefore, we cannot prescribe how MTs should intervene. We 
found that MTs strongly believe that cautiously intervening is positive for the ST as well as the pupils (Chapter 4), and we suggested that by cautiously intervening, MTs searched for a way to fulfil two goals with one action: they searched for one intervention to meet both their mentoring and teaching values as closely as possible. However, whether cautiously intervening really supports ST or pupil learning remains to be seen. Therefore, we recommend studying how various ways of intervening affect pupil and ST wellbeing and development, and which intervening strategies are most effective in this respect.

\section{Pre-, during and post-lesson phases}

To improve the effectiveness of mentoring, it could be useful to study whether and how STs and MTs discuss MTs' roles and intervening during STs' lessons with each other in pre- and post-lesson conversations. It is possible that STs and MTs may have agreed on MTs' interventions and, therefore, MTs' guidance during STs' teaching could be related to STs' learning goals and needs (Feiman-Nemser, 2001). We suggest further research to specifically examine how MTs' guiding of STs during their lessons is related to MTs' and STs' pre- and post-lesson conversations. Additionally, now that we have shown that reinforcing the mentor role affected a change in MTs' value premises and intervening, this might also affect MTs' practical reasoning concerning the ST guidance during pre- and post-lesson conversations, and might result in a change in how MTs and STs discuss the MTs' roles and intervening during the STs' lessons. Therefore, it could be useful to study whether and how MTs' mentoring strategies in pre- and postlesson conversations might change due to providing information about the learning of STs and the importance of the mentor role. More specifically, we suggest further research to examine how MTs' guidance before and after the STs' teaching, as well as during STs' teaching, could relate more to the STs' learning goals and needs (e.g., Feiman-Nemser, 2001). When MTs' intervening during STs' teaching is incorporated into the pre-, during and post-lesson phases, and directly related to STs' learning goals, this could make MTs' guidance before, during and after STs' teaching more deliberate and, therefore, better able to support STs' learning during their teaching practice and could help MTs with the tension they experience when they combine the mentor and teacher roles. 


\section{Mentoring research}

Currently, most mentoring research focuses only on the mentor tasks and ignores the influence of the responsibility MTs feel for their pupils. For example, research investigating mentoring principles such as clinical supervision (which requires MTs to observe STs' teaching in a process of pre-lesson preparation, observations and post-lesson evaluation; e.g., Kent, 2001), scaffolding or co-teaching might ignore the dilemmas MTs face due to their responsibility toward the ST as well as the pupils. This might influence the research findings. Consequently, research should consider MTs' tendency to act as teachers.

\section{Conclusion}

In this dissertation, we showed that in primary education in the Netherlands, when MTs mentor an ST in their own classroom, MTs experience tension between their mentor and teacher roles, specifically when the ST is teaching the MT's pupils. We found that, in general, the teacher role overrules the mentor role, which shows up in MTs' intervening, which is frequent, intuitive, quite intense and they guide the pupils rather than the ST. These findings can be explained by MTs' ingrained habits as teachers (as a reaction to a problematic teaching situation, i.e. a situational premise); MTs' strong value premises concerning teaching and pupils' learning; and the fact that MTs, in the end, are more concerned about the pupils' wellbeing than STs' learning. This is combined with MTs' weak empirical premises concerning the learning of STs and MTs' lack of awareness of their role as an MT and of the ST as a learner. We also found that MTs' premises and intervening can be changed, and that Fenstermacher's (1986) practical argument is a valuable heuristic to gain insight into MTs' reasoning processes and inducing change. This series of studies is promising in that it could help improve MTs' contributions to STs' learning and help MTs with the delicate balance between their mentor and teacher roles. 


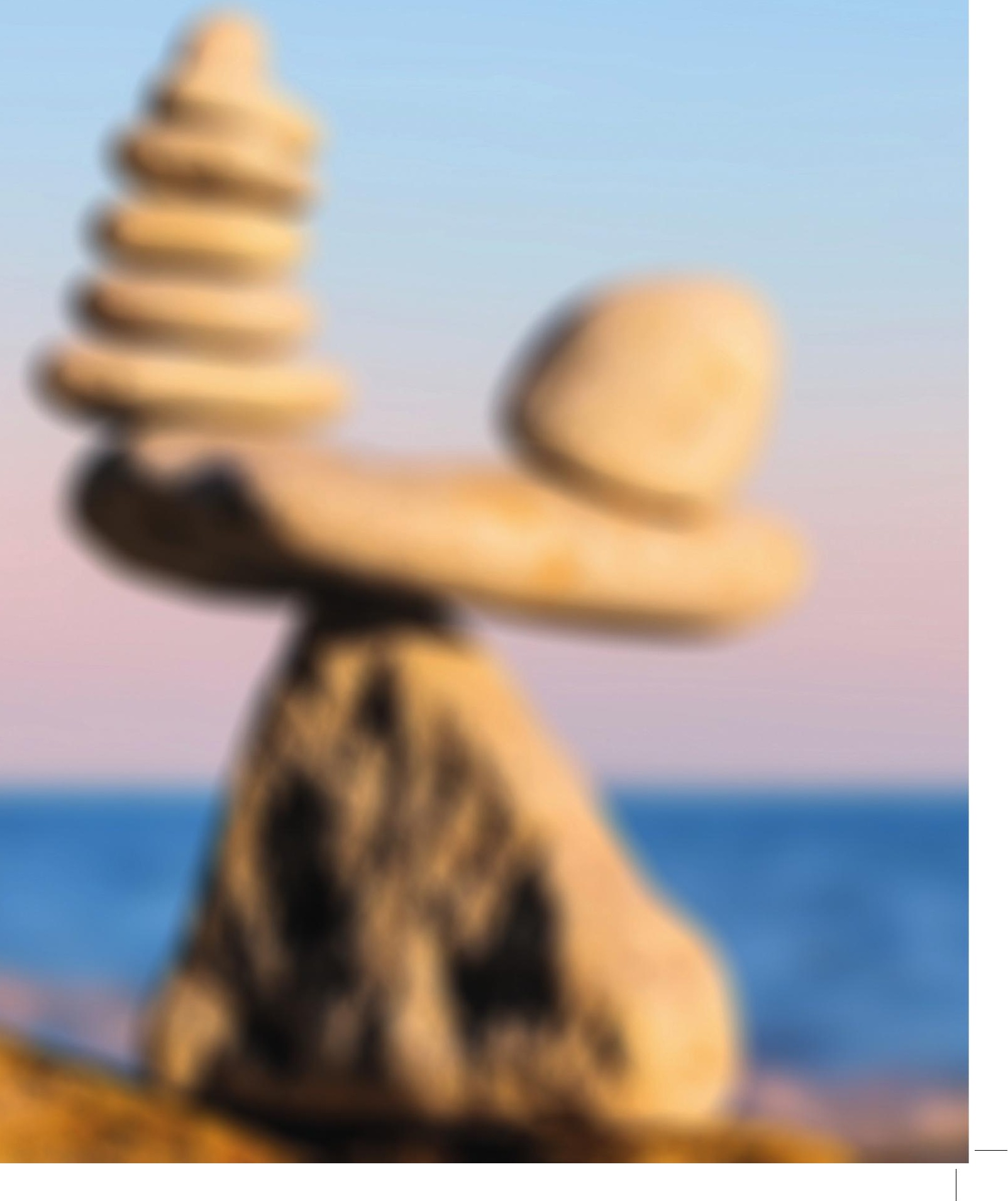




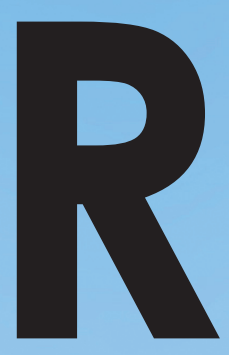




\section{REFERENCES}

Aguinis, H., \& Bradley, K. J. (2014). Best practice recommendations for designing and implementing experimental vignette methodology studies. Organizational Research Methods, 17, 351-371. doi:10.1177/109442811454795

Akkerman, S., Admiraal, W., Brekelmans, M., \& Oost, H. (2008). Auditing quality of research in social sciences. Quality and Quantity, 42, 257-274. doi:10.1007/s11135-006-9044-4

Alsup, J. (2006). Teacher identity discourses: Negotiating personal and professional spaces. New Jersey: Lawrence Erlbaum Associates.

Anderson, D. (2007). The role of cooperating teachers' power in student teaching. Education, 128(2), 307-323.

Awaya, A., McEwan, H., Heyler, D., Linsky, S., Lum, D., \& Wakukawa, P. (2003). Mentoring as a journey. Teaching and Teacher Education, 19, 45-56. doi:10.1016/S0742-051X(02)00093-8

Beck, C., \& Kosnik, C. (2002). Components of a good practicum placement: Student teacher perceptions. Teacher Education Quarterly, 29(2), 81-98.

Ben-Peretz, M., \& Rumney, S. (1991). Professional thinking in guided practice. Teaching and Teacher Education, 7, 517-530. doi:10.1016/0742-051X(91)90046-R

Borko, H., \& Mayfield, V. (1995). The roles of the cooperating teacher and university supervisor in learning to teach. Teaching \& Teacher Education, 11, 501-518. doi:10.1016/0742-051X(95)00008-8

Bowen, G. A. (2006). Grounded theory and sensitizing concepts. International Journal of Qualitative Methods, 5, 12-23. doi:10.1177/160940690600500304

Boyle-Baise, M., \& McIntyre, D. J. (2008). What kind of experience? Preparing teacher in PDS or community settings. In: M. Cochran-Smith, S. Feiman-Nemser, D.J. McIntyre \& K. E. Demers (Eds.), Handbook of research on teachers education; Enduring questions in changing context ( $3^{\text {rd }}$ ed., pp307-329). New York: Routledge.

Bullough, R. V. (2005). Being and becoming a mentor: School-based teacher educators and teacher educator identity. Teaching and Teacher Education, 21, 143-155. doi:10.1016/j. tate.2004.12.002

Bullough, R. V., \& Draper, R. J. (2004). Making sense of a failed triad: Mentors, university supervisors, and positioning theory. Journal of Teachers Education, 55, 407- 420. doi:10.1177/0022487104269804 
Cabaroglu, N., \& Tillema, H. H. (2011). Teacher educator dilemmas: A concept to study pedagogy. Teacher and Teaching: Theory and Practice, 17, 559-573. doi:10.1080/1354 0602.2011 .602210

Calderhead, J. (1981). Stimulated recall: A method for research on teaching. British Journal of Educational Psychology, 51, 211-217. doi:10.1111/j.2044-8279.1981.tb02474.x

Calderhead, J. (1991). The nature and growth of knowledge in student teaching. Teaching and Teacher Education, 7, 531-535. doi:10.1016/0742-051X(91)90047-S

Clarke, A., Triggs, V., \& Nielsen, W. (2014). Cooperating teacher participation in teacher education: A review of the literature. Review of Educational Research, 84, 163-202. doi:10.3102/0034654313499618

Cochran-Smith, M., \& Demers, K. E. (2008). How do we know what we know? Research and teacher education. In M. Cochran-Smith, S. Feiman-Nemser, D. McIntyre, \& K. E. Demers (Eds.), Handbook of research on teacher education: Enduring issues in changing contexts (3rd ed., pp. 1009-1016). London: Routledge press.

Cohen, J. (1988). Statistical power analysis for the behavioral sciences (2nd ed.). New York: Academic Press.

Collison, J., \& Edwards, A. (1994). How teachers support student learning. In: I. Reid, H. Constable, \& R. Griffiths (Eds). Teacher education reform: Current evidence (pp. 131136). London: Paul Chapman.

Confrey, J. (1987). Bridging research and practice. Educational Theory, 37, 383-394. doi:10.1111/j.1741-5446.1987.00383.x

Crasborn, F., Hennissen, P., Brouwer, N., Korthagen, F., \& Bergen, T., (2011). Exploring a two-dimensional model of mentor teacher roles in mentoring dialogues. Teaching and Teacher Education, 27, 320-331. doi:10.1016/j.tate.2010.08.014

Cross, R. (1999). What time constraints face the junior school teacher taking on the role of student mentor? Mentoring \& Tutoring: Partnership in Learning, 7, 5-21. doi:10.1080/0968465990070101

David, H. A. (1988). The Method of Paired Comparisons. New York: Oxford University Press.

Edwards, A. (1998). Mentoring student teachers in primary schools: Assisting students teachers to become learners. European Journal of Teacher Education, 21, 47-62. doi:10.1080/0261976980210106 
Edwards, A., \& Collison, J. (1995). What do teacher mentors tell student teachers about pupil learning in infant school? Teachers and Teaching: Theory and Practice, 1, 265-279. doi:10.1080/1354060950010208

Edwards, A., \& Protheroe, L. (2004). Teaching by proxy: understanding how mentors are positioned in partnerships. Oxford Review of Education, 30, 183-197. doi:10.1080/0305498042000215511

Edwards, A., \& Protheroe, L. (2010). Learning to see in classrooms: What are student teachers learning about teaching and learning while learning to teach in schools? British Educational Research Journal, 29, 227-242. doi: 10.1080/0141192032000060957

Elliott, B., \& Calderhead, J. (1993). Mentoring for teacher development: Possibilities and caveats. In D. McIntyre, H. Hagger, \& M. Wilkin. (Eds.), Mentoring perspectives on schoolbased teacher education (pp. 166-189). London: Kogan Page.

Eraut, M. (2004). Informal learning in the workplace. Studies in Continuing Education, 26, 247-273. doi:10.1080/158037042000225245

Eraut, M. (2011). How researching learning at work can lead to tools for enhancing learning. In M. Malloch, L. Cairns, K. Evans, \& B. N. O'Connor (Eds.), Sage handbook of workplace learning (pp. 181-197). London: Sage.

Evans, L., \& Abbott, A. (1997). Developing as mentors in school-based teacher training. Teacher Development, 1, 135-148. doi:10.1080/13664539700200010

Evertson, C. M., \& Weinstein, C. S. (2006). Handbook of classroom management: Research, practice, and contemporary issues. Mahwah, NJ: Lawrence Erlbaum Associates.

Feiman-Nemser, S. (2001). Helping novices learn to teach: Lessons from an exemplary support teacher. Journal of Teacher Education, 52, 17-30. doi:10.1177/0022487101052001003

Feldmann, L. J., (2001). Classroom civility is another of our instructor responsibilities. College Teaching, 49, 137-140. doi:10.1080/87567555.2001.10844595

Fenstermacher, G. D. (1986). Handbook of research on teaching philosophy of research on teaching: Three aspects. In M. C. Wittrock (Ed.), Handbook of research on teaching (3rd ed., pp. 37-49). New York: Macmillan.

Fenstermacher, G. D. (1987). A reply to my critics. Educational Theory, 37, 413-422. doi:10.1111/j.1741-5446.1987.00413.x

Fenstermacher, G. D. (1994). Chapter 1: The knower and the known: The nature of knowledge in research on teaching. Review of Research in Education, 20(1), 3-56. doi:10.3102/0091732X020001003 
Fenstermacher, G. D., \& Richardson, V. (1993). The elicitation and reconstruction of practical arguments in teaching. Journal of Curriculum Studies, 25, 101-114. doi:10.1080/0022027930250201

Furlong, J. (2000). School mentor and university tutors: Lessons from the English experiment. Theory into Practice, 39, 12-19. doi:10.1207/s15430421tip3901_3

Gholami, K., \& Husu, J. (2010). How do teachers reason about their practice? Representing the epistemic nature of teachers' practical knowledge. Teaching and Teacher Education, 26, 1520-1529. doi:10.1016/j.tate.2010.06.001

Glaser, B., \& Strauss, A. (1967). The discovery of grounded theory: Strategies for qualitative research. New York: Aldine.

Glenn, W. J. (2006). Model versus mentor: Defining the necessary qualities of the effective cooperating teacher. Teacher Education Quarterly, 33(1), 85-95.

Glickman, C. D., \& Gordon, S. P. (1987). Clarifying developmental supervision. Educational Leadership, 44(8), 64-68.

Goodfellow, J. (2000). Knowing from the inside: Reflective conversations with and through the narratives of one cooperating teacher. Reflective Practice, 1, 25-42. doi:10.1080/713693136

Gould, D. (1996). Using vignettes to collect data for nursing research studies: How valid are the findings? Journal of Clinical Nursing, 5, 207-212. doi.10.1111/j.1365-2702.1996. tb00253.x

Graham, P. (1997). Tensions in the mentor teacher-student teacher relationship: Creating productive sites for learning within a high school English teacher education program. Teaching and Teacher Education, 13, 513-527. doi:10.1016/S0742-051X(96)00053-4

Green, T. F. (1976). Teacher competence as practical rationality. Educational Theory, 26, 249-258. doi:10.1111/j.1741-5446.1976.tb00732.x

Grimmett, P. P., \& Ratzlaff, H. C. (1986). Expectations for the cooperating teacher role. Journal of Teacher Education, 37, 41-50. doi:10.1177/002248718603700607

Hagger, H., \& McIntyre, D. (2006). Learning teaching from teachers: Realizing the potential of school-based teacher education. Maidenhead, UK: Open University Press.

Hall, K. M., Draper, R. J., Smith, L. K., \& Bullough, R. V. (2008). More than a place to teach: Exploring the perceptions of the roles responsibilities of mentor teachers. Mentoring \& Tutoring: Partnership in Learning, 16, 328-345. doi:10.1080/13611260802231708 
Halstead, J. M. (1996). Values and values education in schools. Values in Education and Education in Values, 3-14. Retrieved from https://files.eric.ed.gov/fulltext/ED393218. pdf

Hammerness, K., Darling-Hammon, L., Bransford, J., Berliner, D., Cochran-Smith, M., McDonald, M., \& Zeichner, K. (2005). How teachers learn and develop. In. L. DarlingHammond \& J. Bransford (Eds.) Preparing teachers for a changing world (pp. 358-389). San Francisco: Jossey-Bass.

Haney, J. J., \& McArthur, J. (2002). Four case studies of prospective science teachers' beliefs concerning constructivist teaching practices. Science Education, 86, 783-802. doi:10.1002/sce.10038

Hawkey, K. (1997). Roles, responsibilities, and relationship in mentoring: A literature review and agenda for research. Journal of Teacher Education, 48, 325-335. doi:10.1177/0022487197048005002

Heck, R. H., Thomas, S., \& Tabata, L. (2012). Multilevel modeling of categorical outcomes using IBM SPSS. New York: Routledge.

Hermans, H. J. M. \& Hermans-Jansen, E. (1995). Self-narratives: The construction of meaning in psychotherapy. New York, NY: Guilford.

Hobson, A. J. (2002). Student teachers' perceptions of school-based mentoring in initial teacher training (ITT). Mentoring \& Tutoring: Partnership in Learning, 10, 5 - 20. doi:10.1080/13611260220133117

Hobson, A. J., Ashby, P., Malderez, A., \& Tomlinson, P. D. (2009). Mentoring beginning teachers: What we know and what we don't. Teaching and Teacher Education, 25, 207216. doi:10.1016/j.tate.2008.09.001

Hopper, B. (2001). The role of the HEI tutor in initial teacher education schoolbased placements. Mentoring \& Tutoring: Partnership in Learning, 9, 211- 222. doi:10.1080/13611260120111996

Hox, J. J., Moerbeek, M., Van de Schoot, R. (2018). Multilevel analysis. New York: Routledge

Hughes, R. (1998). Considering the vignette technique and its application to a study of drug injecting and HIV risk and safer behaviour. Sociology of Health \& Illness, 20, 381-400. doi.10.1111/1467-9566.00107

Izadinia, M. (2015). Talking the talk and walking the walk: Pre-service teachers' evaluation of their mentors. Mentoring \& Tutoring: Partnership in Learning, 23, 341-353. doi:10.10 $80 / 13611267.2015 .1096550$

Jacques, K. (1992). Mentoring in initial teacher education. Cambridge Journal of Education, 22, 337-351. doi:10.1080/0305764920220306 
Jaspers, W. M., Meijer, P. C., Prins, F., \& Wubbels, T. (2014). Mentor teachers: Their perceived possibilities and challenges as mentor and teacher. Teaching and Teacher Education, 44, 106-116. doi:10.1016/j.tate.2014.08.005

Jaspers, W. M., Prins, F., Meijer, P. C., \& Wubbels, T. (2018). Mentor teachers' practical reasoning about intervening during student teachers' lessons. Teaching and Teacher Education, 75, 327-342. doi:10.1016/j.tate.2018.07.004

Jaspers, W. M., Prins, F., Mainhard, T., Meijer, P. C., \& Wubbels, T. (Submitted). Mentor teachers' intervening during student teachers' lessons in primary education: A multilevel vignette study.

Jones, L., Reid, D., \& Bevins, S. (1997). Teachers' perceptions of mentoring in a collaborative model of initial teacher training. Journal of Education for Teaching, 23, 253-261. doi:10.1080/02607479719990

Jones, M. (2001). Mentor's perception of their roles in school-based teacher training in England and Germany. Journal of Education for Teaching, 2, 75-94. doi:10.1080/0260747012004255-5

Kagan, D. M. (1992). Implications of research on teacher belief. Educational Psychologist, 27, 65-90. doi:10.1207/s15326985ep2701_6

Kelchtermans, G. (1993). Getting the story, understanding the lives: From career stories to teachers' professional development. Teaching and Teacher Education, 9, 443-456. doi:10.1016/0742-051X(93)90029-G

Kent, S. I. (2001). Supervision of student teachers: practices of cooperating teachers prepared in a clinical supervision course. Journal of Curriculum and Supervision, 16(3), 228-244.

Killian, J. E., \& Wilkins, E. A. (2009). Characteristics of highly effective cooperating teacher: A study of their backgrounds and preparation. Action in Teacher Education, 30, 67-83. doi:10.1080/01626620.2009.10734453

Kvale, S. (2007). Doing interviews. London: Sage

Kwan, T., \& Lopez-Real, F. (2005). Mentors' perceptions of their roles in mentoring student teachers. Asia-Pacific Journal of Teacher Education, 33, 275-287. doi:10.1080/13598660500286267

Lave, J., \& Wenger, E. (1991). Situated learning: Legitimate peripheral participation. Cambridge: University press.

Leatham, K. R., \& Peterson, B. E. (2010). Secondary mathematics cooperating teachers' perceptions of the purpose of student teaching. Journal Mathematic Teacher Education, 13, 99-119. doi:10.1007/s10857-009-9125-0 
Lewis, C. C., \& Hurd, J. (2011). Lesson study step by step. Portsmouth, NH: Heinemann.

Liljedahl, P., Oesterle, S., \& Bernèche, C. (2012). Stability of beliefs in mathematics education: A critical analysis. Nordic Studies in Mathematics Education, 17(3-4), 101-118.

Lopez-Real, F., \& Kwan, T. (2005). Mentors' perceptions of their own professional development during mentoring. Journal of Education for Training, 31, 15-24. doi:10.1080/02607470500043532

Malderez, A., Hobson, A. J., Tracey, T., \& Kerr, K. (2007). Becoming a student teacher: Core features of the experience. European Journal of Teacher Education, 30, 225-248. doi:10.1080/02619760701486068

Maynard, T. (1996). The limits of mentoring: the contribution of the higher education tutor to primary students teachers' school-based learning. In J. Furlong \& R. Smith (Eds.), The role of higher education in initial teacher training (pp. 101-118). London: Kogan Page.

Maynard, T. (2000). Learning to teach or learning to manage mentors? Experiences of school-based teacher training. Mentoring \& Tutoring: Partnership in Learning, 8, 17-30. doi:10.1080/713685510

Martin, D. (1997). Mentoring in one's own classroom: An exploratory study of contexts. Teaching and Teacher Education, 13, 183-197. doi:10.1016/S0742-051X(96)00013-3

McIntyre, J., \& Killian, J. (1987). The influence of supervisory training of cooperating teachers on preservice teachers' development during early field experiences. Journal of Educational Research, 80, 277-282. doi.org/10.1080/00220671.1987.10885767

Miles, M. B., Huberman, A. M., \& Saldaña, J. (2014). Qualitative data analysis: A method sourcebook (3rd ed.) Thousands Oaks, CA: Sage Publications.

Morine-Dershimer, G. (1987). Practical examples of the practical argument: A case in point. Educational Theory, 37, 395-407. doi:10.1111/j.1741-5446.1987.00395

Morine-Dershimer, G. (1988). Premises in the practical arguments of preservice teachers. Teaching and Teacher Education, 4, 215-229. doi:10.1016/0742051X(88)90002-9

Munby, H. (1987). The dubious place of practical arguments and scientific knowledge in the thinking of teachers. Educational Theory, 37, 361-368. doi:10.1111/j.17415446.1987.00361.x

Nettle, E. B. (1998). Stability and change in the beliefs of student teachers during practice teaching. Teaching and teacher education, 14(2), 193-204. doi:10.1016/S0742051X(97)00031-0 
Oosterheert, I. E., \& Vermunt, J. D. (2001). Individual differences in learning to teach: Relating cognition, regulation and affect. Learning and Instruction, 11, 133-156. doi:10.1016/S0959-4752(00)00019-0

Orland, L. (2001). Reading a mentoring situation: One aspect of learning to mentor. Teaching and Teacher Education, 17, 75-88. doi:10.1016/S0742-051X(00)00039-1

Orland-Barak, L. (2001). Learning to mentor as learning a second language of teaching. Cambridge Journal of Education, 23, 53-68. doi:10.1080/03057640123464

Orland-Barak, L. (2002). What's in a case? What mentors' cases reveal about the practice of mentoring. Journal of Curriculum Studies, 34, 451-468. doi:10.1080/00220270110091140

Orland-Barak, L. (2005). Lost in translation: Mentors learning to participate in competing discourses of practice. Journal of Teacher education, 56, 355-366. doi:10.1177/0022487105279566

Orland-Barak, L. (2010). Learning to mentor-as-praxis. Foundations for a curriculum in teacher education. London: Springer.

Orland-Barak, L., \& Hasin, R. (2010). Exemplary mentors' perspectives towards mentoring across mentoring contexts: Lessons from collective case studies. Teaching and Teacher Education, 26, 427-437. doi:10.1016/j.tate.2009.05.009

Orland-Barak, L., \& Yinon, H. (2005). Sometimes a novice and sometimes an expert: Mentors' professional expertise as revealed through their stories of critical incidents. Oxford Review of Education, 31, 557-578. doi:10.1080/03054980500355468

Pajares, F. (1992). Teachers' beliefs and educational research: Cleaning up a messy construct. Review of Educational Research, 62, 307-332. doi: 10.3102/00346543062003307

Patrick, R. (2013). "Don't rock the boat": Conflicting mentor and pre-service teacher narratives of professional experience. The Australian Educational Researcher, 40, 207226. doi:10.1007/s13384-013-0086-z

Pendlebury, S. (1990). Practical arguments and situational appreciation in teaching. Educational Theory, 40, 171-179. doi:10.1111/j.1741-5446.1990.00171.x

Pillen, M., Beijaard, D., \& Den Brok, P. (2013). Tensions in beginning teachers' professional identity development, accompanying feelings and coping strategies. European Journal of Teacher Education, 36, 240-260. doi: 10.1080/02619768.2012.696192

Post, D. M. (2007). The cooperating teacher I's: Effective mid-lesson responses to student teachers' critical teaching incidents. Action in Teacher Education, 29, 61-70. doi:10.108 0/01626620.2007.10463440 
Rajuan, M., Beijaard, D., \& Verloop, N. (2007). The role of the cooperating teacher: Bridging the gap between the expectations of cooperating teachers and student teachers. Mentoring \& Tutoring: Partnership in Learning, 15, 223-242. doi:10.1080/13611260701201703

Richardson, V. (1990). Significant and worthwhile change in teaching practices. Educational Researcher, 19, 10-18. doi:10.2307/1176411

Richardson-Koehler, V. (1988). Barriers to the effective supervision of student teaching: A field study. Journal of Teacher Education, 39, 28-34. doi:10.1177/002248718803900206

Rippon, J. H., \& Martin, M. (2006). What makes a good induction supporter? Teaching and Teacher Education, 22(1), 84-99.

Rock, M. L., Gregg, M., Thead, B. K., Acker, S. E., Gable, R. A., \& Zigmond, N. P. (2009). Can you hear me now? Evaluation of an online wireless technology to provide real-time feedback to special education teachers-in-training. Teacher Education and Special Education: The Journal of the Teacher Education Division of the Council for Exceptional Children, 32, 64-82. doi:10.1177/0888406408330872

Roehler, L. R., Duffy, G. G., Herrmann, B. A., Conley, M., \& Johnson, J. (1988). Knowledge structures as evidence of the "personal": Bridging the gap from thought to practice. Journal of Curriculum Studies, 20, 159-165. doi:10.1080/00220272.1988.11070787

Roehrig, A. D., Bohn, C. M., Turner, J. E., \& Pressley, M. (2008). Mentoring beginning primary teachers for exemplary teaching practices. Teaching and Teacher Education, 24, 684-702. doi:10.1016/j.tate.2007.02.008

Rokeach, M. (1968). Beliefs, attitudes, and values: A theory of organization and change. San Francisco: Jossey-Bass.

Schoenberg, N. E., \& Ravdal, H. (2000). Using vignettes in awareness and attitudinal research. International Journal of Social Research Methodology, 3, 63-74. doi:10.1080/136455700294932

Schön. D. (1983). The reflective practitioner: How professionals think in action. New York: Basis Books.

Schwille, S. A. (2008). The professional practice of mentoring. American Journal of Education, 115, 139-167. doi:10.1086/590678

Shi, Y., Leite, W., \& Algina, J. (2010). The impact of omitting the interaction between crossed factors in cross-classified random effects modelling. British Journal of Mathematical and Statistical Psychology, 63, 1-15. doi:10.1348/000711008X398968

Smith, T. M., \& Ingersoll, R. M. (2004). What are the effects of induction and mentoring on beginning teacher turnover? American Educational Research Journal, 41, 681-714. doi:10.3102/00028312041003681 
Stanulis, R. N. (1995). Classroom teachers as mentors: Possibilities for participation in a professional development school context. Teaching and Teacher Education, 11, 331-344. doi:10.1016/0742-051X(94)00035-5

Sugrue, C. (1997). Student teachers' lay theories and teaching identities: Their implications for professional development. European Journal of Teacher Education, 20, 213-225. doi:10.1080/0261976970200302

Sundli, L. (2007). Mentoring - A new mantra for education? Teaching and Teacher Education, 23, 201-214. doi:10.1016/j.tate.2006.04.016

Thurstone, L. L. (1927). A law of comparative judgment. Psychological Review, 34(4), 273.

Tidwell, D. L., \& Heston, M. L. (1998). Self-study through the use of practical argument. In M.L. Hamilton, S. Pinnegar, T. Russell, J. Loughran, \& V. K. LaBoskey (Eds.), Reconceptualizing teaching practice: Self-study in teacher education (pp. 45-66). London: Falmer Press.

Tillema, H. H., Smith, K., \& Leshem, S. (2011). Dual roles- conflicting purposes: A comparative study on perceptions on assessment in mentoring relations during practicum. European Journal of Teacher Education, 34, 139-159. doi:10.1080/02619768.2010.543672

Van Eekelen, I. M., Boshuizen, H. P. A., \& Vermunt, J. D. (2005). Self-regulation in higher education teacher learning. Higher Education, 50, 447-471. doi:10.1007/s10734-0046362-0

Van Velzen, C., Volman, M., \& Brekelmans, M. (2014). Modelling and scaffolding as mentoring tools in co-teaching [Modelling en scaffolding als begeleidingsinstrumenten tijdens het samen lesgeven door vakbegeleiders en leraren in opleiding]. Pedagogische Studiën, 91(3), 169-185.

Vesterinen, O., Toom, A., \& Krokfors, L. (2014). From action to understanding - student teachers' learning and practical reasoning during teaching practice. Reflective Practice, 15, 618-633. doi:10.1080/14623943.2014.900028

Voerman, L., Meijer, P. C., Korthagen, F., \& Simons, R. J. (2015). Promoting effective teacher-feedback: from theory to practice through a multiple component trajectory for professional development. Teachers and Teaching, 21, 990e1009. doi:10.1080/135 40602.2015.1005868

Wang, C. (2010). What mathematics mentor teachers decide: Intervening in practice teachers' teaching. Procedia-Social and Behavioral Sciences, 8, 41-49. doi:10.1016/j. sbspro.2010.12.006 
Wang, J. (2001). Contexts of mentoring and opportunities for learning to teach: A comparative study to mentoring practice. Teaching and Teacher Education, 17, 51-73. doi:10.1016/S0742-051X(00)00038-X

Wang, J., \& Odell, S. J. (2002). Mentored learning to teach according to standardsbased reform: A critical review. Review of Educational Research, 72, 481-546. doi:10.3102/00346543072003481

Wang, J., Odell, S., \& Schwille, S. (2008). Effects of teacher induction on beginning teachers' teaching: A critical review of literature. Journal of Teacher Education, 59, 132-152. doi:10.1177/0022487107314002

Weasmer, J., \& Woods, A. M. (2003). The role of the host teacher in the student teaching experience. The Clearing House: A Journal of Educational Strategies, Issues and Ideas, 76, 174-177. doi:10.1080/00098650309601998

Williams, E. A., Butt, G. W., Gray, C., Leach, S., Marr, A., \& Soares, A. (1998). Mentors' use of dialogue within a secondary initial teacher education partnership. Educational Review, 50, 225-239. doi:10.1080/0013191980500302

Woods, A. M., \& Weasmer, J. (2003). Great expectations for student teaching: Explicit and implied. Education, 123, 681-688.

Zanting, A., Verloop, N., \& Vermunt, J. D. (2001). Student teachers' beliefs about mentoring and learning to teach during teaching practice. British Journal of Educational Psychology, 71, 57-80. doi:10.1348/000709901158398

Zanting, A., Verloop, N., Vermunt, J. D., \& Van Driel, J. H., (1998). Explicating practical knowledge: An extension of mentor teachers' roles. European Journal of Teacher Education, 21, 11-28. doi:10.1080/0261976980210104

Zeichner, K. (2005). Becoming a teacher educator: A personal perspective. Teaching and Teacher Education, 21, 117-124. doi:10.1016/j.tate.2004.12.001 


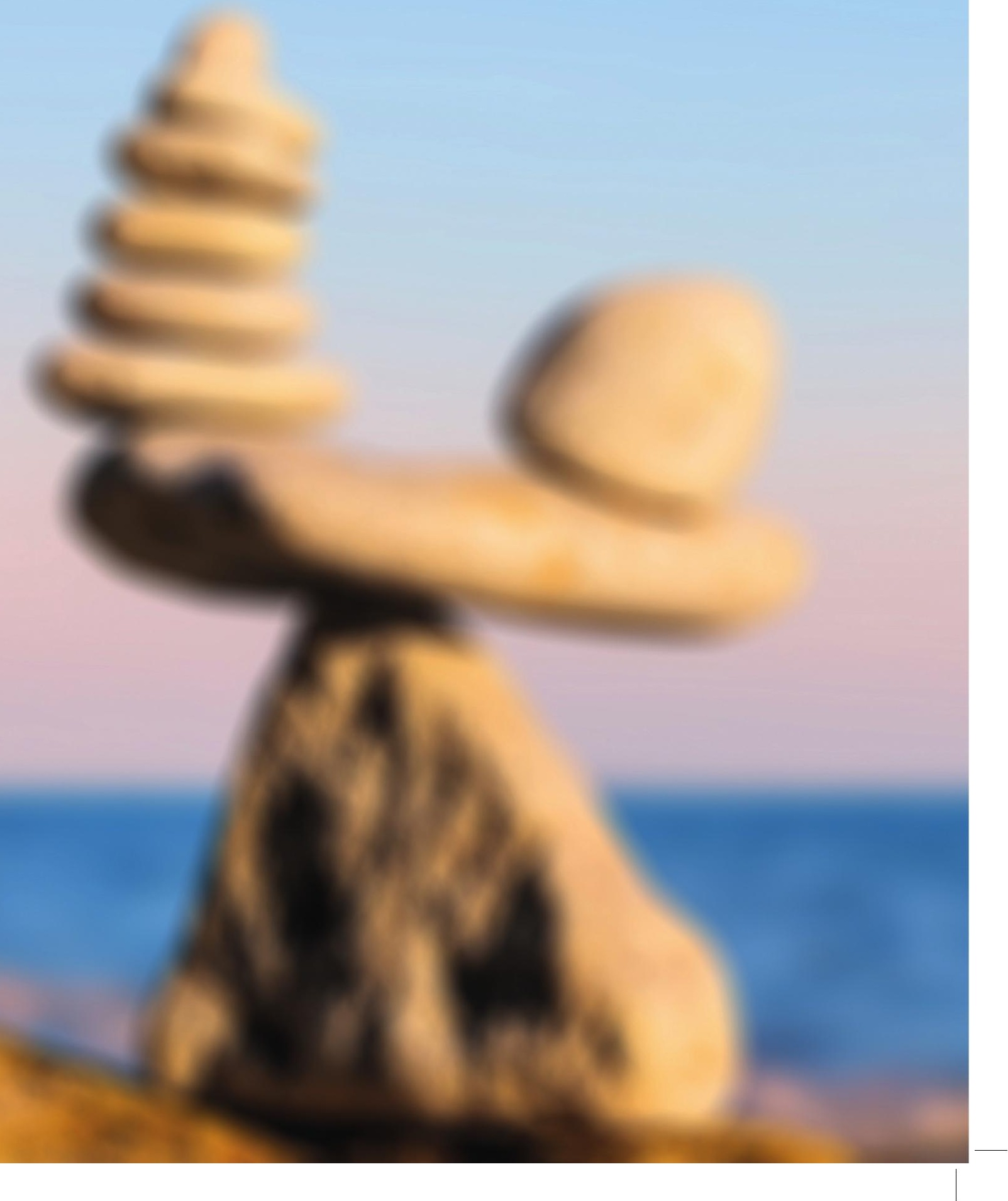




\section{APPENDIX}

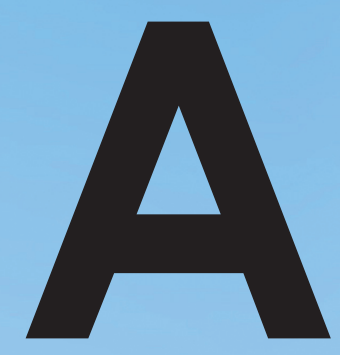

Nederlandse samenvatting

Woord van dank

About the author 


\section{NEDERLANDSE SAMENVATTING}

\section{Mentoren van leraren in opleiding in het primair onderwijs: Een lastig evenwicht tussen de mentorrol en leerkrachtrol}

Stel je voor, je bent een leerkracht in groep 4 in het basisonderwijs, en je bent je 25 lieve 7- en 8-jarige leerlingen aan het lesgeven, zoals je dat vijf dagen in de week gewend bent te doen. Het is dinsdag, dus vandaag is een derdejaars student die stageloopt bij jou in de klas ook aanwezig. Straks zal de student een rekenles geven van ongeveer een uur en jullie hebben de les samen goed voorbereid. Na de pauze begint de student haar les en jij zit achter in de klas en observeert je leerlingen en de student. Eerst gaat alles goed, maar na een tijdje beginnen steeds meer leerlingen te kletsen. Je besluit nog even te wachten. Vijf minuten later is bijna geen enkele leerling meer taakgericht aan het werk. Wat zou je doen?

Deze situatie illustreert het dilemma dat mentoren in het primair onderwijs geregeld ervaren als ze een student begeleiden in hun klas. Aan de ene kant voelen mentoren zich verantwoordelijk voor de leerlingen en aan de andere kant zijn ze verantwoordelijk voor het leren van de student. In de situatie zoals hierboven is het de vraag wat mentoren zouden doen. Zouden ze bijvoorbeeld ingrijpen? En als ze zouden ingrijpen, wanneer, hoe en waarom zouden ze dat dan doen?

Een beter inzicht in het ingrijpen van mentoren zou mentoren kunnen helpen om te gaan met het lastige evenwicht tussen de mentorrol en leerkrachtrol, en kan uiteindelijk een bijdrage leveren aan het goed begeleiden van leraren in opleiding wanneer ze het lesgeven oefenen. Dit proefschrift gaat over het combineren van de mentorrol en leerkrachtrol in het primair onderwijs, het (mogelijke) rolconflict dat mentoren zouden kunnen ervaren wanneer de student de leerlingen van de mentor lesgeeft en de invloed die deze dubbele rol heeft op het ingrijpen door mentoren tijdens de les van de student. Specifiek hebben we onderzocht wat de percepties en ervaringen van mentoren zijn als ze de mentorrol en leerkrachtrol combineren (hoofdstuk 2), hoe, wanneer en waarom mentoren ingrijpen en wat daarbij hun overwegingen zijn 
(hoofdstuk 3), welke factoren het ingrijpen van mentoren voorspellen (hoofdstuk 4) en of het ingrijpen kan worden beïnvloed (hoofdstuk 5).

We bespreken eerst het begeleiden van het leren van studenten op de werkplek en daarna gaan we in op mentoring in het primair onderwijs. Vervolgens geven we een overzicht van de resultaten van de vier studies. Tot slot volgt een algemene conclusie met aanbevelingen voor de praktijk en vervolgonderzoek.

\section{Het begeleiden van het leren van studenten op de werkplek}

Dit onderzoek is uitgevoerd in de Nederlandse context van werkplekleren door leraren in opleiding in het primair onderwijs (de basisschool). In Nederland volgen studenten tijdens hun lerarenopleiding in het algemeen tegelijkertijd cursussen aan de opleiding en lopen ze stage op verschillende scholen. Vergeleken met andere landen besteden de studenten relatief veel tijd in de stagescholen, namelijk een kwart van hun studietijd. Tijdens de stage bereiden studenten lessen voor, geven ze lessen en evalueren ze die. Andere manieren waarop studenten tijdens hun stage leren is onder andere door een meer ervaren leerkracht te zien lesgeven, te reflecteren, expliciet relaties te leggen tussen wat ze leren op de opleiding en wat ze zien in de scholen, en door hun eigen lesgeven te onderzoeken. De begeleiding van de student in zijn of haar leerproces in de stageschool ligt over het algemeen bij de leerkracht van de klas waar de student bij is geplaatst. In Nederland wordt deze begeleider doorgaans aangeduid met de term praktijkopleider. In het Engels wordt onder andere de term mentor teacher gebruikt. In deze samenvatting gebruiken we de term mentor.

Mentoren begeleiden de student bij het oefenen en het verkrijgen van nieuwe kennis, opvattingen, en vaardigheden die de student in staat stellen les te geven. Mentoren kunnen dit doen door bijvoorbeeld het voordoen van goed lesgeven, het bieden van ondersteuning en uitdaging aan de student, het voorbereiden, observeren en nabespreken van lessen, het discussiëren over en reflecteren op de ervaringen van de student en het praten over de complexe processen die spelen tijdens het lesgeven. Vanuit de literatuur weten we dat studenten en mentoren het stagelopen (het werkplekleren) het belangrijkste aspect van de lerarenopleiding vinden en dat 
mentoren een belangrijke invloed hebben op de ontwikkeling van de student. Echter, er zijn ook studies die aangeven dat mentoring weinig invloed heeft op het leren van de student en dat het behoorlijk complex is om een goede mentor te zijn. Om mentoring te verbeteren zijn allerlei studies uitgevoerd, maar de meeste van deze studies richten zich op wat mentoren voor en na de les van de student zouden moeten doen. Wat mentoren doen tijdens het lesgeven, wanneer de student het lesgeven aan het oefenen is, is minder goed bekend. Juist op dit specifieke moment van lesgeven kan de student, als lerende, begeleid worden in het leren lesgeven. Daarnaast zijn de meeste studies die mentoring hebben onderzocht niet uitgevoerd in het primair onderwijs, maar in het voortgezet onderwijs, en nemen deze studies niet mee dat de mentor ook nog leerkracht is van de leerlingen in de klas waarin de student het lesgeven oefent.

\section{Mentoring in het primair onderwijs}

In het primair onderwijs in Nederland zijn mentoren wanneer ze een student begeleiden niet alleen lerarenopleider en verantwoordelijk voor het begeleiden van de student in zijn of haar ontwikkeling, maar zijn ze als leerkracht ook verantwoordelijk voor de ontwikkeling en het welbevinden van de leerlingen. Deze combinatie van beide rollen kan een uitdaging zijn. Juist in het primair onderwijs, mogelijk meer dan in het voortgezet onderwijs, zijn mentoren bezorgd over hun leerlingen. Het zou kunnen zijn dat de relatie die leerkrachten in het primair onderwijs met hun leerlingen hebben verschilt van de leerkracht-leerling relatie van leerkrachten in het voortgezet onderwijs, omdat basisschoolleerkrachten minder en jongere leerlingen lesgeven en meer tijd met hen doorbrengen dan mentoren in het voortgezet onderwijs. Bovendien geven leerkrachten in het primair onderwijs over het algemeen alle lessen aan één klas, terwijl in het voortgezet onderwijs de leerkracht gewoonlijk in één vak lesgeeft aan meerdere klassen. Deze verschillen hebben mogelijk invloed op de mentorrol in beide contexten en leiden mogelijk tot een grotere spanning tussen de mentorrol en de leerkrachtrol bij mentoren in het primair onderwijs dan in het voortgezet onderwijs. Een specifieke situatie waarin mentoren deze spanning kunnen ervaren is het lesgeven door de student aan de leerlingen van de mentor waarbij de mentor merkt dat de student een fout maakt of het moeilijk heeft met het lesgeven. Zulke situaties kunnen waardevolle leermomenten zijn voor de student omdat die dan de gelegenheid krijgt 
te leren van zijn of haar fouten en daarmee het lesgeven kan verbeteren. Maar in dergelijke situaties vinden mentoren het vaak lastig om niet direct in te grijpen en de student toe te staan fouten te maken. Immers, een simpele interventie zou direct de situatie kunnen verbeteren. Als mentoren bezorgder zijn om het welbevinden van de leerlingen dan het leren van de student, als mentoren het lastig vinden de studenten de ruimte te geven om hun leerkrachtvaardigheden te oefenen, en als mentoren ingrijpen tijdens het oefenen van de student, zou het kunnen zijn dat het leren van de student onder druk komt te staan.

\section{De studies in dit proefschrift}

Hoewel verschillende studies noemen dat mentoren de neiging hebben in te grijpen, zijn er maar weinig onderzoeken naar het ingrijpen, de overwegingen van mentoren voor hun ingrijpen, factoren die het ingrijpen voorspellen en helemaal niet naar de vraag of het ingrijpen zou kunnen worden veranderd. Dit proefschrift heeft tot doel inzicht te verkrijgen in de mogelijkheden en uitdagingen die mentoren in het primair onderwijs ervaren wanneer ze de mentorrol en leerkrachtrol combineren, en meer specifiek wilden we het ingrijpen door mentoren wanneer studenten lesgeven beter begrijpen. We wilden weten welke factoren gerelateerd zijn aan het ingrijpen, en of en hoe we deze factoren konden voorspellen en beïnvloeden. Dergelijke inzichten zijn een stap richting het uiteindelijk verbeteren van de begeleiding door de mentoren tijdens het lesgeven door de student.

We hebben vier empirische studies uitgevoerd, die we hier samenvatten.

\section{Studie 1: Hoe ervaren mentoren de combinatie van de mentorrol en de leer- krachtrol?}

We zijn het onderzoek (hoofdstuk 2) begonnen met het verkennen van de percepties en ervaringen van mentoren wanneer ze de mentorrol en de leerkrachtrol combineren. Het doel was inzicht te verkrijgen in de mogelijkheden en uitdagingen die mentoren ervaren. In zeven retrospectieve semigestructureerde interviews hebben we mentoren bevraagd over hun rol als mentor, hun rol als leerkracht en de combinatie van die twee rollen. We vonden dat alle mentoren twee processen meemakten wanneer ze beide rollen combineren. 
Het eerste proces, sequentiële rolontwikkeling, beschrijft de ontwikkeling van beide rollen in een bepaalde volgorde. Mentoren gaven aan dat het feit dat ze leerkracht zijn bijdraagt aan het versterken van hun mentorrol en het ontwikkelen als mentor. Andersom gaven ze aan dat een goede leerkracht zijn een voorwaarde is om een goede mentor te worden. Bovendien ervoeren de mentoren dat het zijn van mentor de competentie en het welzijn als leerkracht positief beïnvloedde, bijvoorbeeld doordat ze zich bewust werden van hun eigen onderwijs en nieuwe lesideeën kregen. We vonden ook dat het sequentieel ontwikkelen van beide rollen een uitdaging is. Mentoren waren duidelijk van mening dat het leerkracht zijn hun primaire rol is en de mentorrol werd slechts als een extra taak gezien.

Het tweede proces, simultaan taken uitvoeren, beschrijft de combinatie van de mentorrol en leerkrachtrol bij het gelijktijdig uitvoeren van beide taken tijdens het begeleiden van de student. De belangrijkste bijdrage die mentoren zeiden te leveren aan de ontwikkeling van de student is het beschikbaar stellen van de klas en de leerlingen. Door te leren door te doen kunnen de studenten het lesgeven oefenen. Mentoren noemden als voordeel van het hebben van een student dat ze een extra paar handen in de klas hebben. Bovendien geeft de aanwezigheid van de student de mentor de mogelijkheid andere niet-mentor gerelateerde taken uit te voeren, zoals het corrigeren en beoordelen van het werk van de leerlingen. Mentoren ondervonden ook uitdagingen bij het tegelijkertijd uitvoeren van beide taken, zoals planningsproblemen en het omgaan met zwakke studenten. Het meest interessant vonden wij dat mentoren ook (impliciet) aangaven dat ze spanning ervaren vanwege de verantwoordelijkheid die ze hebben voor zowel de leerlingen als de student. Mentoren vonden het lastig te beslissen wanneer en hoe de verantwoordelijkheden worden overgedragen aan de student en te beslissen om wel of niet in te grijpen tijdens de les van de student als de mentor het lesgeven van de student niet goed vond gaan. In deze situaties hadden mentoren de neiging in te grijpen door de leerlingen te begeleiden. Mentoren waren vooral gericht op het welzijn en de ontwikkeling van hun leerlingen en minder op de ontwikkeling van hun studenten. Omdat deze bevindingen nog amper in de literatuur waren beschreven en van invloed lijken te zijn op de begeleiding van studenten tijdens het oefenen van het lesgeven hebben we ons in de volgende studies gericht op de 
uitdaging die mentoren ervaren in het combineren van de mentorrol en leerkrachtrol tijdens het lesgeven van de student.

\section{Studie 2: (Hoe) grijpen mentoren in en welke overwegingen hebben ze daar-}

\section{bij?}

In hoofdstuk 3 hebben we ons gericht op het combineren van de mentorrol en leerkrachtrol tijdens het lesgeven van de student. Het doel van de studie was het verkrijgen van inzicht in de overwegingen van de mentoren over of, wanneer en hoe ze ingrijpen tijdens de les van de student. In semigestructureerde interviews $(N=18)$ werden mentoren gevraagd uit te leggen waarom ze in bepaalde situaties die ze hadden meegemaakt hadden ingegrepen of niet. We ontwikkelden een coderingssysteem op basis van het concept praktisch argument (practical argument) van Fenstermacher (1986), dat bestaat uit een reeks premissen, namelijk situationele premissen (die beschrijven de context of situatie waarin een actie plaatsvindt), waardenpremissen (morele en ethische overtuigingen), en empirische premissen (uitspraken over de gevolgen van acties). Uit onze bevindingen bleek dat mentoren tijdens het lesgeven van studenten vrij vaak ingrijpen, voornamelijk gericht op de leerlingen, en soms behoorlijk nadrukkelijk, bijvoorbeeld door de les over te nemen. De redenen die mentoren noemden voor hun ingrijpen hebben we samengevat in een overzicht bestaande uit premissen, elk onderverdeeld in verschillende subthema's. Uit het redeneren van mentoren over het al dan niet ingrijpen blijkt dat mentoren over het algemeen voor elke specifieke situatie, bewust dan wel onbewust afwegen: 1) de situationele premissen, namelijk kenmerken van de student, de leerlingen, de mentor en de les, en de geobserveerde situationele trigger, bijvoorbeeld een student die een fout maakt in de inhoud van de les of een student die moeite heeft met klassenmanagement; 2) de mentorwaarden en leerkrachtwaarden; en 3) hun algemene empirische premissen, zoals ideeën en theorieën over begeleiden en lesgeven, en hun specifieke empirische premissen over zichzelf als mentor, een specifieke student en specifieke leerlingen. De persoonlijke afweging door de mentor van deze premissen voor een bepaalde situatie leidde tot het al dan niet daadwerkelijk ingrijpen. 


\section{Studie 3: Welke factoren voorspellen het ingrijpen?}

De twee kwalitatieve studies van hoofdstuk 2 en hoofdstuk 3 leidden tot een goed begrip van de combinatie van de leerkrachtrol en mentorrol, van het ingrijpen van mentoren, en van het redeneren van mentoren over het ingrijpen. Uiteindelijk kwamen we tot een overzicht van premissen die gerelateerd zijn aan het ingrijpen van mentoren. In hoofdstuk 4 hebben we met behulp van een grotere steekproef $(N=159)$ de relatie tussen enkele van deze premissen en de intentie tot ingrijpen kwantitatief getest. We onderscheidden daarbij twee aspecten, namelijk de nadrukkelijkheid van ingrijpen, en de richting van ingrijpen (de leerlingen, de student, of niet ingrijpen). We onderzochten hoe drie situationele kenmerken, namelijk de ervaring van de student (eerstejaars of derdejaars), het type trigger (een student die een fout maakt in de inhoud van de les of een student die moeite heeft met klassenmanagement), en de sterkte van de trigger (oplopend van laag naar hoog) en twee persoonlijke kenmerken, namelijk de waarden- en empirische premissen van de mentoren, bijdragen aan het ingrijpen. We ontwikkelden veertien vignetten (beschrijvingen van realistische situaties), gebaseerd op de premissen van Fenstermacher (1986) en onze bevindingen van hoofdstuk 3, waarin we systematisch het type trigger, de sterkte van de trigger, en de ervaring van de student hebben gemanipuleerd. 159 mentoren hebben voor elk vignette aangegeven of en hoe nadrukkelijk ze in dergelijke situaties zouden ingrijpen, en op wie hun ingrijpen zou zijn gericht. De waarden- en empirische premissen van de mentoren hebben we gemeten met een vragenlijst.

We vonden dat mentoren in bijna negentig procent van de gepresenteerde vignetten zouden ingrijpen met ten minste enige nadrukkelijkheid. Mentoren hadden de intentie ook behoorlijk intensief in te grijpen en voornamelijk gericht op de leerlingen. Daarnaast vonden mentoren leerkrachtwaarden belangrijker dan mentorwaarden. We vonden ook dat mentoren geloven in empirische premissen die kunnen leiden tot tegenstrijdige acties. Zo menen mentoren over het algemeen dat het goed is voor de student als tijdens de les van de student niet wordt ingegrepen, terwijl ze tegelijkertijd ook van mening zijn dat nadrukkelijk ingrijpen positief is voor de leerlingen. De nadrukkelijkheid van ingrijpen door mentoren was zowel toe te schrijven aan de situatie ( $17 \%$ van de variantie) als aan de mentor (28\% van de variantie). De richting 
van het ingrijpen werd ook beïnvloed door zowel situationele als persoonlijke factoren. Hoe meer mentoren de voorkeur gaven aan leerkrachtwaarden boven mentorwaarden, hoe nadrukkelijker het ingrijpen was en hoe vaker het ingrijpen gericht was op de leerlingen. De richting en nadrukkelijkheid van het voorgenomen ingrijpen werden beide beïnvloed door het type trigger en de ernst van de trigger. Mentoren grepen nadrukkelijker in en richtten zich voornamelijk op de student als de ernst van de trigger hoger was en als een student een fout maakte in de lesinhoud in vergelijking met wanneer de student problemen had met het klassenmanagement. Het derde situationele kenmerk, de ervaring van de student (eerstejaars of derdejaars) was, in tegenstelling tot onze verwachting op basis van de tweede studie, geen voorspellende factor voor de nadrukkelijkheid en de richting van het ingrijpen.

\section{Studie 4: Kunnen we het ingrijpen beïnvloeden?}

Toen we inzicht hadden in de waarden- en empirische premissen die van invloed zijn op het ingrijpen van mentoren, hebben we in hoofdstuk 5 onderzocht of we de overwegingen van mentoren over hun ingrijpen konden beïnvloeden door die waardenen empirische premissen te versterken. In een between subject pre-test post-test experiment hebben we de impact onderzocht van het versterken van de mentorrol of de leerkrachtrol op de waardenpremissen en de empirische premissen van de mentoren, en op de beoogde richting en intensiteit van ingrijpen. We gebruikten de gegevens uit hoofdstuk 4 als pre-test en na drie weken, net voordat de mentoren de post-test invulden, hebben we de interventie uitgevoerd. Het tonen van een video van ongeveer drie minuten waarin een onderwijswetenschapper werd geïnterviewd over zijn onderzoek over het begeleiden van studenten versterkte de premissen. In de eerste conditie versterkten we mentorwaarden- en empirische premissen. De onderwijswetenschapper benadrukte in het interview het belang van de mentorrol (waardenpremisse) en verstrekte informatie uit onderzoek dat de relatie beschrijft tussen onderwijssituaties en het welzijn en de ontwikkeling van studenten (empirische premissen). De tweede conditie was een controleconditie zonder interventie. In de derde conditie versterkten we de leerkrachtwaarden- en empirische premissen. De onderwijswetenschapper benadrukte in het interview het belang van de leerkrachtrol (waardenpremisse) en verstrekte informatie uit onderzoek dat de relatie beschrifft 
tussen onderwijssituaties en het welzijn en de ontwikkeling van leerlingen (empirische premissen). Multilevel-analyses toonden aan dat door het benadrukken van de mentorrol de nadrukkelijkheid waarmee mentoren zouden ingrijpen sterk werd beïnvloed. $47 \%$ van de variantie in de nadrukkelijkheid van ingrijpen werd verklaard door onze interventie, wat een groot effect is. We ontdekten ook dat mentoren de waarden met betrekking tot de rol die versterkt was relatief belangrijker vonden, en dit was een groot effect ( $36 \%$ verklaarde variantie). Mentoren waarvan de mentorrol was versterkt grepen significant minder nadrukkelijk in dan de controlegroep, en mentoren waarvan de leerkrachtrol was versterkt grepen significant nadrukkelijker in dan de controlegroep. Bovendien waren mentoren waarvan de mentorrol was versterkt het meer eens met de empirische premisse dat "niet ingrijpen positief is voor de student" (15\% verklaarde variantie). Een video van drie minuten veranderde dus het beoogde ingrijpen van mentoren aanzienlijk, wat veelbelovend is om veranderingen tot stand te brengen.

\section{Algemene discussie}

In het laatste hoofdstuk, hoofdstuk 6, hebben we de belangrijkste drie conclusies van de vier empirische studies op een rij gezet.

In de eerste plaats is de leerkrachtrol in het algemeen sterker dan de mentorrol. Mentoren zijn van mening dat leerkracht-van-de-leerlingen-zijn het belangrijkste is en dat het mentorschap slechts een extra taak is. Mentoren zijn vooral gericht op het welzijn en de ontwikkeling van hun leerlingen en minder op de ontwikkeling van hun studenten. Dit uit zich in de wijze waarop mentoren ingrijpen, namelijk vrij vaak, intuïtief, behoorlijk nadrukkelijk en voornamelijk gericht op de leerlingen en minder op de student. Een mogelijke verklaring hiervoor is dat mentoren, wanneer ze problematische situaties waarnemen, intuïtief reageren als leerkracht door de leerlingen aan te spreken. Ze zijn immers gewend dit de hele dag te doen, een ingesleten leerkrachtgewoonte. Bovendien voelen mentoren zich sterk verantwoordelijk voor de leerlingen en vinden ze leerkrachtwaarden belangrijker dan mentorwaarden. Een andere verklaring is dat mentoren zichzelf niet altijd zien als mentor of als lerarenopleider, en dat ze de student niet altijd als lerende zien. Ook kan het zijn dat 
mentoren zwakkere empirische premissen over (het stimuleren van) de ontwikkeling van de student hebben dan over (het stimuleren van) de ontwikkeling van leerlingen en dat ze daarom niet handelen naar hun empirische mentorpremissen. Een laatste verklaring voor onze bevindingen is de context waarin mentoren hun begeleidersrol uitvoeren, namelijk in hun eigen klas. Vergeleken met het voortgezet onderwijs lijken mentoren in het primair onderwijs meer gericht op hun leerlingen, en lijkt de spanning die mentoren tussen beide rollen ervaren sterker dan wat verwacht kan worden op basis van literatuur over mentoring in het voortgezet onderwijs. Dit betekent dat mentoring in het primair onderwijs conceptueel verschilt van mentoring in het voortgezet onderwijs, en dat bevindingen uit onderzoek uit het voortgezet onderwijs niet zomaar toegepast kunnen worden in het primair onderwijs.

Onze tweede conclusie is dat waardenpremissen en het ingrijpen door mentoren kunnen worden veranderd door het belang van de mentorrol te benadrukken, bijvoorbeeld door hen informatie te geven over onderzoeksbevindingen over het effect van bepaalde situaties op het welbevinden en de ontwikkeling van de student. Dit is belangrijk omdat we gevonden hebben dat mentoren veel, tamelijk intens, en intuïtief, automatisch en routinematig ingrijpen. We hebben laten zien dat door het versterken van waardenpremissen die mentoren al bezitten, deze waarden sterker en mogelijk meer onderbouwd zijn geworden. Dit heeft waarschijnlijk geleid tot een nieuwe balans tussen mentorwaarden en leerkrachtwaarden, wat vervolgens geresulteerd kan hebben in de verandering in het voornemen tot ingrijpen van mentoren.

Tenslotte bleek het praktische argument van Fenstermacher een waardevol model om het redeneren van mentoren over het ingrijpen tijdens de les van de student in kaart te brengen en te veranderen. Juist door de dubbele rol die mentoren uitvoeren, en de overwegingen die mentoren als mentor en als leerkracht hebben, bleek het praktische argument bruikbaar. We konden inzichtelijk maken hoe het waardenconflict eruitziet en hoe dit, samen met de empirische en situationele premissen, leidde tot ingrijpen. Vervolgens hebben we deze inzichten kunnen gebruiken om premissen en de intentie tot handelen te veranderen. 


\section{Aanbevelingen voor de praktijk}

Op basis van ons onderzoek hebben we nu een beter beeld van de factoren die van invloed zijn op het ingrijpen van mentoren en hoe we deze factoren kunnen gebruiken bij het beïnvloeden van de premissen en het ingrijpen. We weten echter nog niet wanneer ingrijpen effectief is en hoe dit af kan hangen van situaties, mentoren en studenten. Daarom kunnen we nog niet aangeven hoe mentoren zouden moeten ingrijpen. Op basis van onze resultaten kunnen we wel tot een aantal aanbevelingen voor de praktijk komen die mogelijk bevorderlijk zijn voor het verbeteren van de bijdragen van mentoren aan het leren van de student, en die mentoren kunnen helpen met het lastige evenwicht tussen de mentorrol en leerkrachtrol.

Ten eerste hebben onze bevindingen implicaties voor mentoren en voor professionaliseringscursussen voor mentoren. Om studenten beter te kunnen begeleiden bij het leren lesgeven, is het belangrijk dat mentoren zich meer bewust worden van hun leerkrachtrol en mentorrol en van de impact die de leerkrachtrol heeft op de mentoracties, specifiek wanneer de student lesgeeft. Ten tweede moeten mentoren worden gestimuleerd zich te realiseren dat studenten leraren en lerenden zijn die begeleid moeten worden in het leren lesgeven, juist ook op het moment van daadwerkelijk oefenen. Dit zou bijvoorbeeld kunnen door mentoren te informeren over onderzoeksbevindingen over studentbegeleiding. Wanneer mentoren zich meer bewust worden van het belang van mentorwaarden en van de student als lerende zou het redeneren van mentoren over het leren van studenten meer in balans kunnen komen met de sterke verantwoordelijkheid die ze voelen voor hun leerlingen. Dit zou uiteindelijk kunnen leiden tot studentbegeleiding die sterker is afgestemd op de leerdoelen en behoeften van de studenten. Ten derde is het belangrijk dat mentoren worden geholpen met het dilemma dat ze ervaren tussen begeleiden en lesgeven en worden ondersteund in het helder krijgen van hun redeneerproces met betrekking tot ingrijpen. Onderbouwd praktisch redeneren kan mentoren helpen zich bewust te worden van de dubbele rol, de soms conflicterende waarden, en van de premissen die ten grondslag liggen aan het al dan niet ingrijpen. Als mentoren inzicht krijgen in hun praktisch redeneren, kunnen ze effectiever met hun waarden omgaan en kunnen ze meer doordacht een afweging maken tussen de ontwikkeling van de leerlingen en 
de student. We bevelen daarom aan om mentoren te stimuleren om hun praktisch redeneren te expliciteren en met behulp van theoretische inzichten te reconstrueren en zo te verbeteren.

Verder zou het goed zijn als mentoren weten dat hun ingrijpen kan veranderen door kennis te nemen van resultaten van wetenschappelijk onderzoek. Ook het overzicht van de premissen en de door ons ontworpen vignetten zouden mentoren kunnen helpen hun dubbele verantwoordelijkheid sterker in overweging te nemen en meer te gaan denken en handelen als mentoren. De reflectie op het praktisch redeneren van mentoren kan ook worden gestimuleerd door een "kritische ander", bijvoorbeeld een collega-mentor, die de mentor bevraagt over specifieke situaties ("Waarom deed je dat?"). Op deze manier worden subjectieve opvattingen meer objectief gemaakt wat kan leiden tot een sterker en meer onderbouwd praktisch argument, zodat de competentie van mentoren kan worden versterkt.

Tenslotte hebben onze bevindingen ook implicaties voor de lerarenopleidingen en de studenten. Als opleiders de student bezoeken op de stageschool zouden ze met mentoren kunnen bespreken hoe ze de combinatie van het leerkracht zijn en het begeleiden van de student ervaren. Ook zouden ze met elkaar kunnen nadenken over hoe de mentor de student tijdens het lesgeven kan begeleiden. Daarnaast is het van belang dat studenten leren hoe ze met hun mentor kunnen omgaan en dat ze bewust worden gemaakt van hun eigen leerproces en hun eigen leerdoelen. Studenten zouden kunnen leren hoe ze kunnen profiteren van en vragen om bewuste begeleiding door de mentor tijdens het oefenen van het lesgeven. We raden aan dat de mentor en de student voorafgaand aan het lesgeven samen met elkaar de begeleiding tijdens het lesgeven bespreken, en afstemmen wat een mentor wel en niet doet tijdens de les van de student. Het ingrijpen van de mentor zou directer kunnen worden gekoppeld aan het leerdoel van de student en meer structureel kunnen worden opgenomen in de fases van voorbespreking, observeren, en nabespreken van de les. Het opnemen van het ingrijpen in onderzoek en theorie over mentoring zal leiden tot een beter en nieuw begrip van mentoring en studentbegeleiding. 


\section{Suggestie voor vervolgonderzoek}

Onze bevindingen leiden tot verschillende suggesties voor vervolgonderzoek. Ten eerste stellen we voor om observatieonderzoek uit te voeren waarbij mentoren, tijdens het lesgeven van de student, geobserveerd worden in hun eigen klas, om meer inzicht te krijgen in de invloed op het ingrijpen van het lesgeven aan de leerlingen van de mentor. Aanvullend zou ook het effect van een interventie en het praktisch redeneren van de mentoren over hun ingrijpen in de eigen klas kunnen worden onderzocht, bijvoorbeeld met behulp van stimulated recall interviews. Een tweede suggestie is te onderzoeken hoe het expliciteren en het reconstrueren van het praktisch argument over het ingrijpen (in de eigen onderwijspraktijk) eruitzien, om zo meer inzicht te krijgen in de ontwikkeling van het praktisch redeneren van mentoren en hoe dit gerelateerd is aan een verandering in ingrijpen. Als derde is het van belang om ook het perspectief van de student mee te nemen, zodat inzicht kan worden verkregen in hoe studenten het ingrijpen door hun mentor ervaren en wat dit doet met hun ontwikkeling en welbevinden. Om de begeleiding door mentoren te verbeteren zou ook onderzocht kunnen worden wat de effecten van verschillende manieren van ingrijpen op het leren en het welbevinden van studenten en leerlingen zijn. Verder bevelen we aan te onderzoeken of en hoe studenten en mentoren met elkaar het ingrijpen bespreken in bijvoorbeeld voor- en nabesprekingen van de les. Daarnaast menen we dat mentoren wellicht een positieve bijdrage zouden kunnen leveren aan het oefenen van het lesgeven door het ingrijpen bewust en expliciet te koppelen aan het leerdoel van de student en het ingrijpen gestructureerd op te nemen in de voor- tijdens- en nafases van de les. Tot slot willen we benadrukken dat veel onderzoek over mentoring, dat bijvoorbeeld de mentorprincipes van scaffolding en co-teaching onderzoekt, de invloed negeert van de sterke verantwoordelijkheid die mentoren voelen voor hun leerlingen. Dit zou de onderzoeksbevindingen kunnen beïnvloeden en daarom is het van belang dat toekomstig onderzoek naar mentoring in het primair onderwijs rekening houdt met de neiging van mentoren zich te gedragen als leerkracht. Concluderend zijn we van mening dat zowel onderwijspraktijk als wetenschappelijk onderzoek meer aandacht zouden moeten besteden aan het lastige evenwicht dat mentoren in het primair onderwijs ervaren tussen de mentorrol en leerkrachtrol. 


\section{WOORD VAN DANK}

Deze week, waarin ik mijn dankwoord schrijf, ontving ik een berichtje van een vriendin: "En bij jullie alles ok? Soort van nieuwe balans gevonden?" Toen ik ongeveer 9 jaar geleden aan dit proefschrift begon, had ik geen idee dat "balans" zo'n belangrijk thema zou worden. Niet alleen "de balans" als inhoudelijk concept in mijn proefschrift, maar ook de balans in het proces van het tot stand komen van mijn proefschrift en het gezin dat zich synchroon aan het ontstaan van mijn proefschrift ontwikkelde en uitbreidde. Maar net als de mentoren in een hectische klas en met hun dubbele verantwoordelijkheid, is het ook mij - en ons gezin - gelukt met dit lastige evenwicht om te gaan. En het resultaat mag er zijn: een prachtig gezin en een prachtig proefschrift. Ik ben er trots op!

Op deze plek wil ik graag een aantal mensen bedanken die belangrijk zijn geweest bij het behouden van de balans en/of het ontstaan van dit proefschrift.

Allereerst wil ik graag mijn onderzoeksbegeleiders, Theo, Paulien en Frans, heel erg bedanken. Beste Theo, vanaf het allereerste begin was je bij dit onderzoeksproject betrokken. Je hebt altijd het overzicht gehouden, was aangenaam kritisch en steunde me op lastige momenten. Dank voor je betrokkenheid. Beste Paulien, je begeleidde mij in mijn eerste stappen van kwalitatief onderzoek doen, en in de balans die ik zocht tussen onderzoek en onderwijs, én tussen werk en gezin. Ook later toen je in Nijmegen werkte was je er altijd om met me mee te denken, en gaf je me steun en (zelf) vertrouwen. Ik heb veel van je geleerd. Dank je wel. Beste Frans, heel erg bedankt voor je begeleiding en de tijd en ruimte die je me gaf. Je zorgde er altijd voor dat ik het vertrouwen had dat het goed zou komen. En dat was ook het belangrijkste wat ik nodig had. Dank!

Ook wil ik graag mijn (oud)kamergenootjes en alle andere (oud)collega's door wie ik me gesteund heb gevoeld bedanken voor het luisteren naar mijn overpeinzingen. Een promotieonderzoek doen is soms een tamelijk eenzaam proces, maar door jullie voelde het geregeld wat minder alleen. Beste Tim, natuurlijk bedankt voor al je hulp 
bij de multilevel analyses, maar bovenal bedankt voor je steun in de laatste fase van mijn onderzoek, je nuchtere kijk, en je luisterend oor!

Beste Marloes en Liesbeth, bedankt voor jullie hulp bij het coderen van de interviews en het meedenken op het moment dat mijn hersens enigszins verweekt waren.

Ook veel dank aan de studenten die een belangrijke bijdrage hebben geleverd in de dataverzameling en die als geen ander wisten hoe de situatie in de klas er uit ziet op het moment dat je als student lesgeeft in de klas van je praktijkopleider.

Veel dank ook gaat uit naar alle praktijkopleiders die hebben meegewerkt aan het onderzoek. Zonder jullie deelname aan de interviews, het mogen meekijken in de klas, en het invullen van de vragenlijsten had dit onderzoek nooit kunnen plaatsvinden.

Lieve Lies en Anouschka, mijn paranimfen, ieder op jullie fantastisch eigen wijze, hebben mij zo fijn bijgestaan. Heel erg bedankt voor jullie support, de steun en het vertrouwen dat jullie mij hebben gegeven.

Lieve vriendinnen. Wat zijn jullie belangrijk geweest de afgelopen jaren in het behouden van de balans tussen werk en onderzoek en ontspannende en gezellige activiteiten! De steun die ik van jullie kreeg uitte zich in vele vormen. Met name het promoten van de noise cancelling koptelefoon, het onbewust benoemen van de coffee club play list, het drinken van kaneelcocktails en gin tonics, en het eten van kreeft, maakte dat ik met name van de eindsprint van mijn onderzoek ook enorm heb genoten. Allemaal, heel erg bedankt.

Beste (oud)teamgenootjes, bedankt voor de sportieve afleiding op en naast het hockeyveld, wat bijdroeg aan een betere balans tussen lichaam en geest. Ook dank aan de (schoolplein)moeders/vaders voor de bemoedigende gesprekjes en het opvangen van de kindjes, zodat ik nog even een paar uurtjes kon werken. 
Lieve Broer en Zus, lieve Pap en Rineke. Gewoon bedankt. Voor alles. Voor alle hulp en steun, juist op die momenten dat ik de balans even helemaal kwijt was. Bedankt dat jullie er altijd zijn. Moge het nog maar lang zo blijven.

Lieve Mama, ook al ben je niet meer hier, tijdens mijn hele promotieonderzoek was je altijd dichtbij. Altijd een fluisterende stem in m'n hoofd die zei: “Je kan het! Nog even doorzetten." En doorzetten heb ik gedaan. Het is af. Dank je wel voor wie ik ben geworden.

Tot slot, lieve Guus en lieve Lise, Lars en Luuk. Als iemand de gevolgen van mijn persoonlijk lastige evenwicht tussen hard werken en een druk gezin heeft mogen ervaren zijn jullie het wel. Het was niet altijd makkelijk, maar het is ons gelukt, met elkaar! Lieve Auchie, dank voor je steun, je hulp, en je geduld. Lieve kindjes, dank voor jullie vrolijke lachjes, zachte aaitjes en fijne knuffels. Ze hebben me enorm geholpen. Dat we nu met elkaar weer een fijne, nieuwe balans mogen vinden. Ik hou van jullie!

Marieke Jaspers

Bunnik, september 2019 


\section{ABOUT THE AUTHOR}

Marieke Jaspers was born in Utrecht, the Netherlands, on November 6, 1983. She completed her secondary education at the Christelijk Gymnasium Utrecht, graduating in 2002. Marieke was always interested in learning and development of children. In 2006 she earned Bachelor degrees in Educational Sciences, Pedagogical Sciences and Teacher Training in Primary Education. After obtaining her Master's degree in Pedagogical Sciences (Orthopedagogy) in 2007, she started the master program Educational Sciences. In her final year she combined working as a teaching assistant and doing her internship in the University Based Teacher Education Programme for Primary Education (in Dutch: Academische Lerarenopleiding Primair Onderwijs ALPO). During this period, she also worked as teacher and as a Remedial Educationalist in special education. After finishing her Masters in 2009 she continued working at the department of Education, Faculty Social and Behavioural Sciences, Utrecht University. As lecturer and member of the ALPO project-group she was involved in the development of the new ALPO-curriculum, and she developed, coordinated, and taught teacher training courses, professional development courses, and pedagogical and educational courses. She also supervised students' Bachelor and Master theses and guided student teachers in their practical development and teacher training.

Marieke started her PhD research on 'mentoring in primary education' in 2010. From 2010 till 2019, she combined being a lecturer at the University with working as a $\mathrm{PhD}$ researcher. She presented her research at international conferences (EARLI-sig 11 conferences in 2012, 2016, 2018 and EARLI conferences in 2015 and 2017) and gave a master class concerning her research topic to mentors connected to the teacher training institute. So far, her PhD-research project resulted in two scientific publications, both in Teaching and Teacher Education.

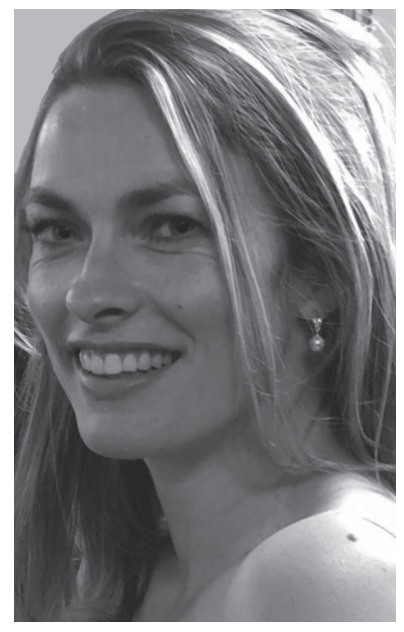

